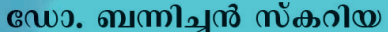

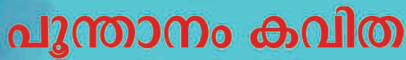

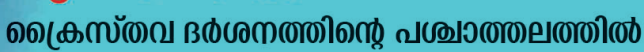

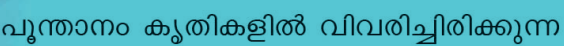

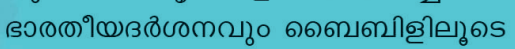

৫ாவைை|నी:

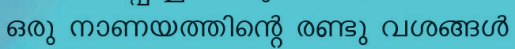

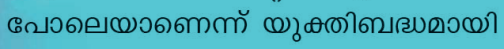

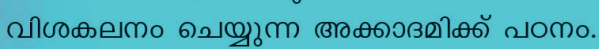

๓ుகரவா

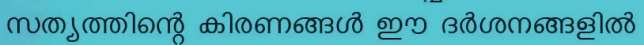

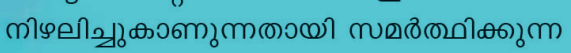

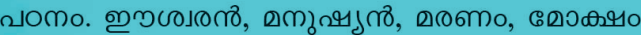

ஊ

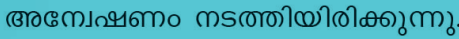

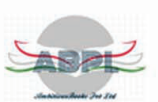

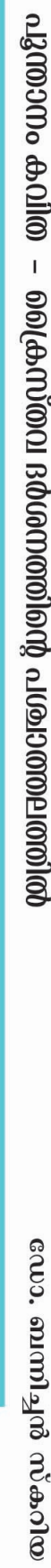

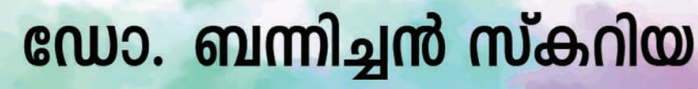

है
$\dot{0}$
$\frac{2}{3}$
$\frac{3}{2}$
$\frac{\sqrt{2}}{3}$

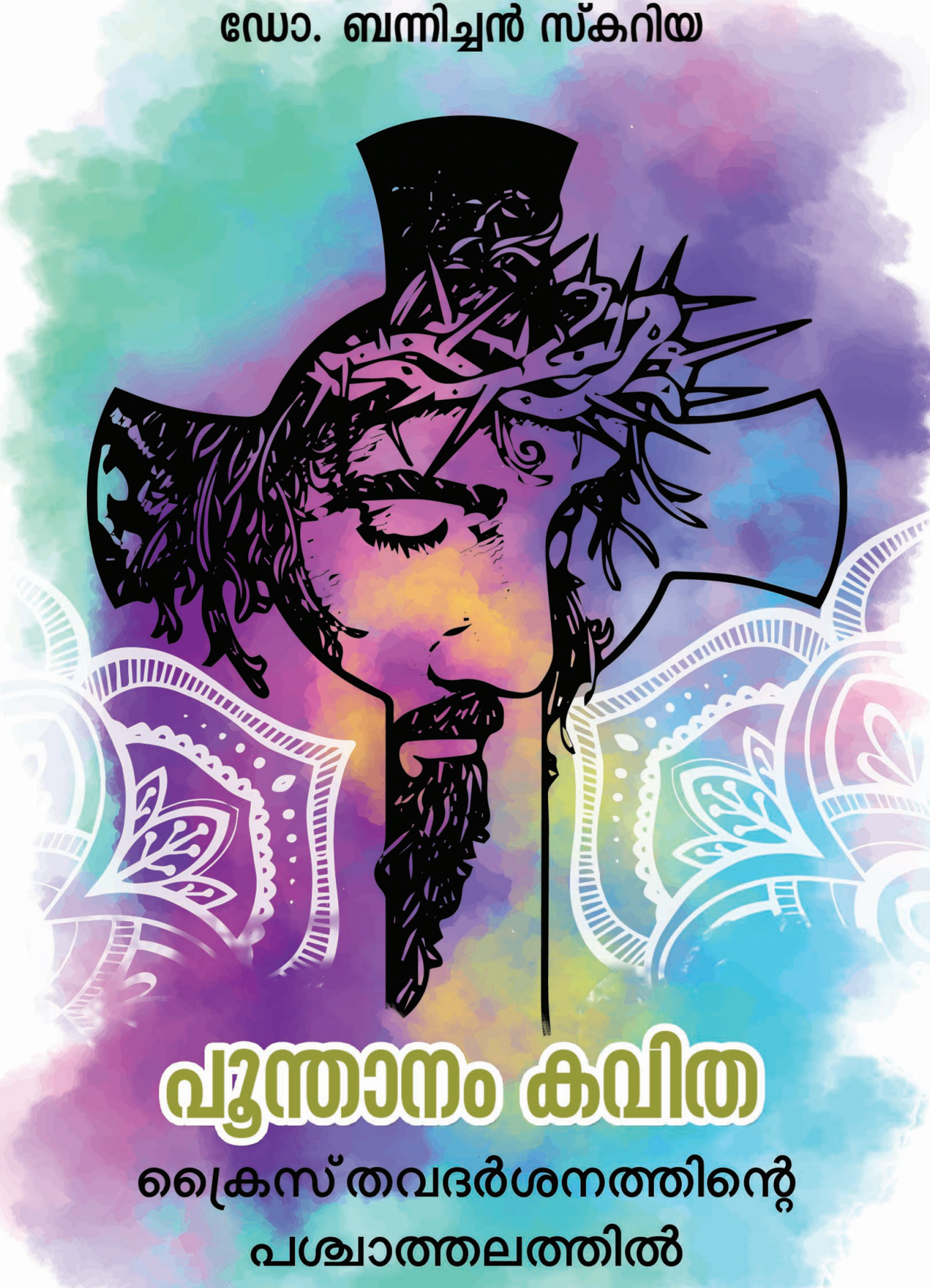




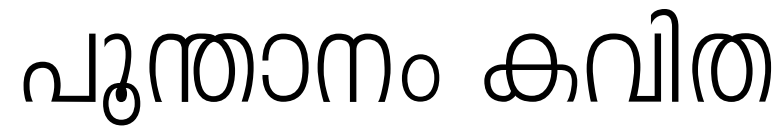

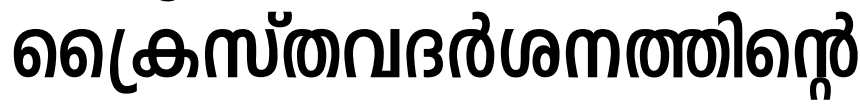 ปவூगரை)

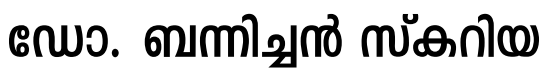




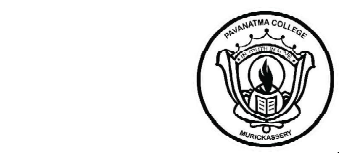

PAVANATMA PUBLICATIONS

Malayalam

\section{Poonthanam Kavitha, \\ Kristhavadarshanathinte Paschathalathil}

(Study)

Author

Dr. Bennichen Scaria

First Edition

March 2020

Cover Design

Anupriya Manuel

Pre Press

Anulal Printers

Murickassery - 685604

Published by

For Pavanatma College,

ABPL Publications, Kerala

www.abplpublications.co.in

No part of the publication may be reproduced stored in a retrieval system or transmitted in any form or by any means without the prior permission from the publisher in writing. 


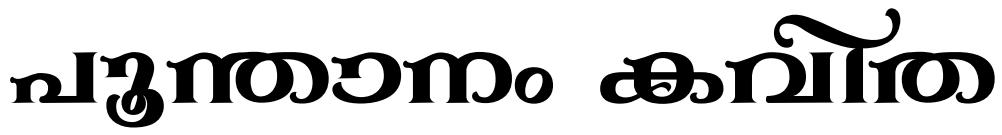

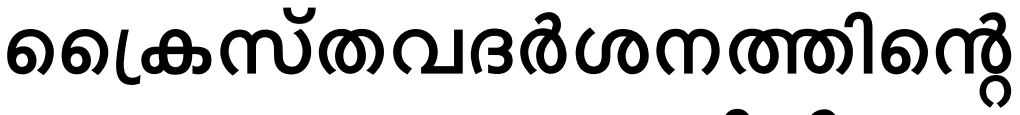 வருரைைரினி}

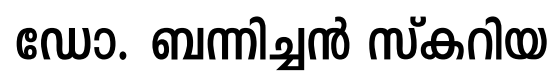

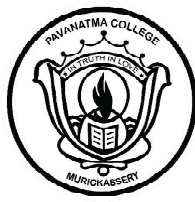

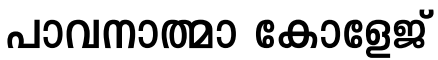




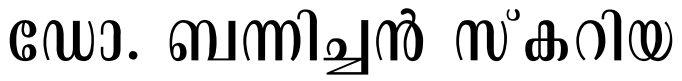

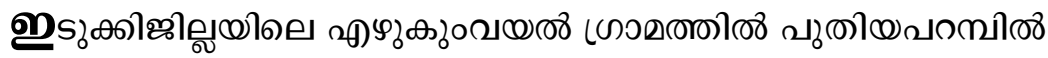

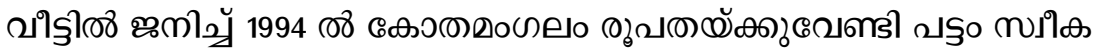

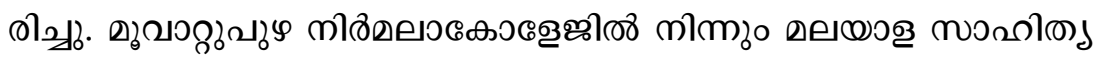

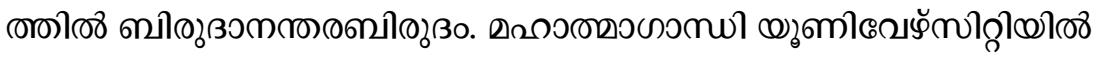

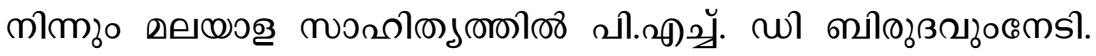

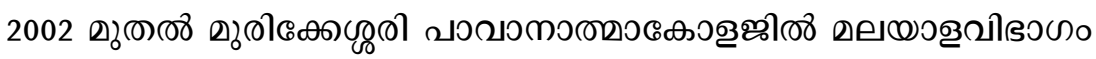

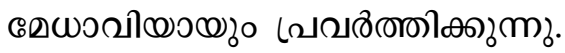

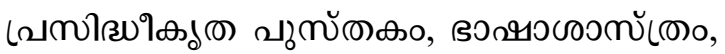

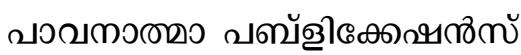

வीerono :

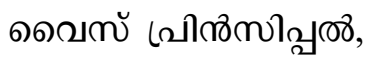

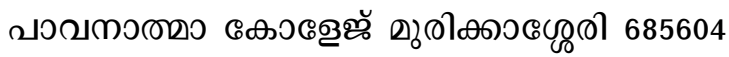




\section{๑รவ0ปว}

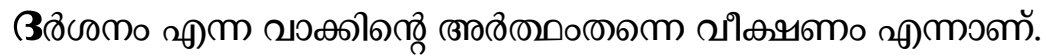

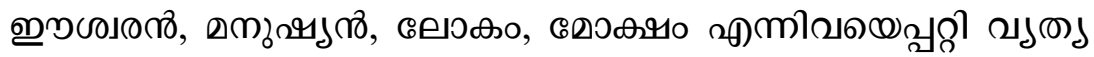

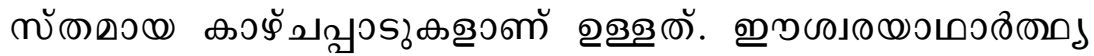

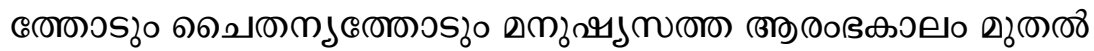

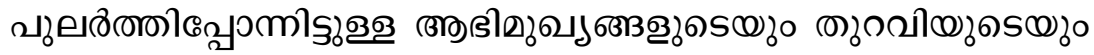

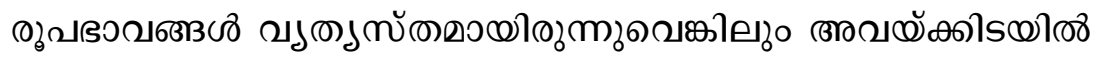

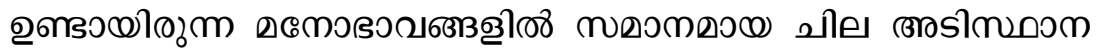

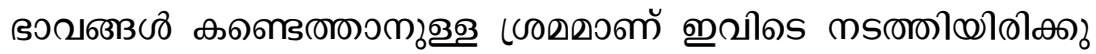

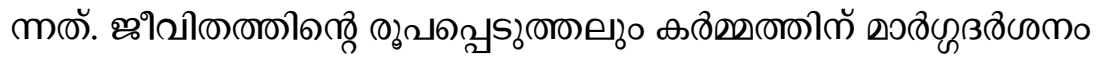

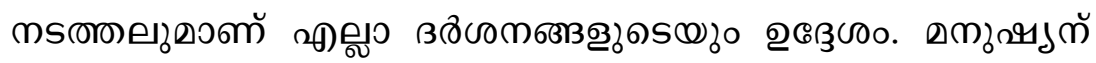

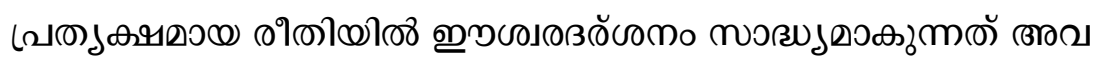

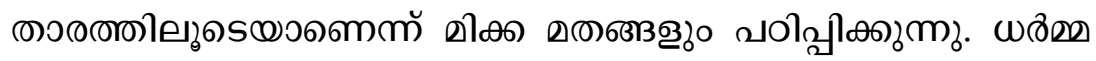

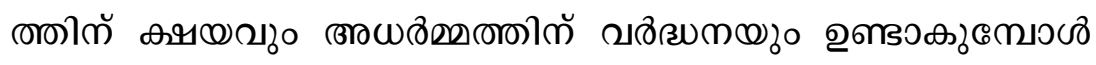

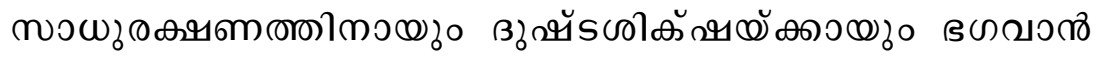

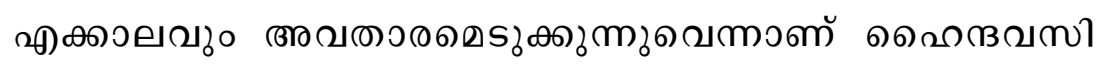

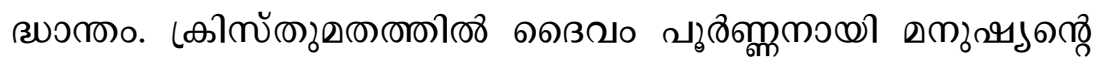

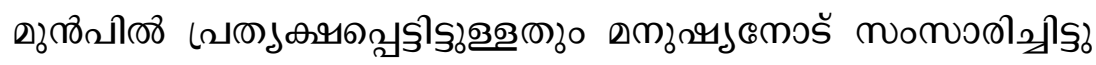

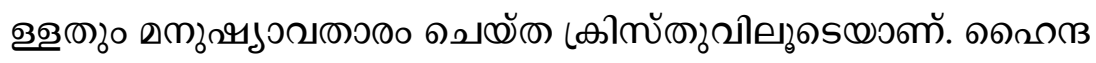

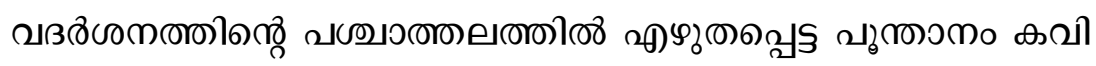

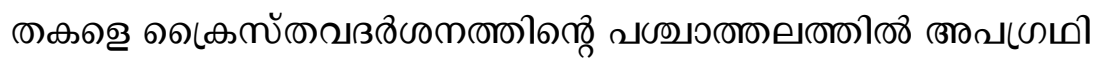

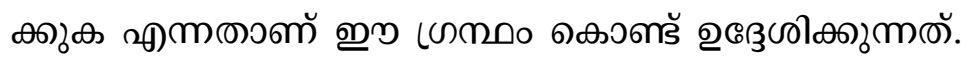




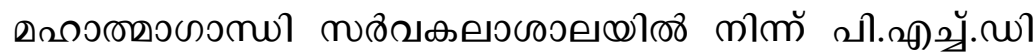

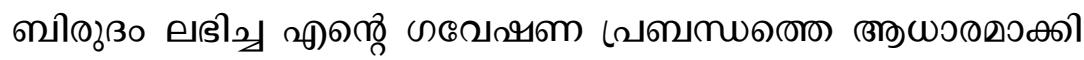

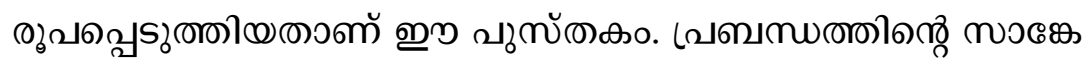

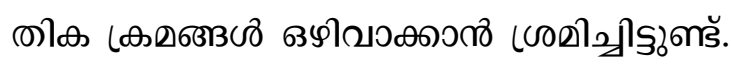

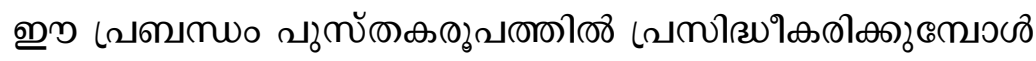

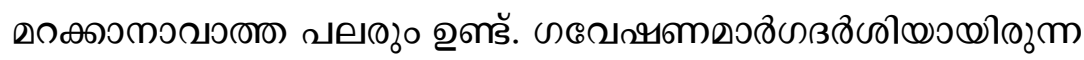

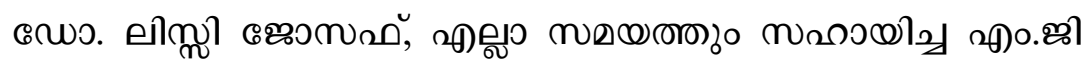

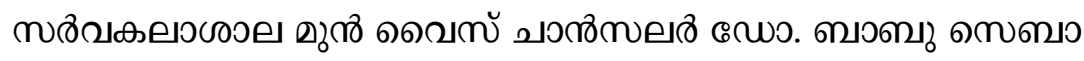

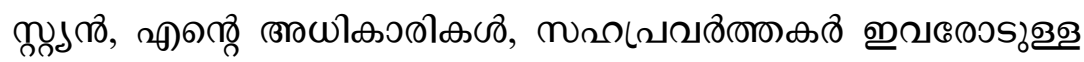

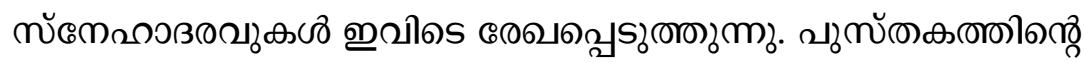

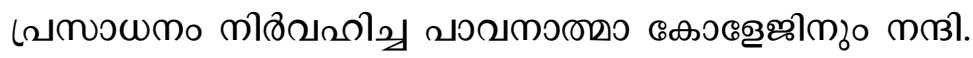





\section{உ6ื่งณ๑๐}

1.

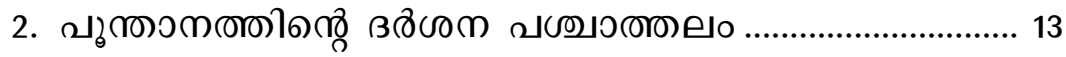

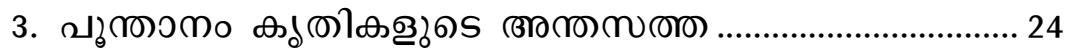

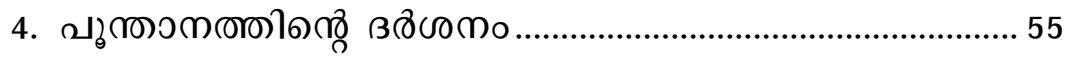

5. வாலைா कவிக -

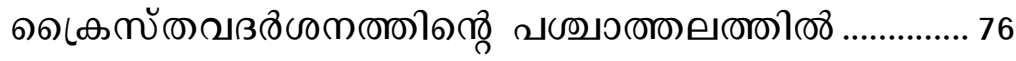





\section{(ஆ) ๑3வ०}

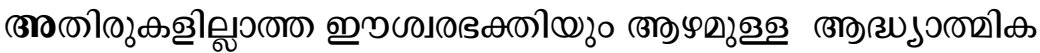

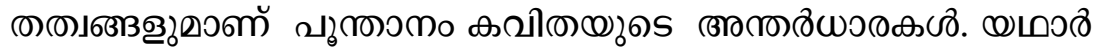

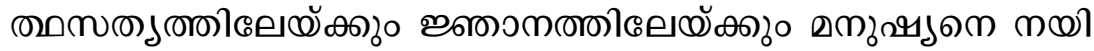

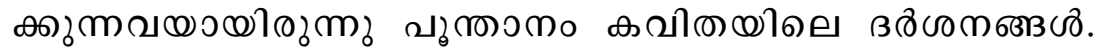

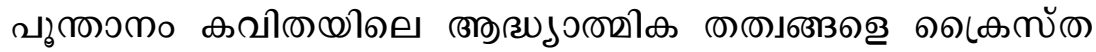

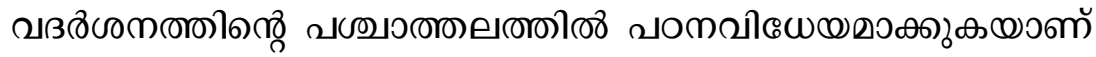

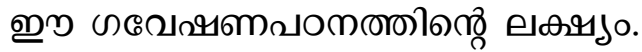

வ

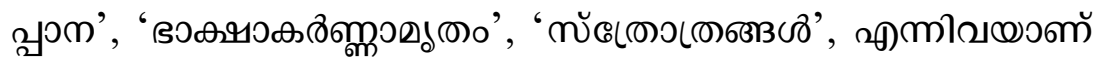

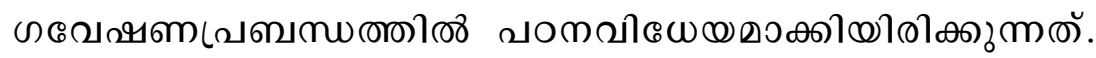
வௌாவЗன் கவிக வெகருவைஷ்

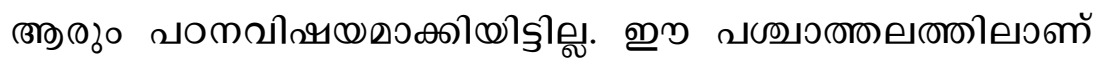

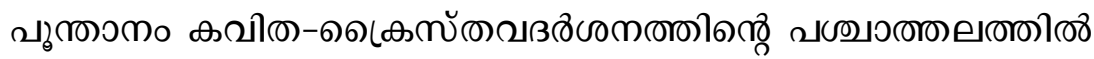

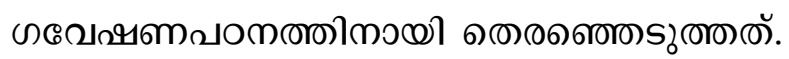

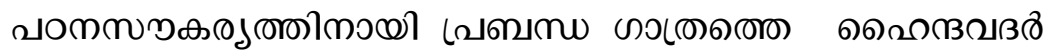

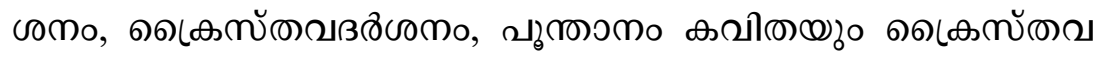

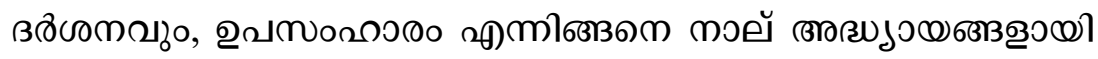

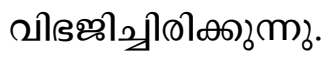


வௌாவ கன்

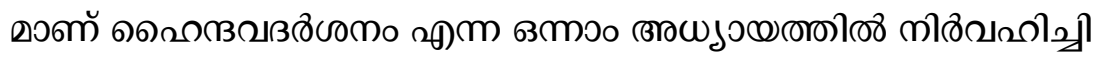

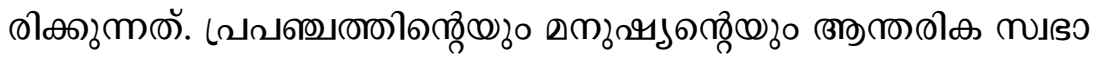

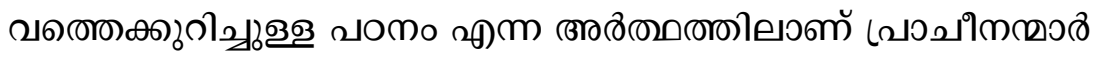

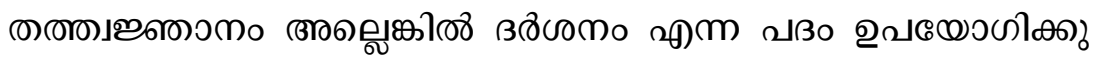

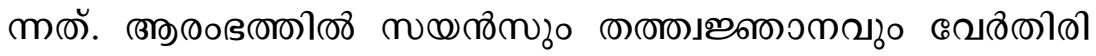

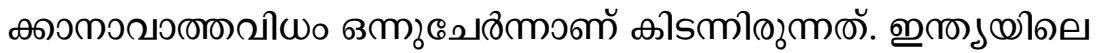

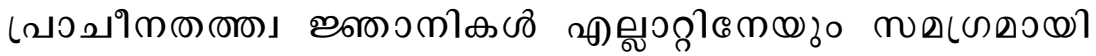

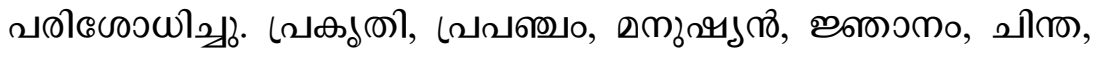

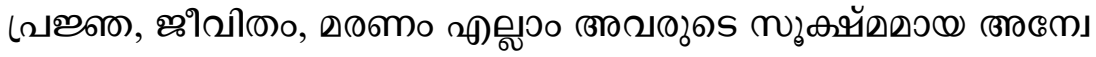

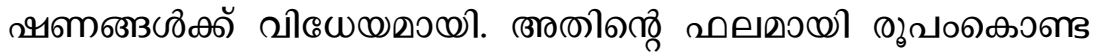

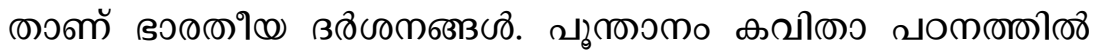

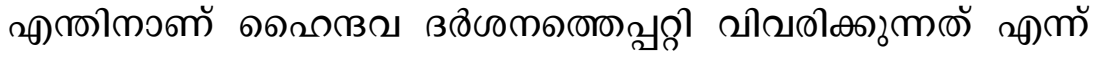

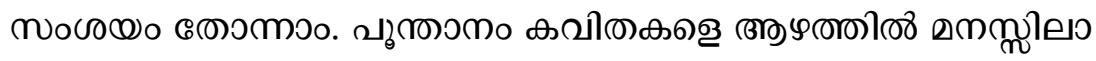

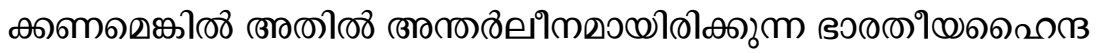

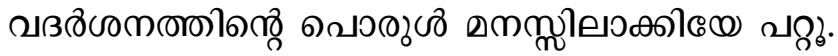

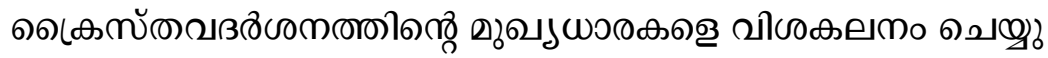

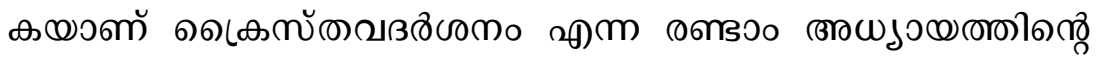

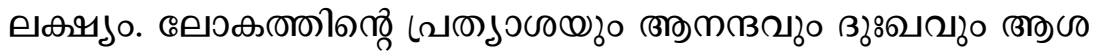

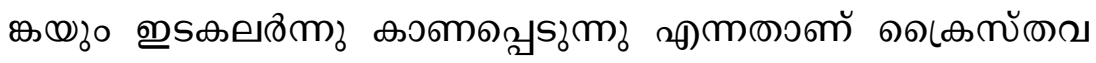

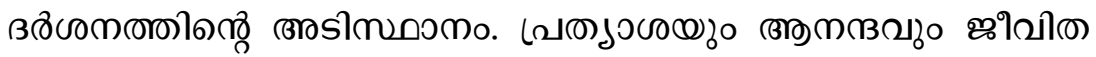

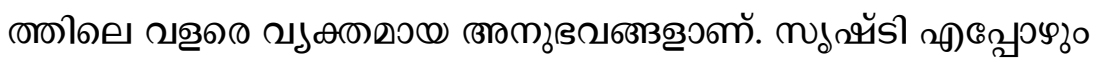

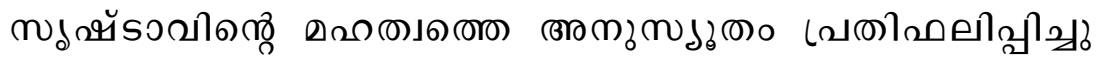

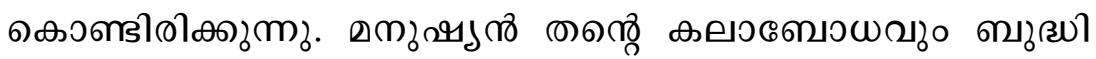

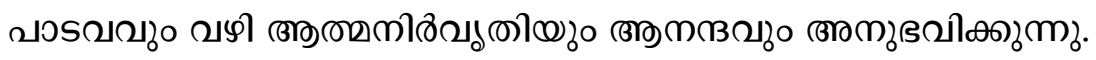

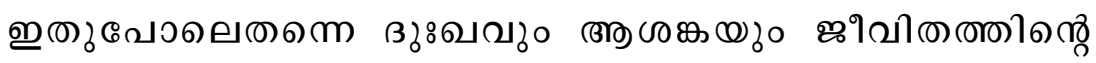

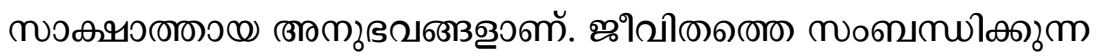




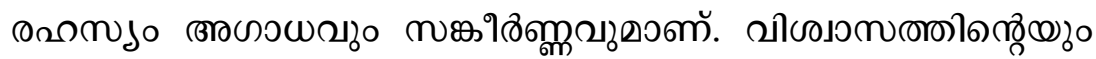

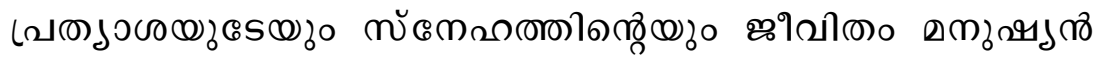

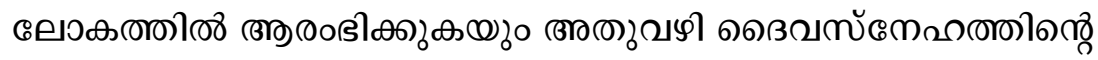

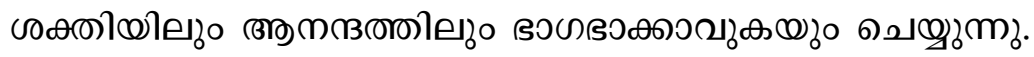

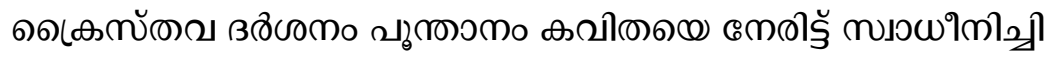

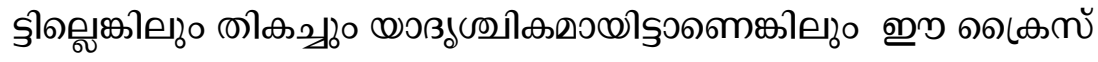
வைßன்

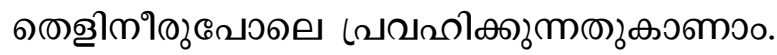

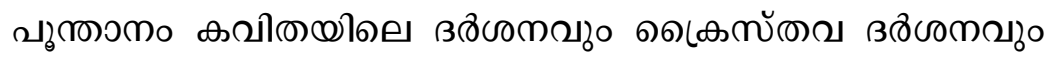

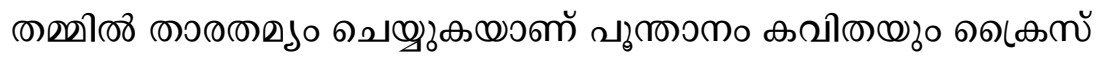

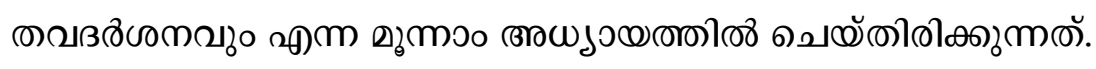
வ

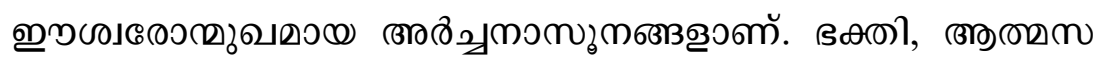

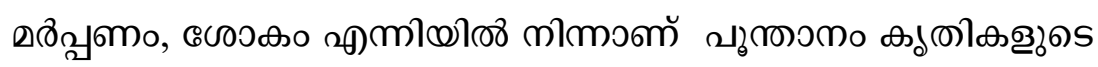

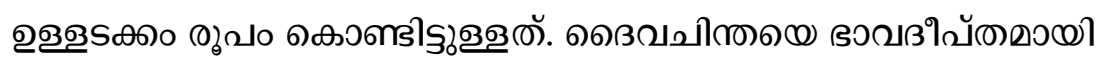

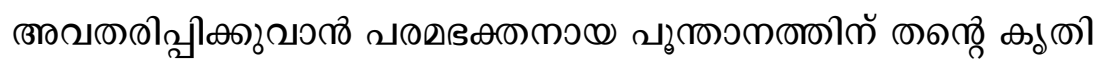

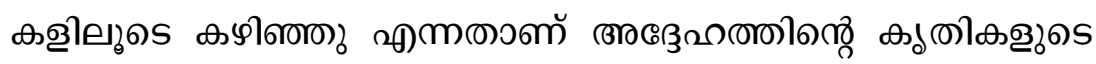

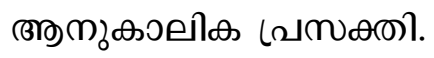

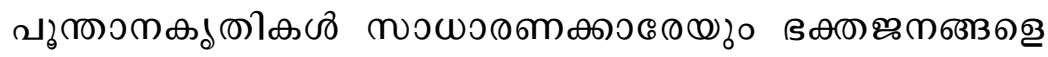

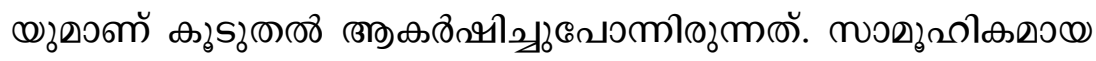

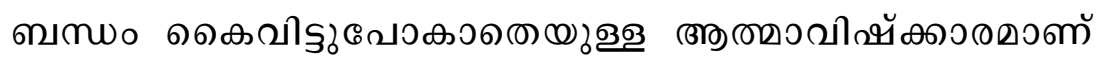

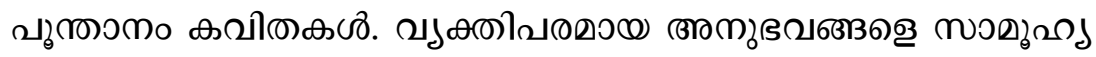

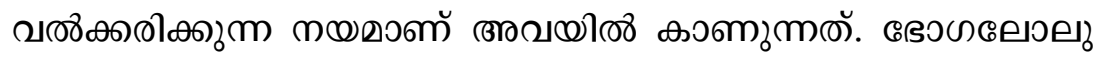

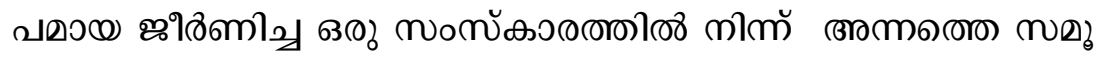

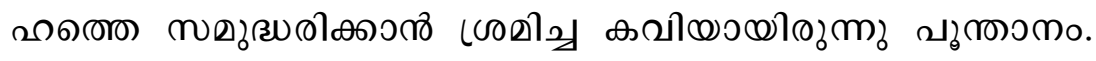

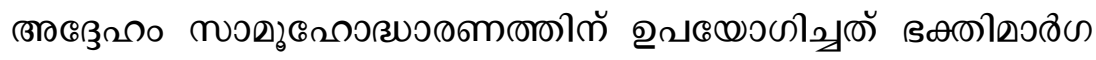




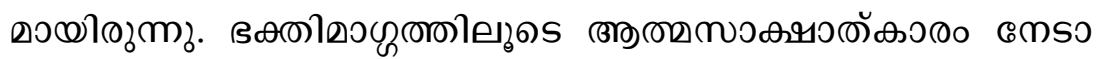

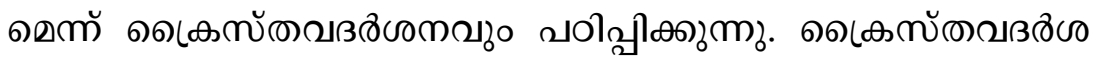

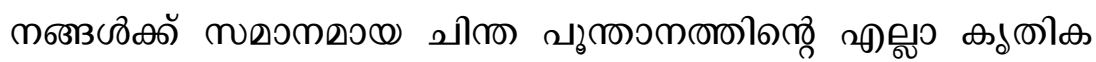

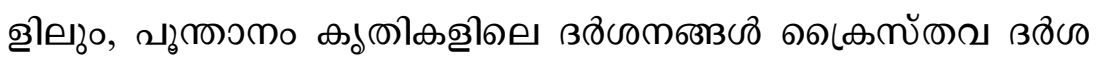

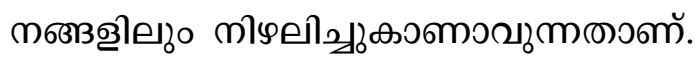

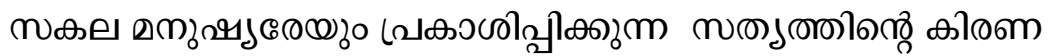

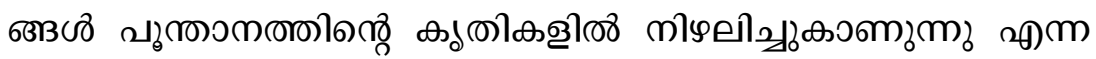
லைஸ̆ ஹற (

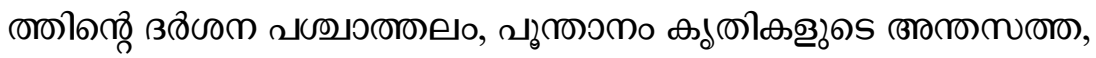

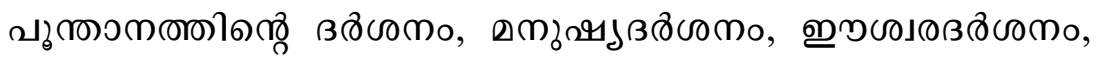

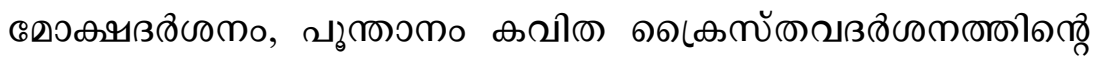

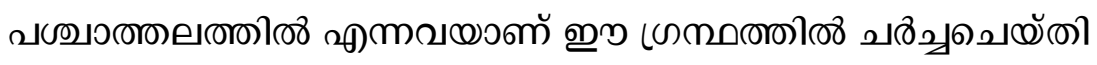
ถிळுாளั. 


\section{2.

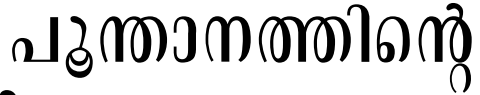

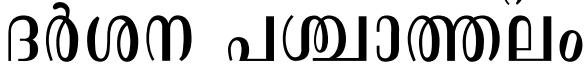

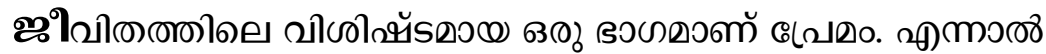

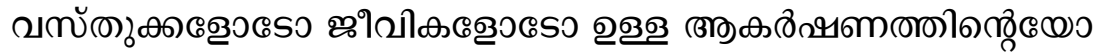

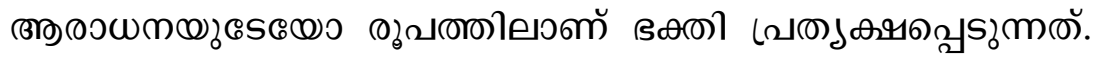

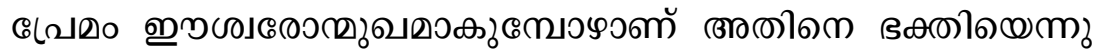
விஷிமூாாரั.

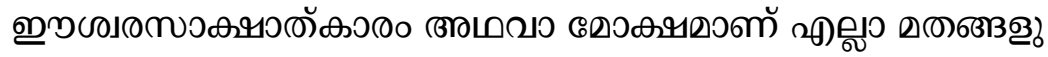

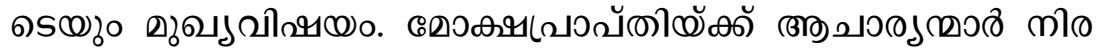

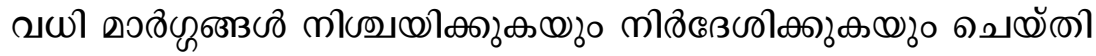

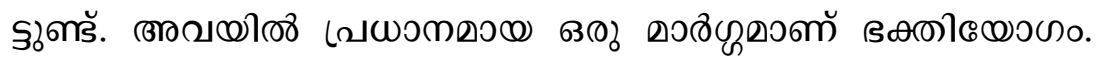

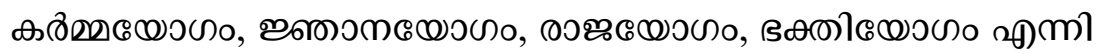

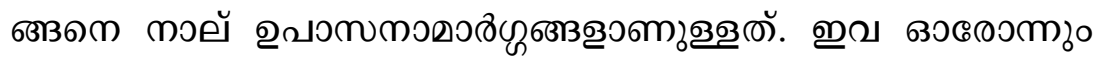

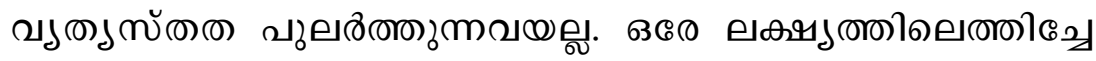

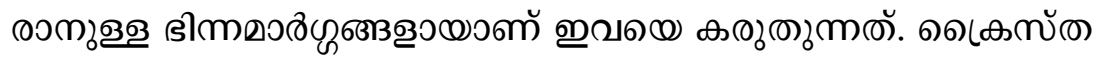

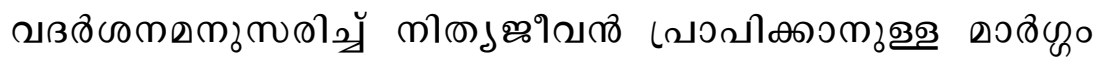

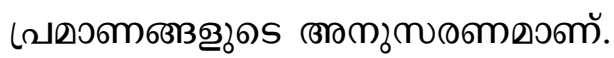




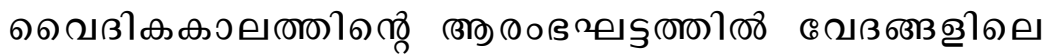

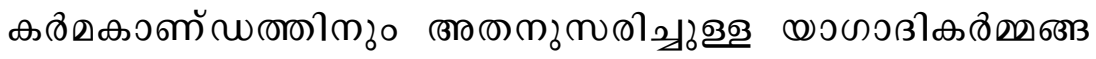

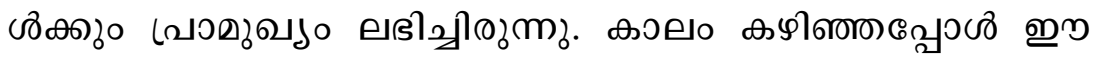

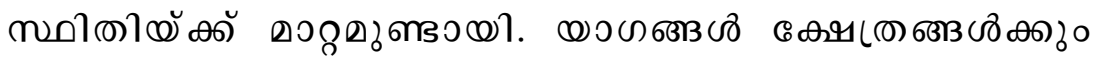

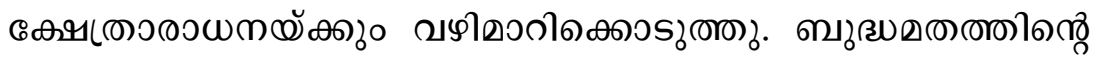

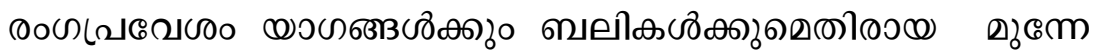

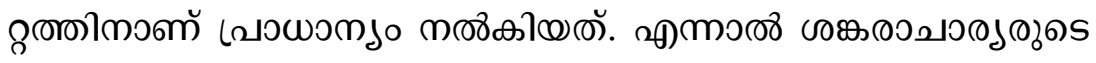

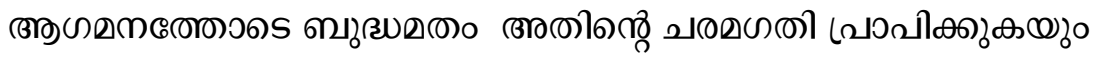

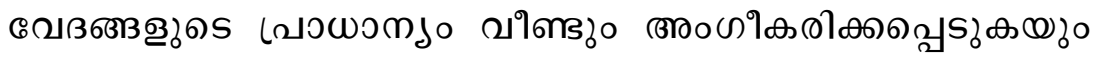

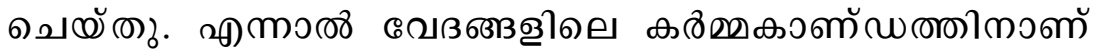

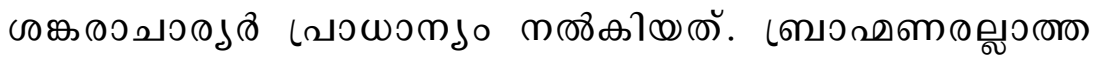

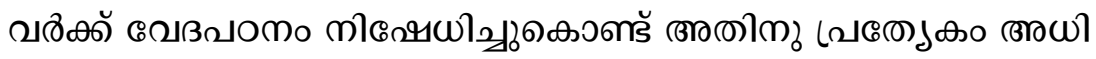

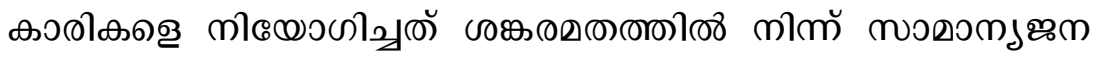

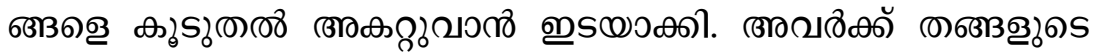

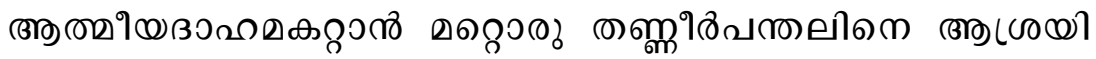

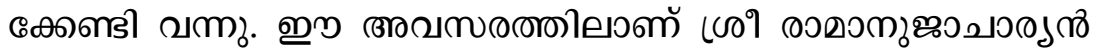

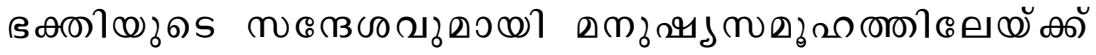

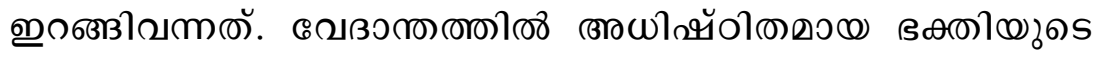

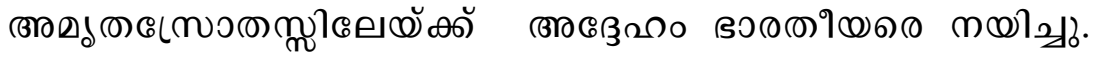

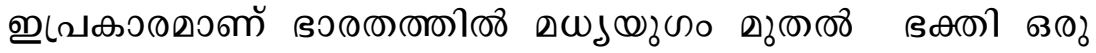

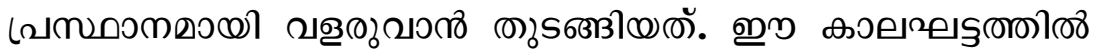

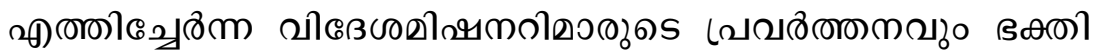

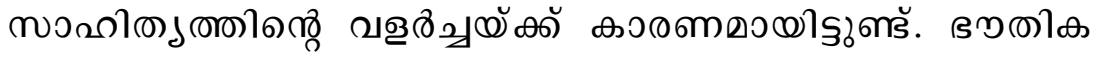

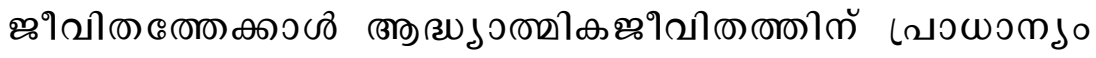

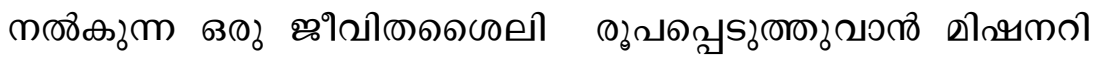

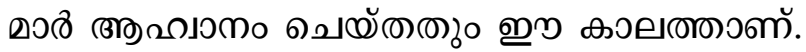




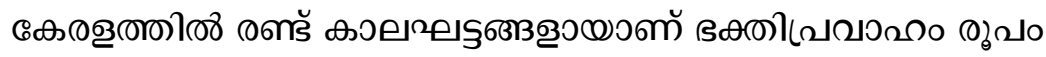

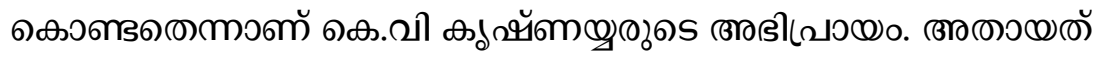

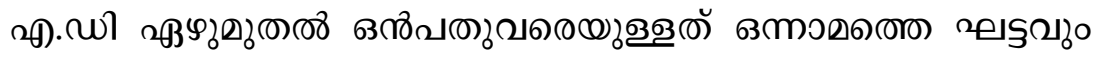

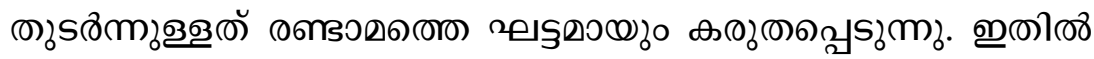

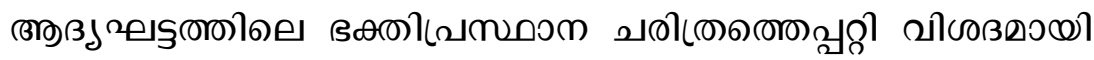

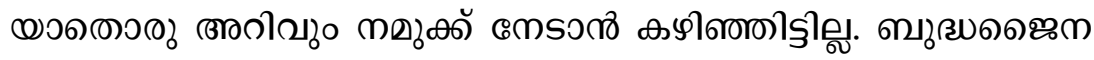

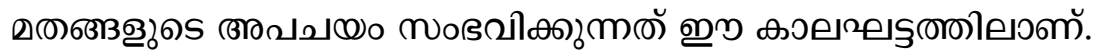

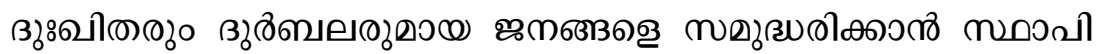

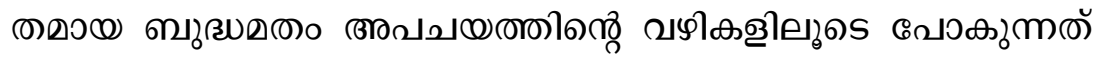

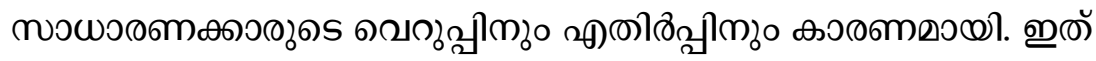

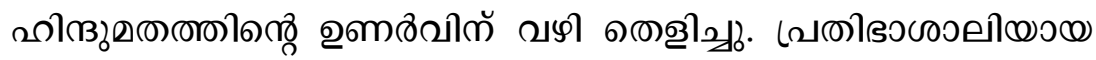

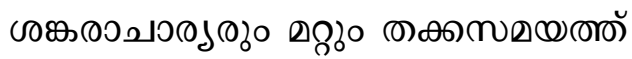

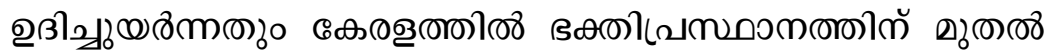

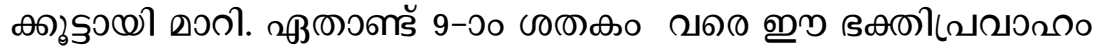

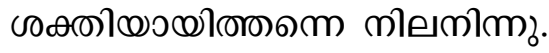

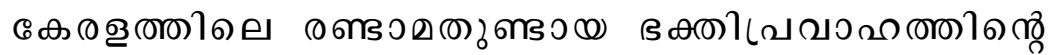

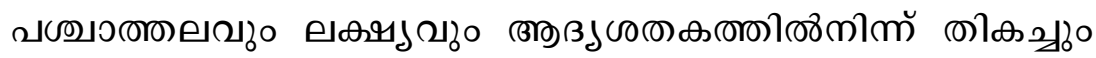

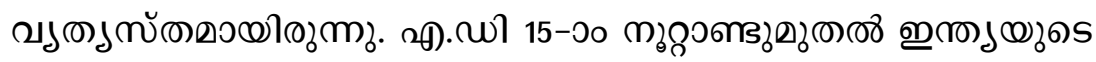

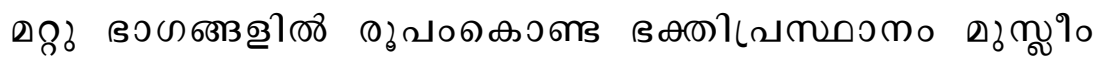

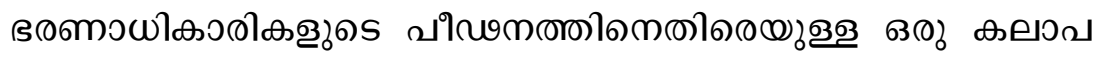

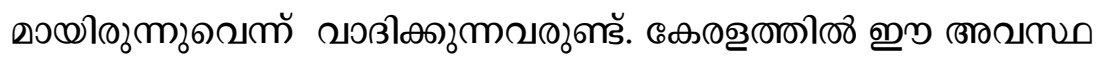

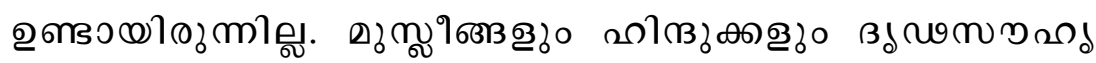

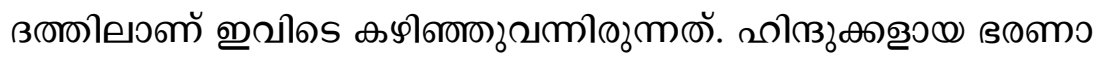

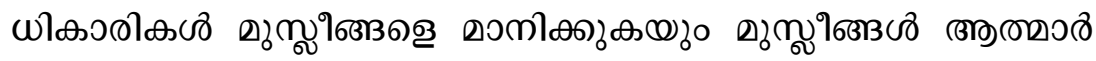

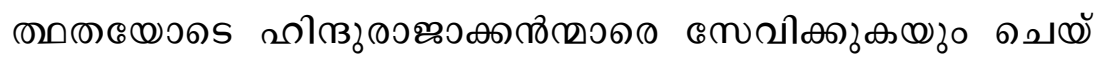

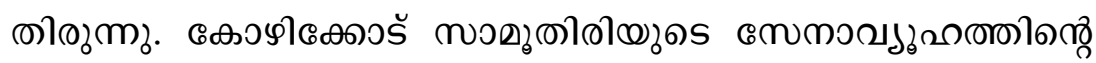




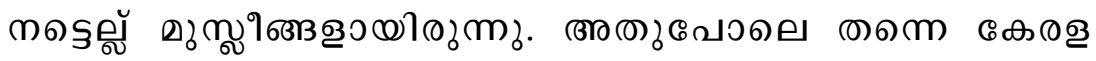

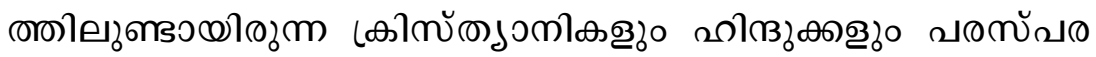

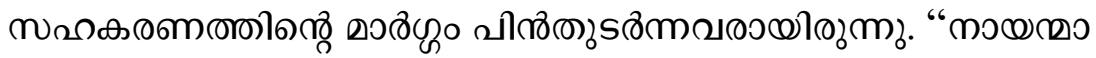

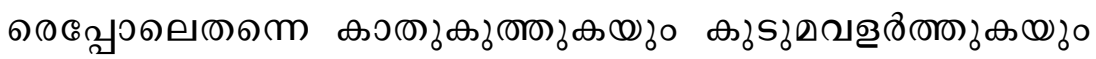

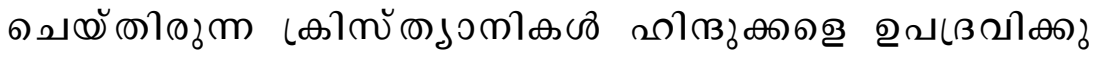

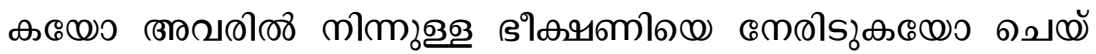

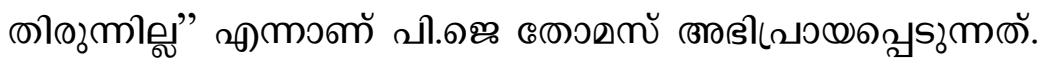

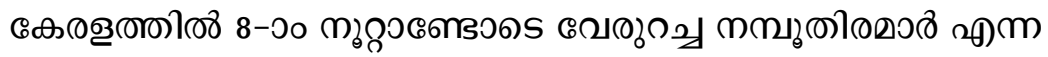

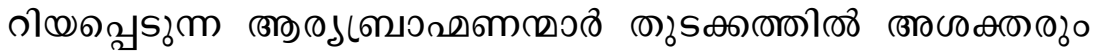

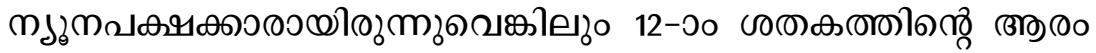

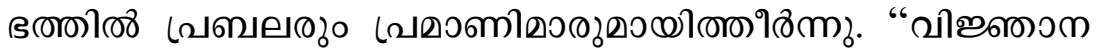

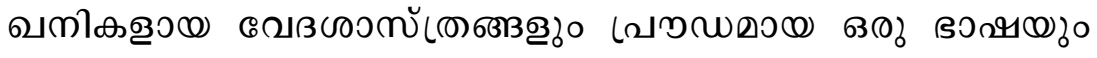

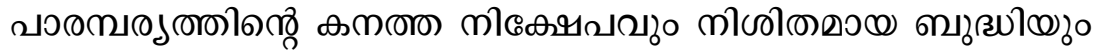

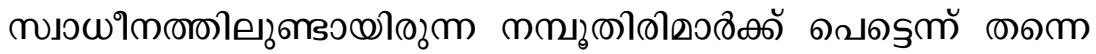

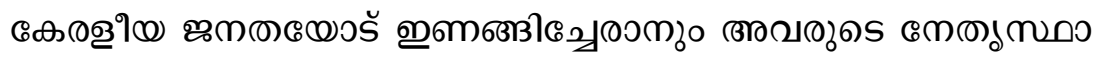

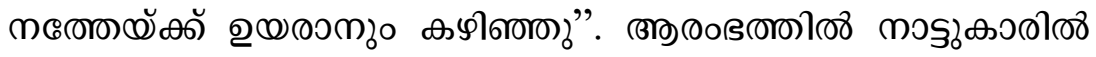

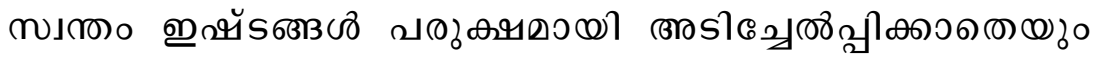

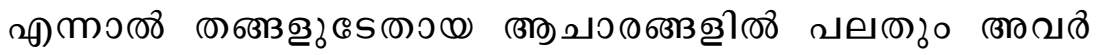

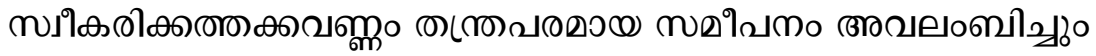

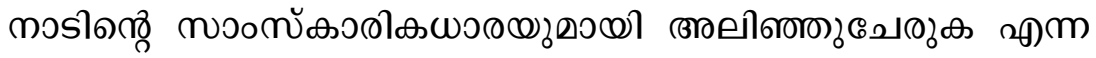

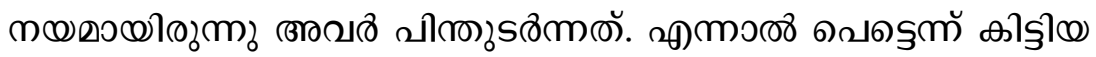

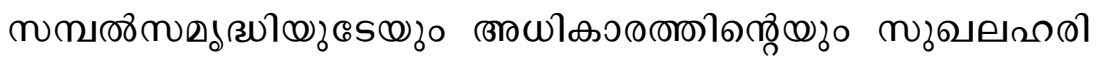

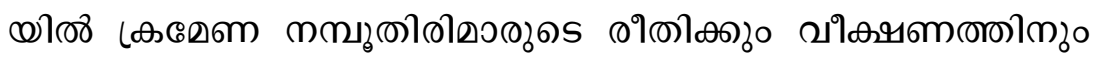

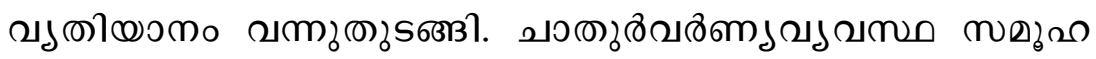

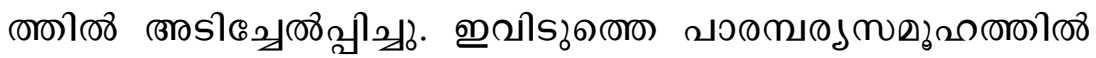

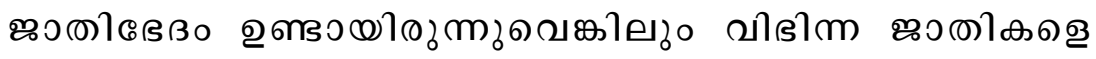




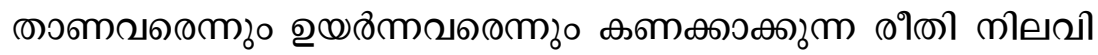

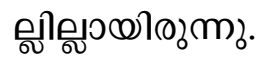

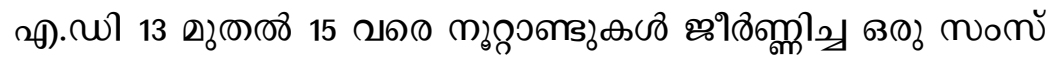

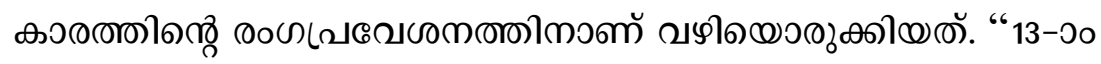

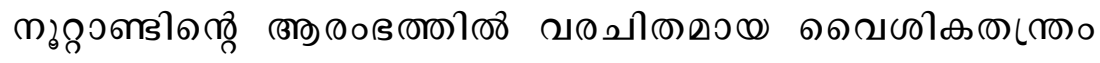

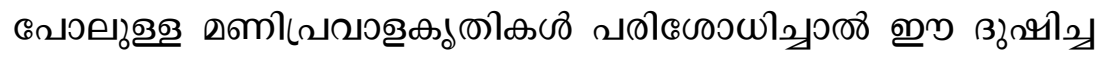

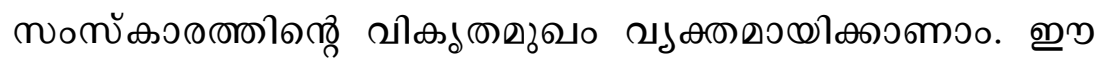

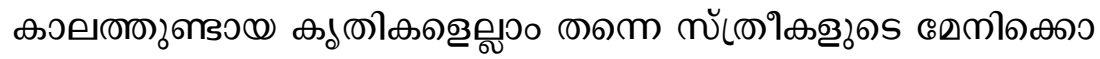

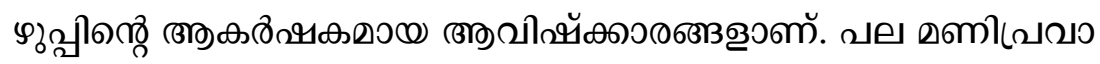

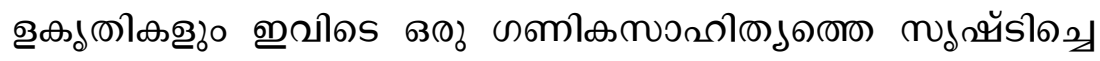

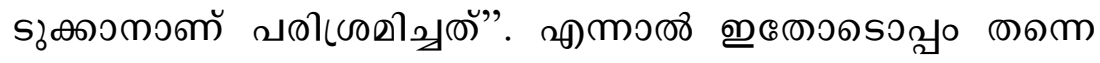

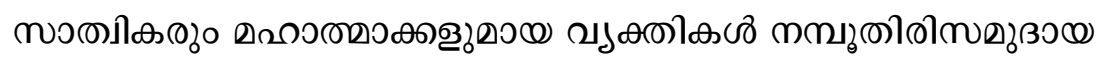

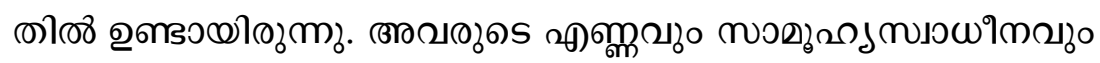

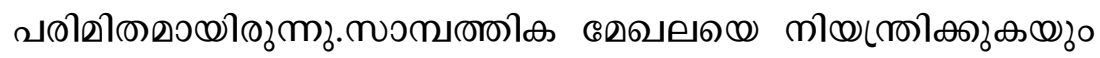

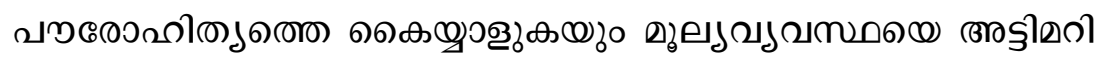

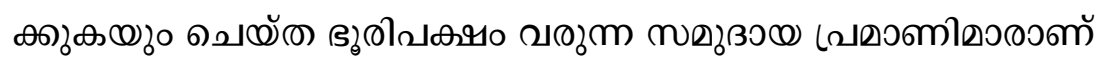

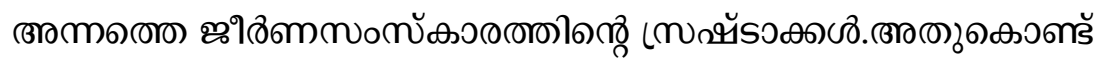

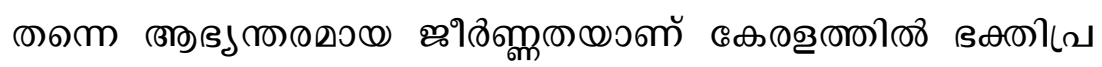

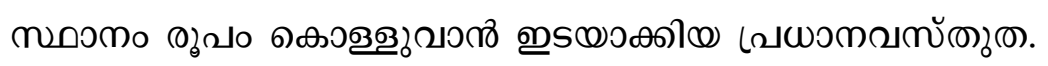

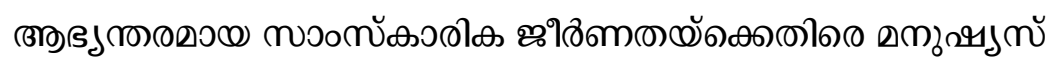

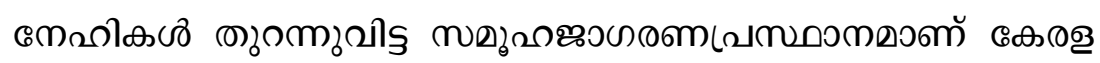

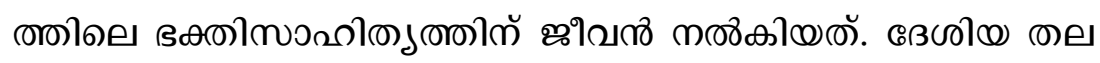

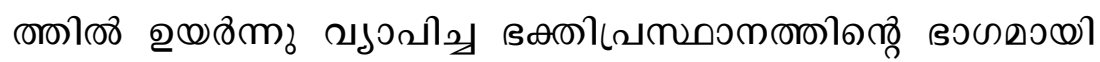

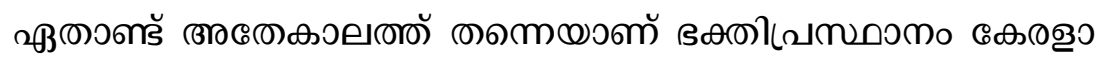

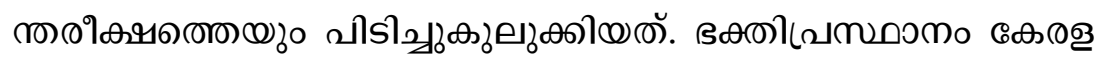

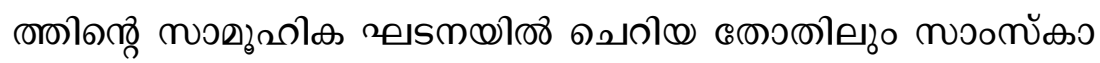




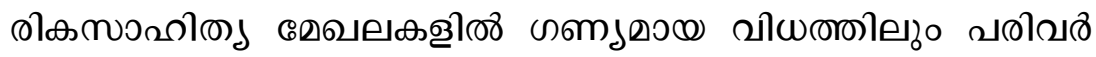

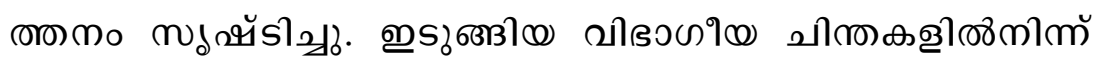

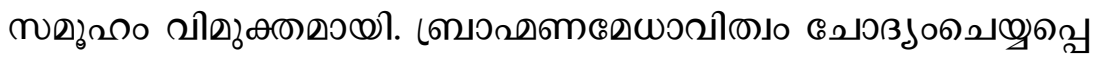

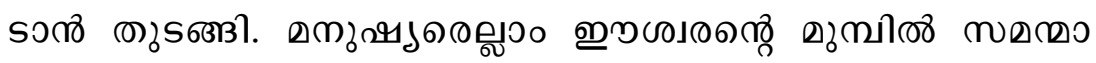

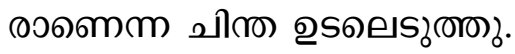

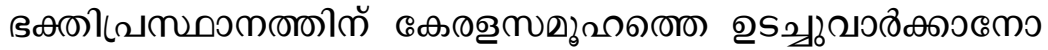

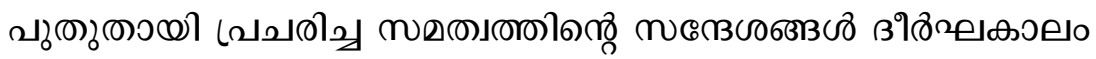

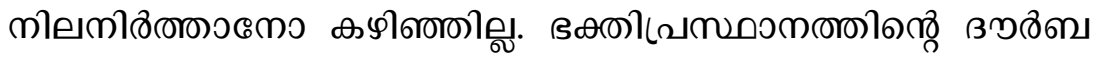

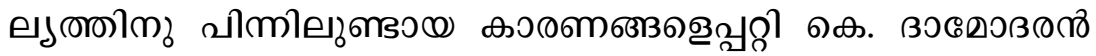

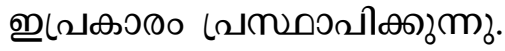

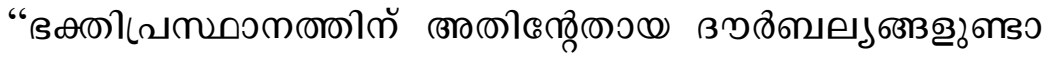

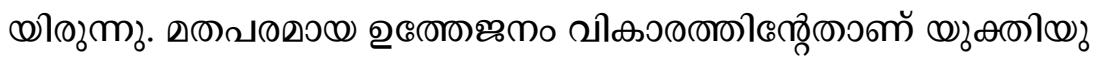

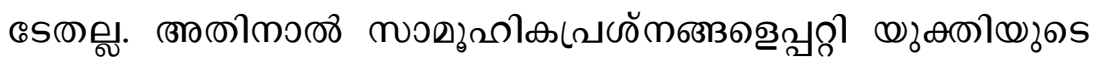

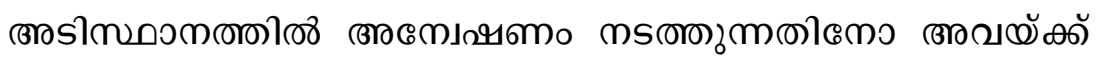

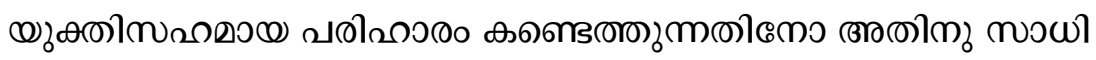

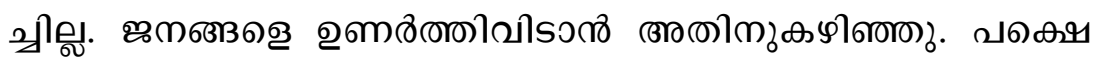

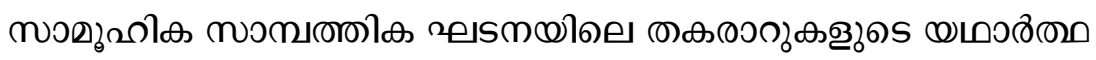

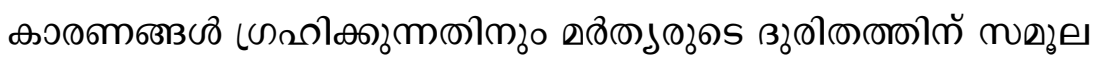

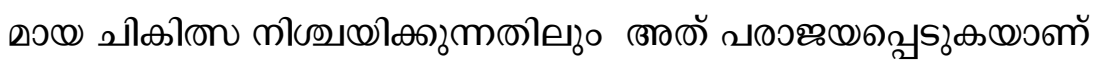

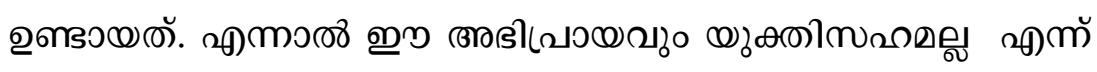

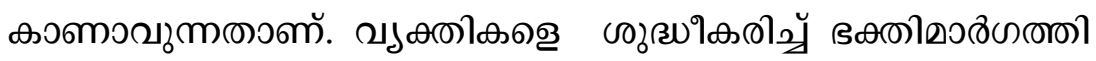

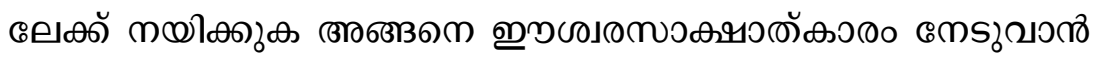

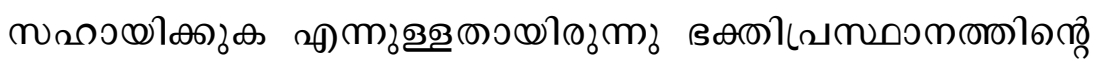

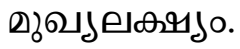

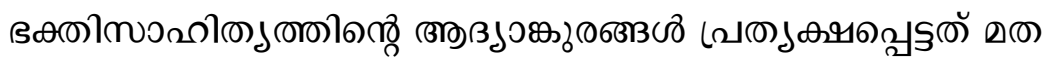

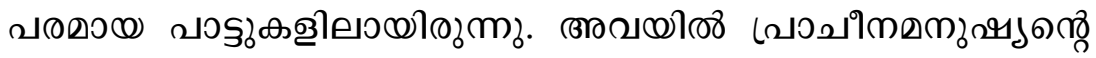




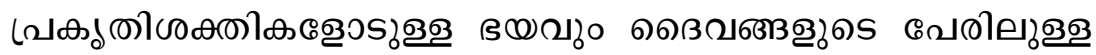

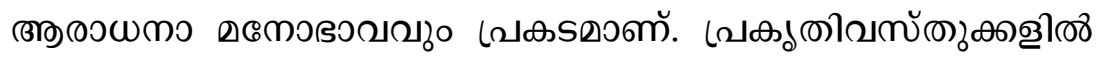

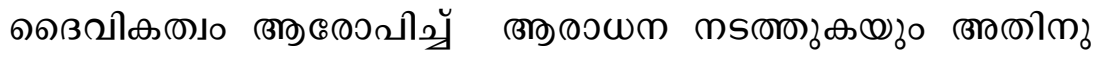

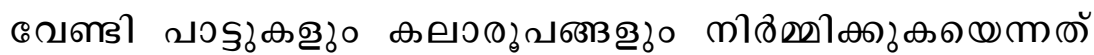

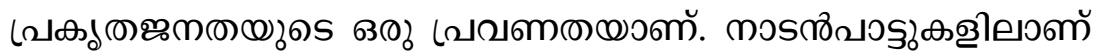

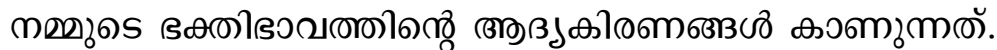

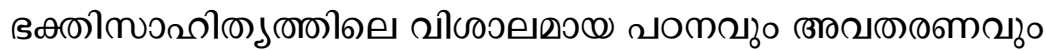

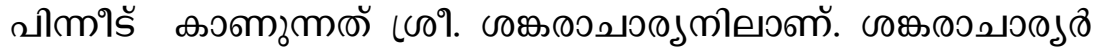

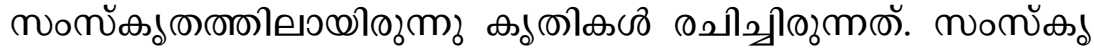

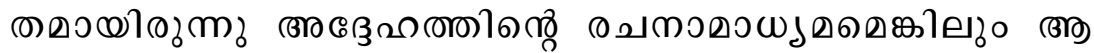

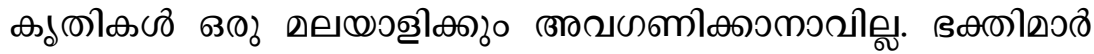

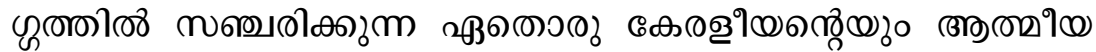

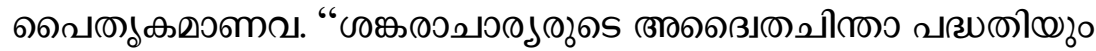

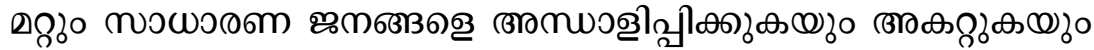

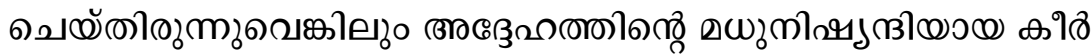

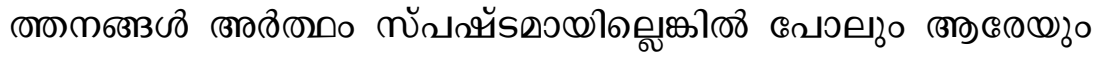

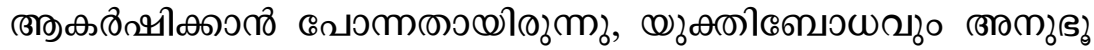

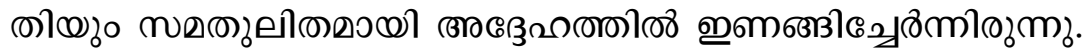

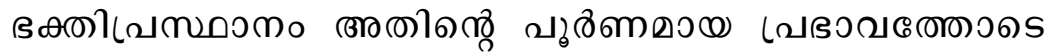

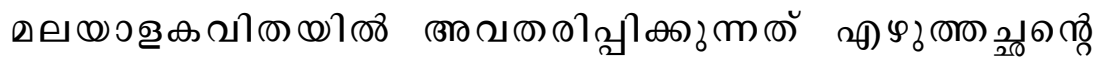

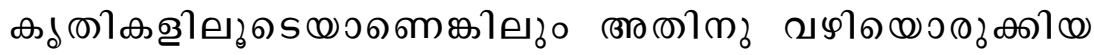

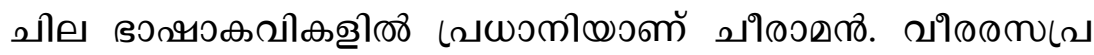

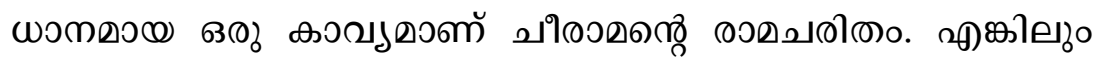

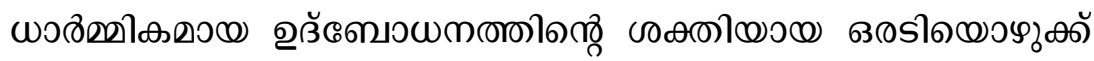

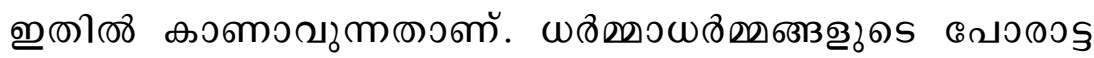

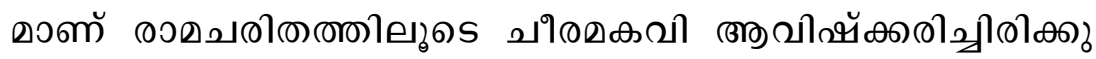

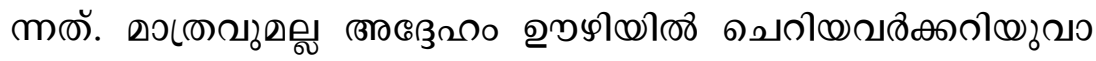




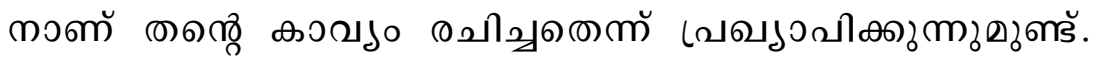

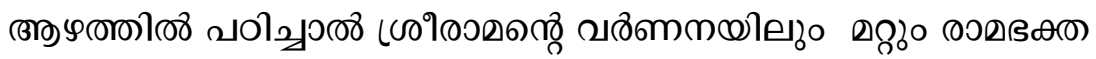

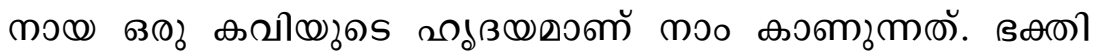

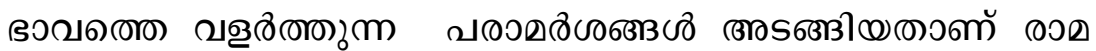
دரிலை.

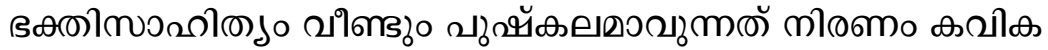

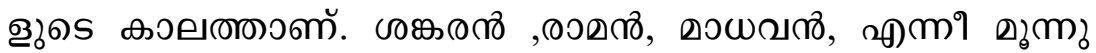

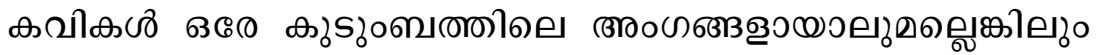

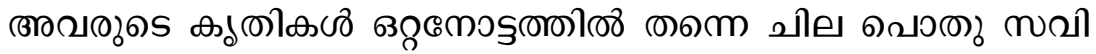

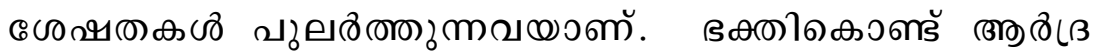

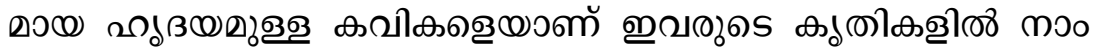

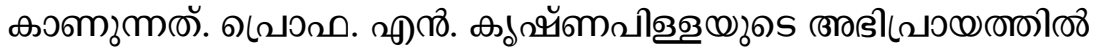

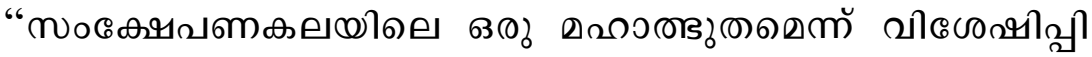

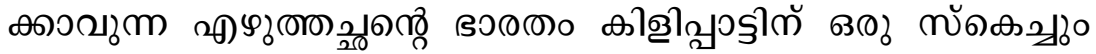

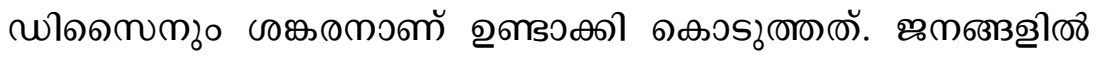

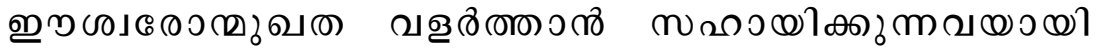
லுm) कஸिएक

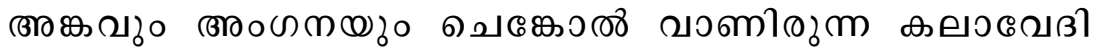

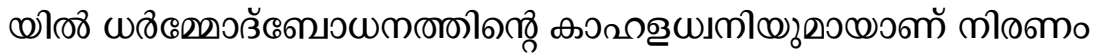

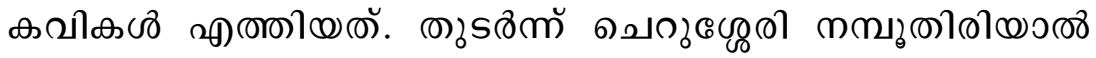

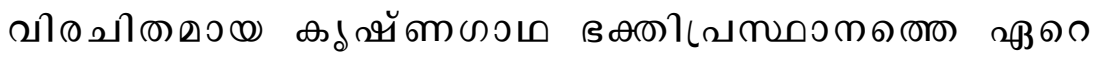

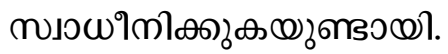

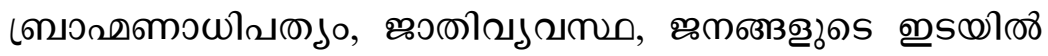

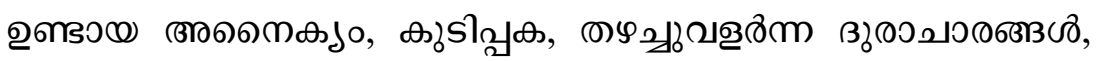

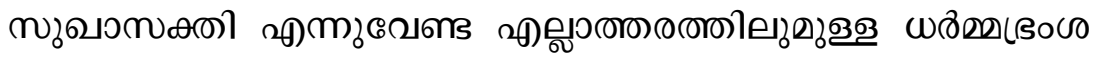

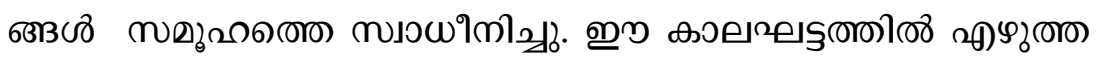

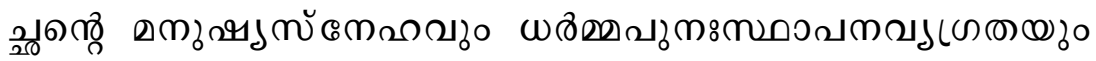




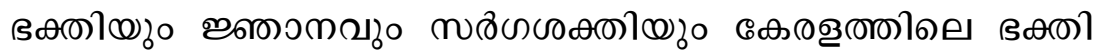

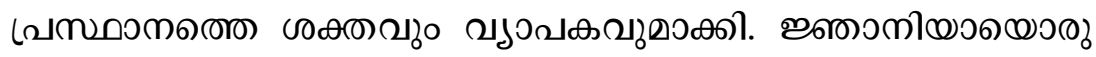
চுத

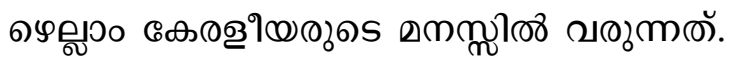

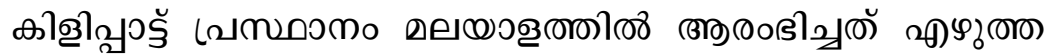

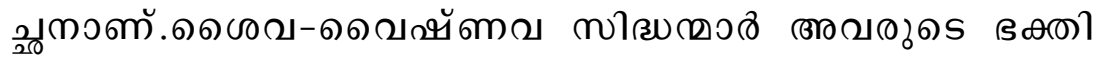

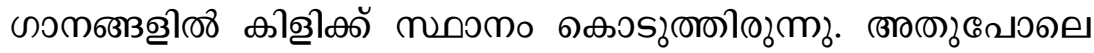

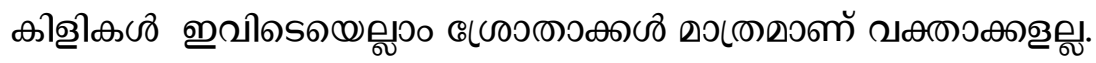

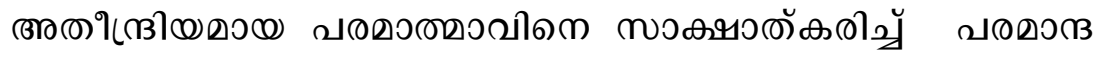

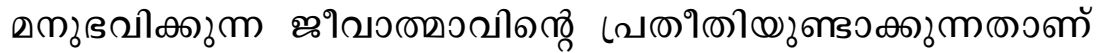

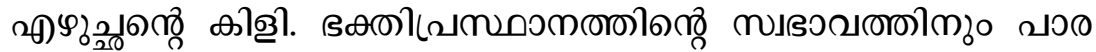

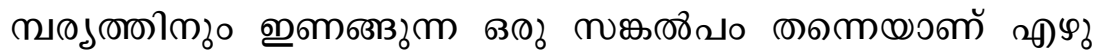

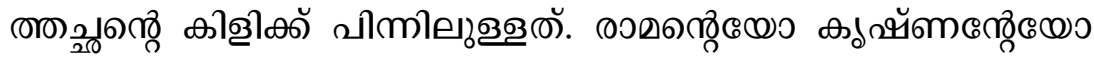
ாலவం ஃறி வலுவன்

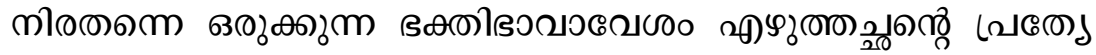

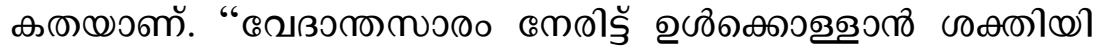

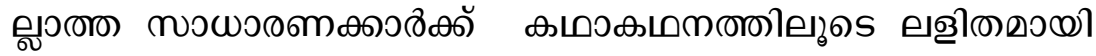

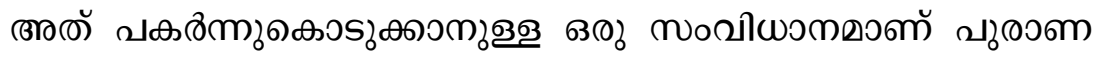

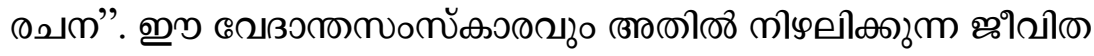

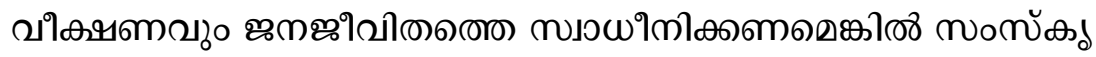

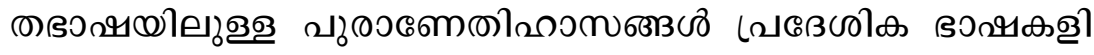

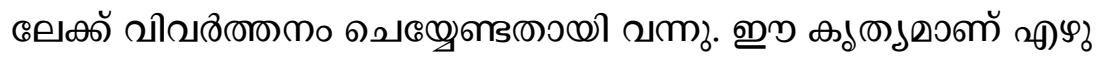

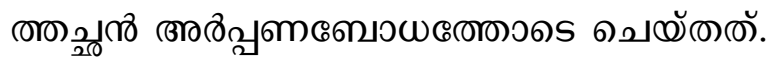

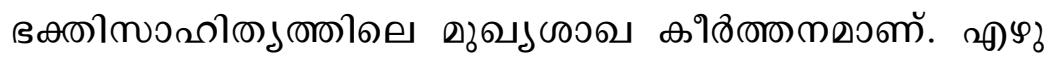
கை ஷி

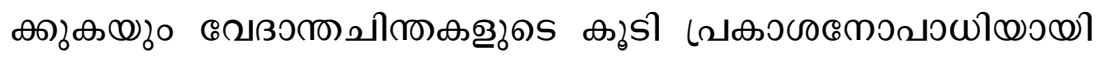




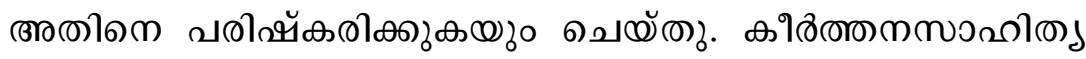

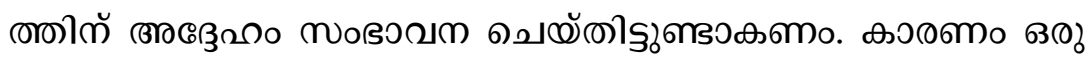

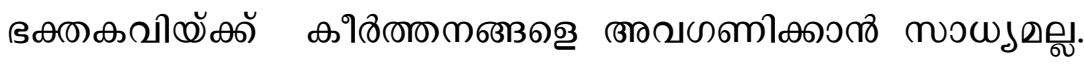

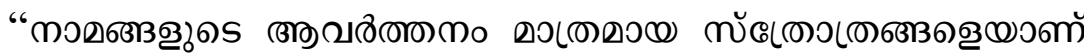

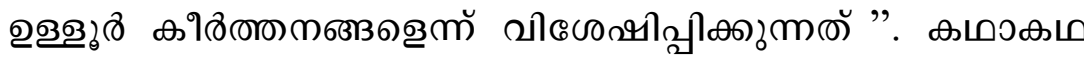

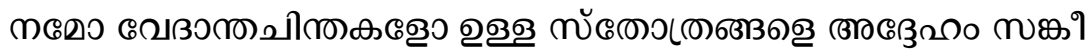

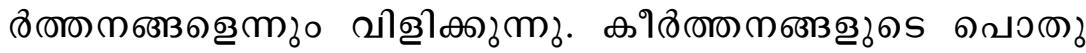

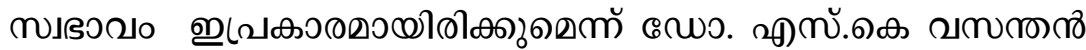

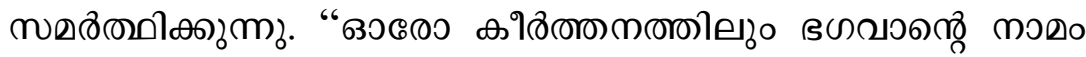

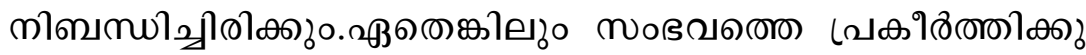

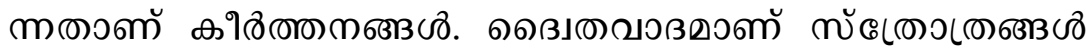

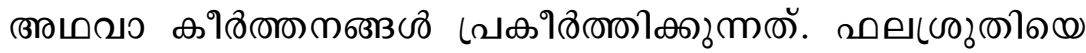

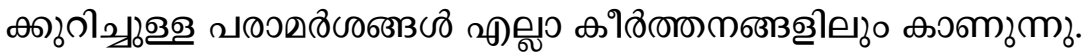

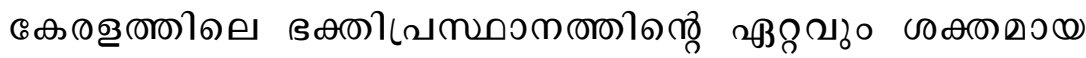

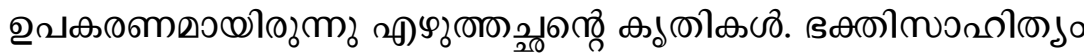

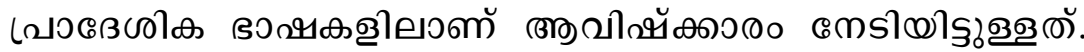

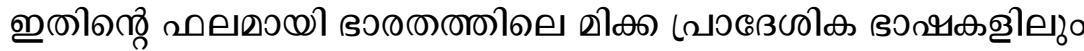

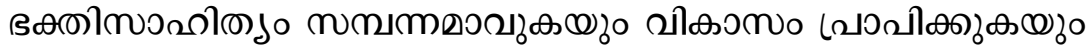

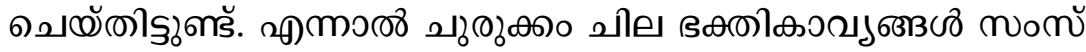

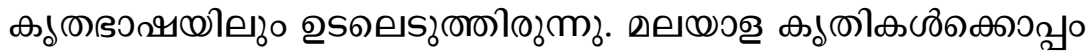

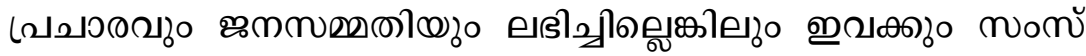

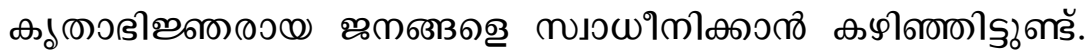

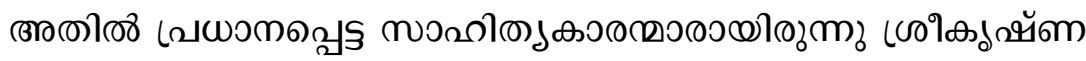

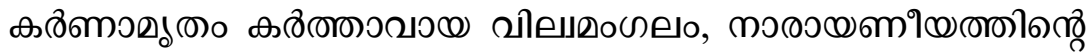

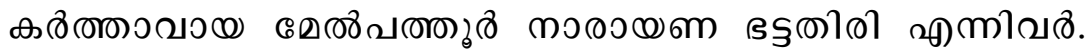

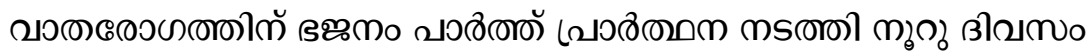

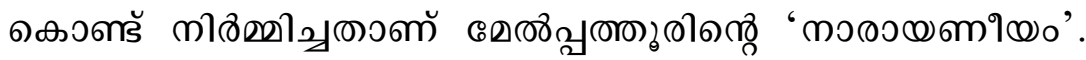




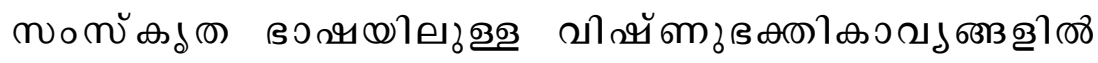

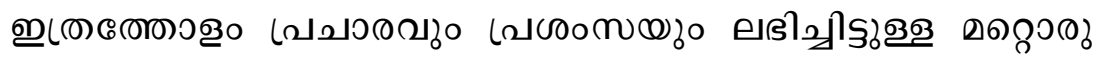

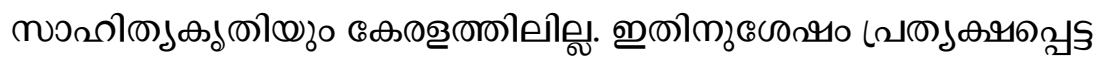

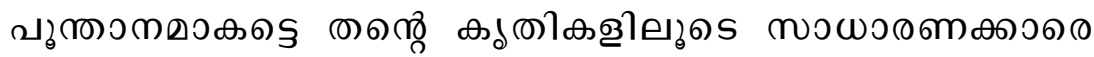

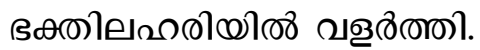




\section{3.

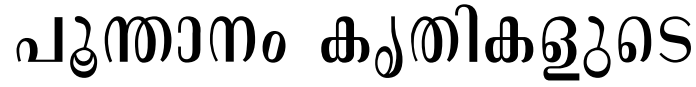

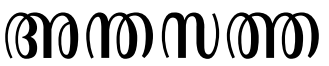

\section{mัromecos}

(క0

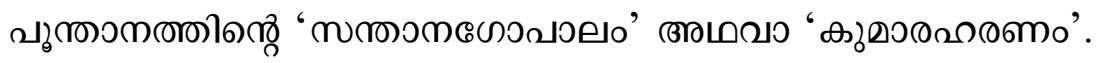

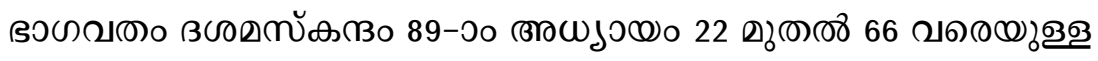

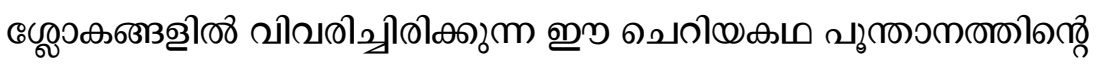

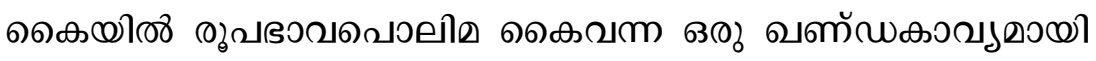

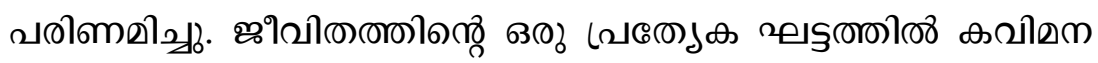

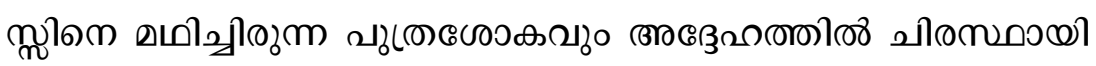

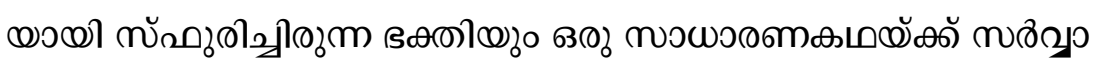

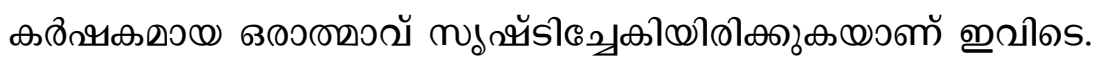

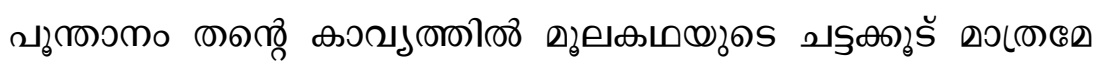

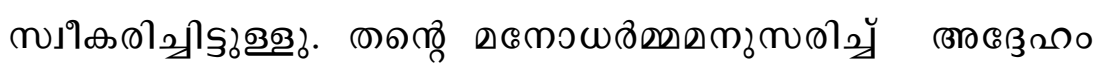

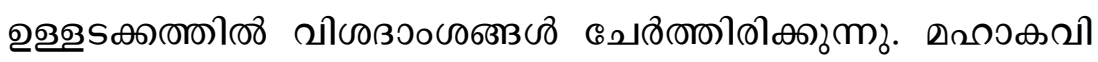

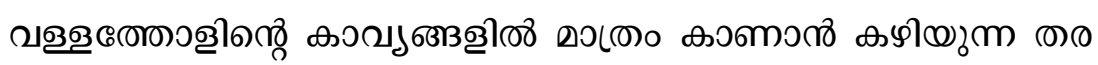

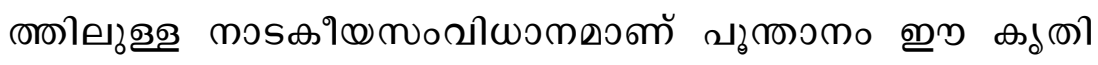

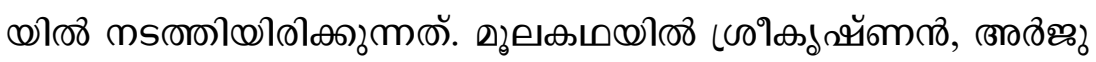




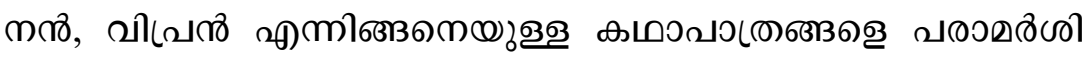

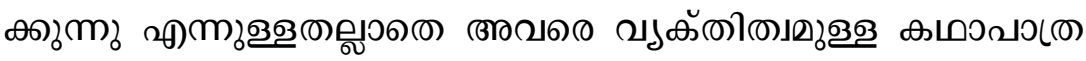

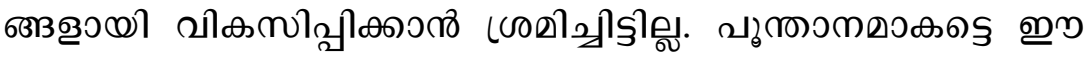

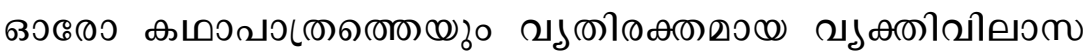

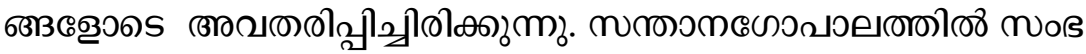

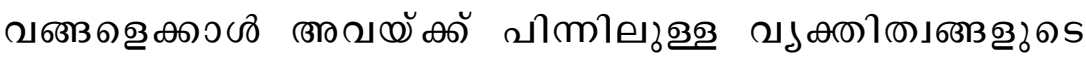

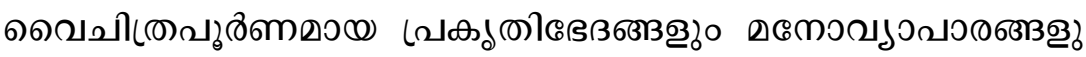

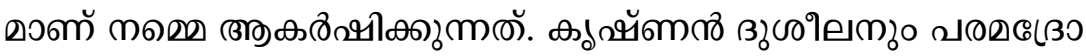

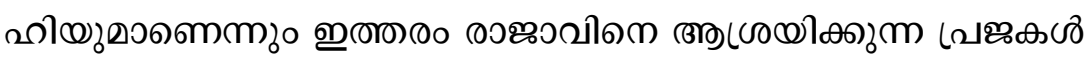

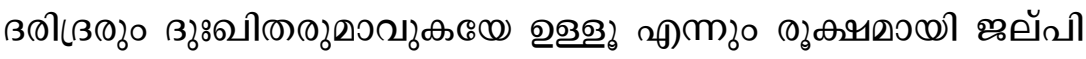

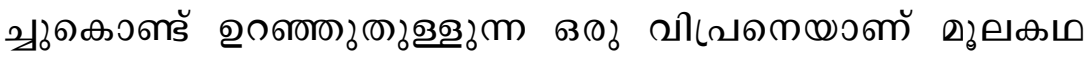

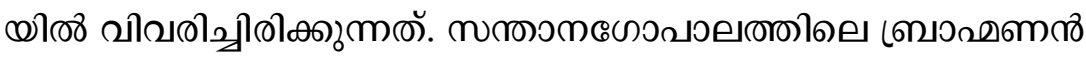

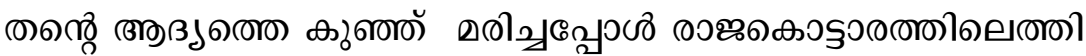

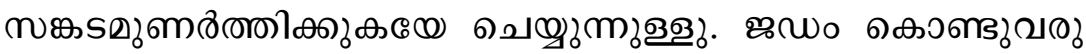

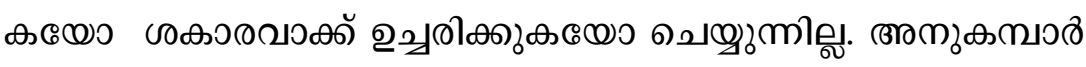

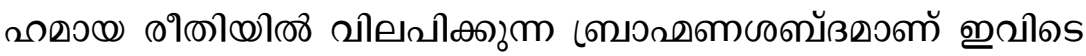

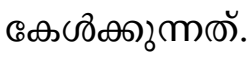

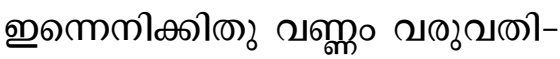

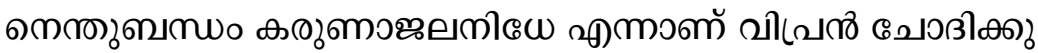

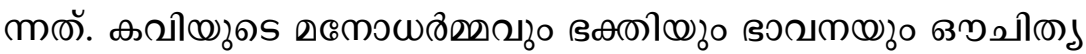

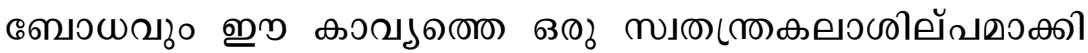

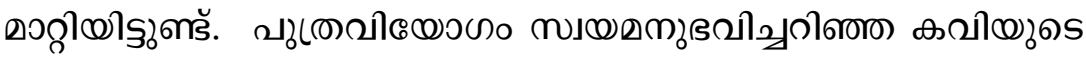

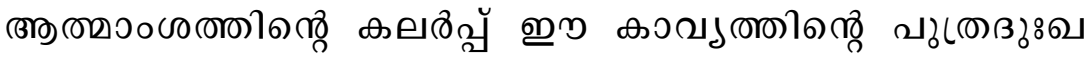

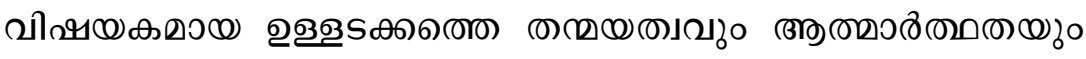

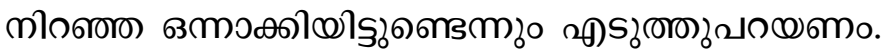


(

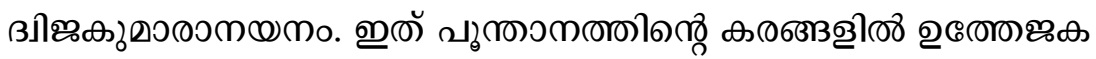

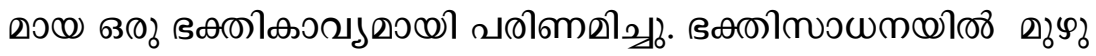

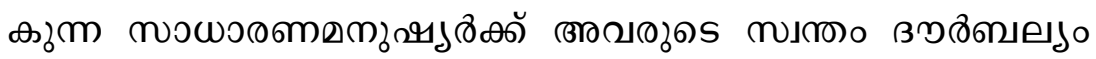

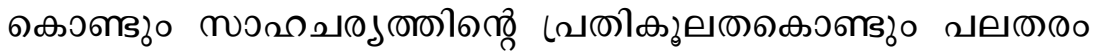

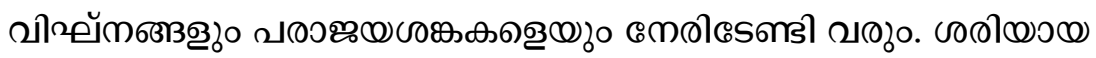

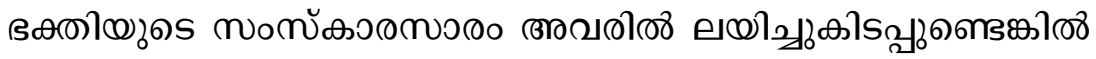

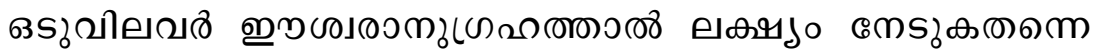

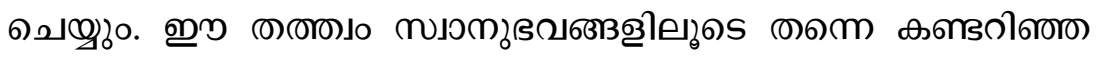

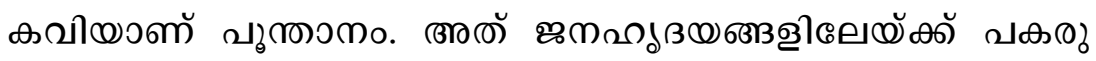

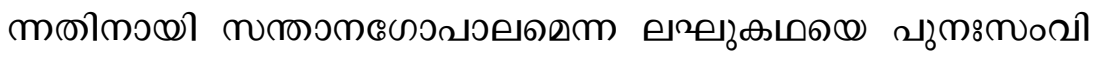

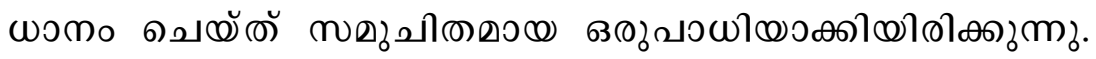
வைடிாัவைகன்

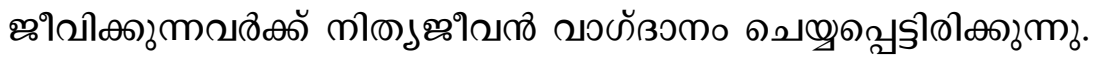

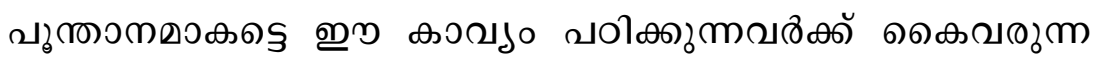

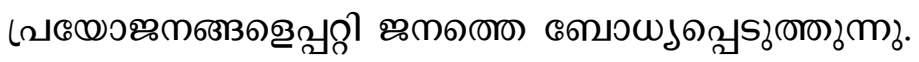

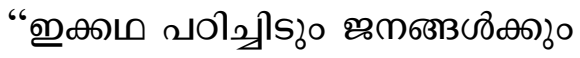

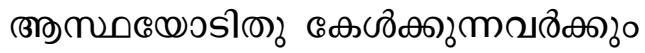

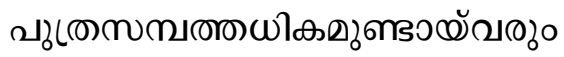

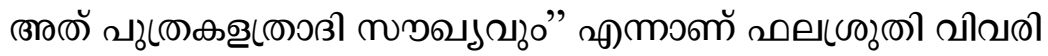

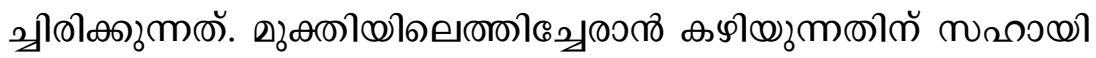

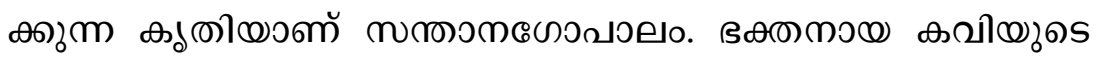

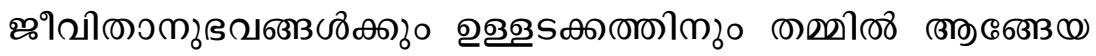

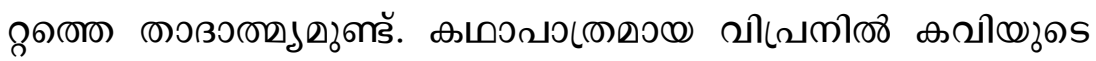

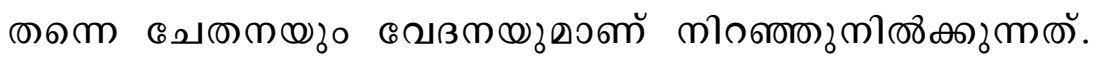

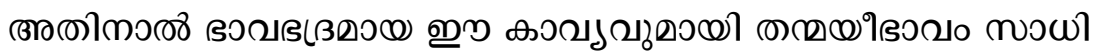




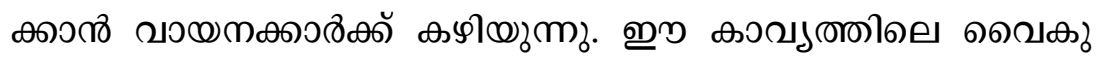

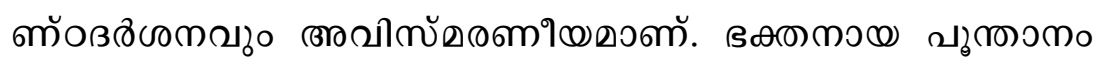

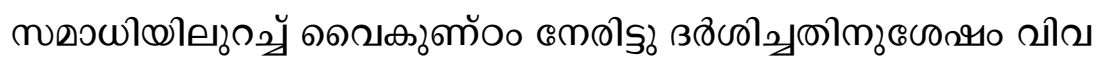

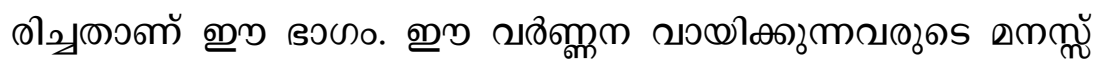

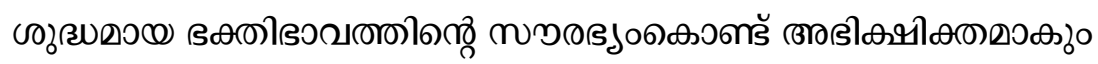

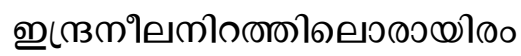

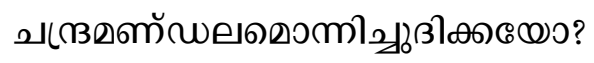

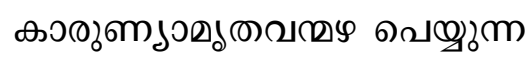

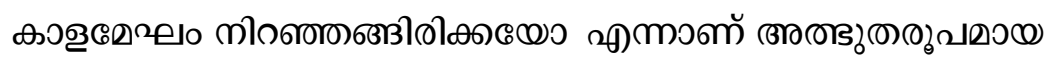

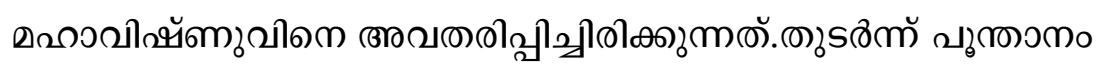

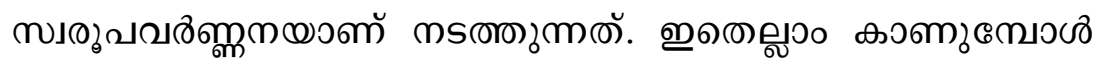

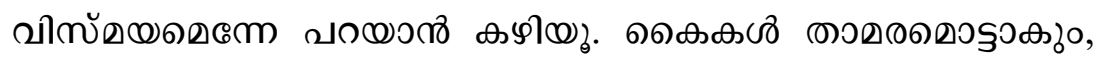

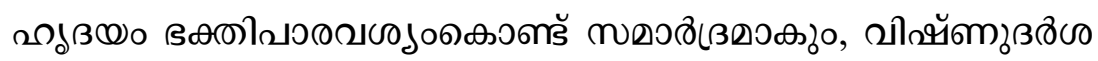

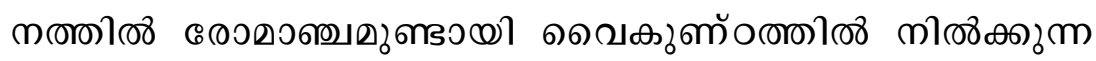

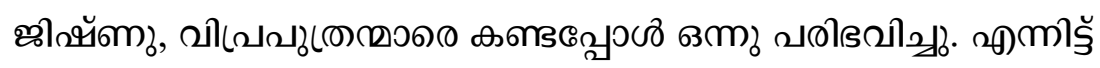

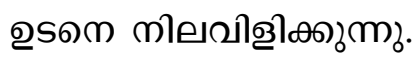

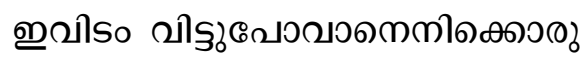

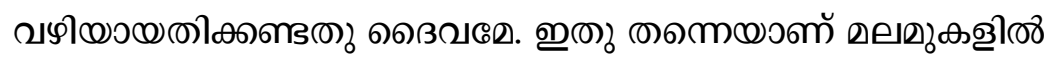

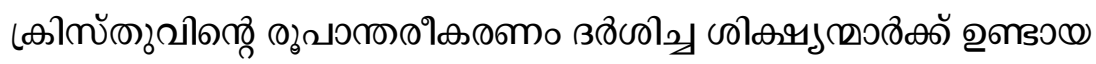

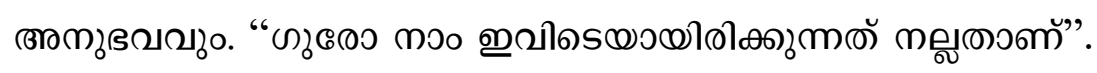

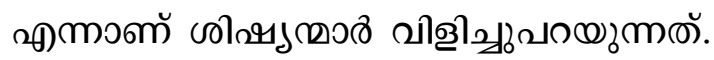

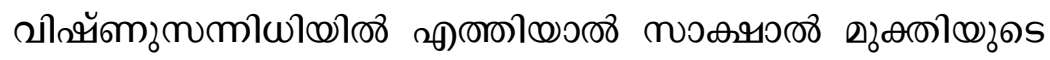

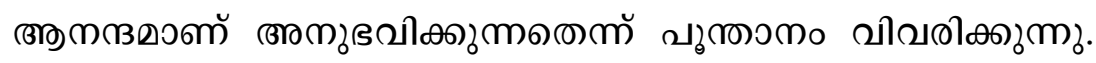

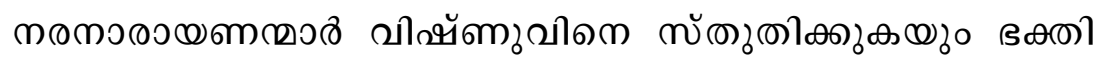

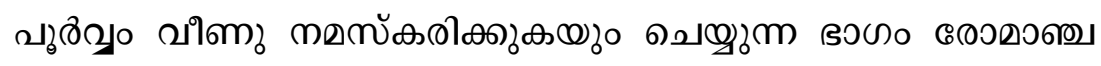




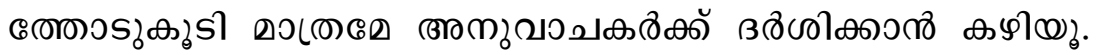

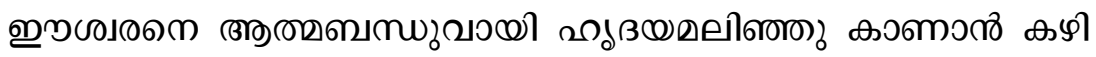

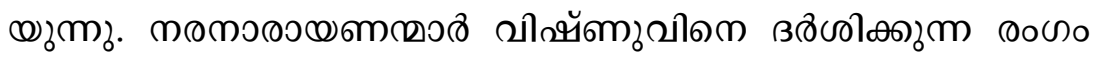

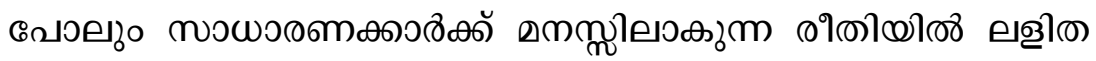

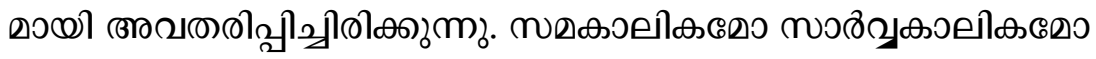

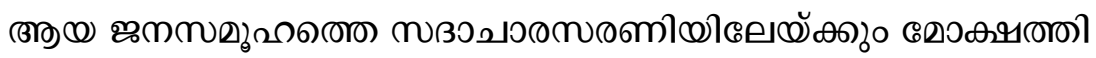

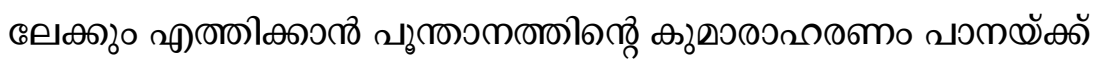

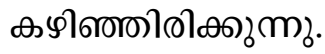

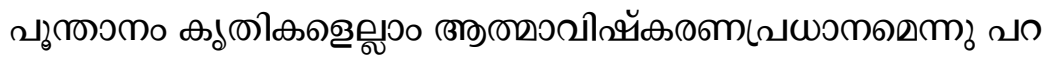

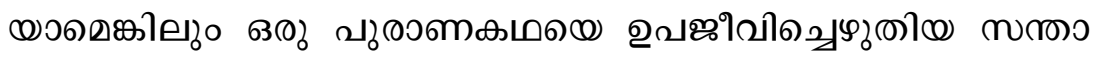

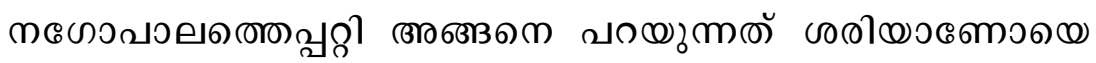

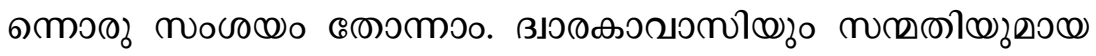

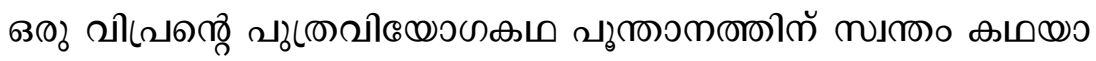

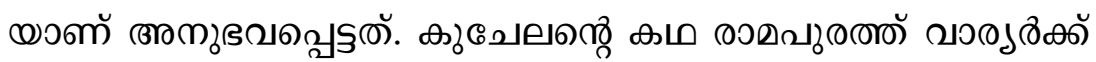

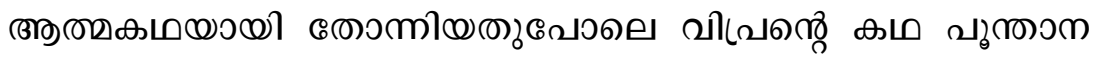

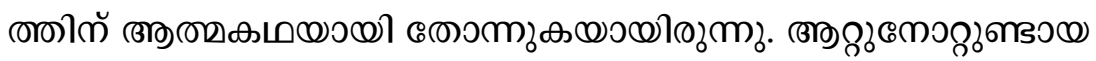

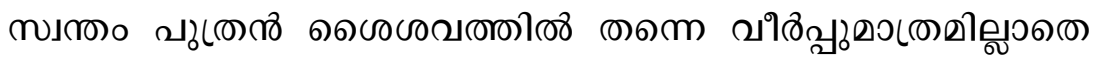

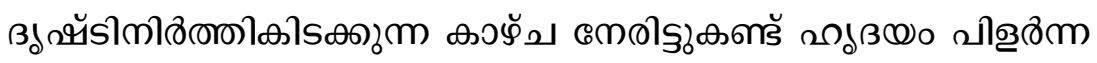

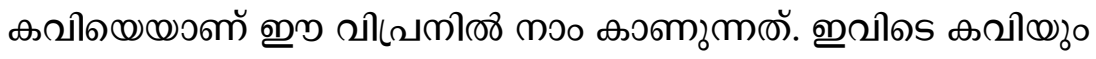

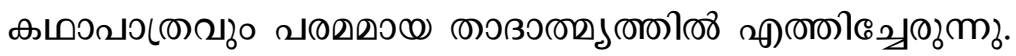

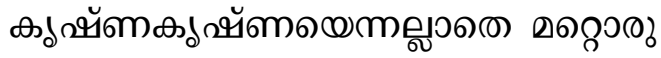

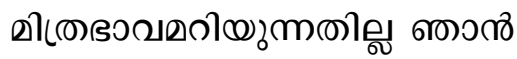

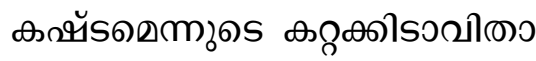

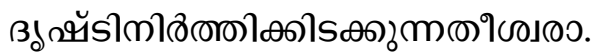




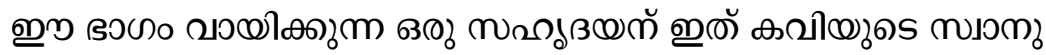

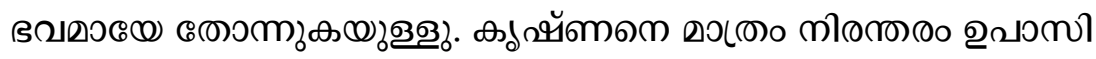

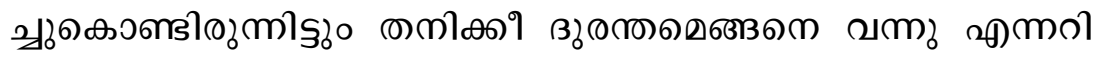

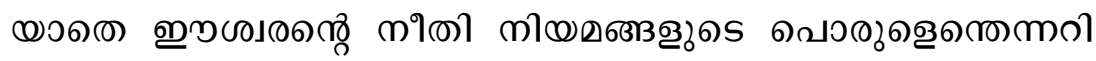

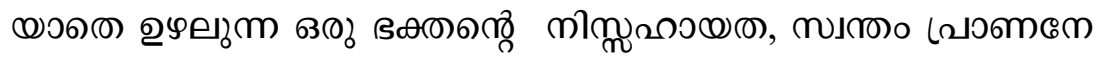

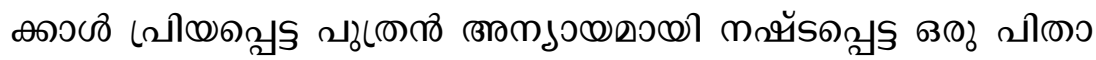

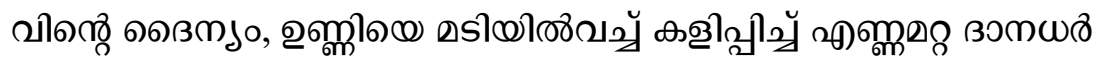

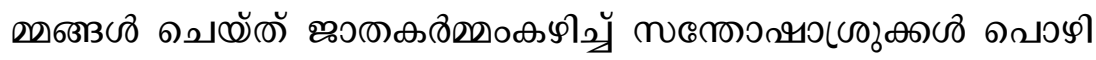

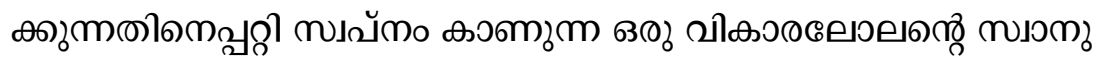

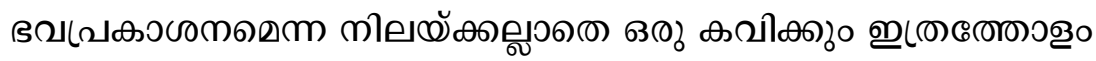

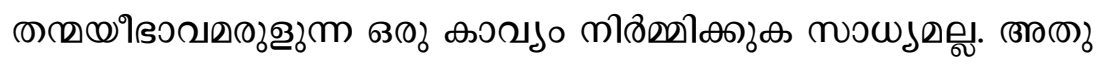

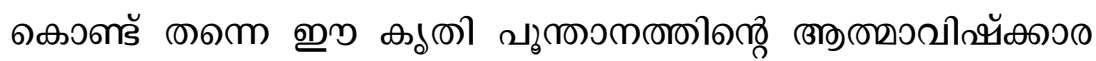

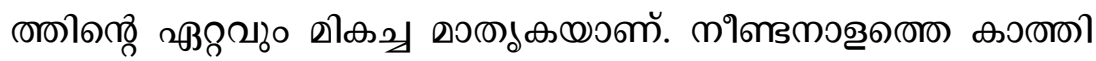

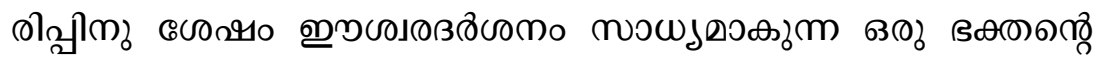

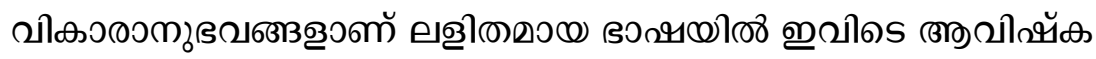

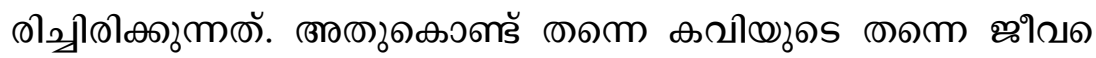

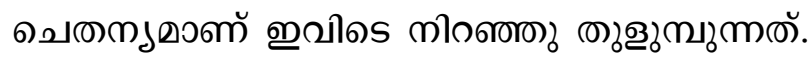

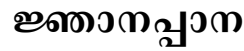

வ

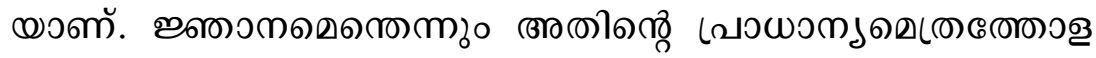

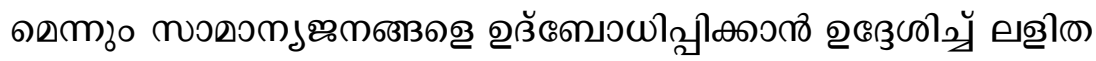

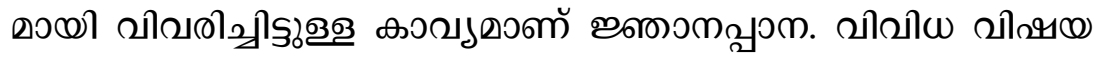

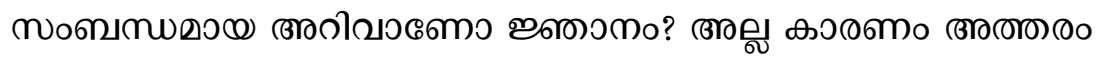

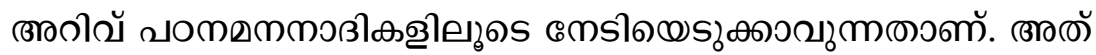

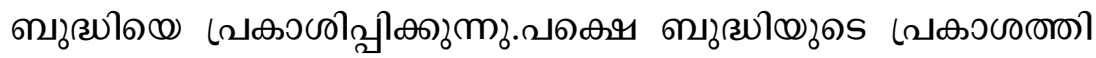

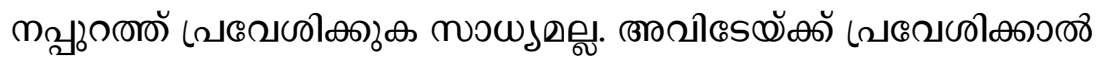

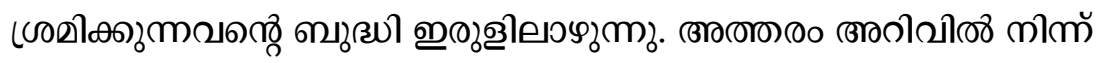




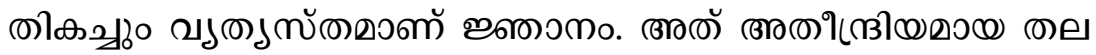

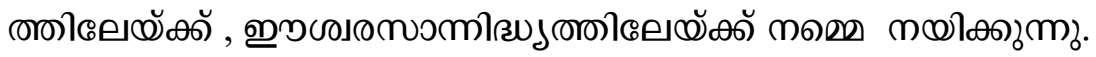

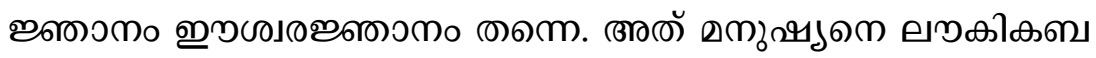

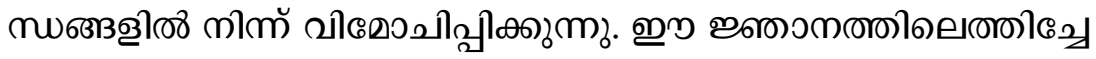

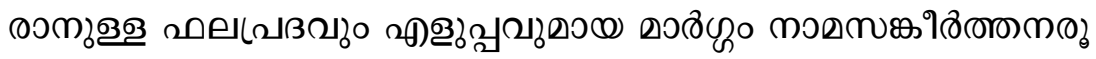

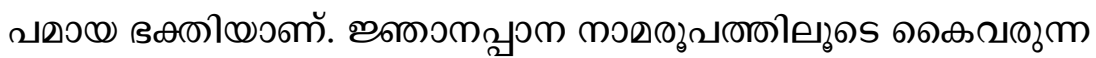

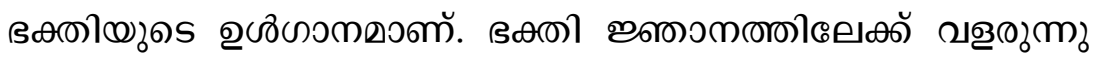

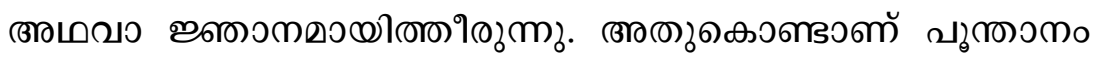

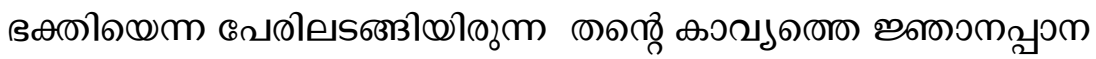
ஆ

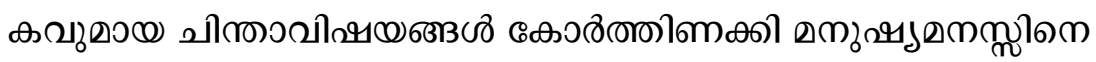

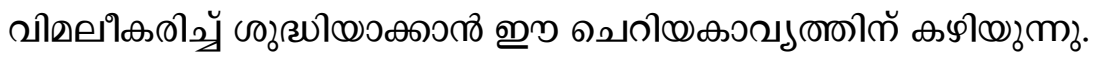

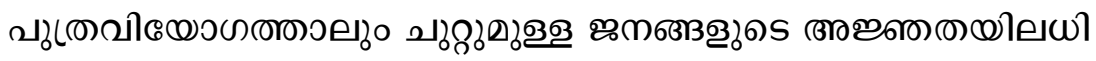

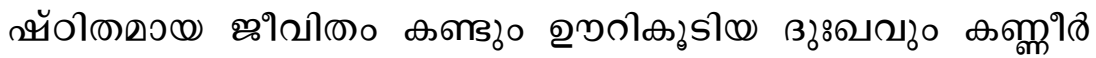

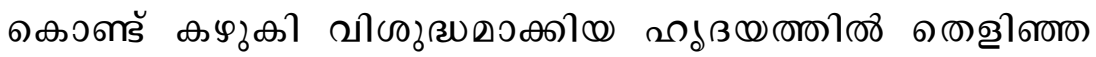

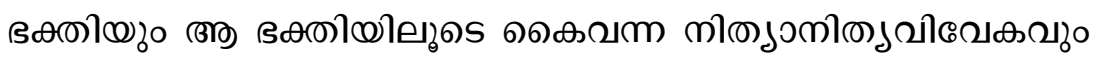

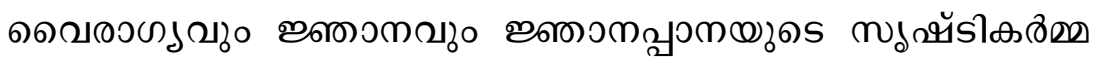

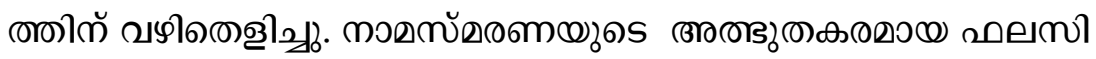

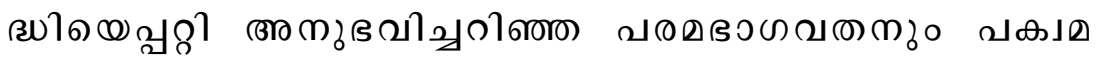

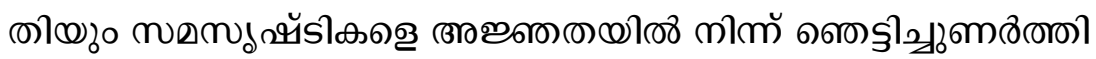

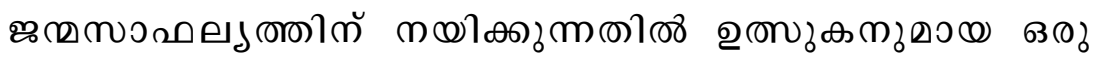

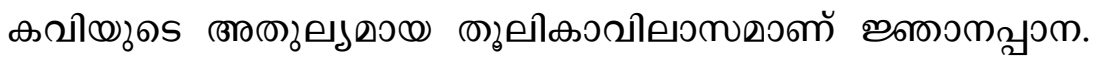

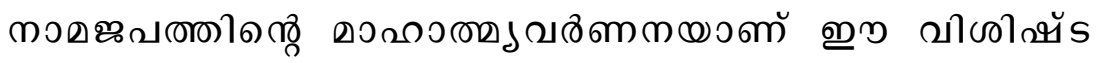

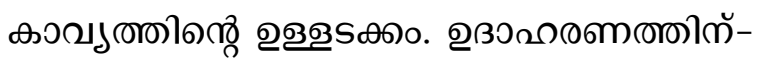




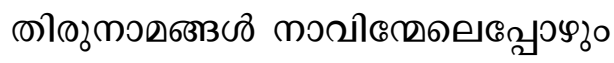

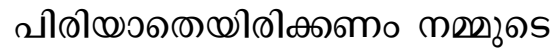

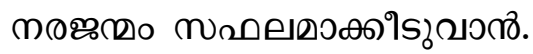

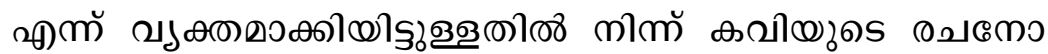

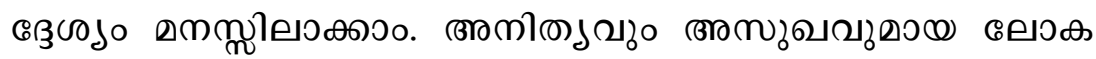

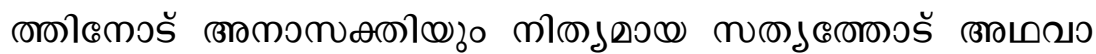

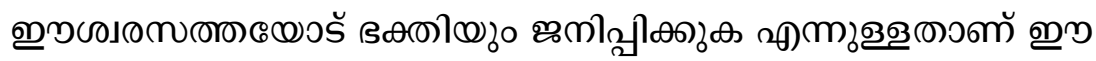

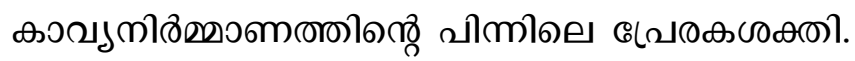

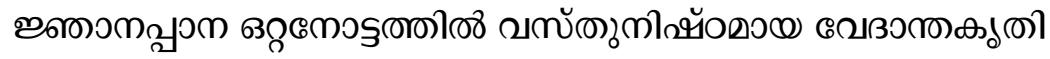

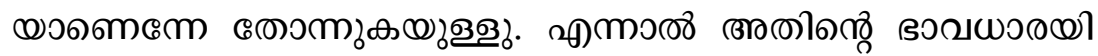

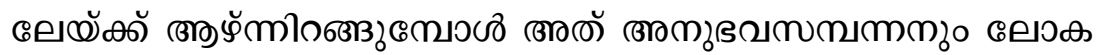

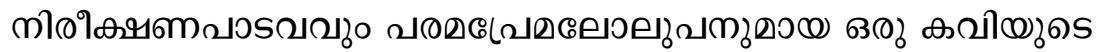

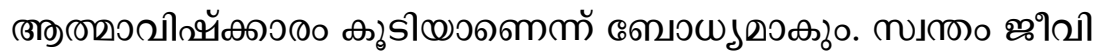

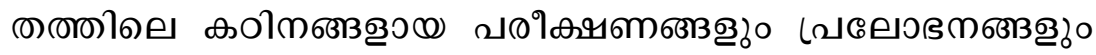

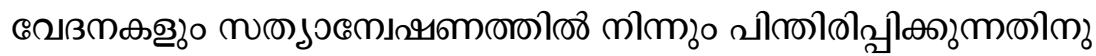

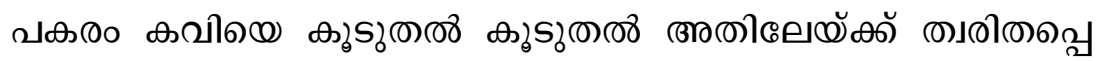

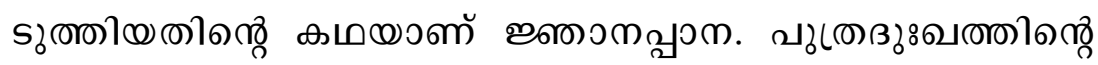

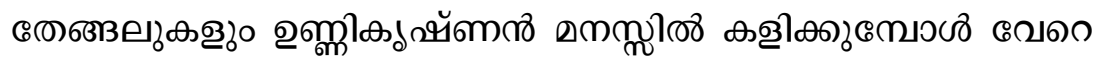

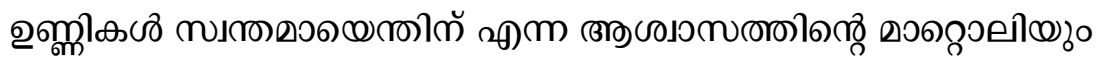

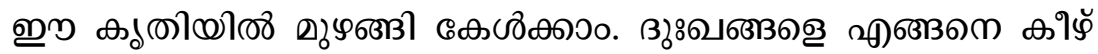

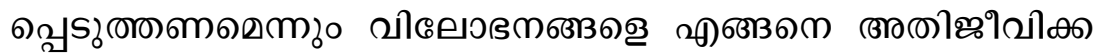

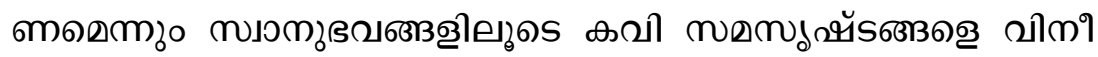

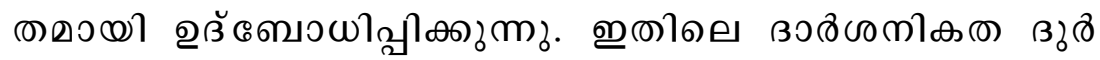

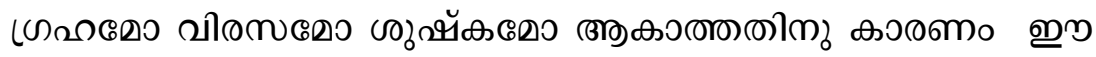

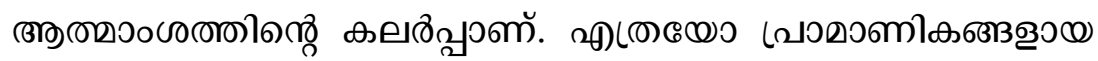

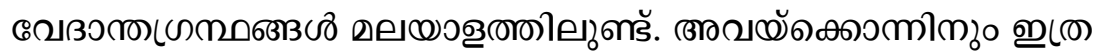




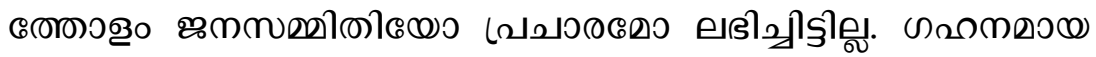

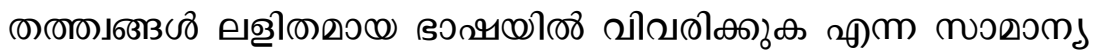

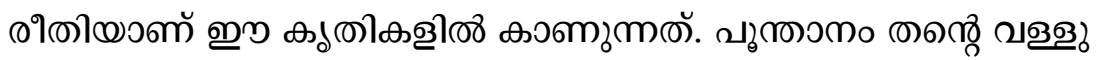

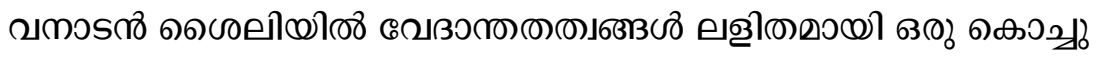

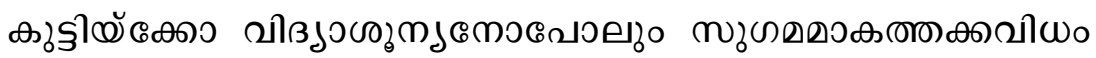

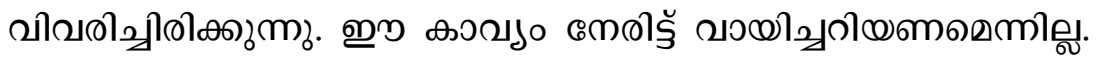

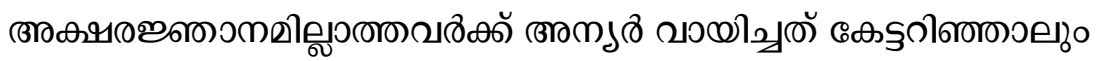

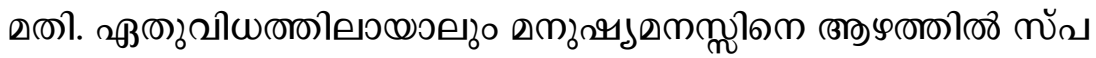

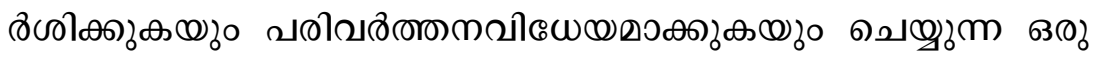

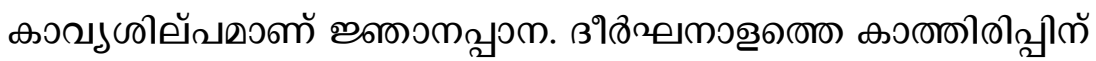

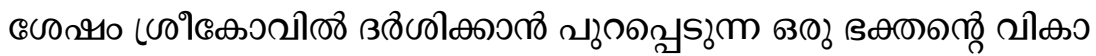

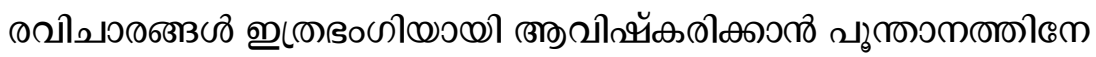
กัติคณ).

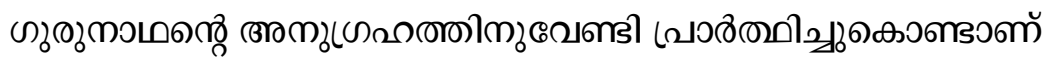

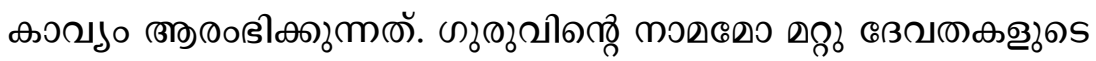

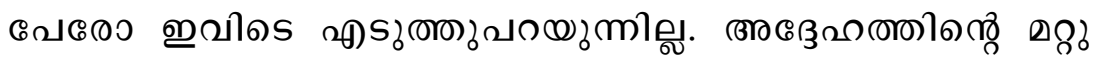

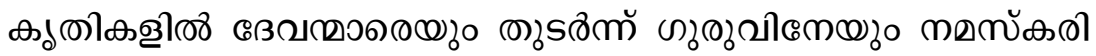

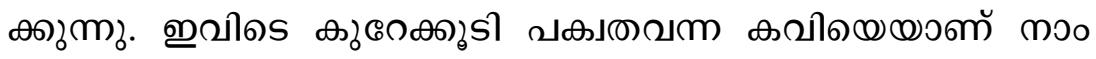

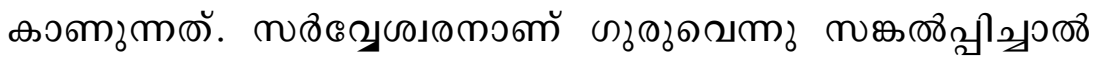

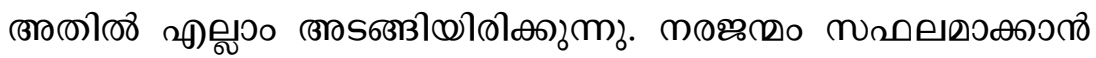

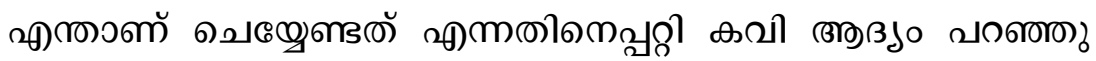

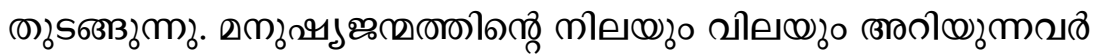

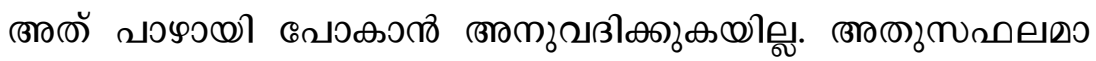

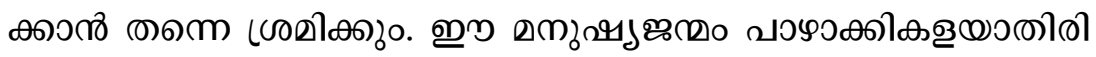

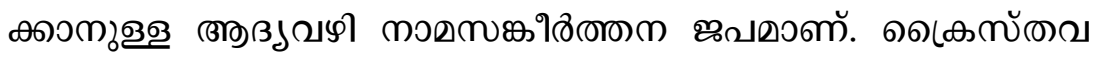

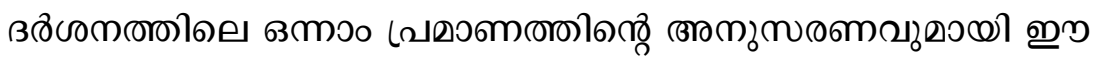

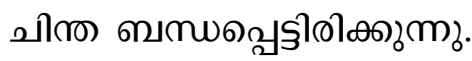




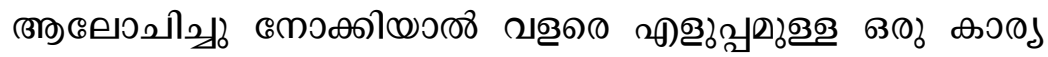

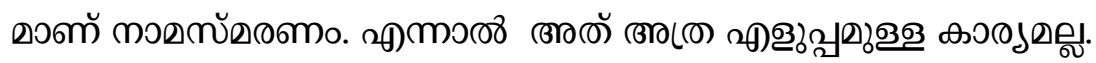

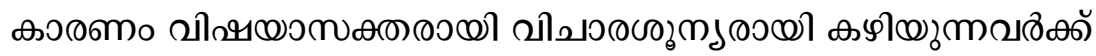

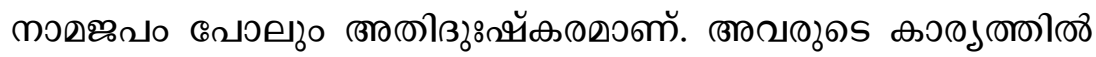

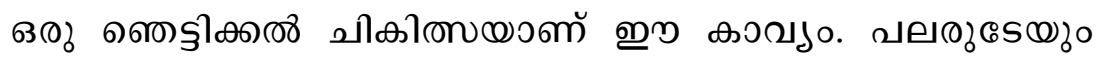

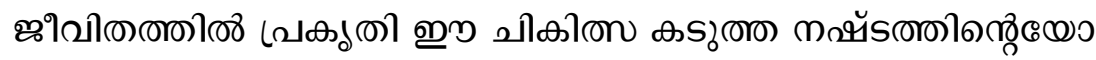

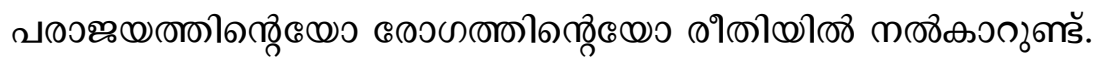

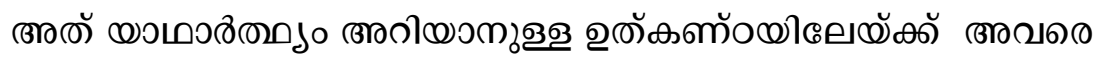

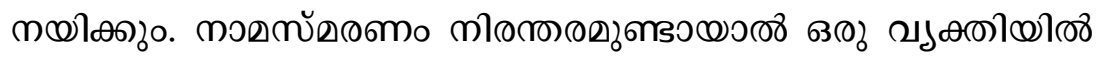

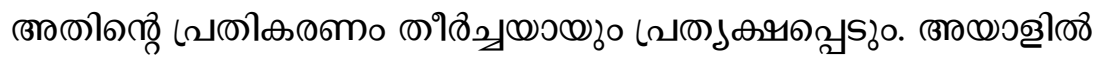

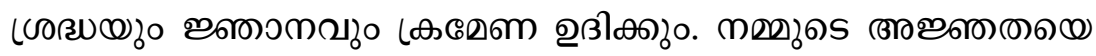

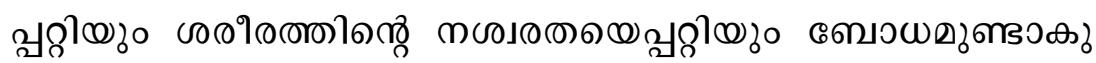

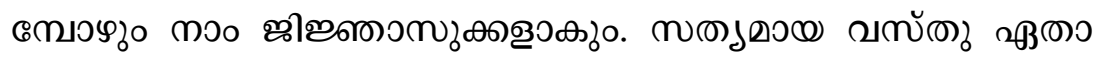

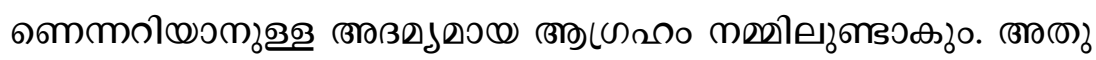

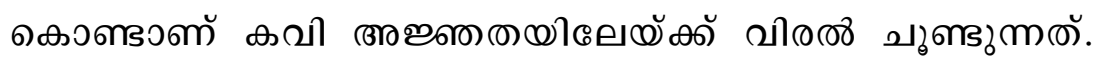

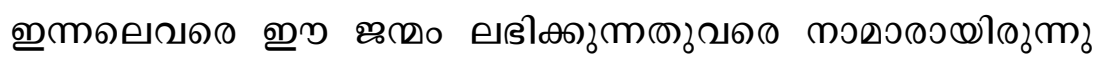

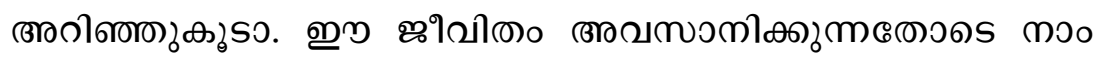

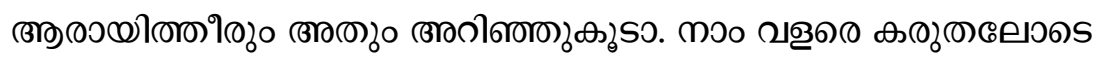

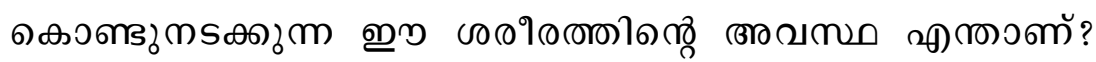

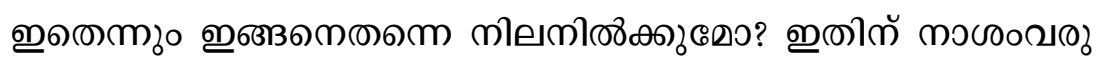

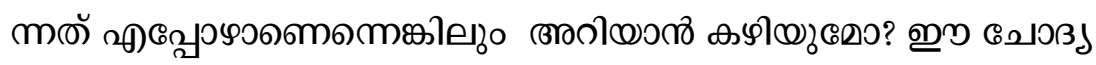

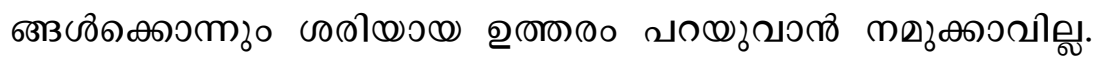

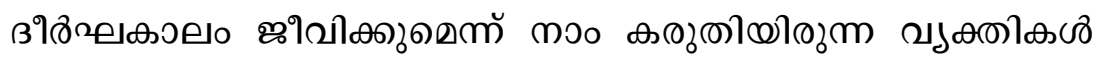

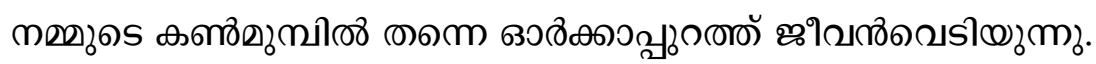

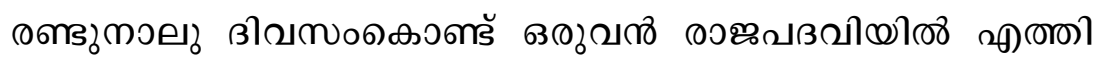

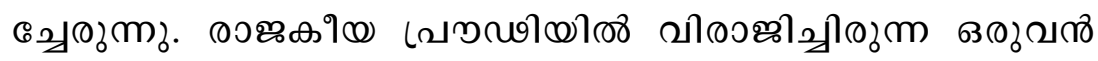

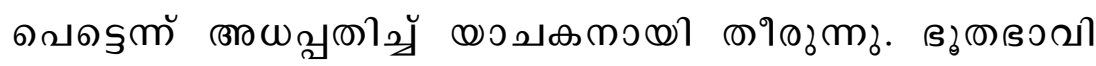




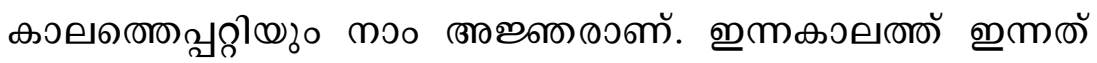

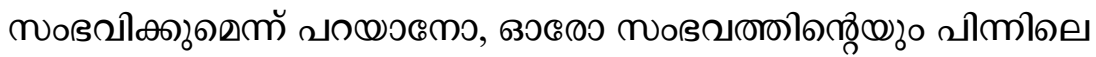

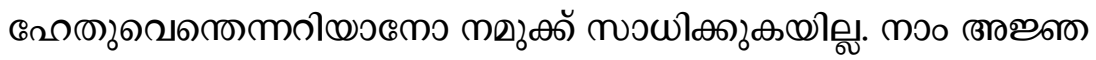

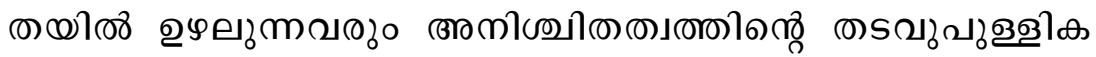

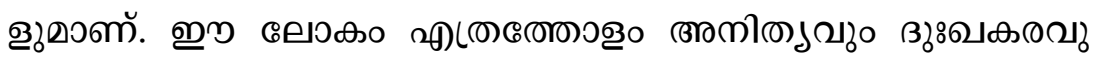

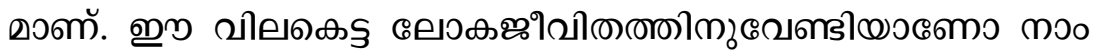

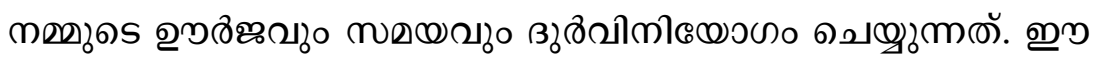

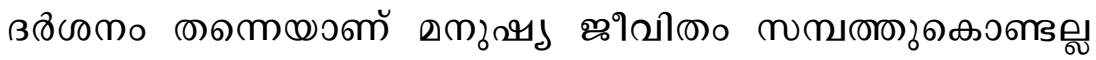

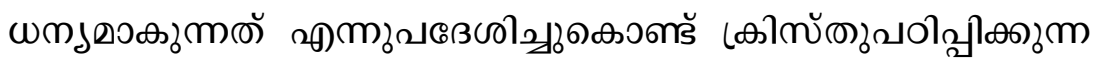

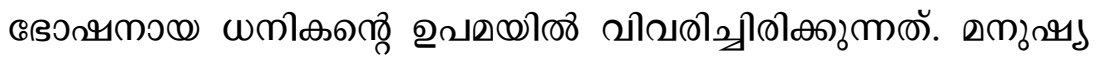

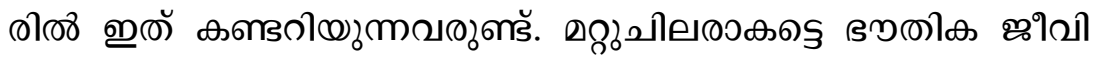

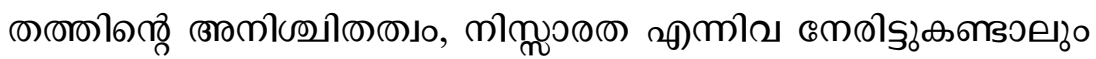

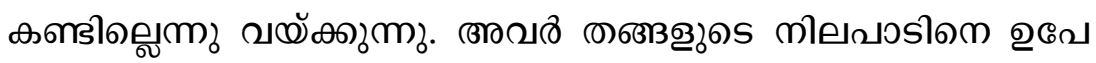

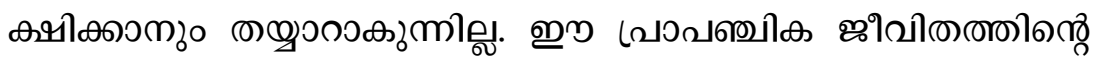

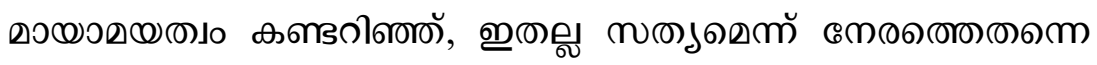

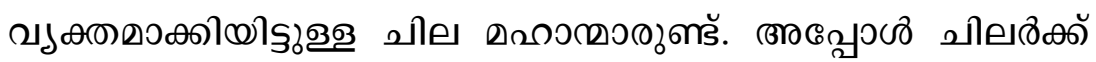

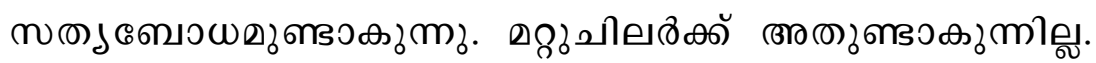

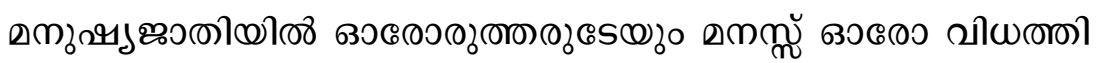

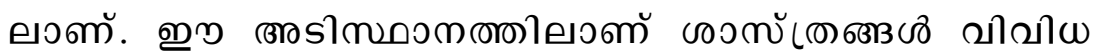

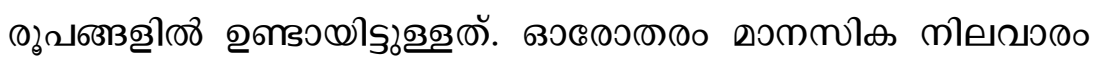

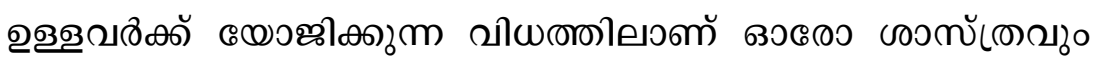

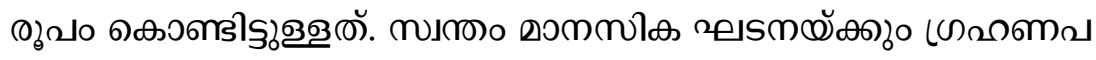

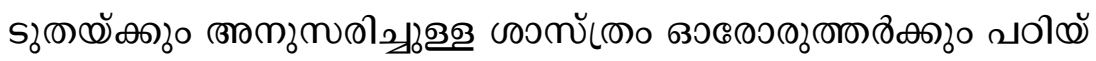

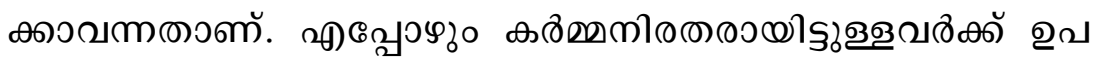
ஷேி2

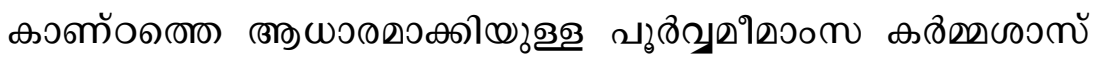

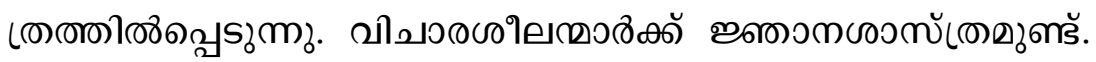




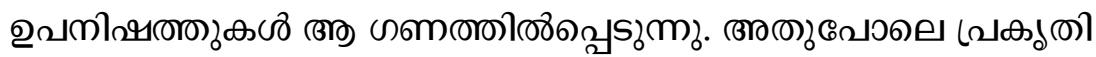

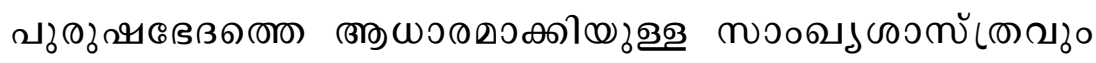

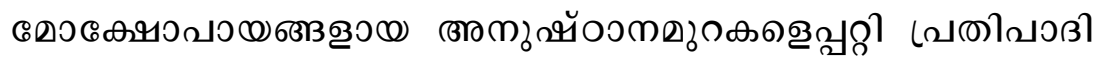

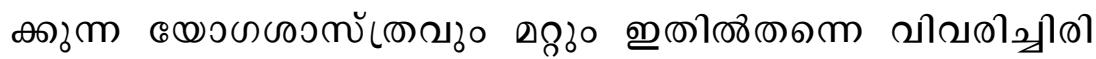

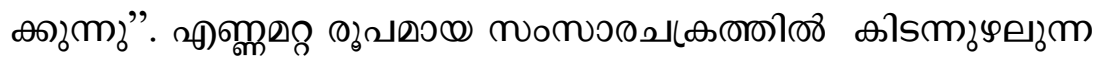

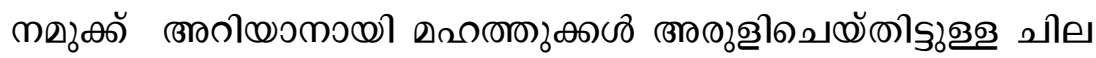

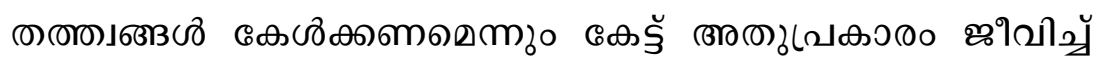

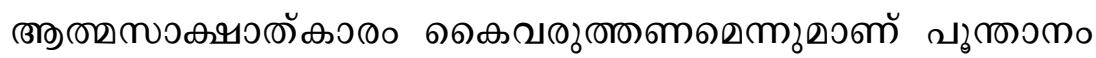

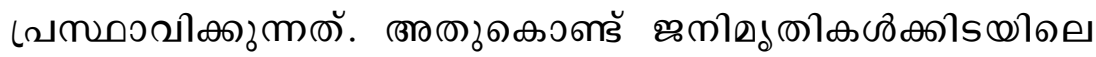

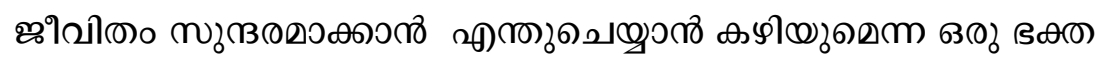

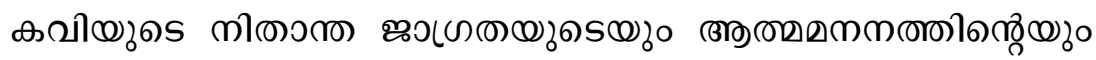

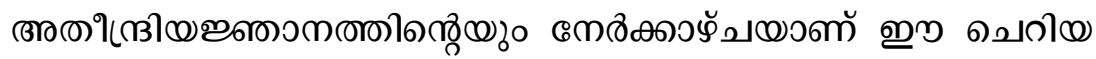

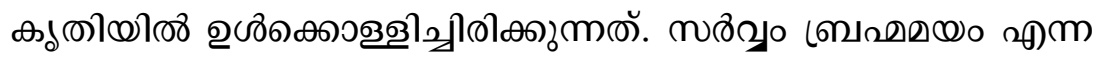

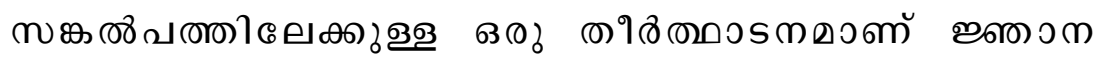
밍․

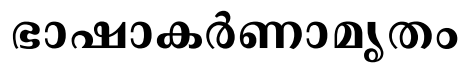

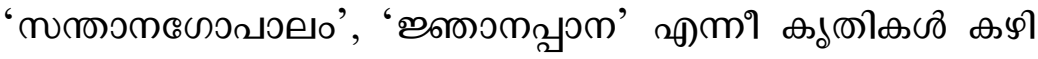

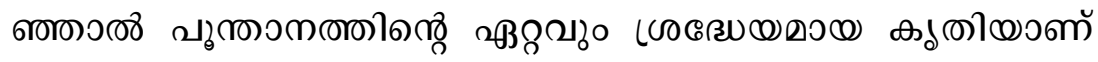

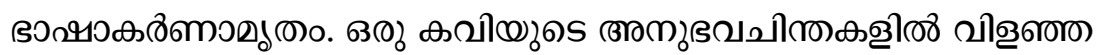

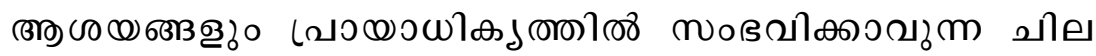

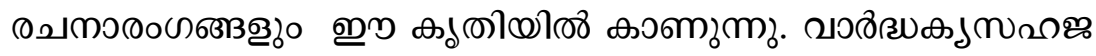

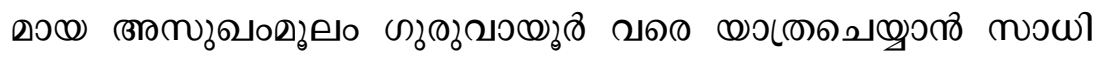

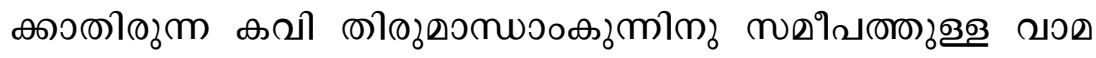

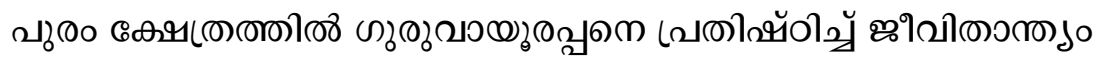

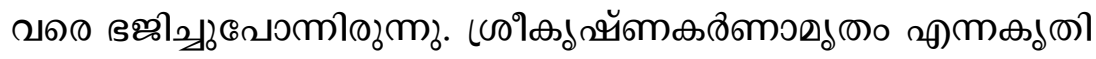

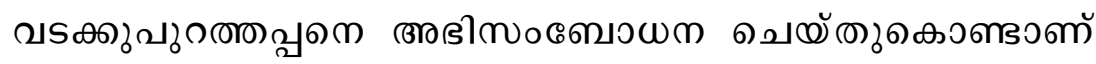




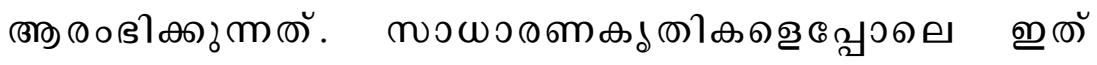

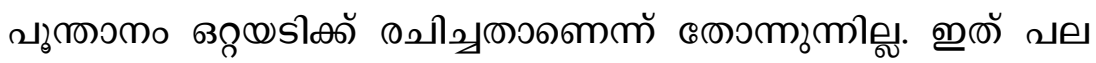

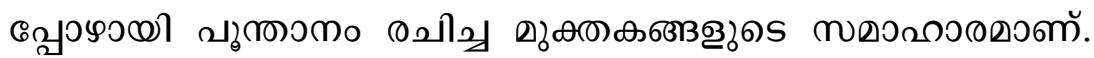

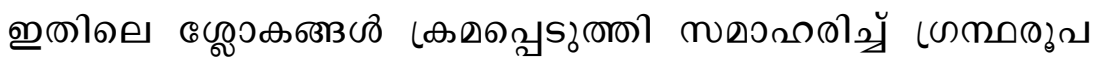

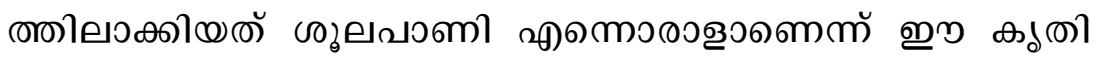

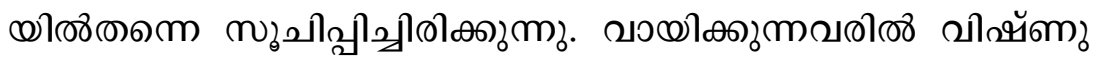

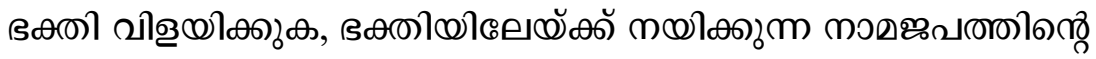

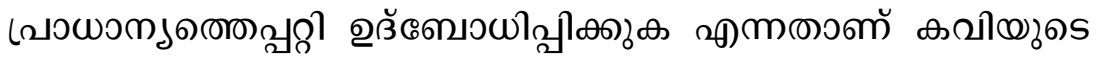

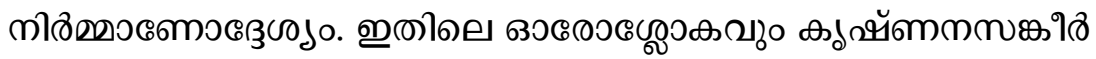

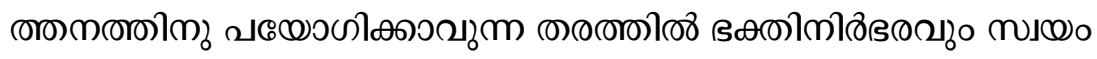

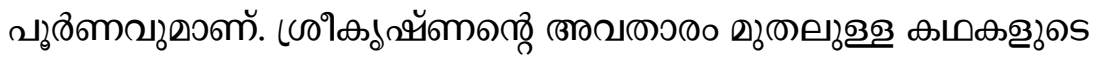

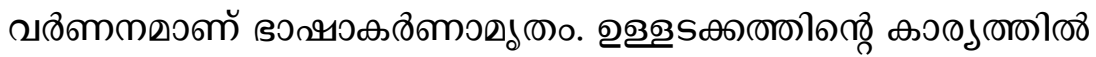

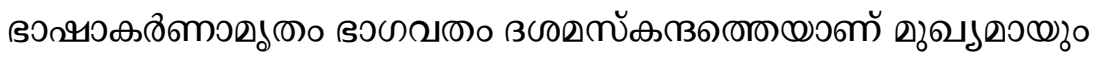

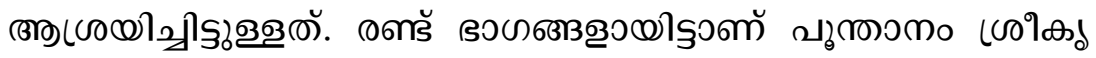

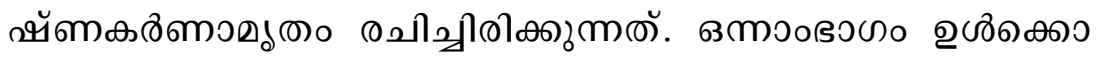

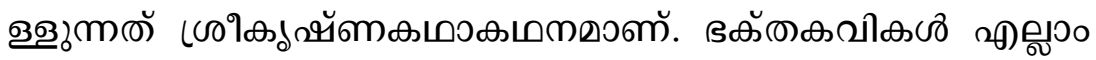

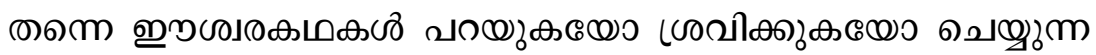

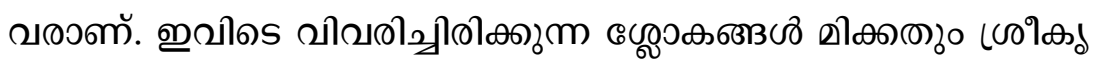

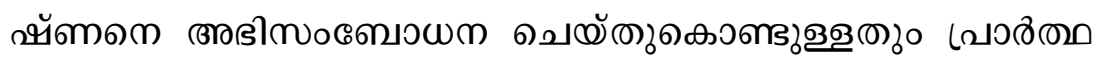

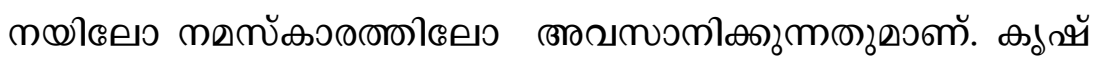

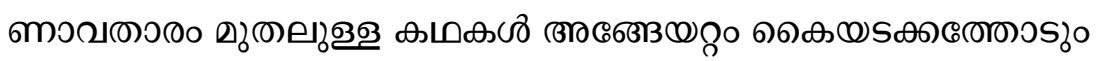

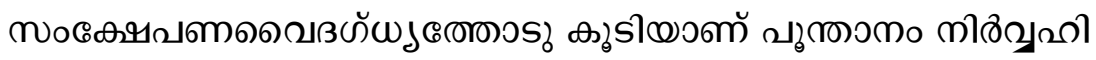

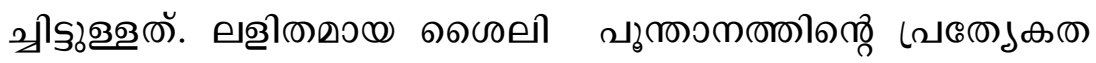

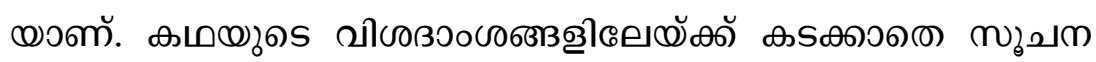
๑லைைஸॅ கவி ாணூகூாகூ.

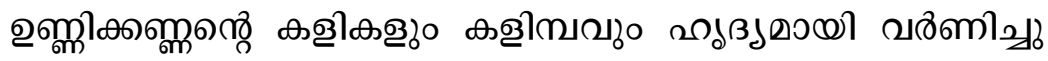

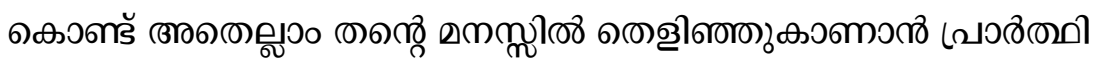




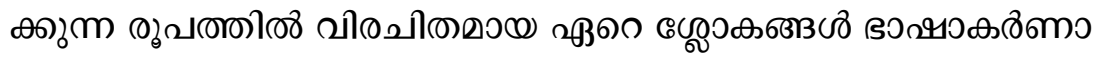

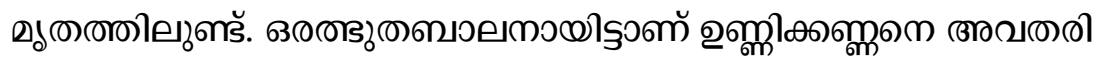

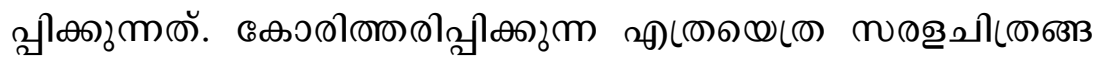

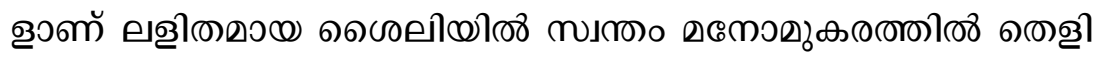

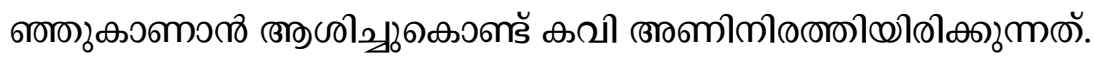

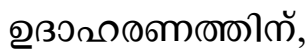

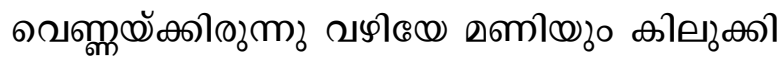

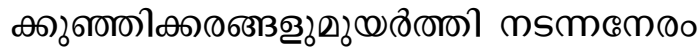

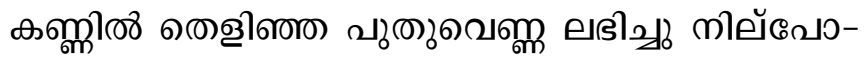

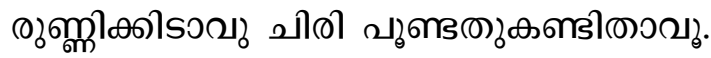

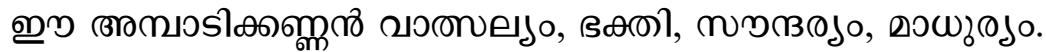

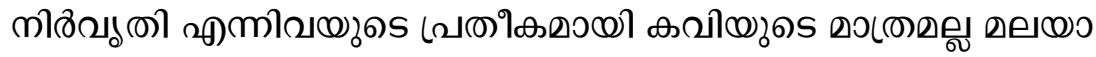

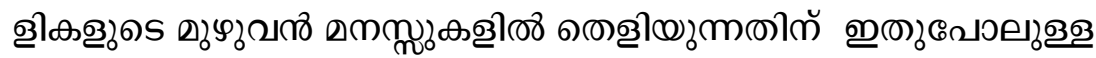

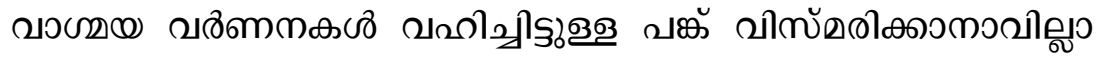

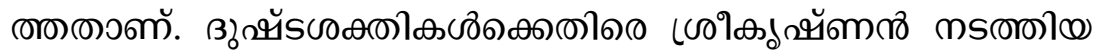

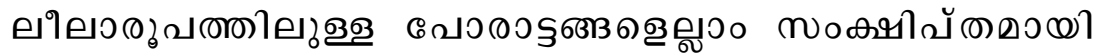

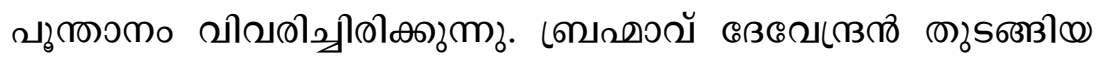

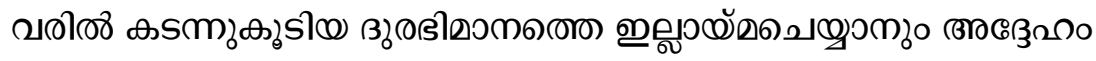

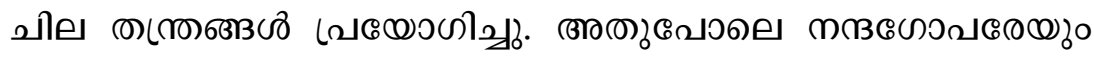

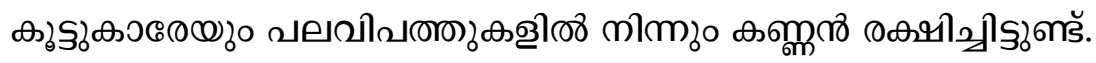

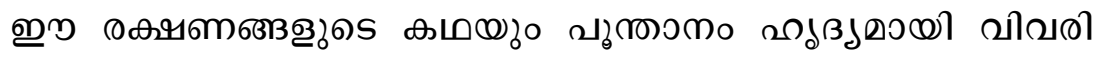

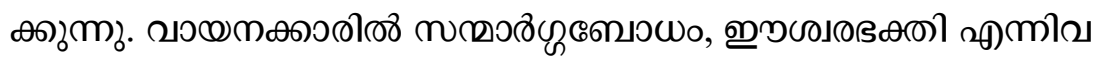

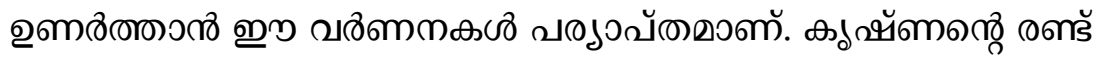

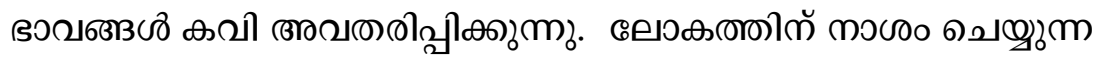

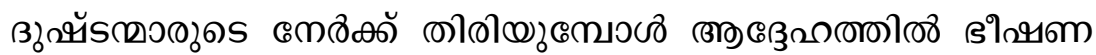

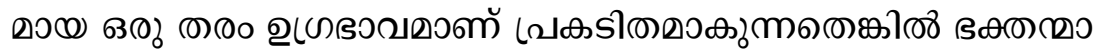




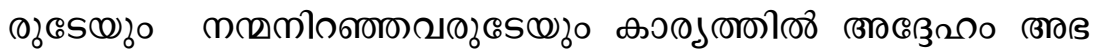

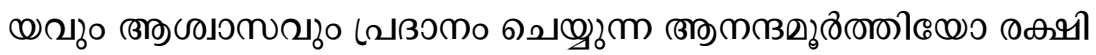

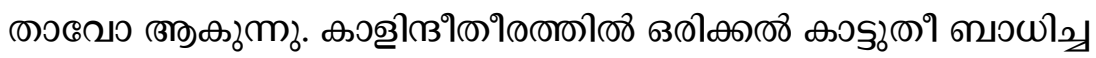

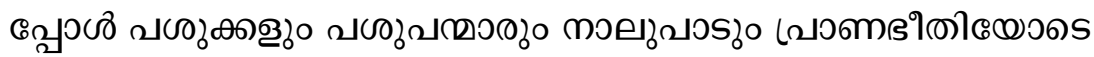

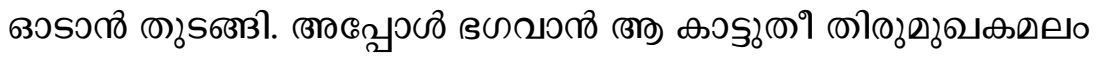

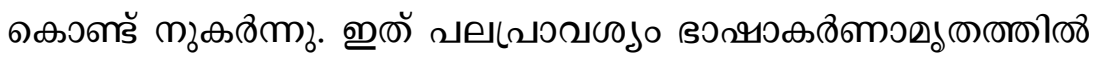

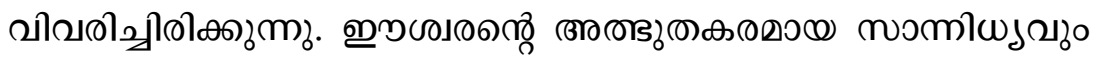

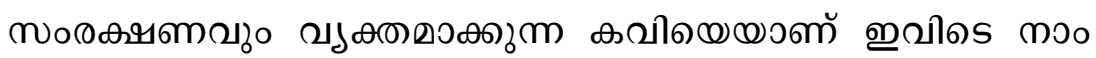

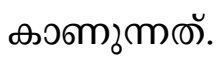

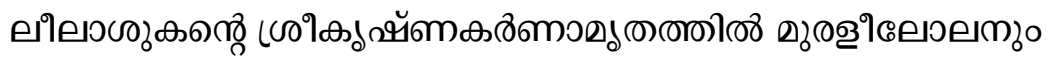

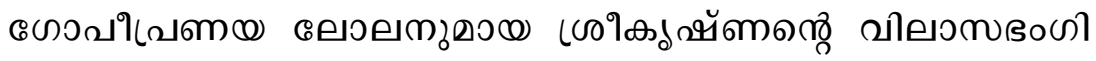

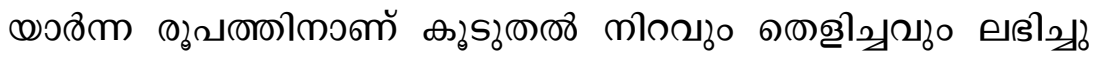

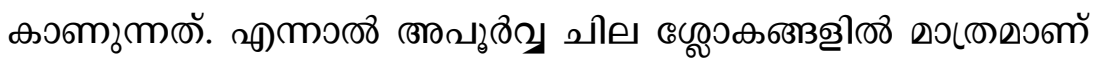

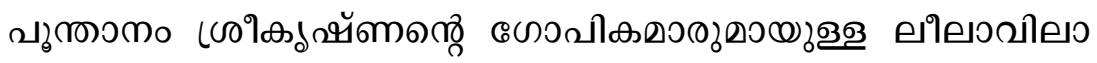

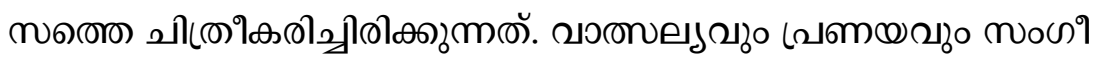

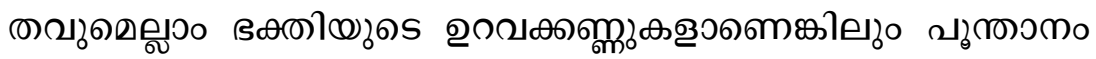

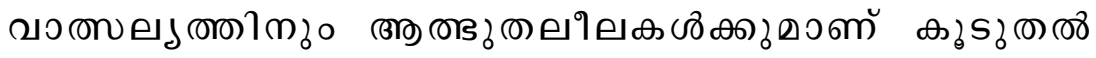

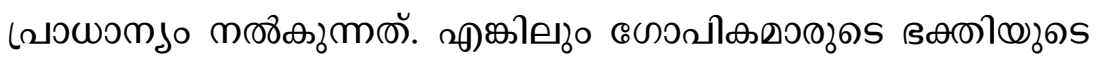

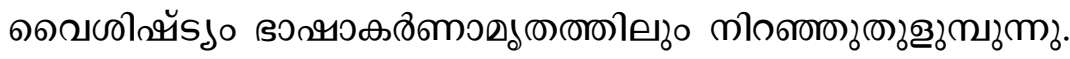

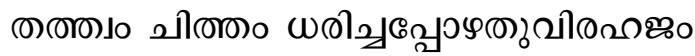

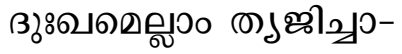

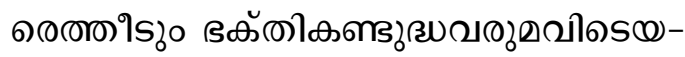

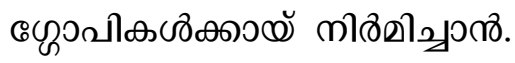

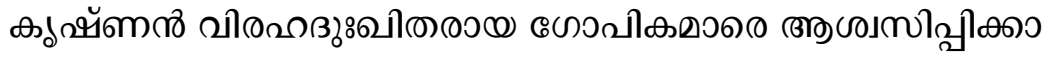

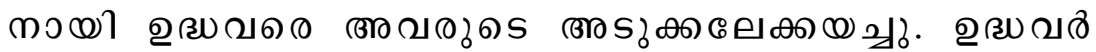




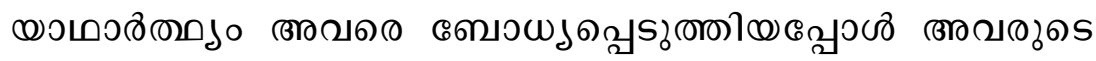

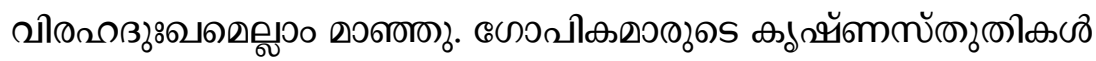

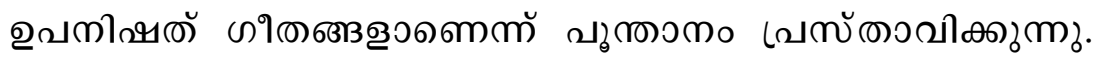

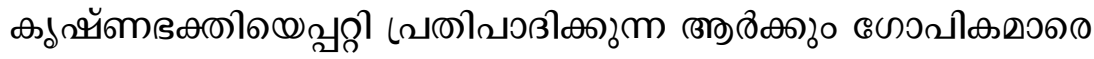

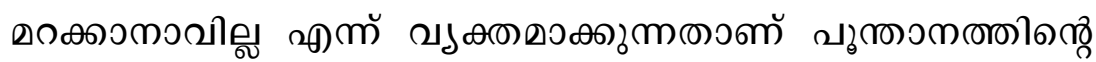
வன்ஸாகலิ.

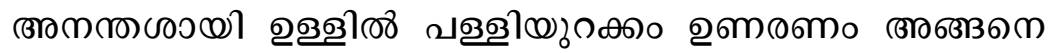

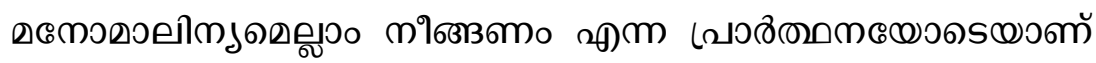

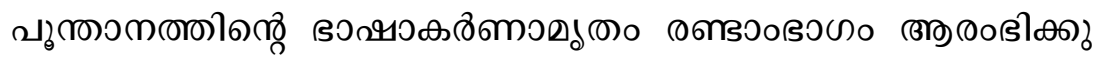

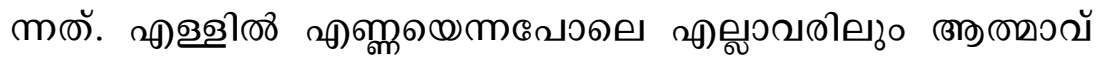

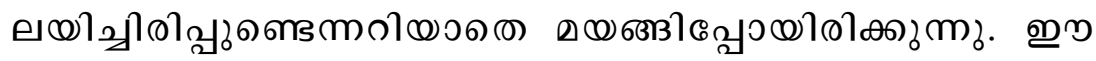

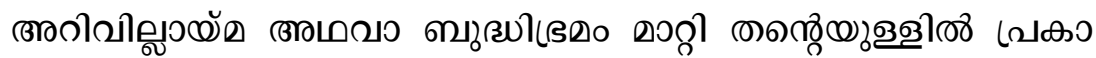

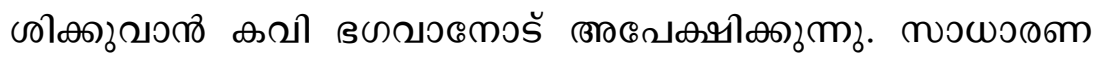

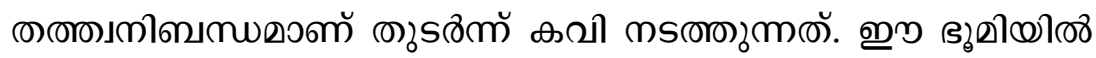

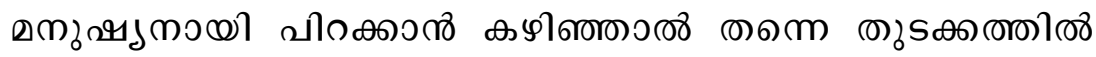

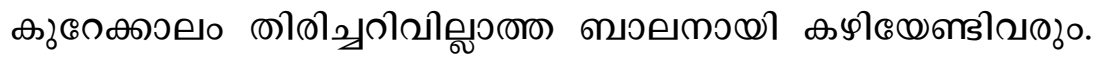

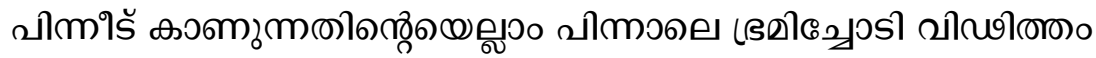

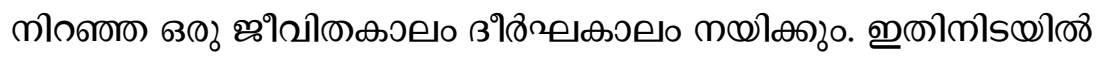

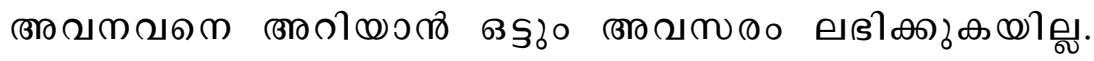

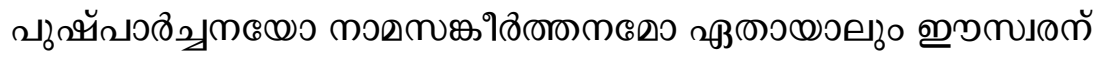

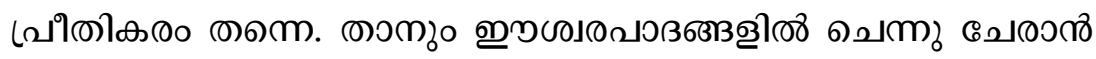

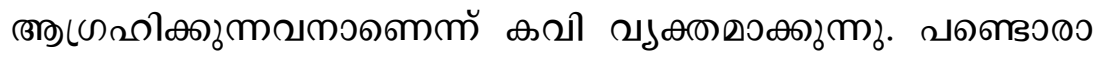

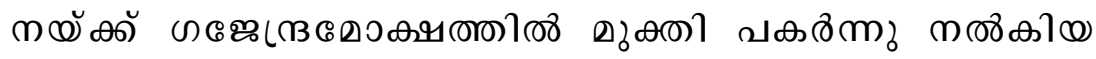

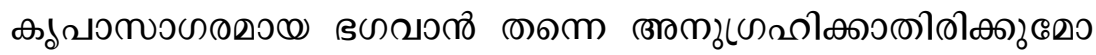

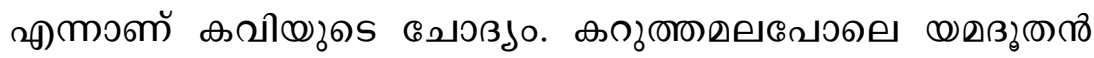

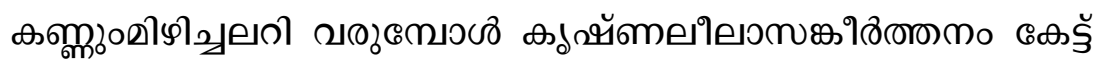




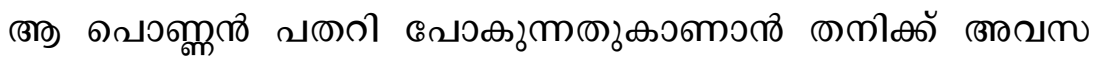

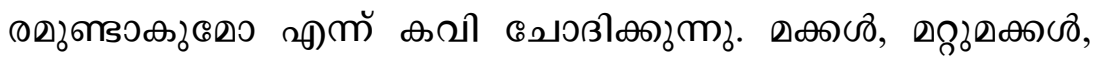

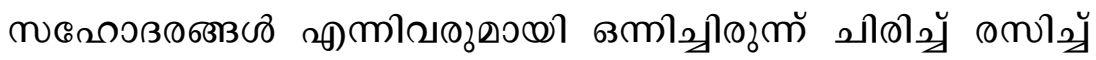

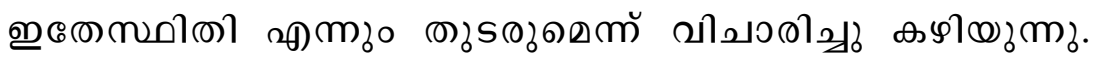

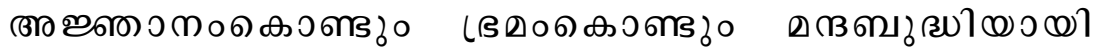

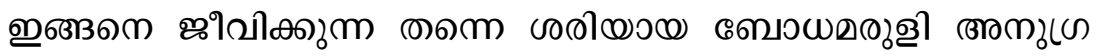

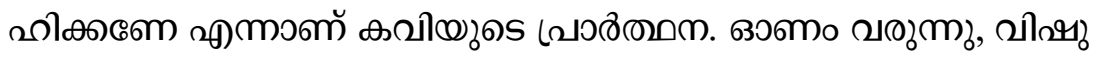

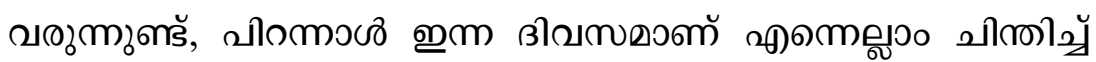

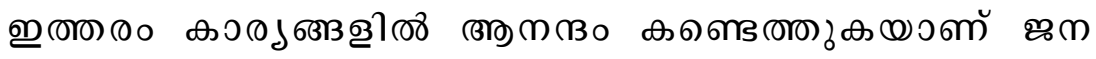

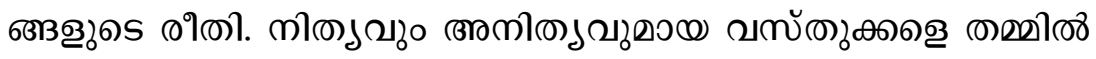

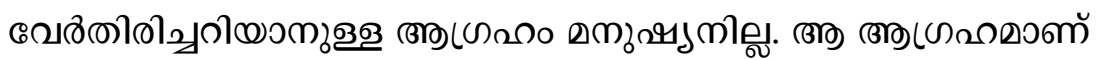

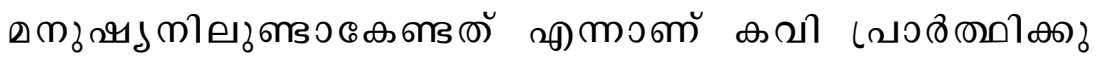

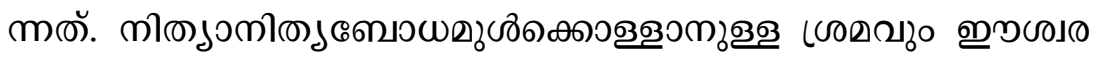

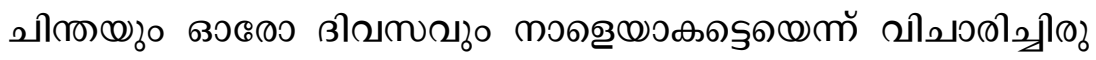

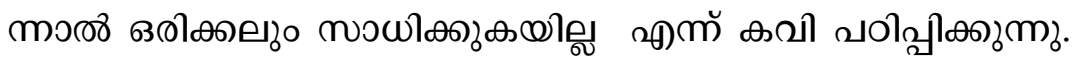

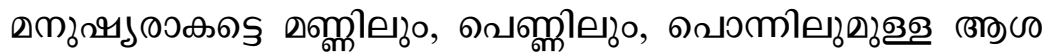

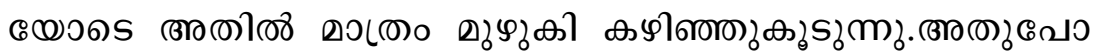

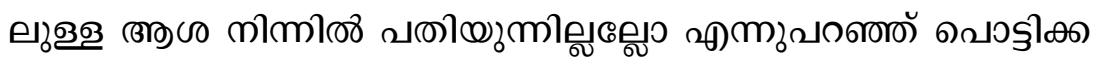

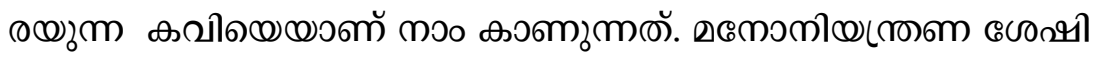

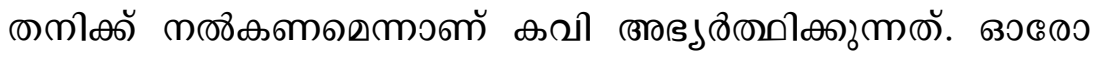

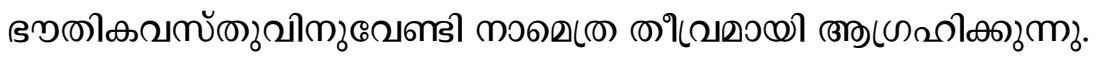
(

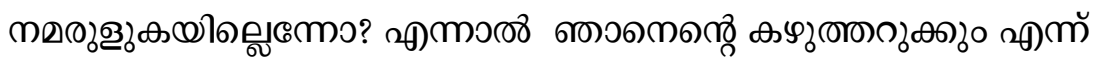

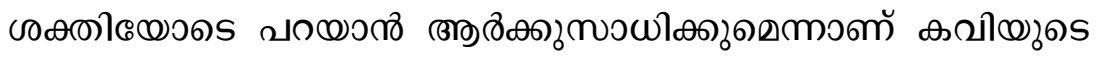

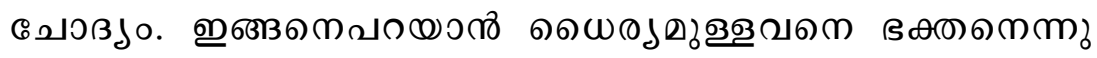

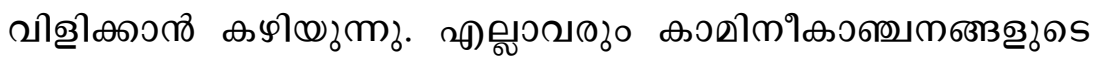




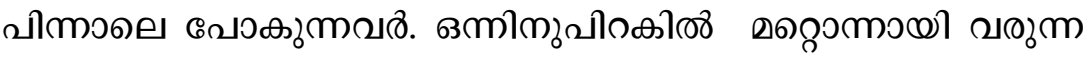

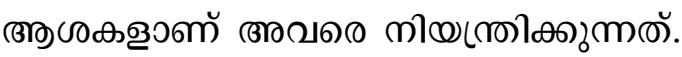

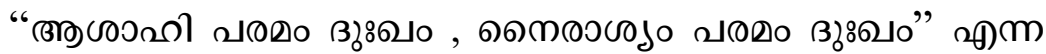

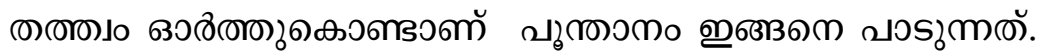

mிmง களรใคอง

கள்

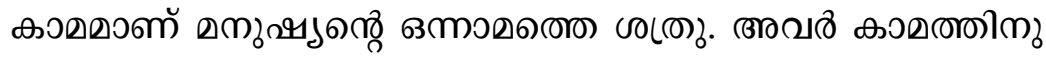

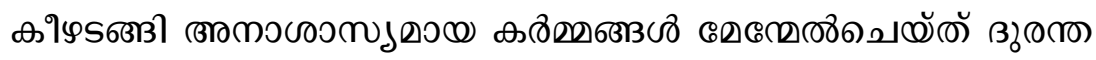

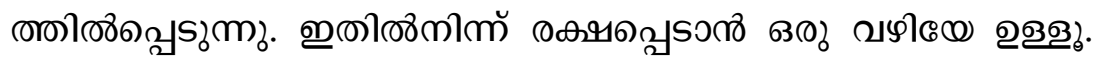

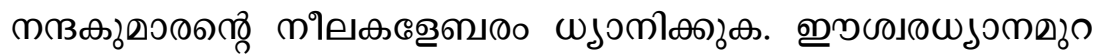

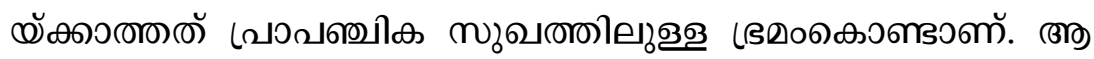

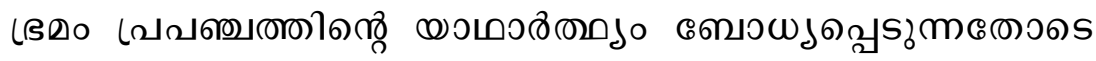

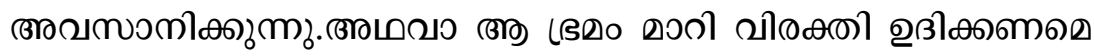

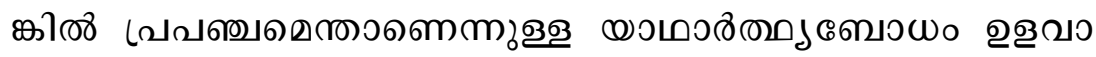

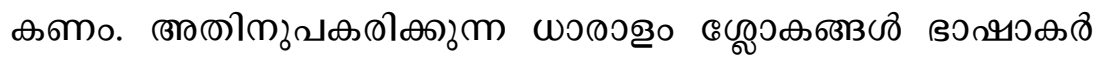

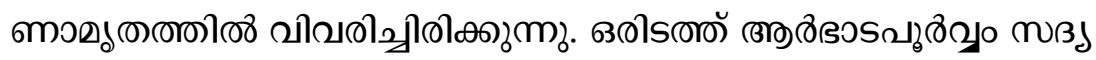

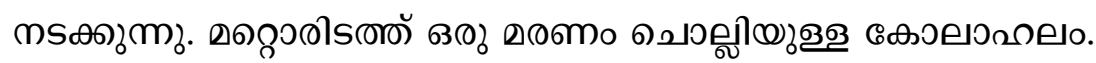

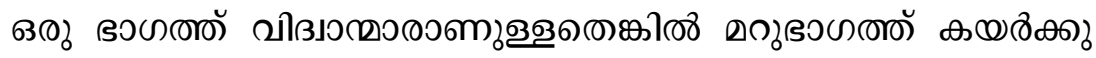

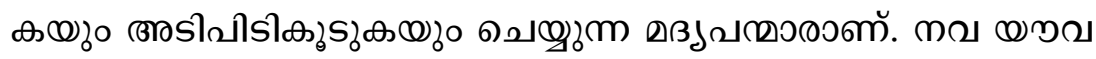

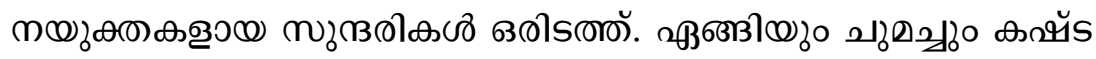

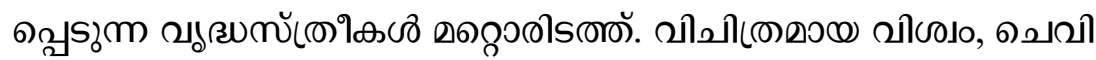

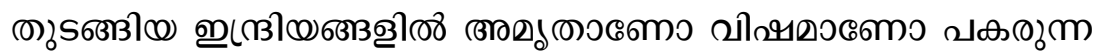

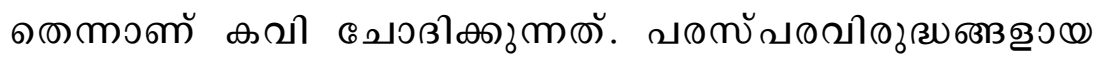

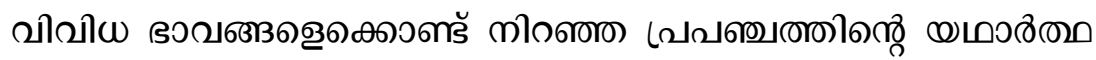

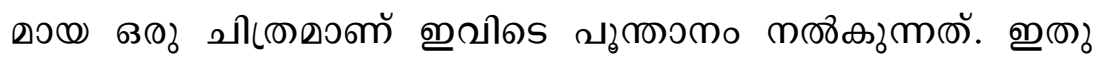




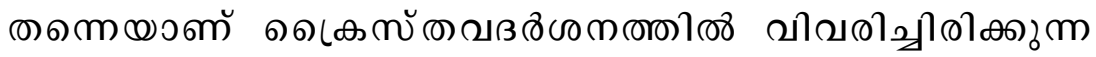

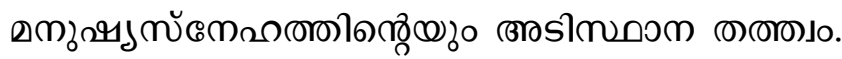

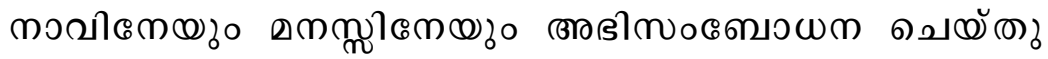

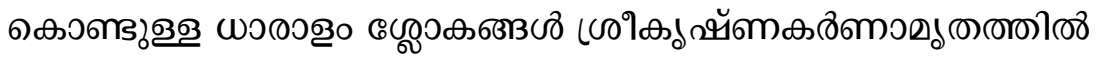

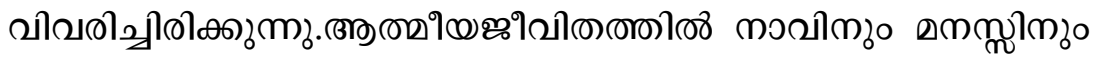

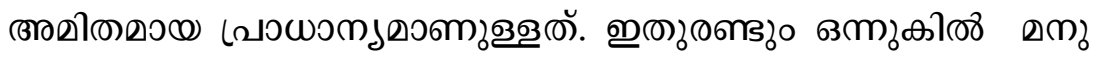

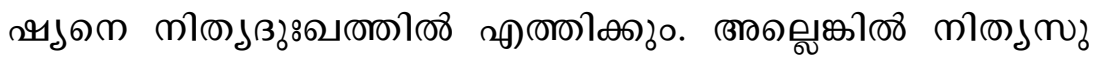

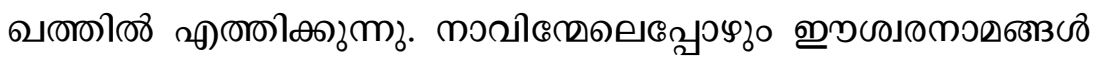

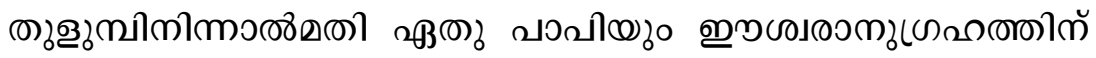

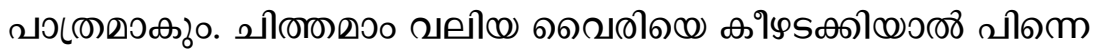

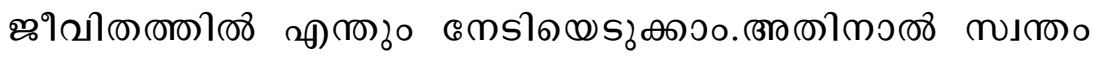

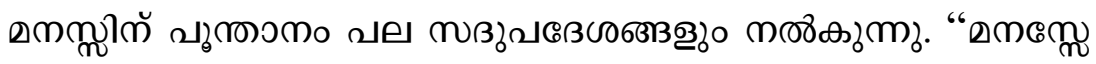

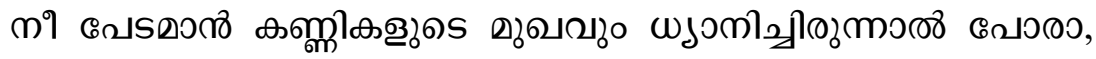

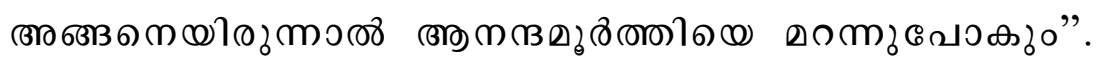

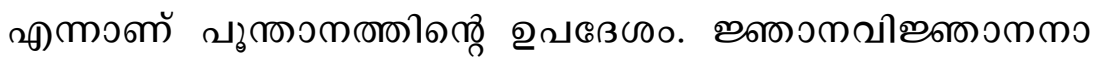

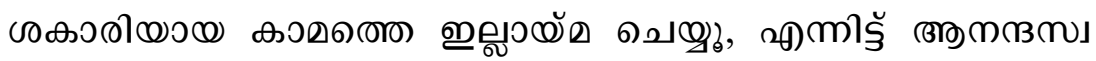

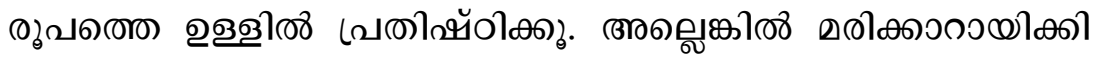

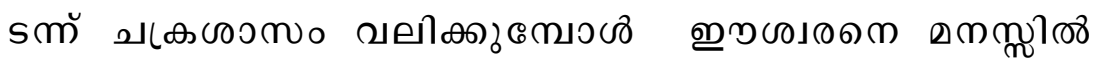

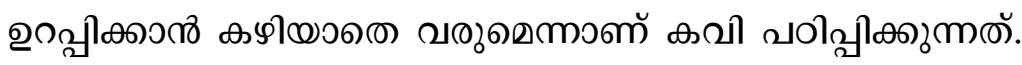

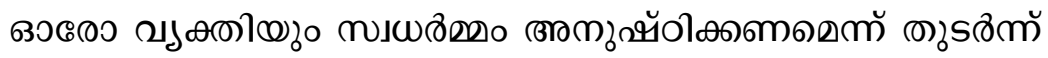
வ

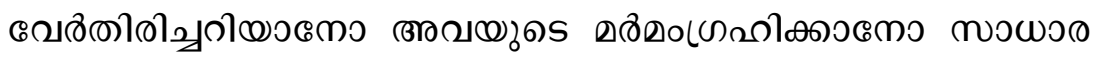

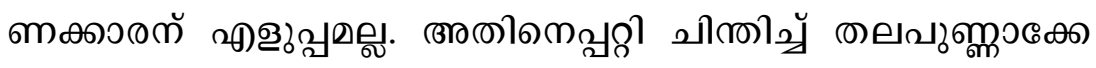

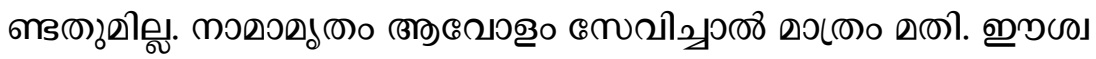

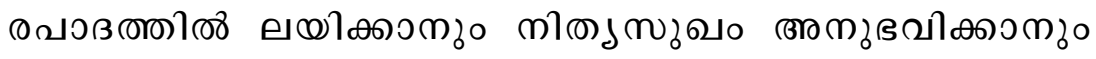

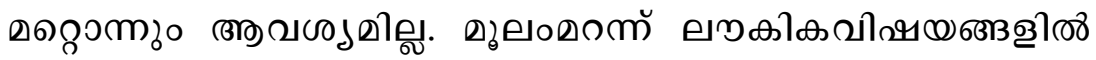




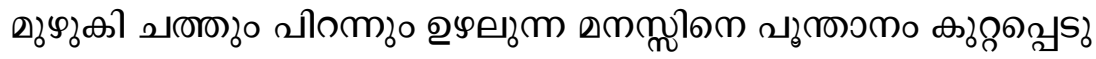

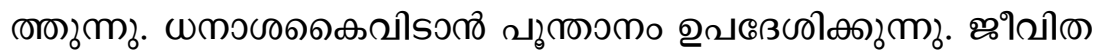

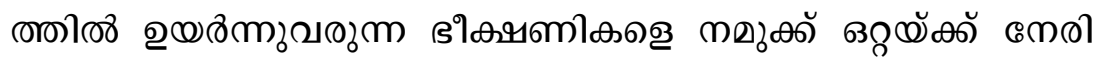

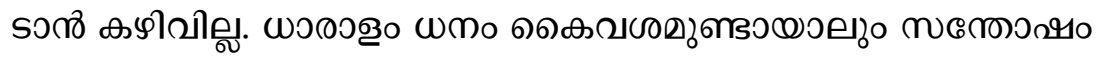

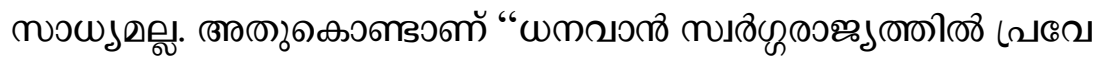

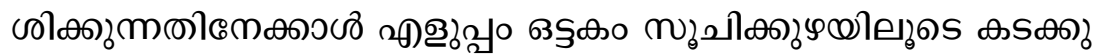

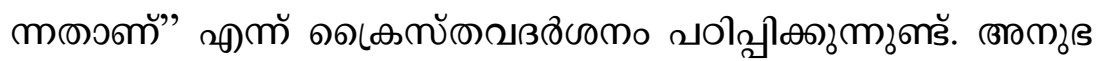

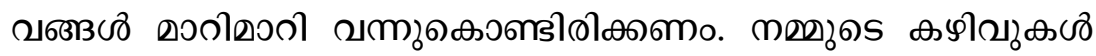

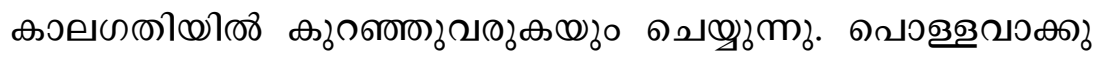

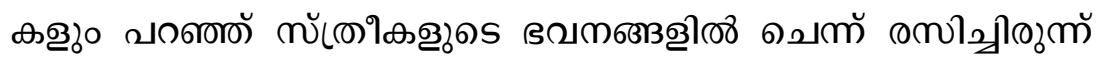

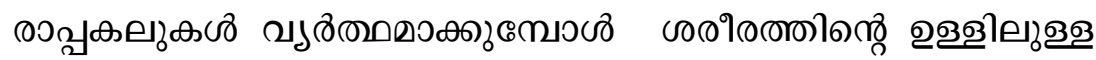

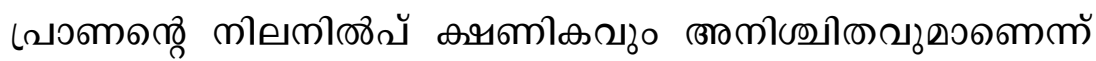

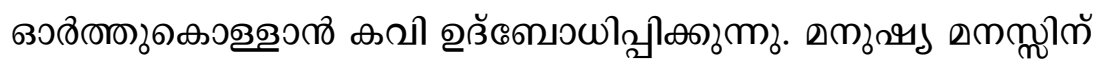

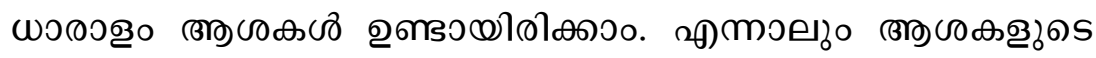

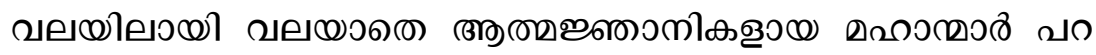

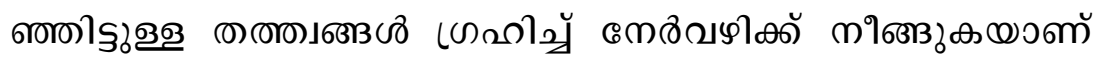

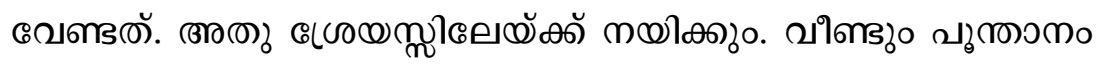

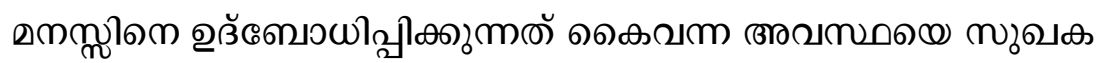

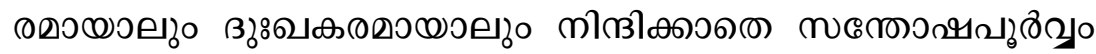

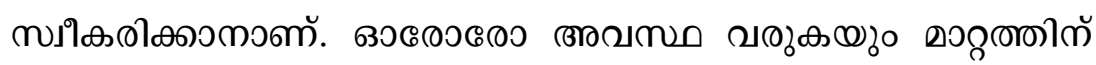

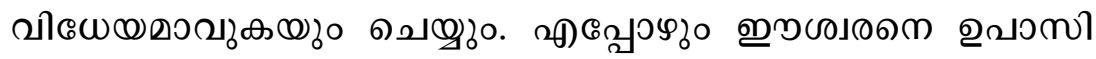

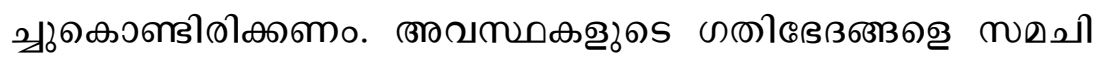

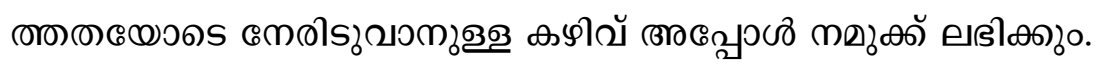

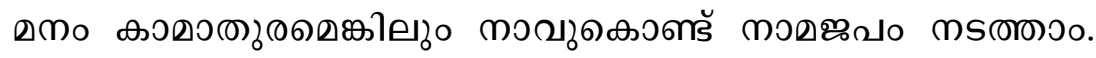

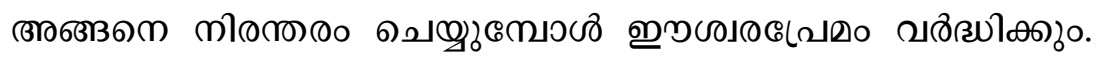

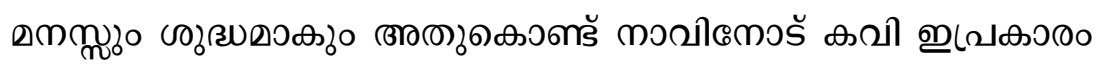

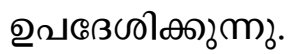




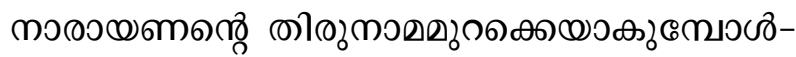

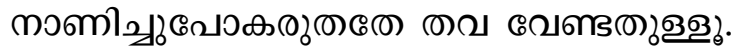

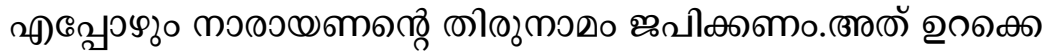

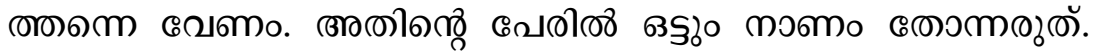

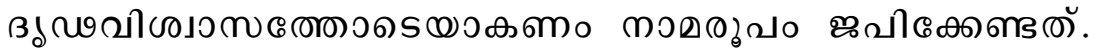

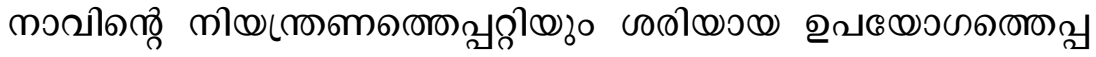

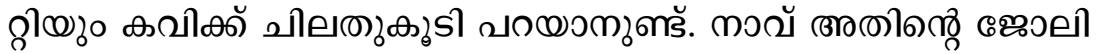

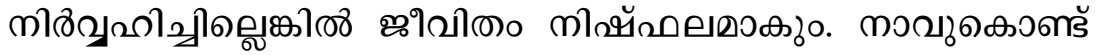

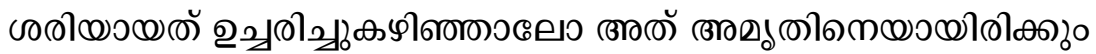

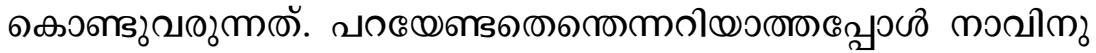

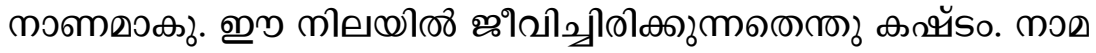

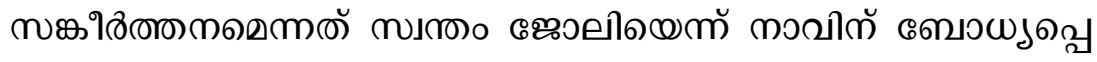

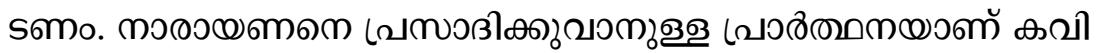

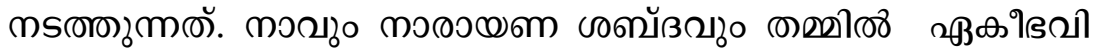

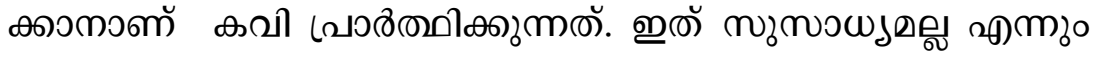

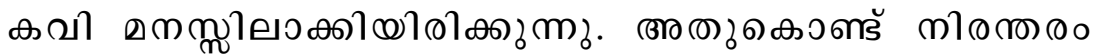

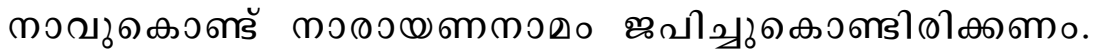

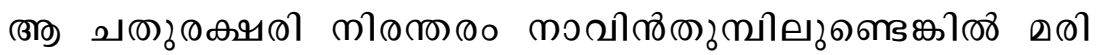

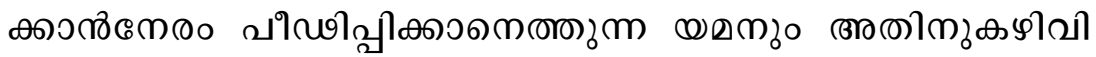

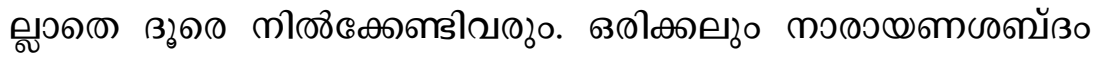

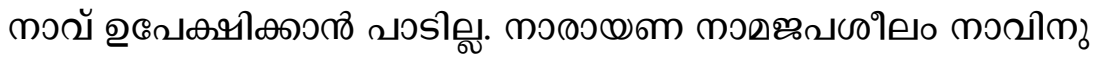

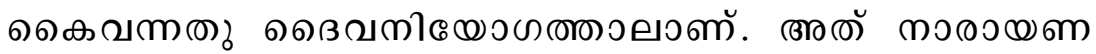

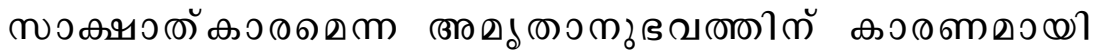

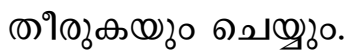

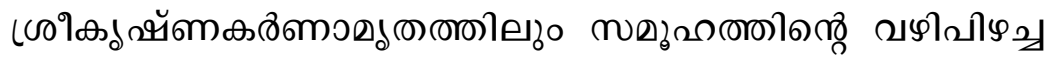

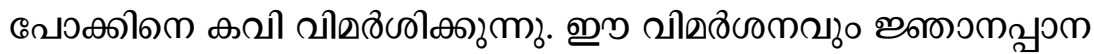




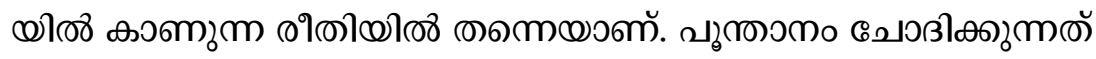

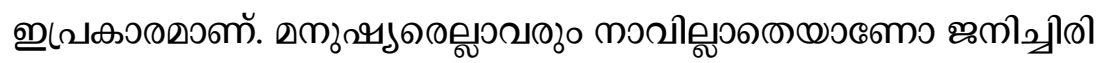

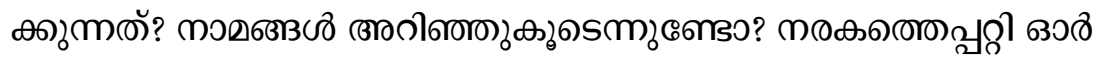

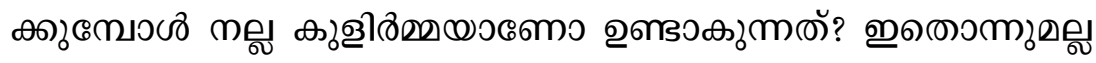

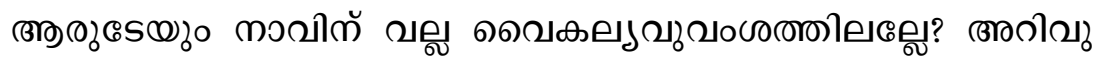

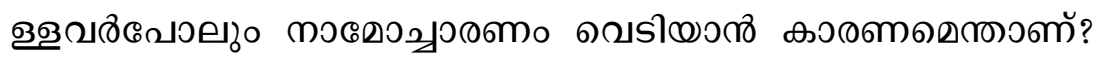

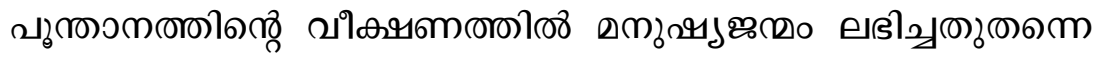

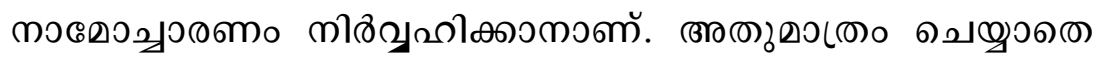

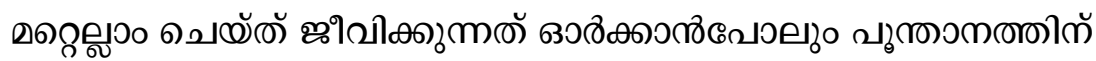

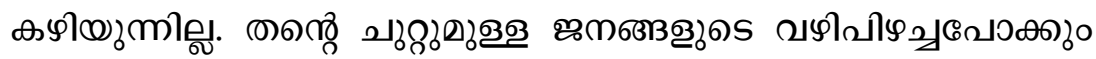

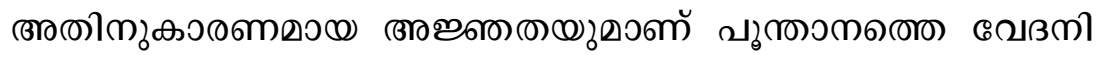

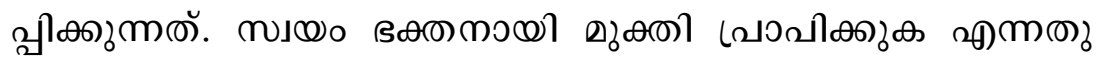

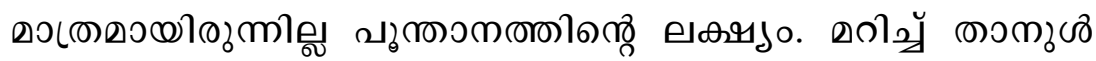

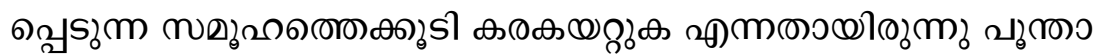

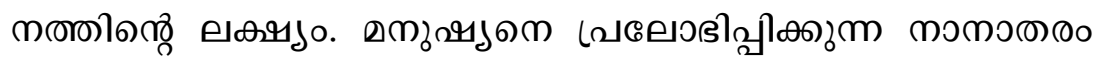

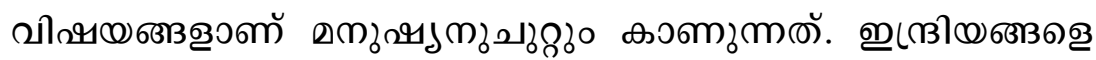

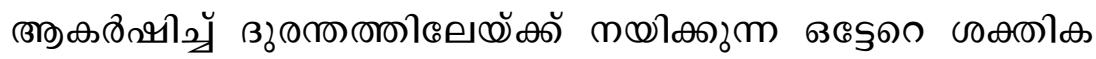

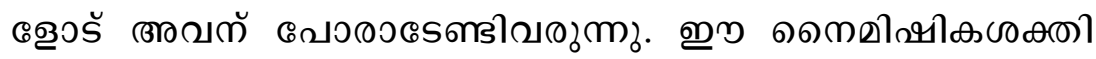

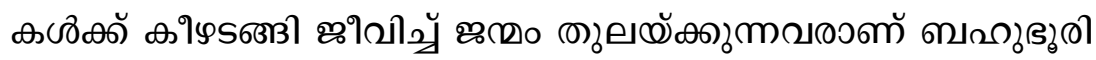

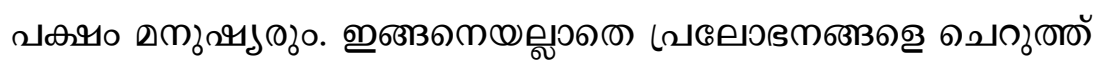

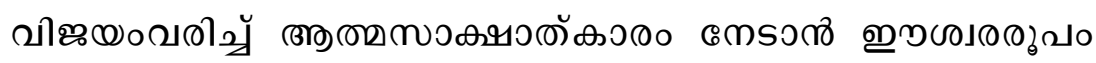

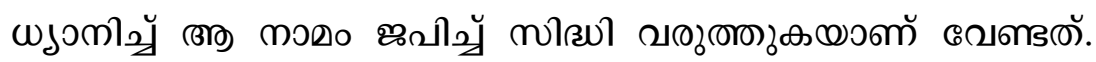

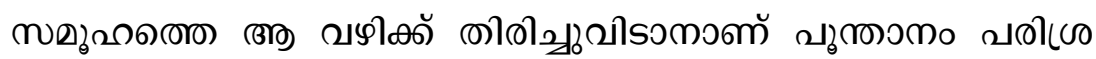

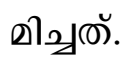

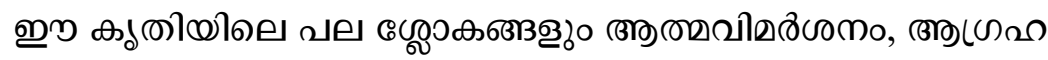

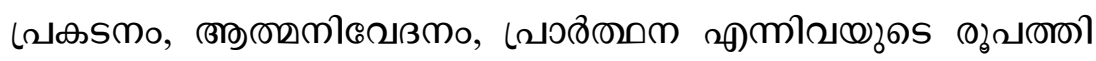

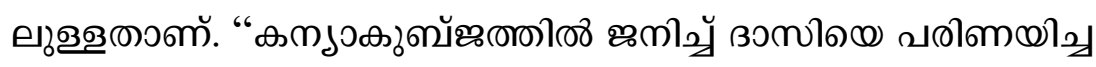




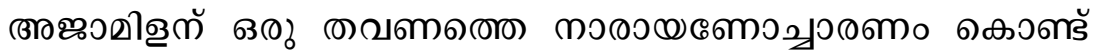

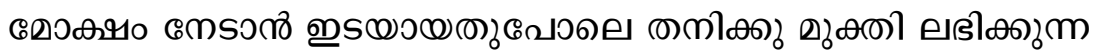

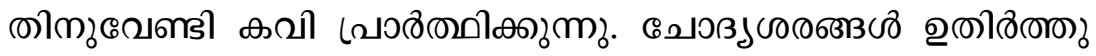

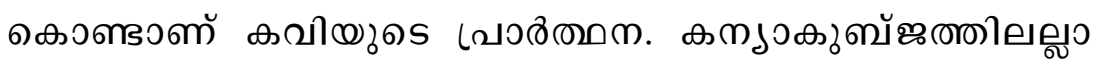

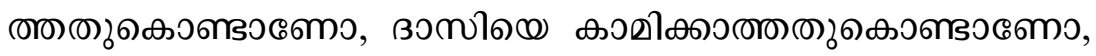

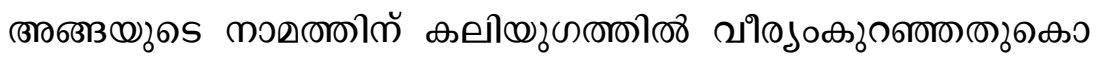

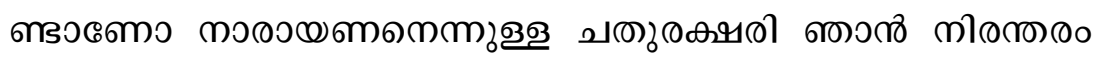

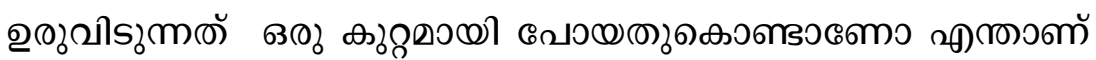

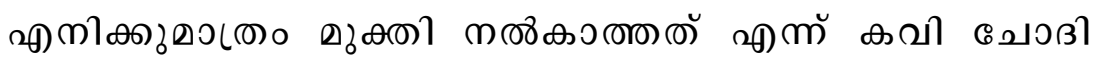

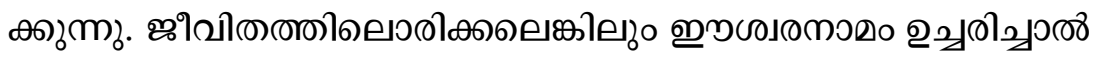

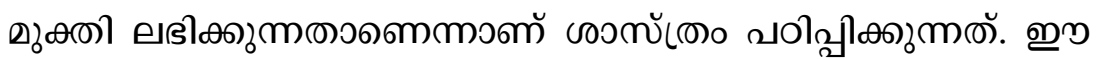

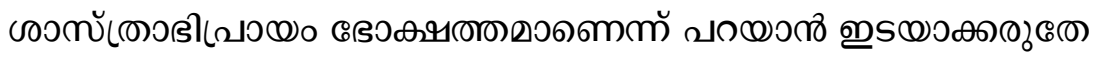

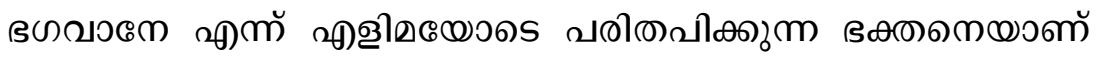

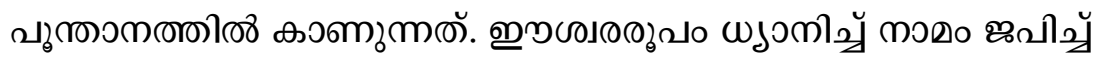

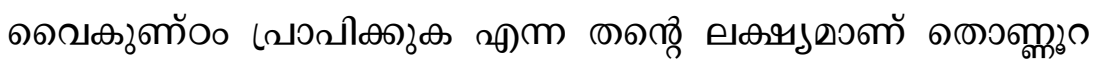

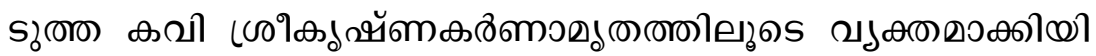

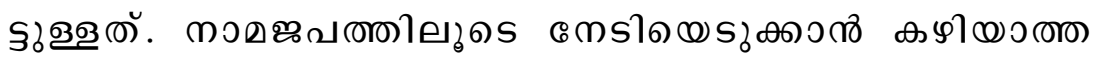

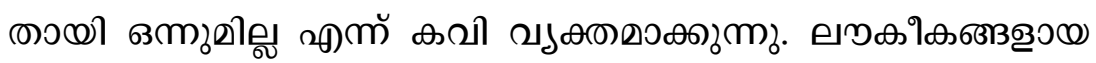

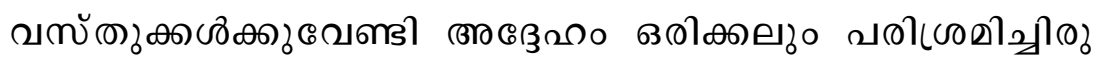

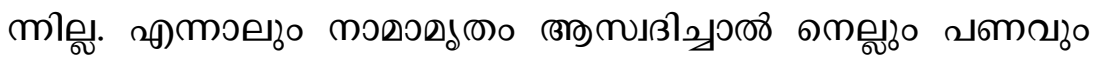

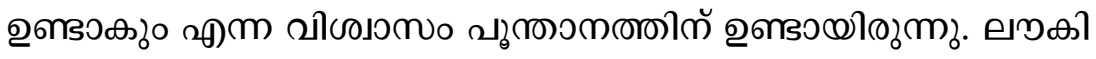

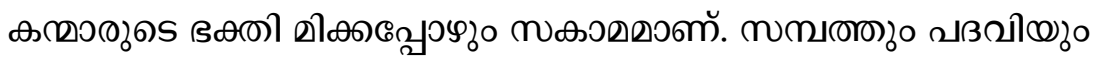

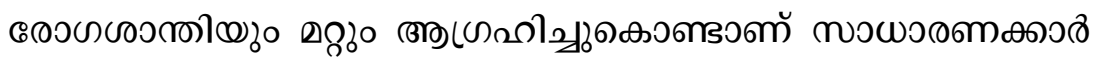

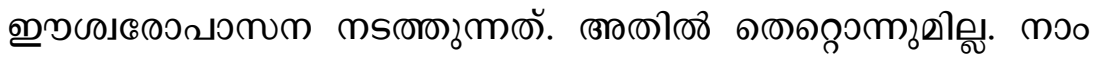

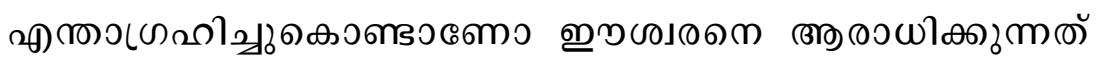

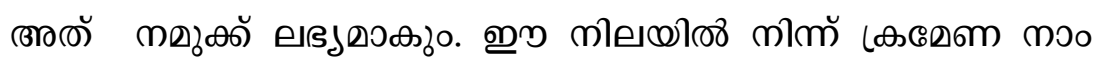

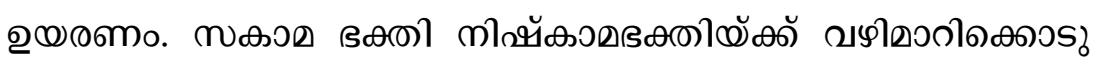




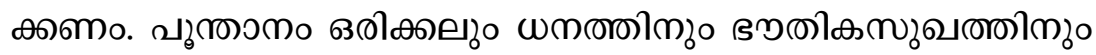

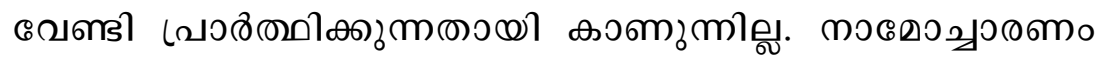

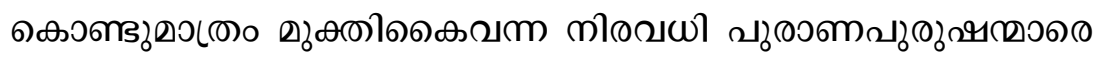

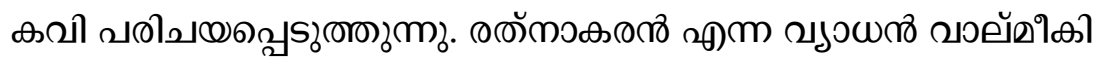

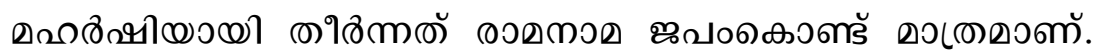

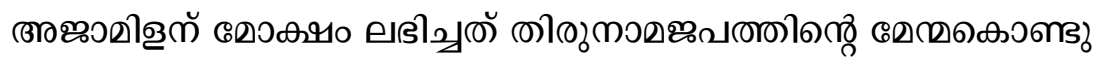

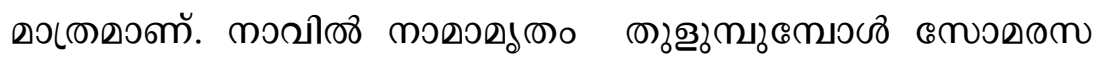

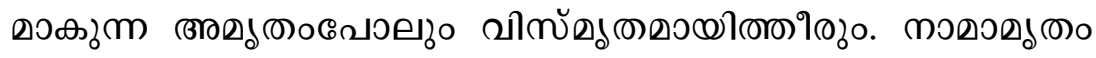

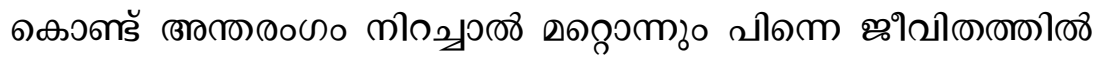

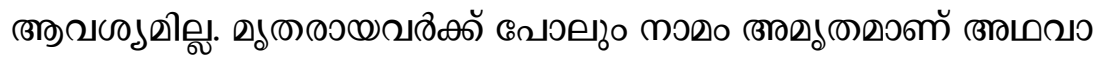

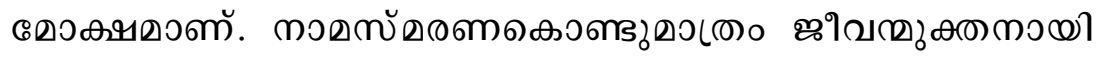

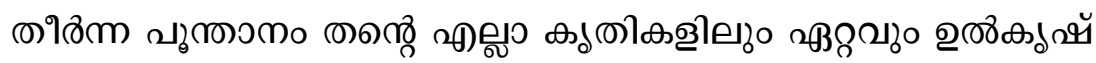

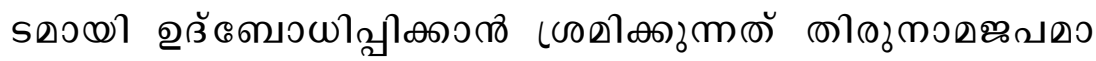

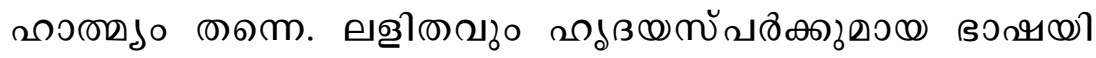

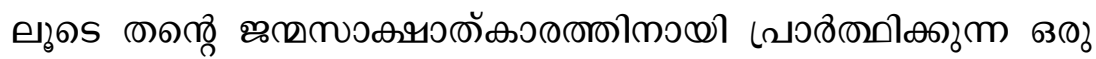

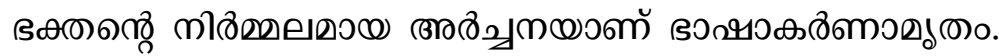

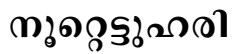

வ

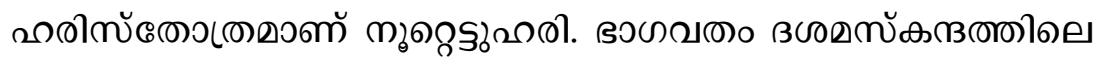

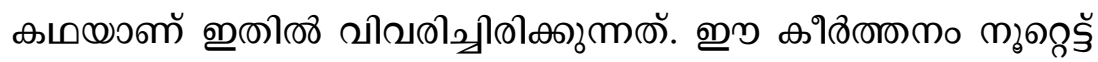

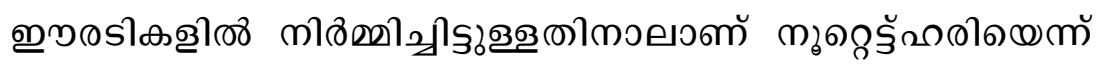

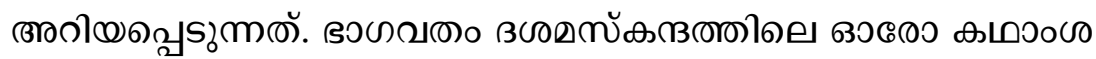

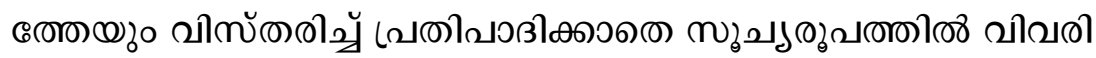

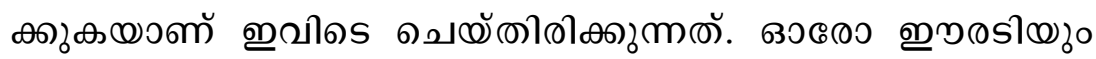

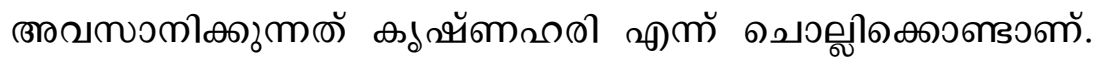

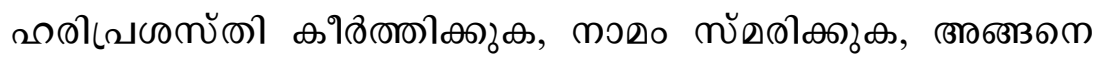




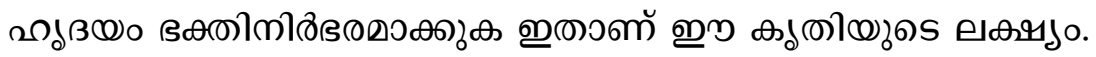

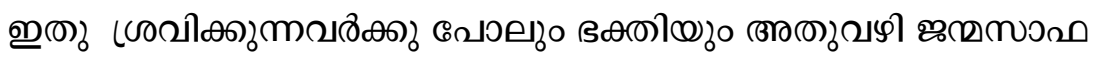

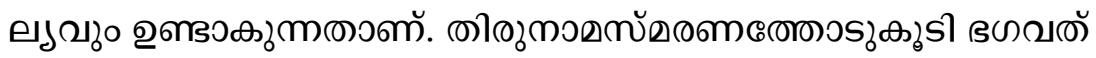

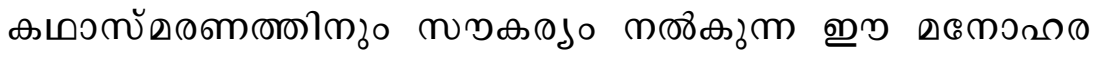

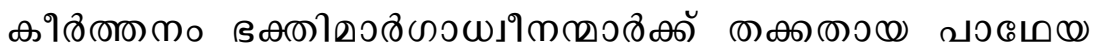
வஸஸ̆. ஊழுகை

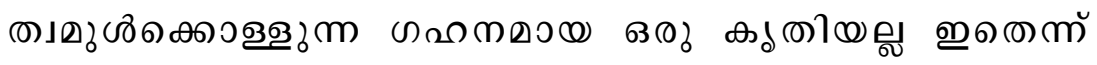

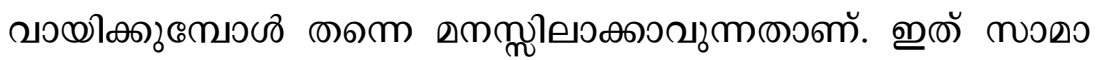

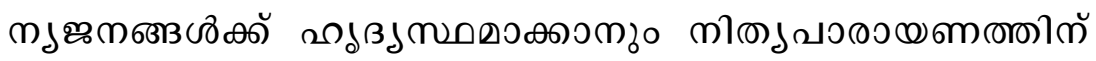

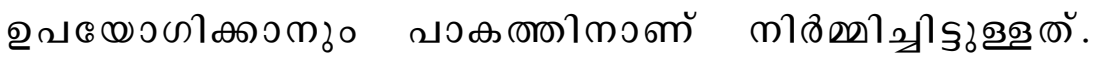

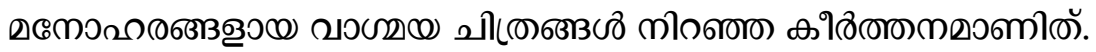

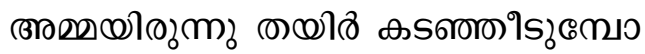

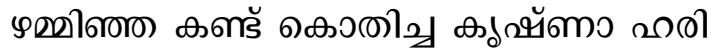

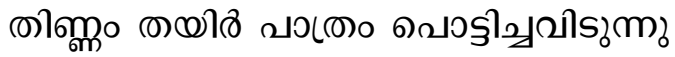

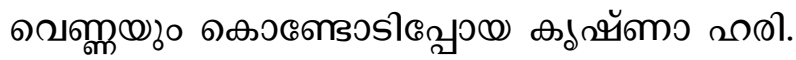

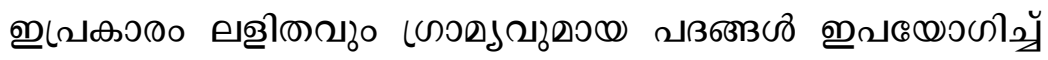

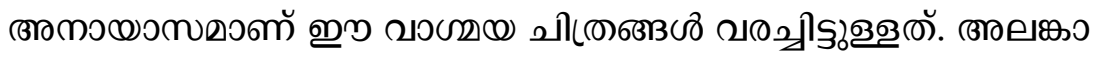

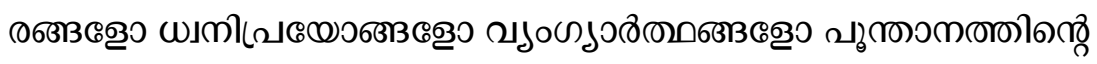

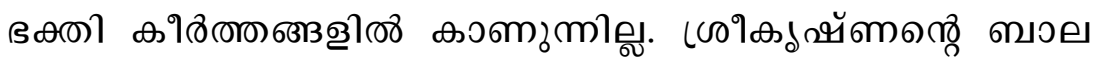

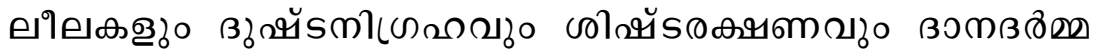

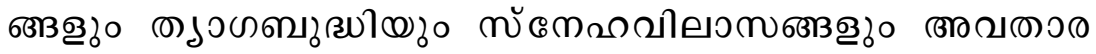

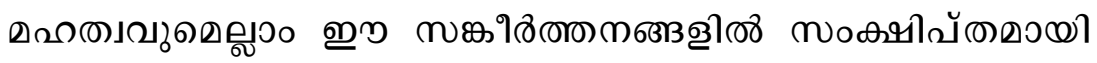

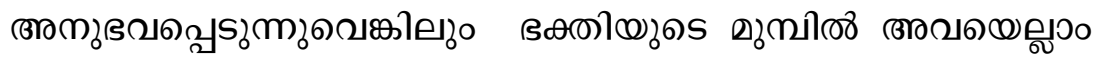

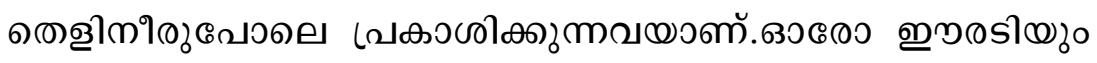

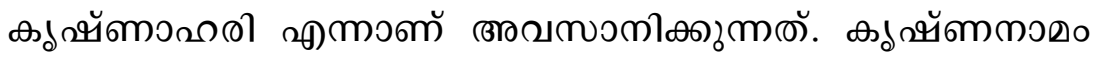

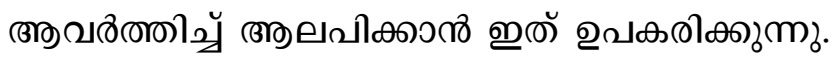




\section{(ூ) (1)}

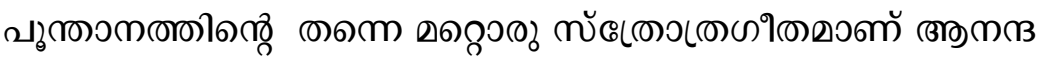

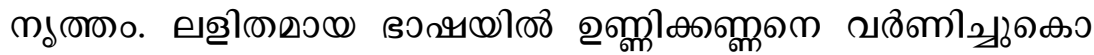

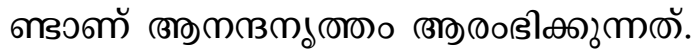

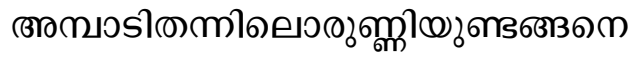

உஸிிெெ๐லக்

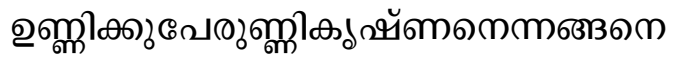

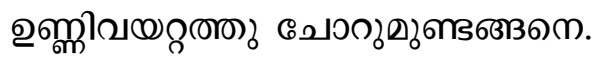

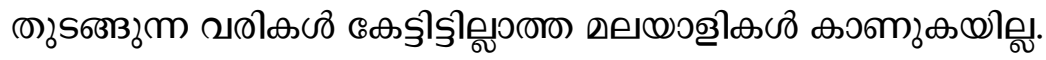

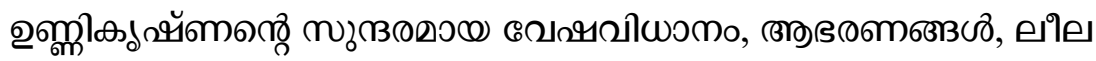

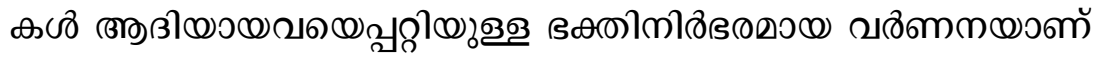

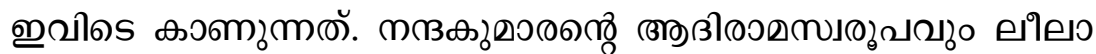

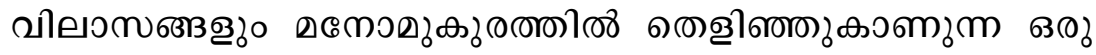

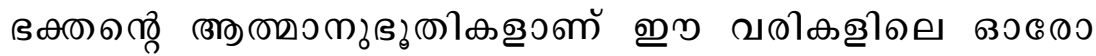

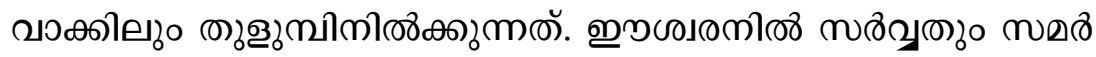

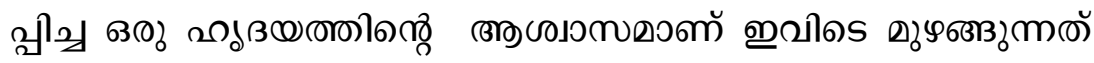

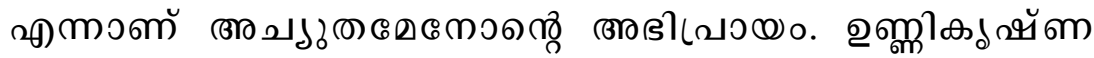

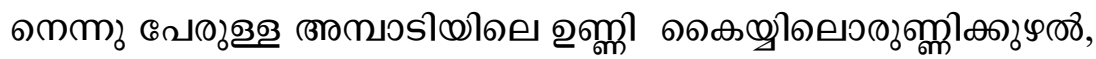

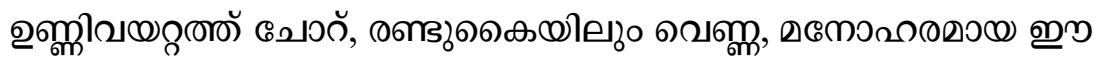

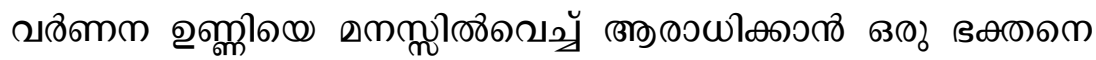

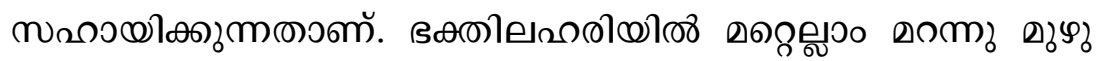

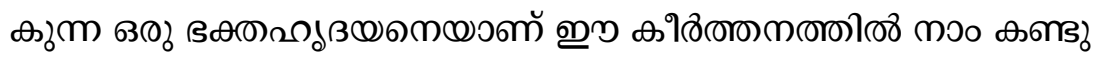

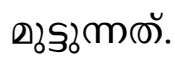

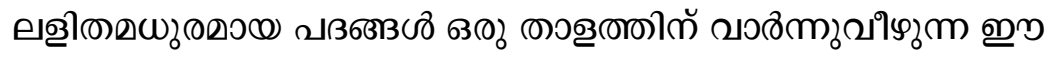

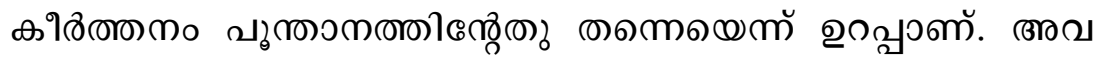




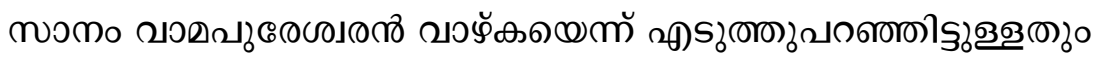

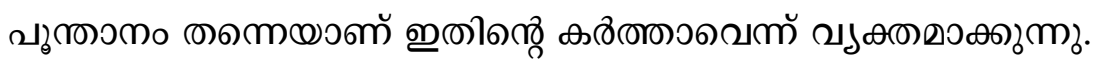

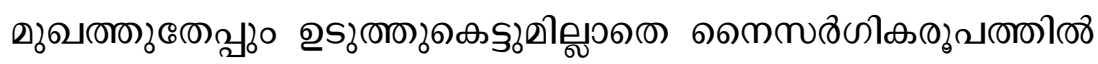

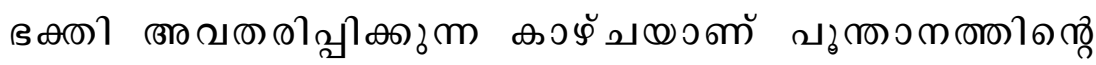

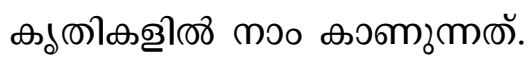

\section{வாரைைை:}

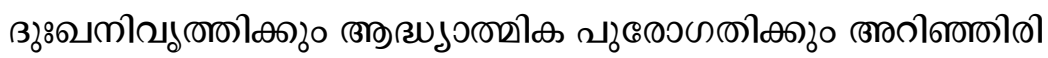

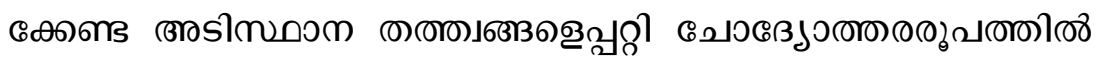

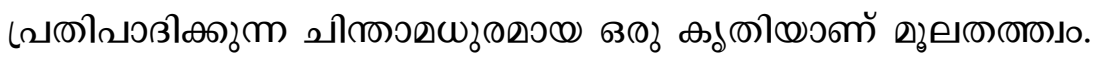

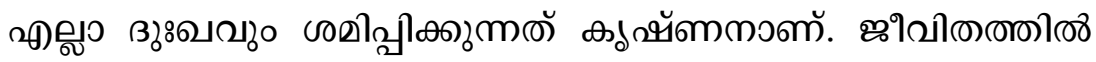

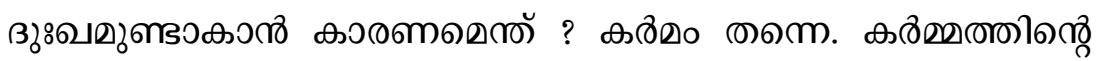

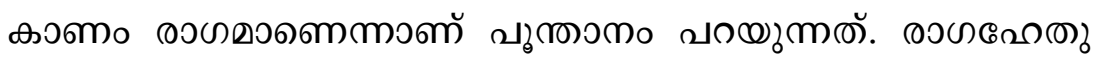

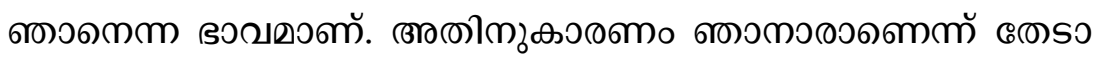

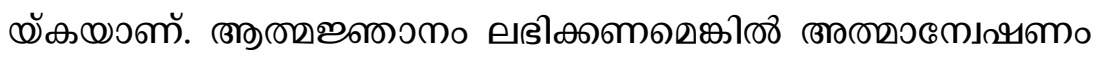

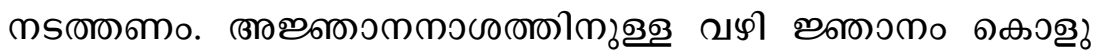

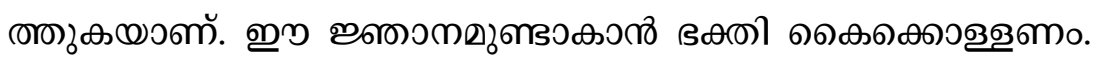

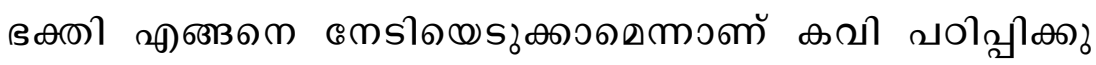

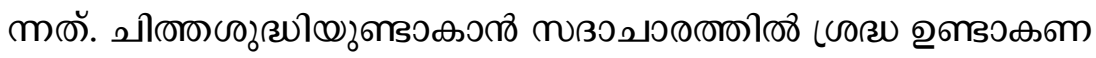

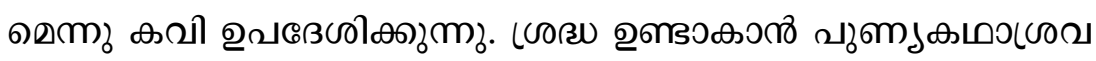

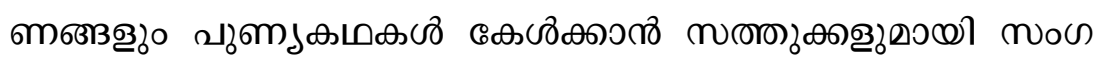

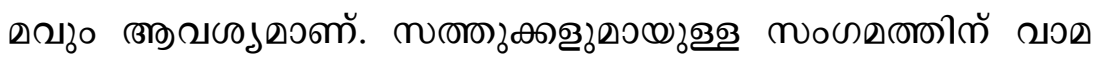

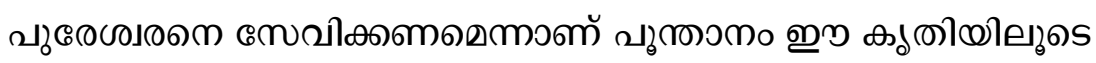
வூமவைலவிாளั. 


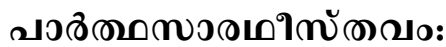

கூருவவஜரை

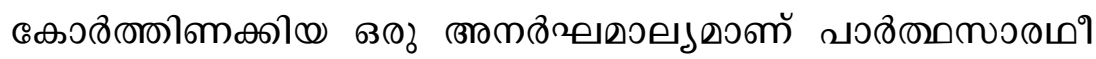
ஸัவைం. (

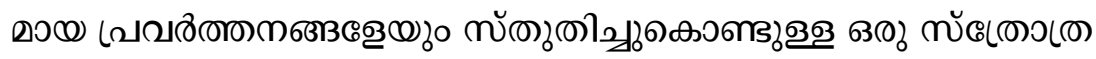

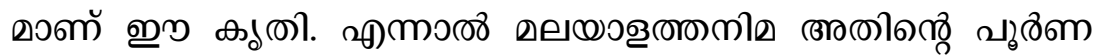

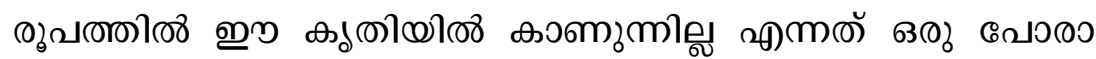

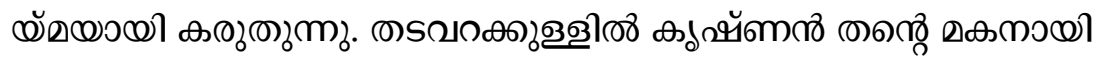

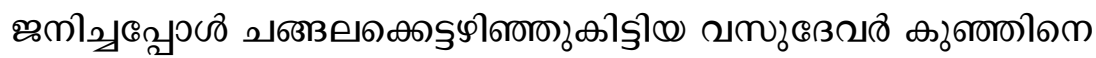

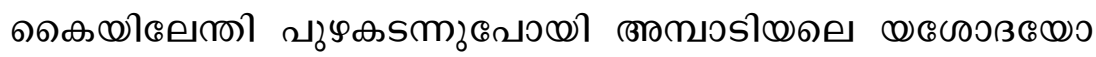

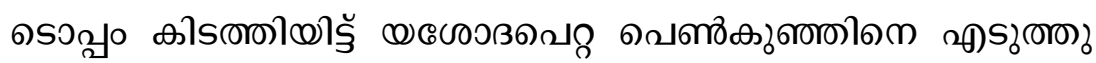

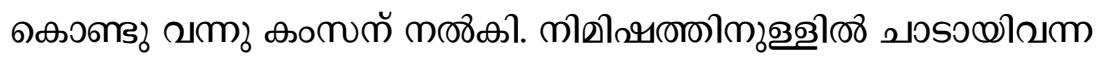

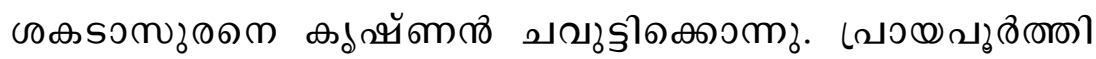

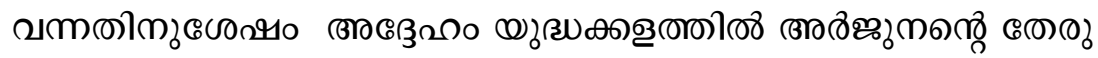

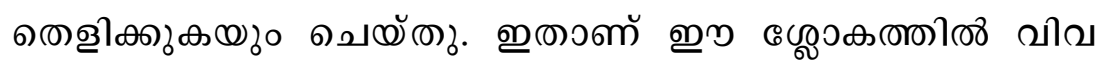

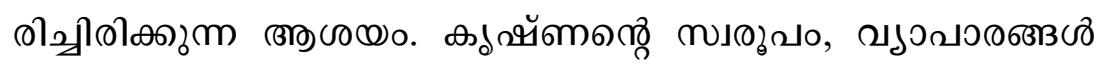

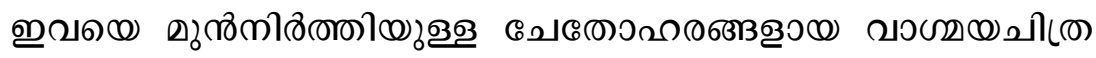

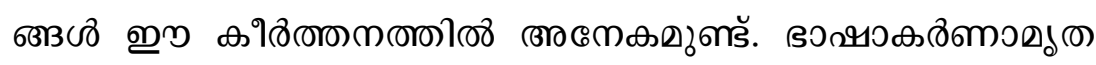

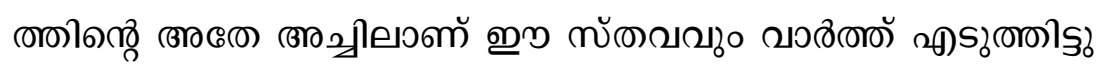

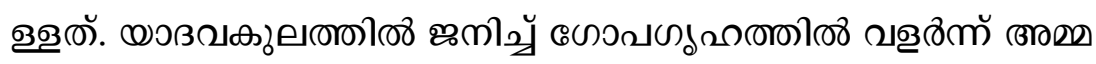

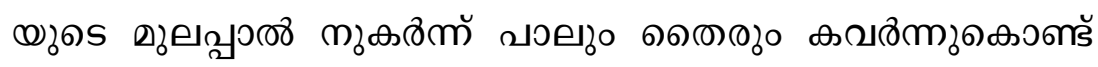

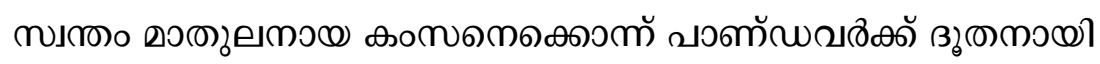

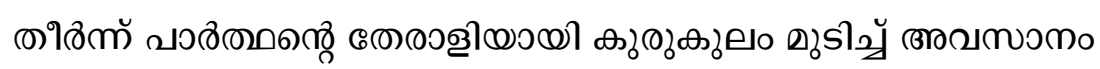

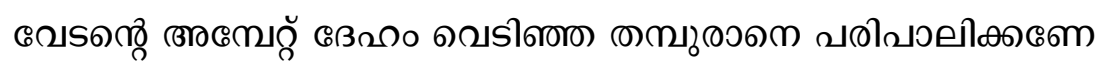

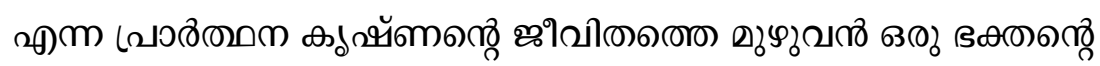

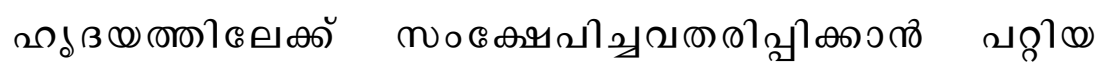




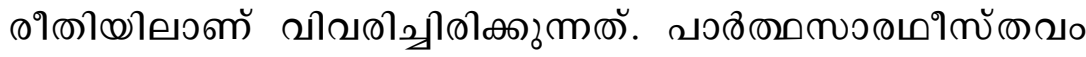

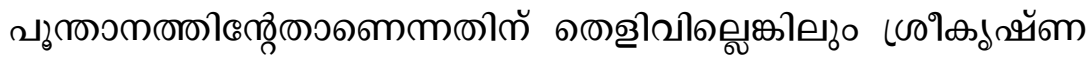

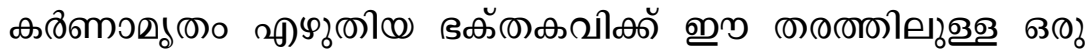

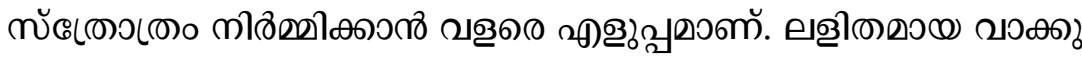

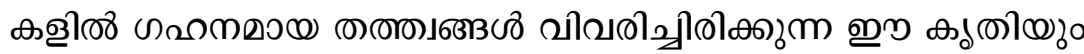

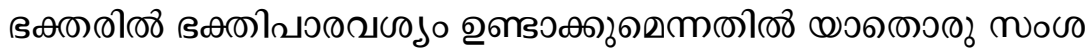
๒வூவிల్ .

\section{๑กภอดหัดใกัญை๐}

வ

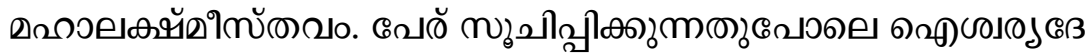

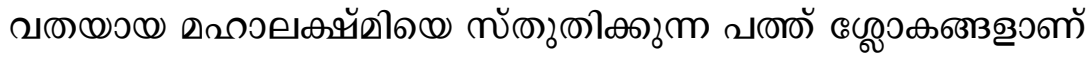

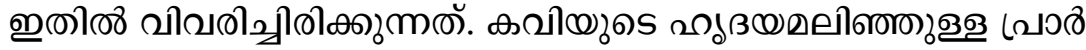

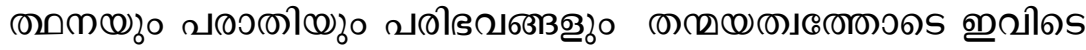

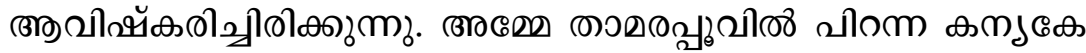

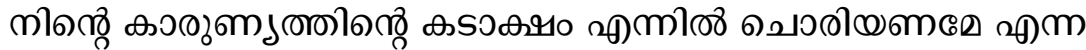

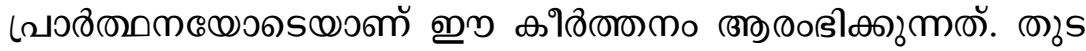

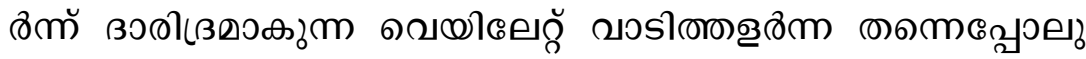

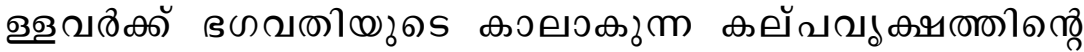

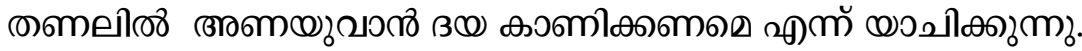

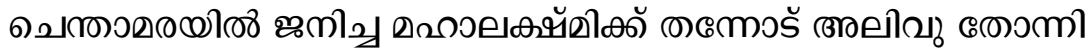

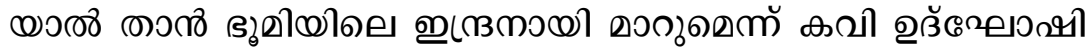

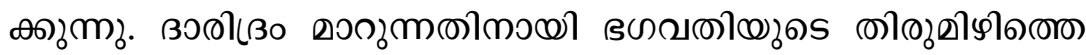

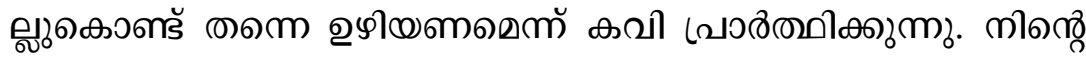

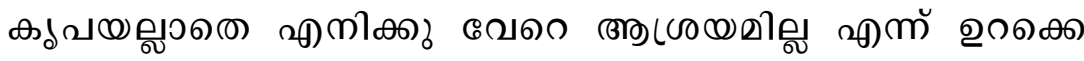

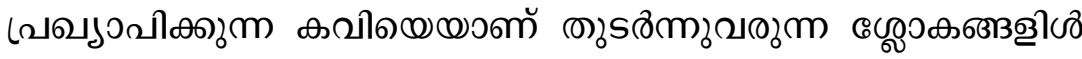

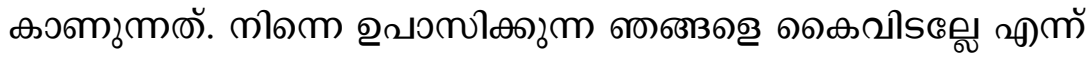




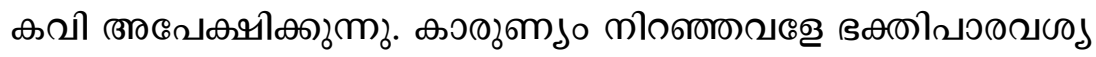

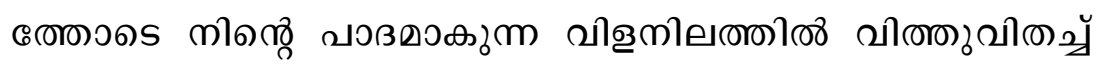

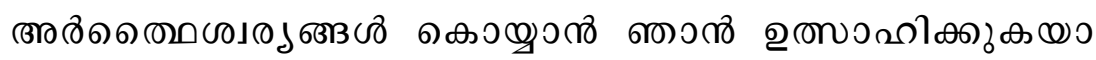

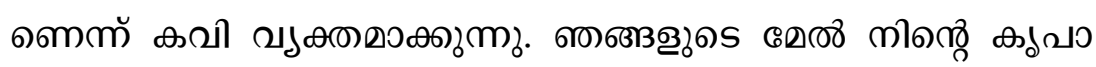

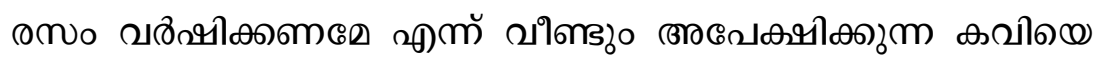

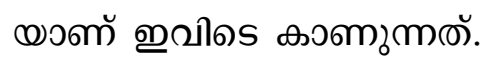

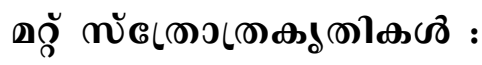

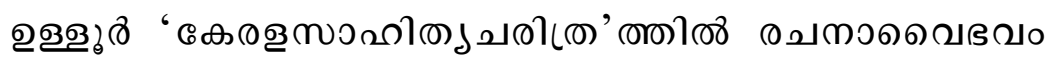

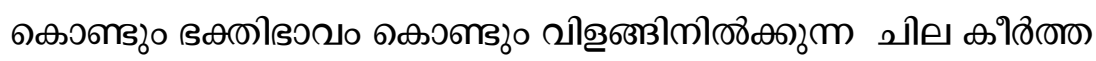

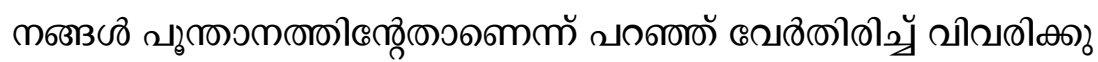

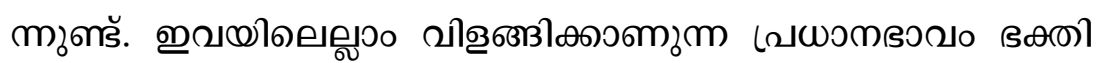

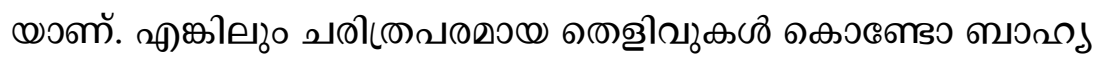

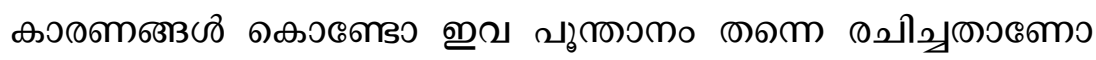

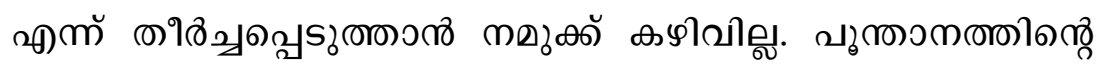

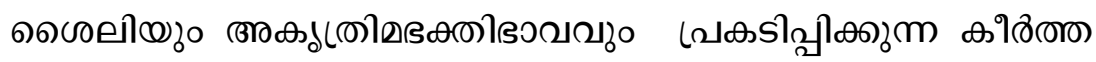

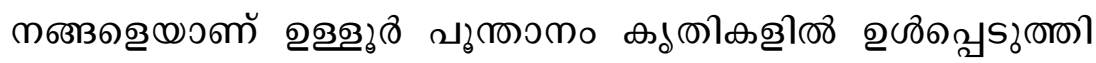

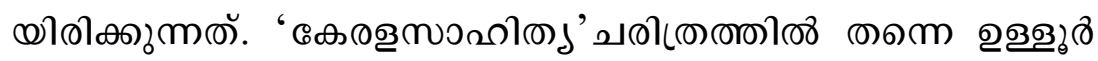

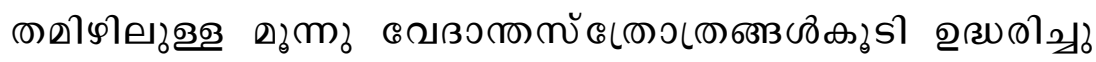

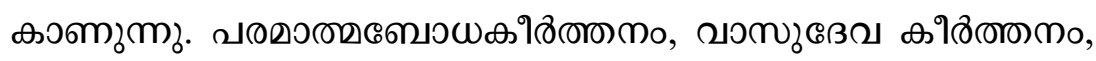

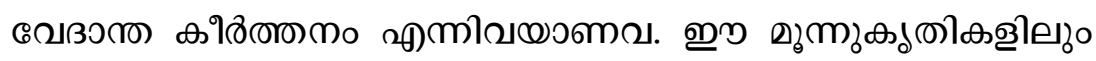
வOவ لృ

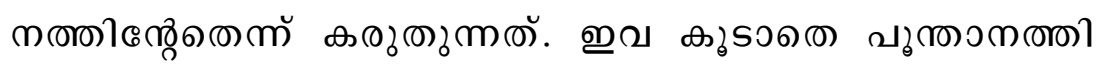

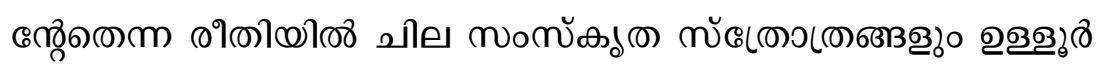

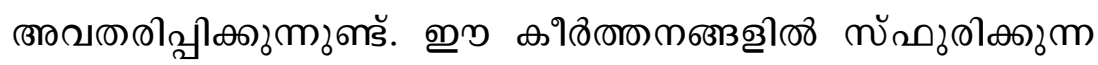

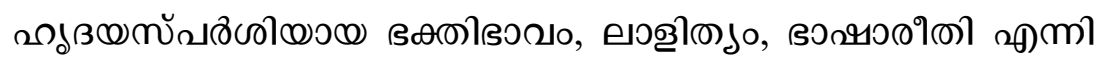

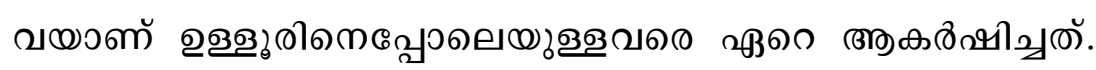




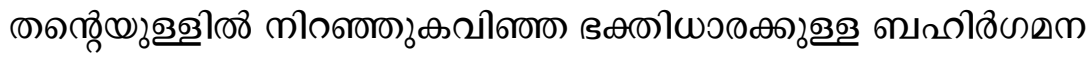

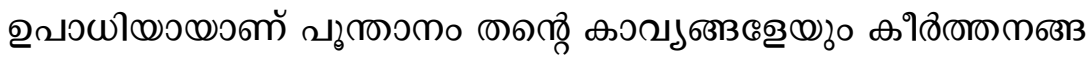

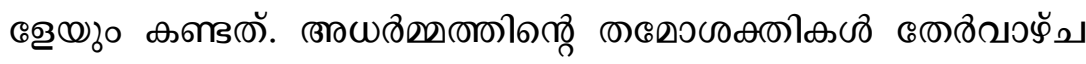

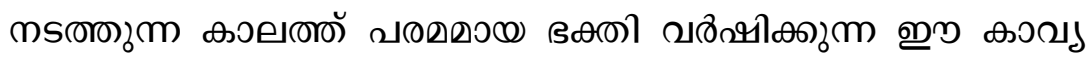

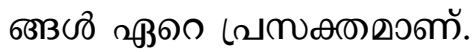




\section{4.

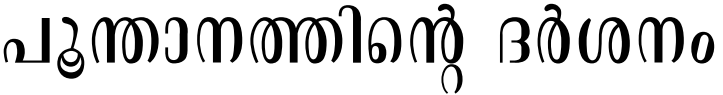

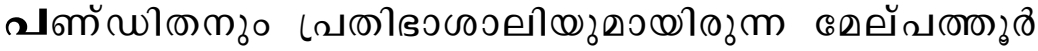

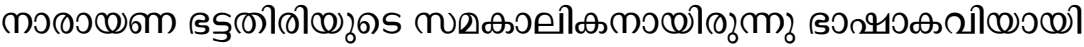

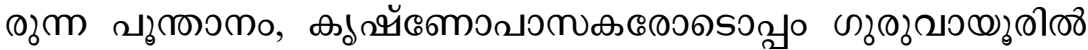
mிரையாஷ

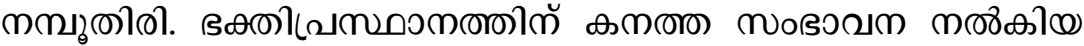

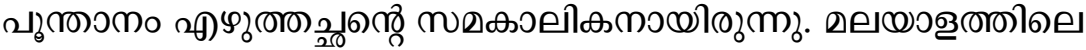

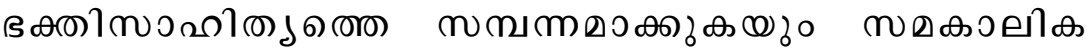

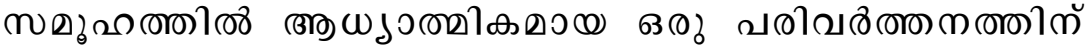

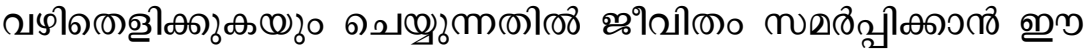

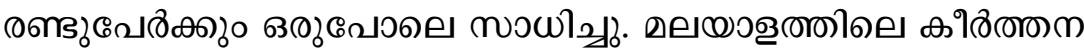

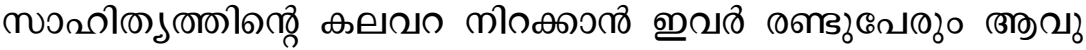

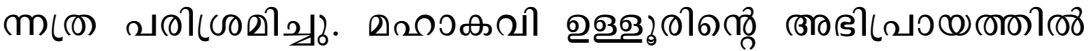

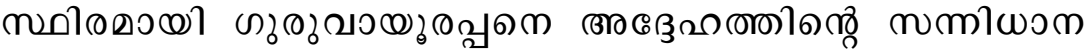

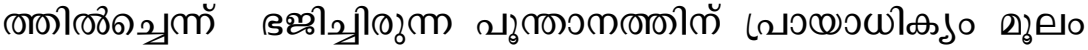

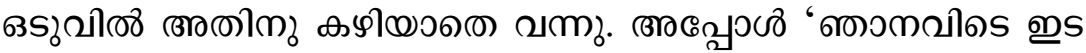

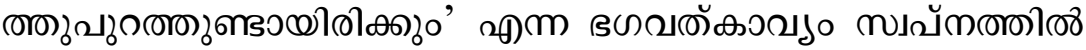

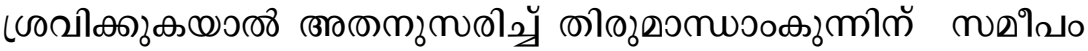

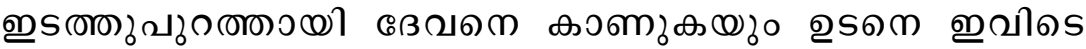

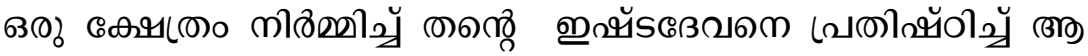

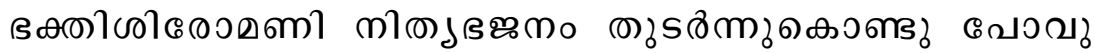

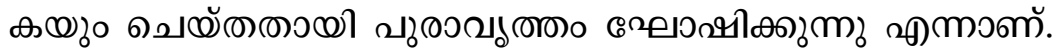




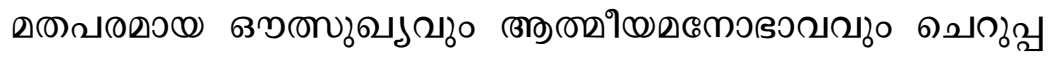

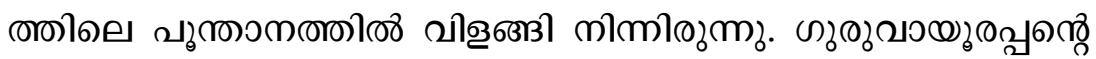

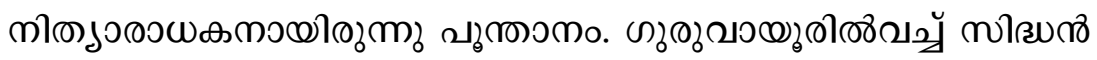

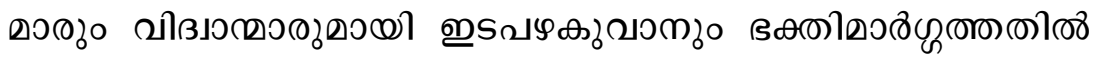

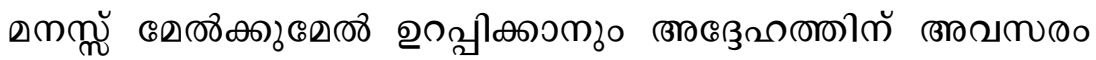

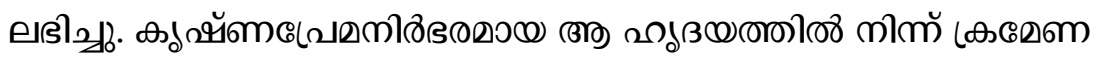

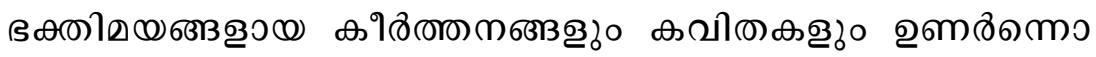

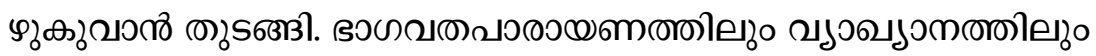

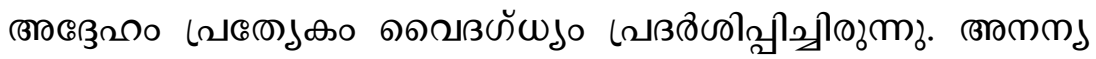

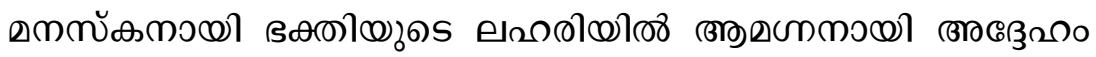

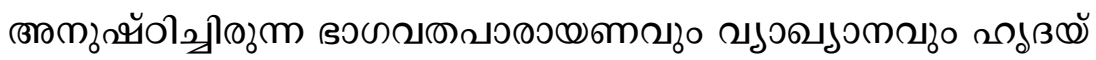

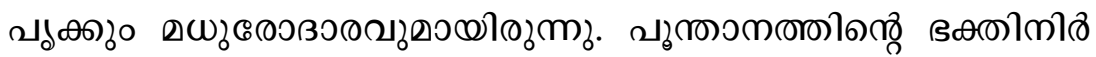

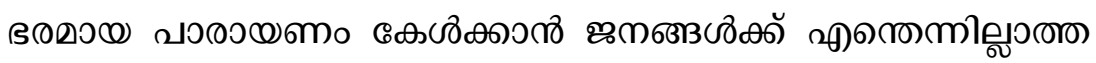

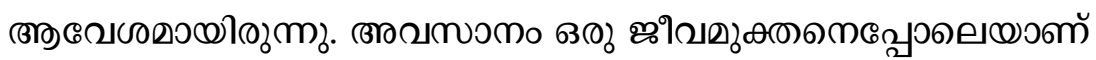

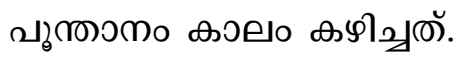

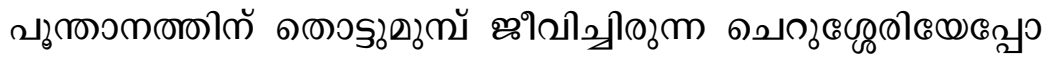

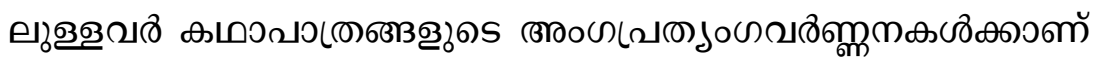

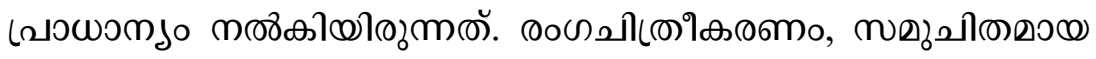

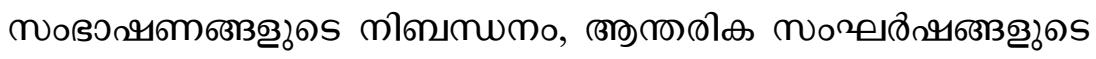

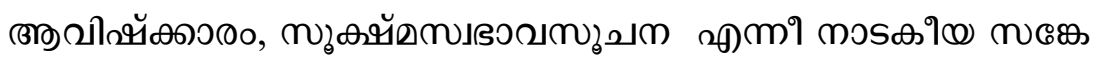

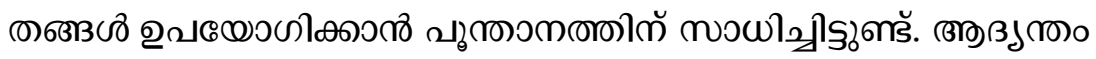

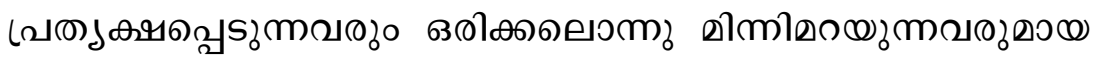

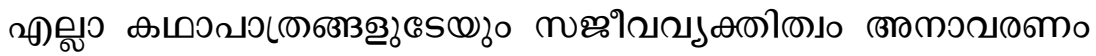

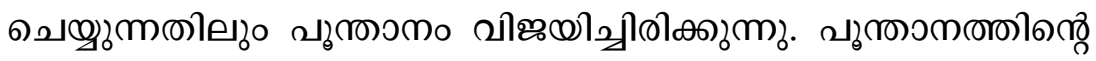

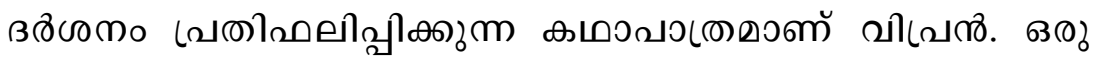

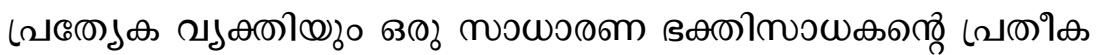




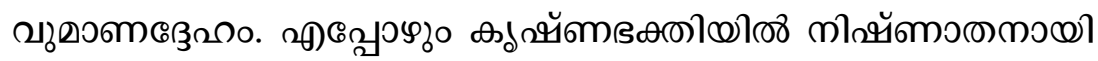

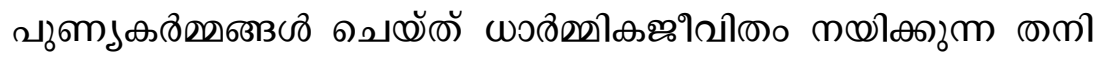

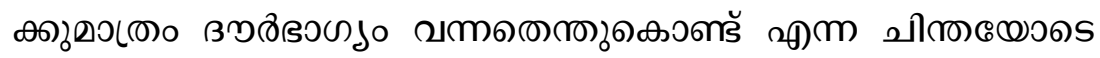

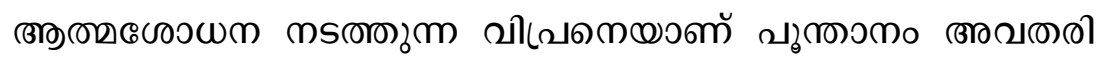

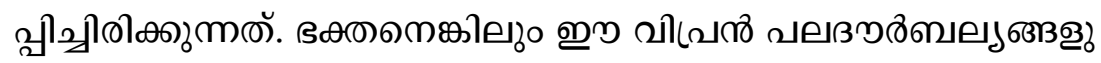

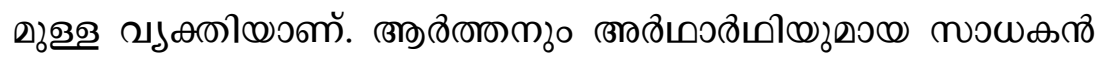

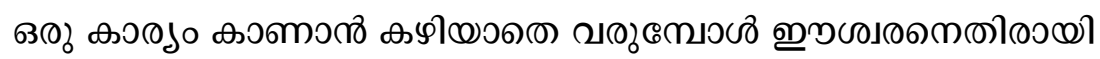

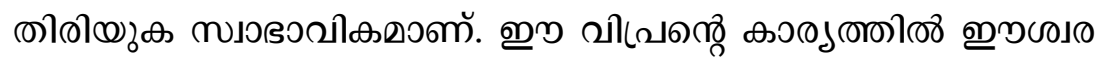

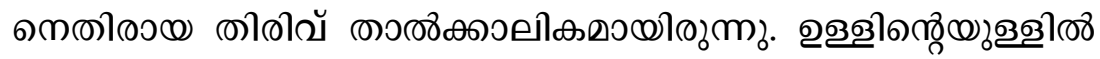

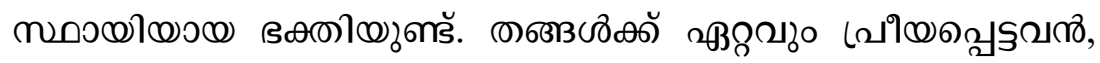

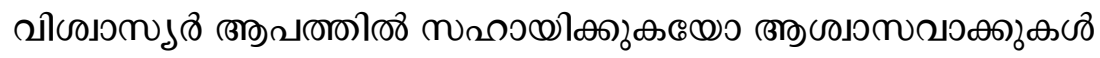

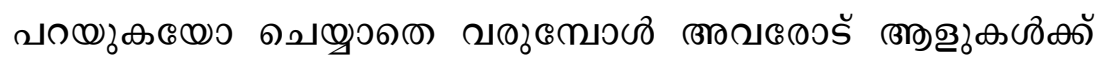

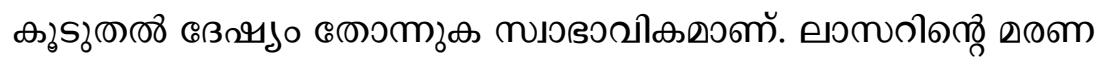

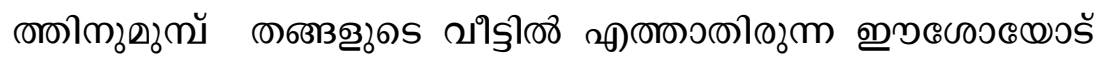

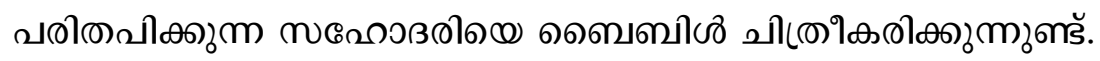
कெ வั

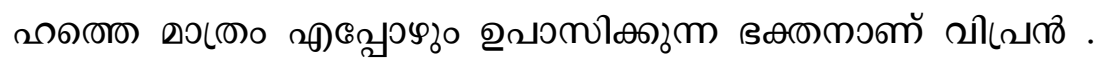

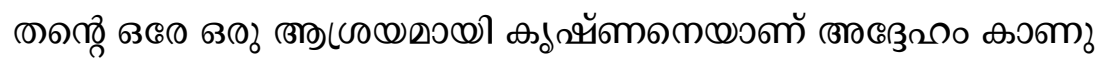

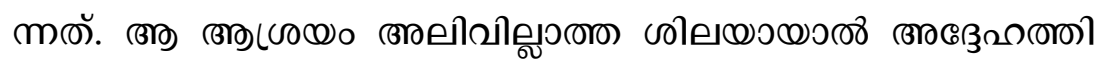

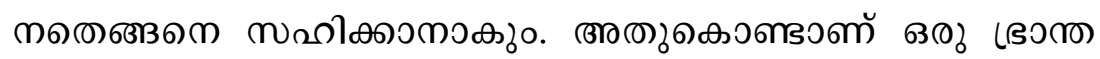

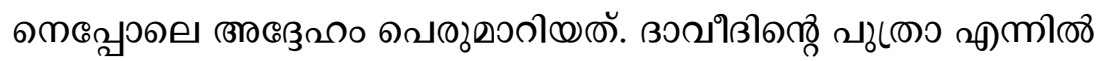

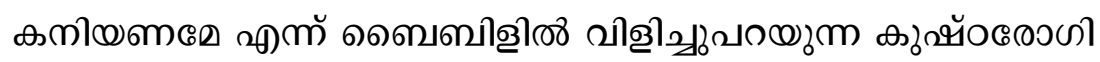

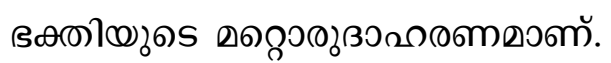

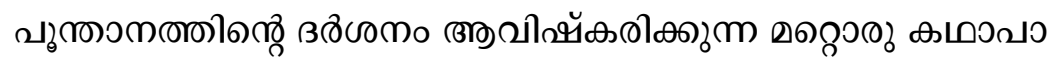

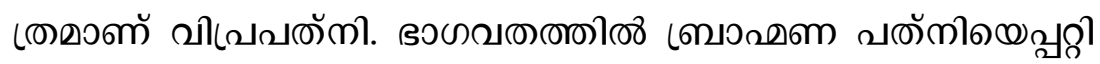

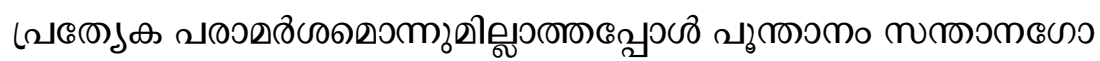

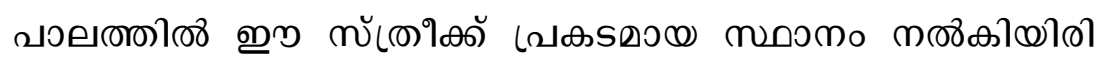




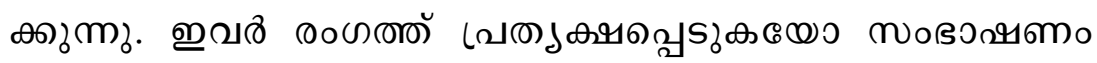

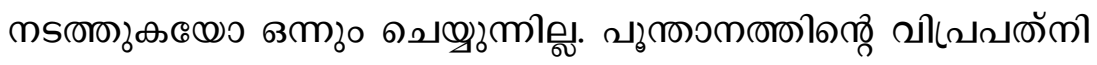

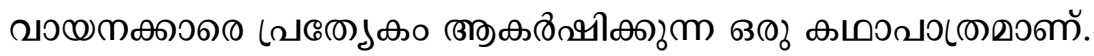

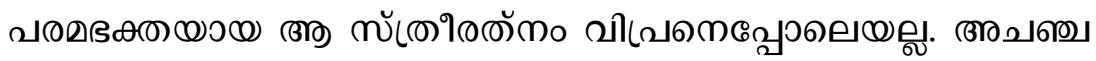

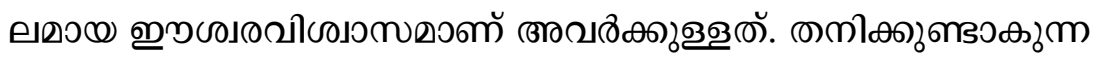

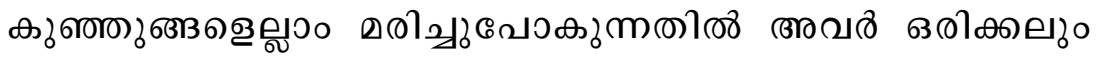

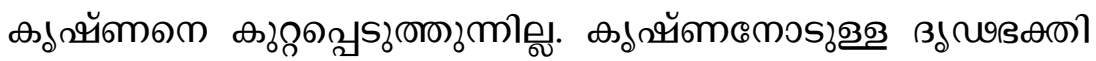

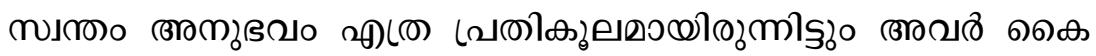

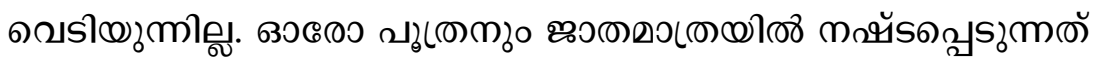

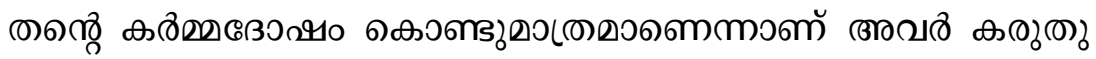

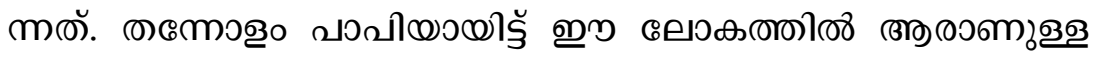

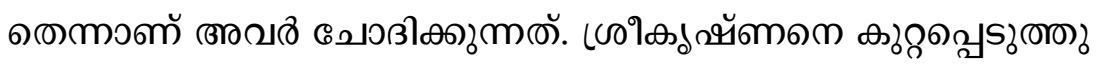

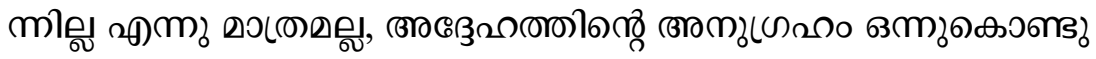

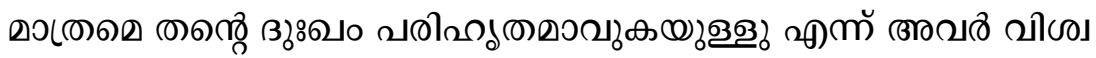

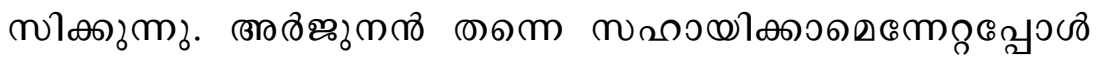

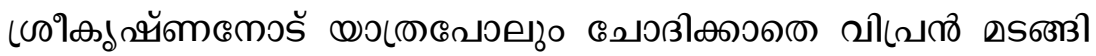

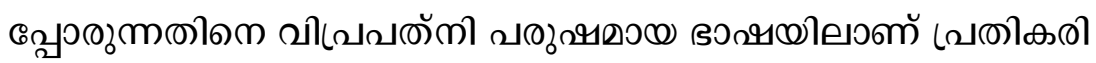

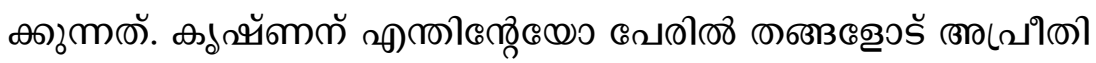

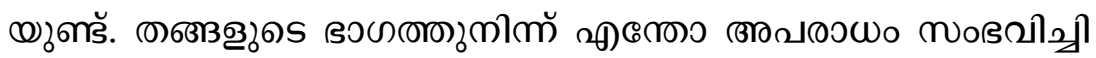

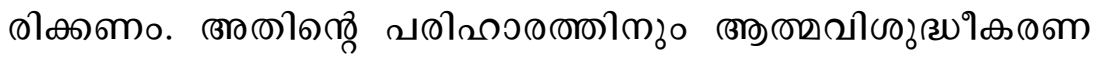

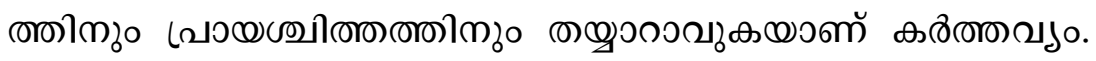

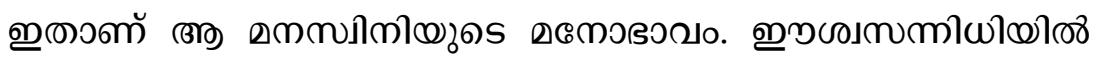

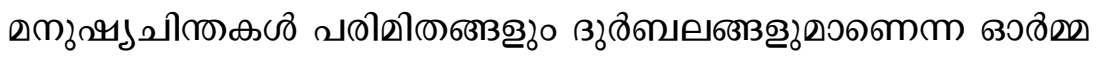

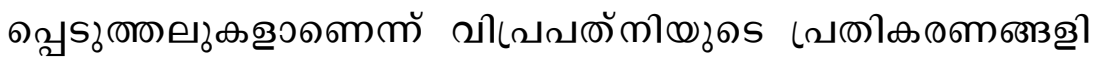

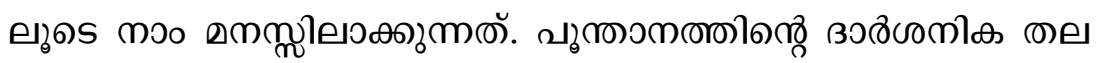

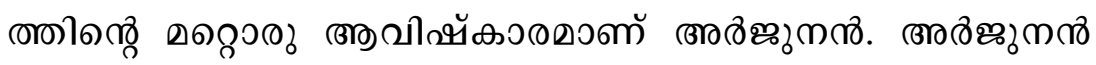

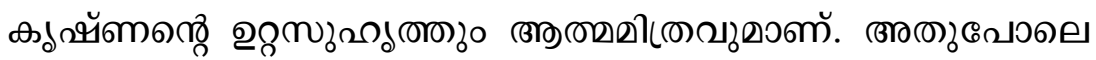




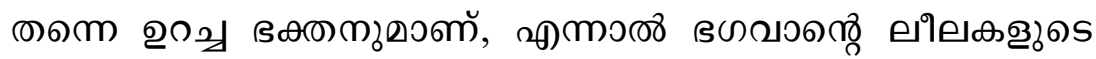

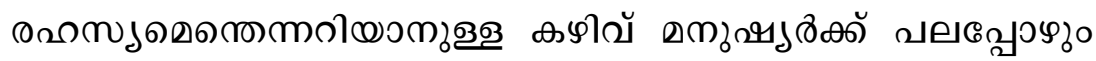

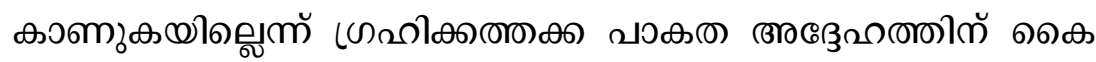

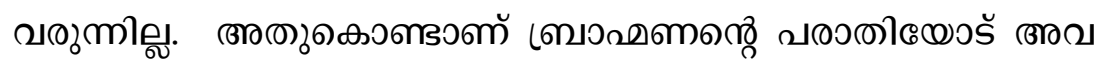

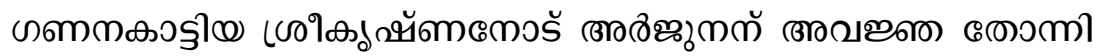

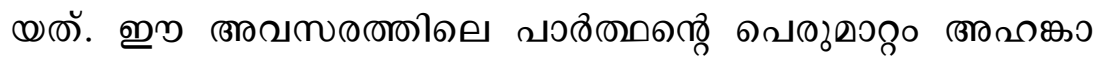

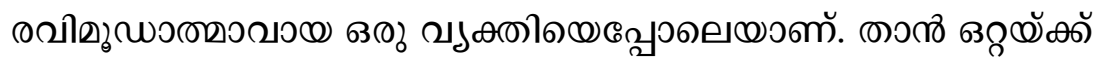

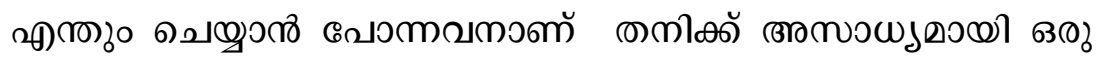

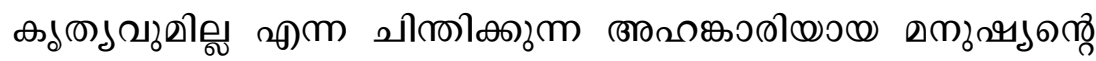

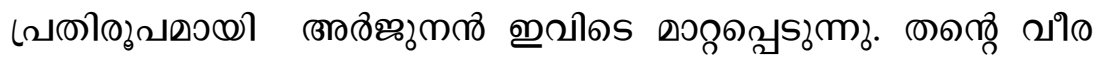

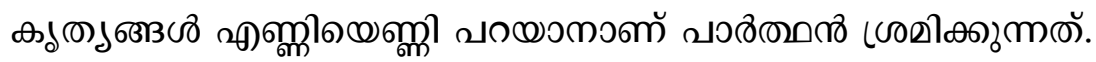

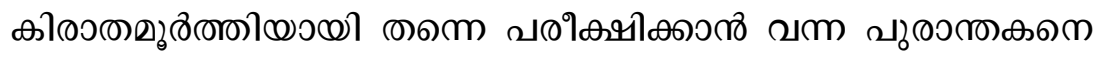

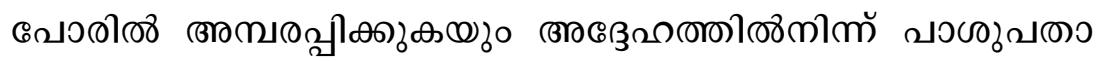

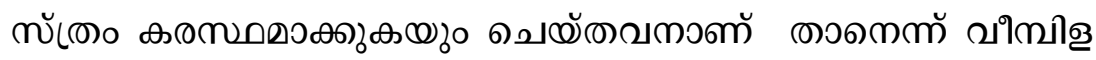

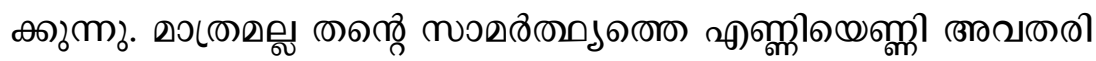

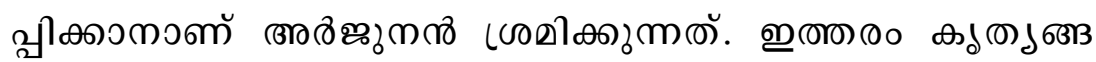

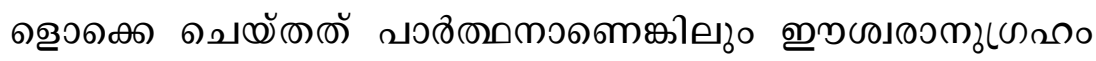

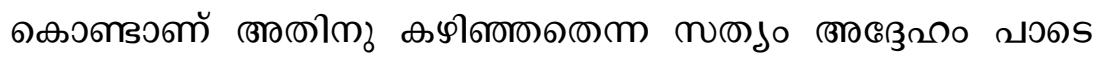

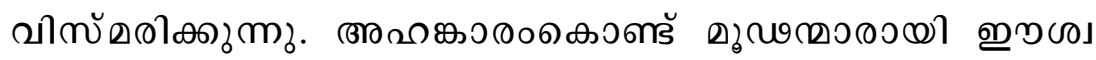

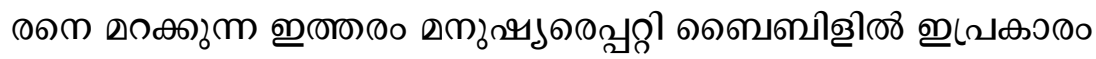

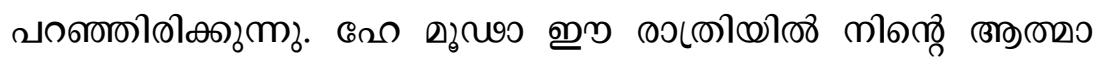

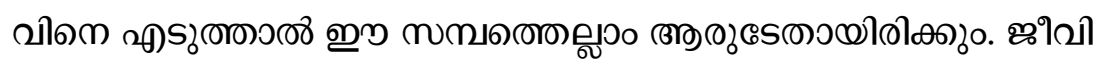

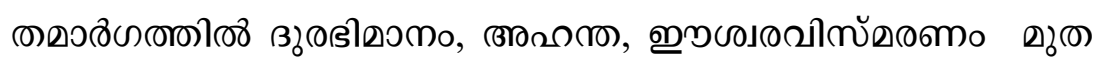

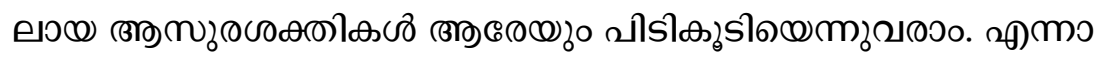

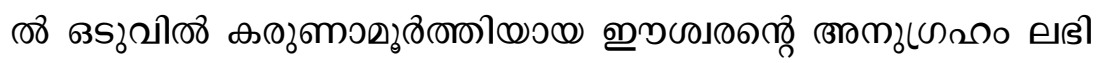

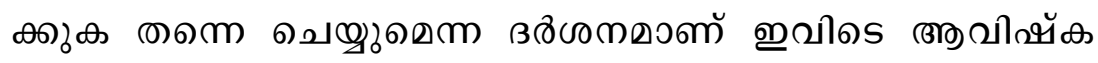

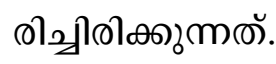




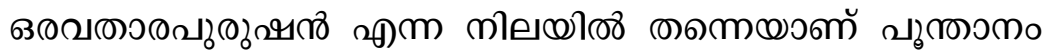
(

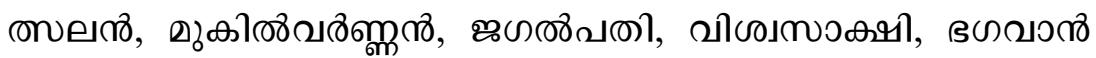

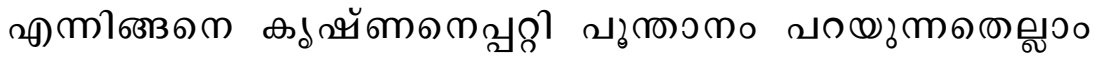

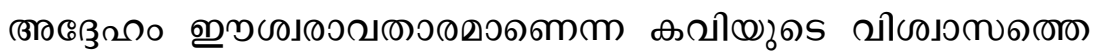

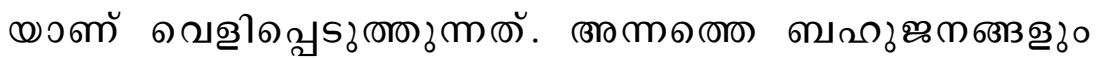

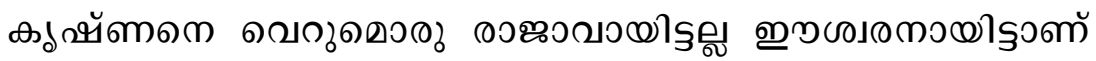

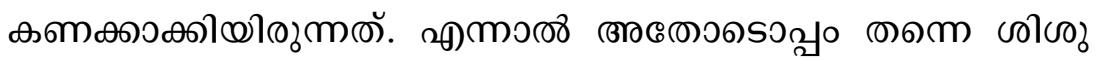
வ

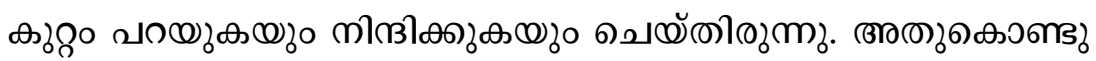

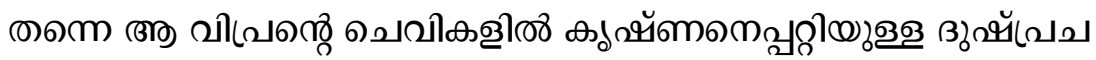

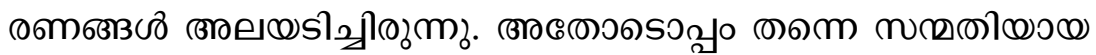

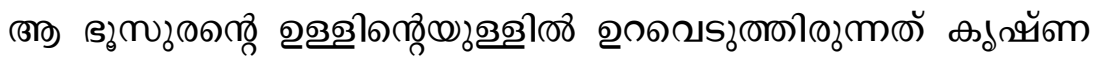

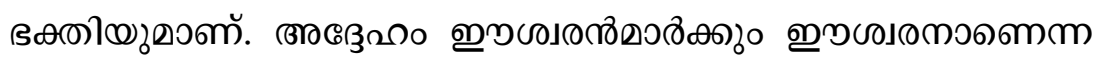

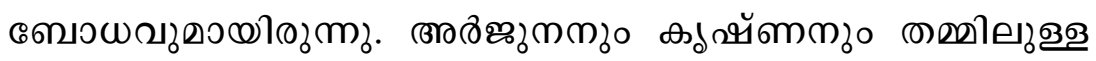

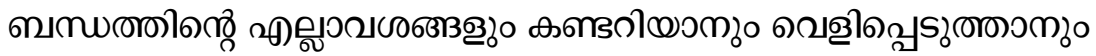

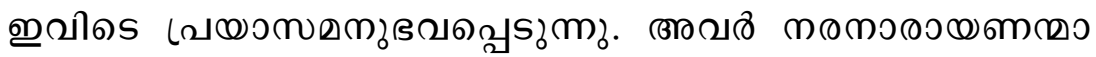

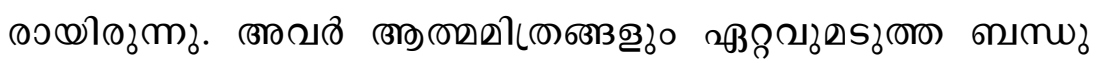

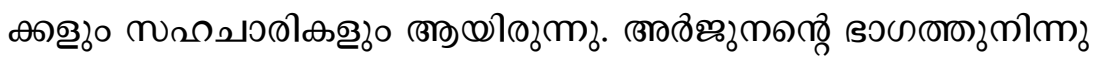

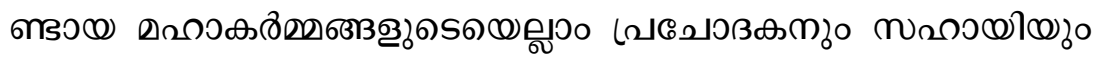
(

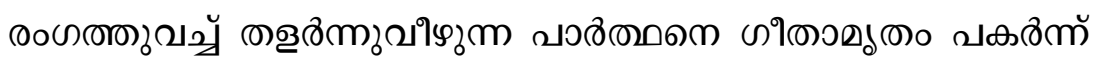

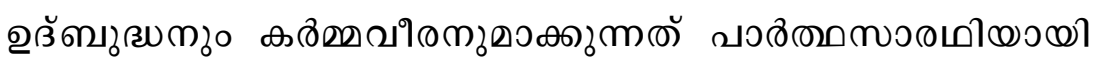

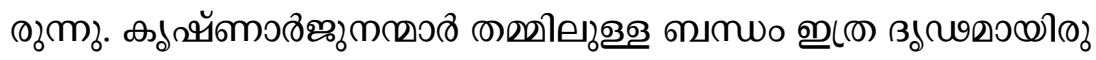

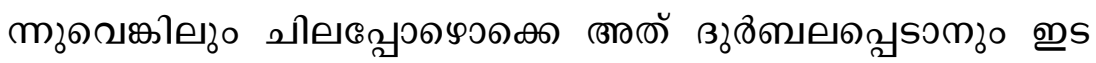

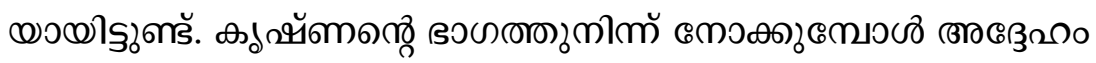

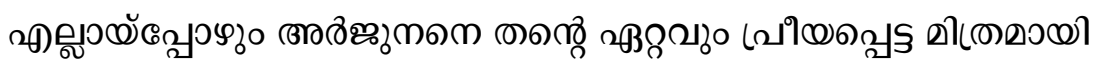




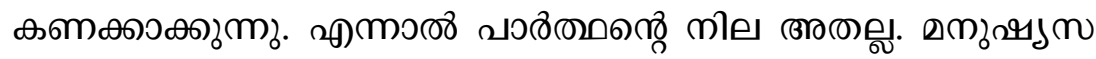

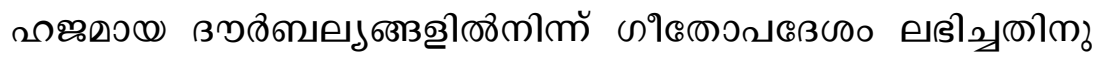

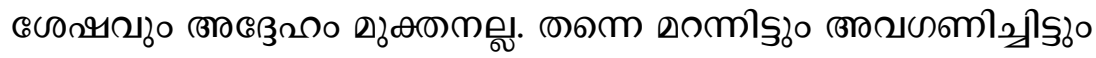

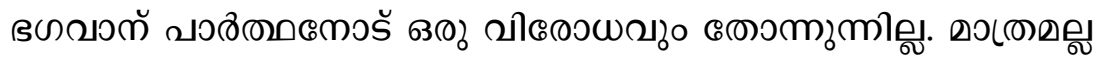

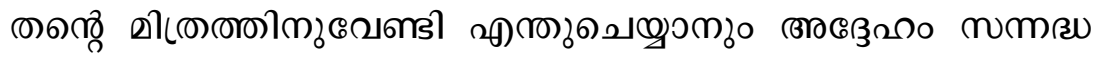

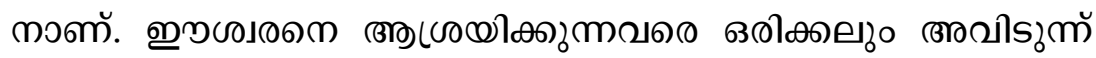

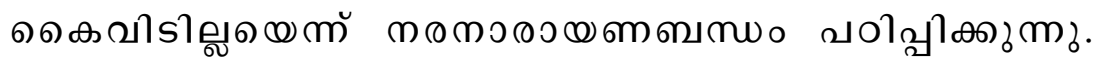

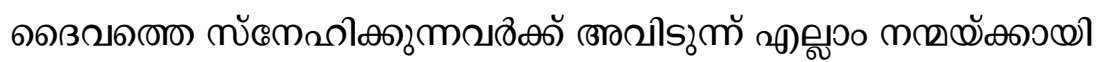

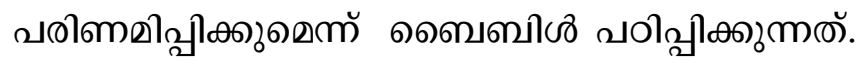

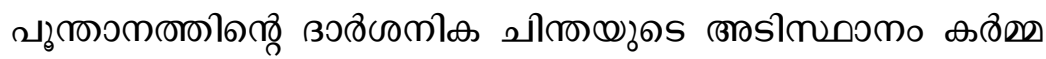

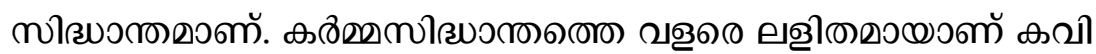

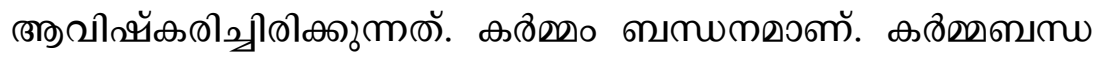

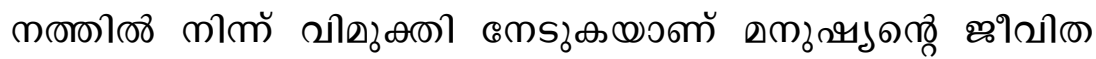

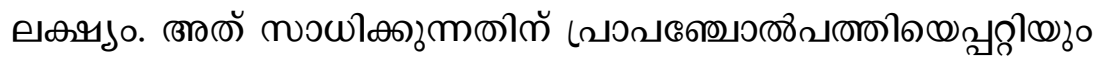

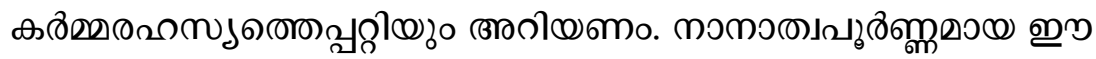

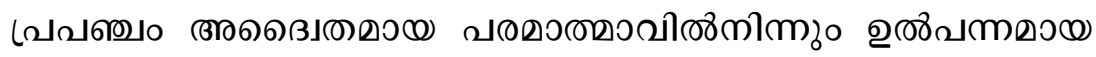

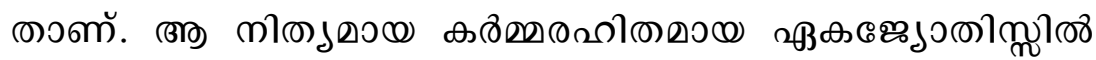

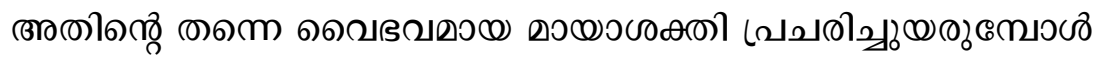

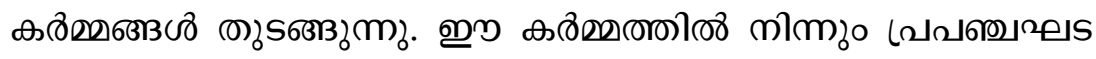

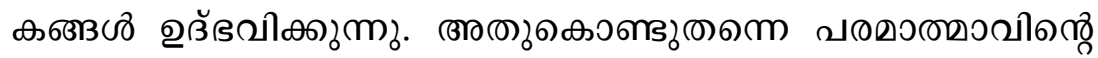

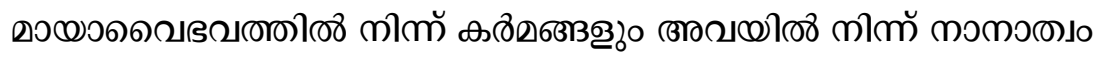

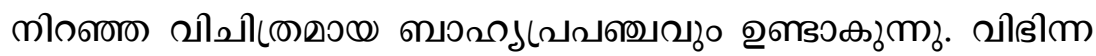

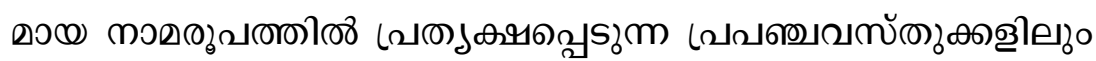

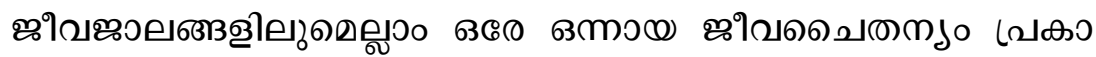

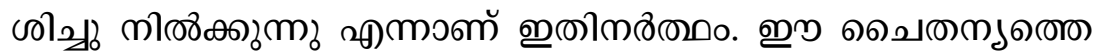

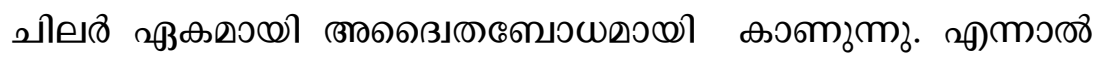

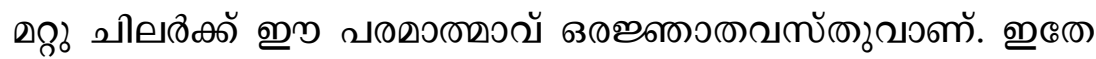




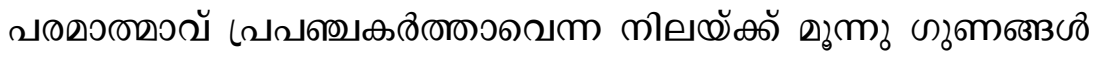

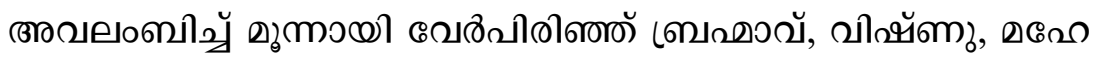

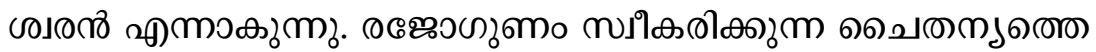

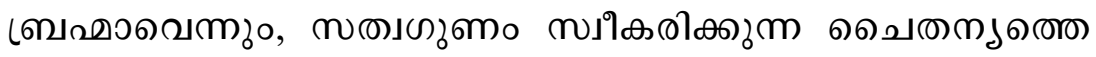

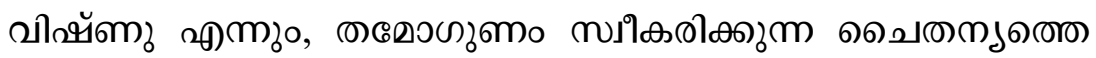

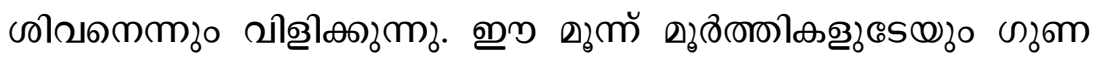

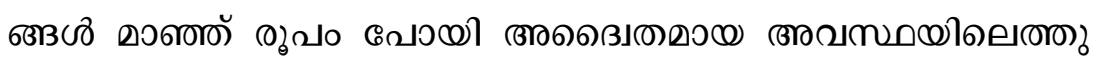

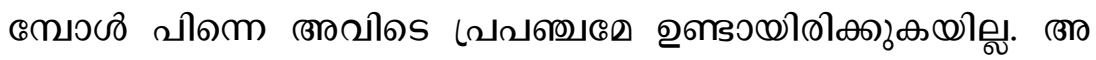

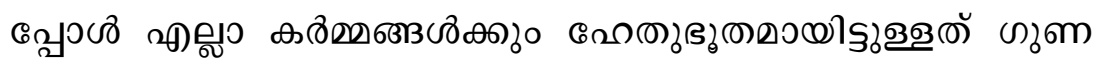

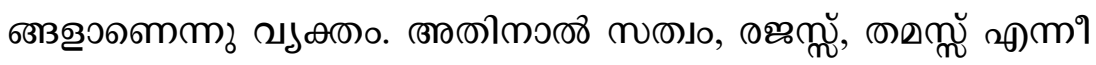

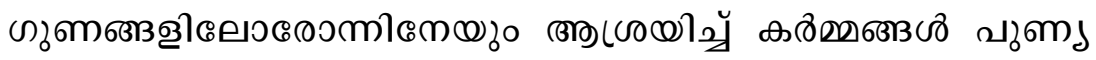

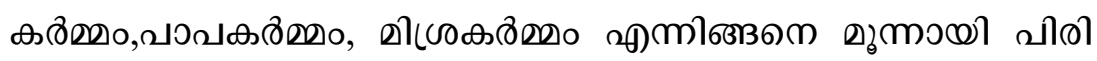

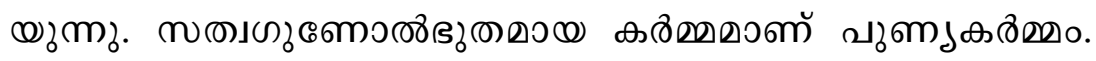

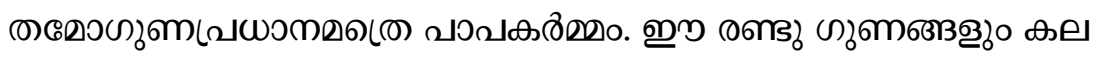

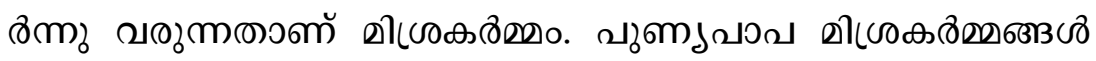

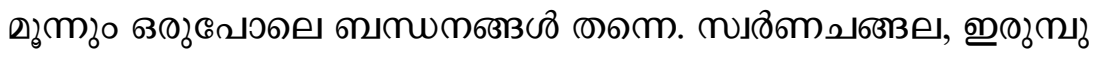

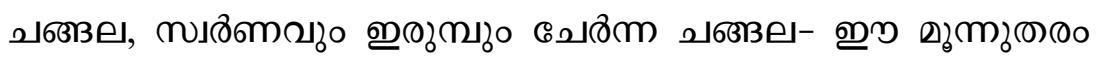

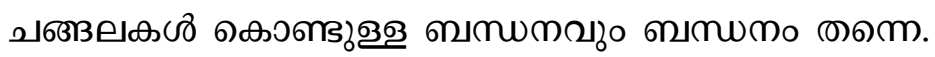

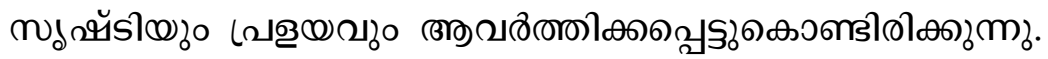

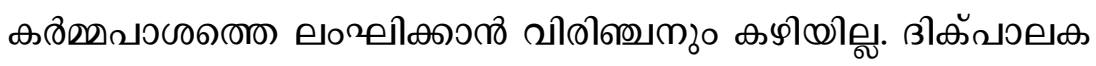

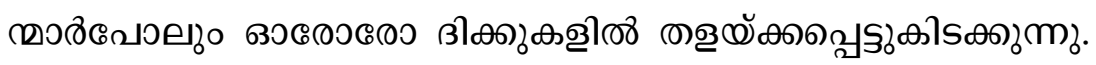

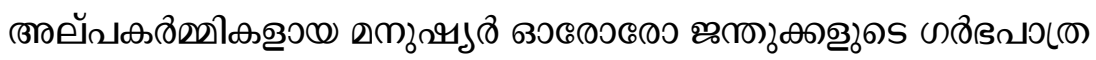

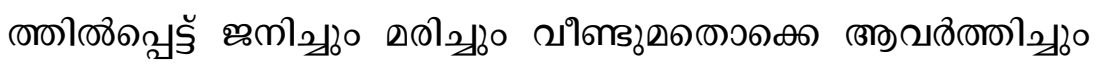

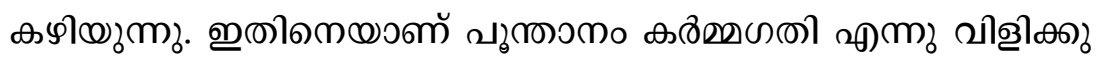

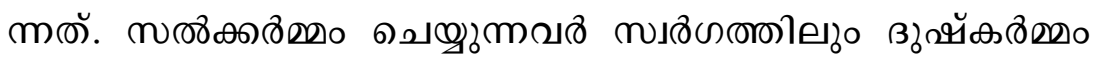

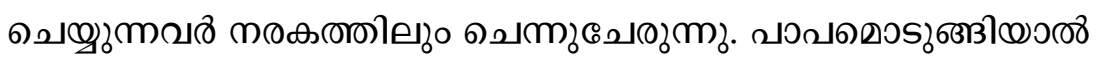

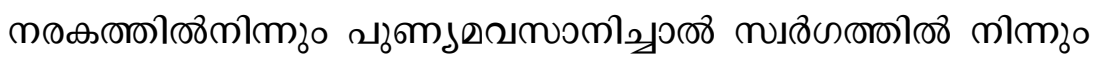




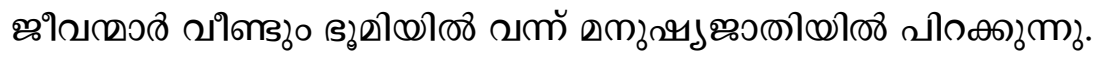

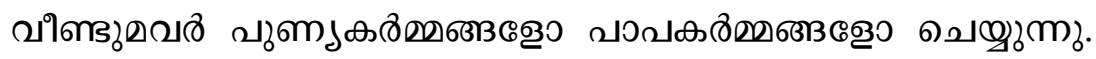

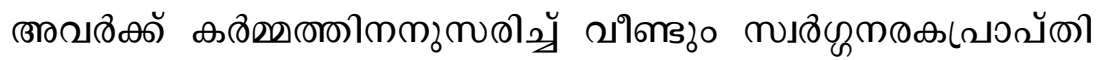

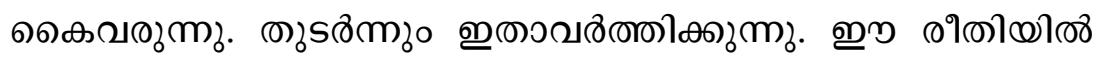

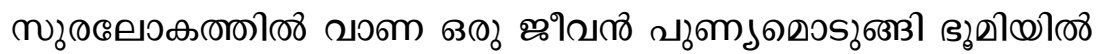

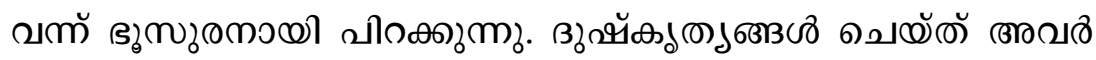

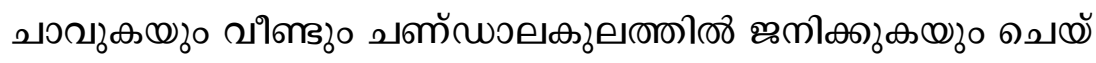

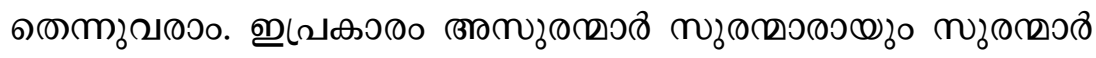

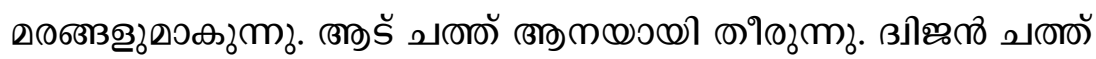

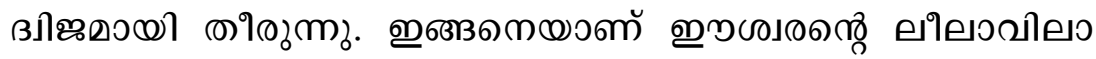
กัฬงช.

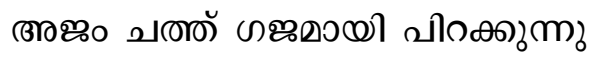

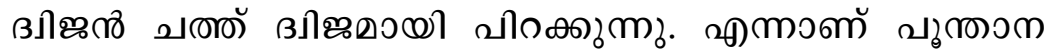
вஷ̊como.

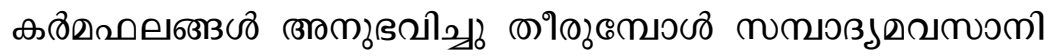

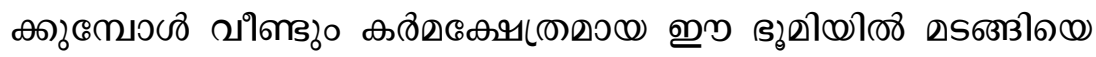

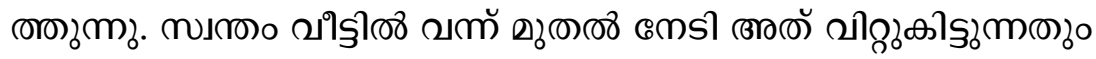

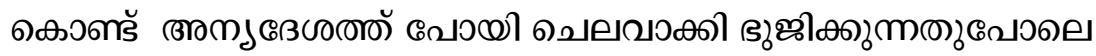

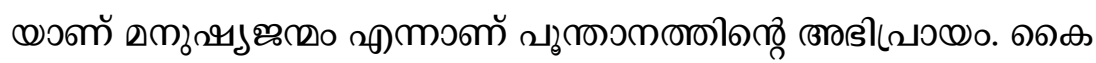
வரேळூ3

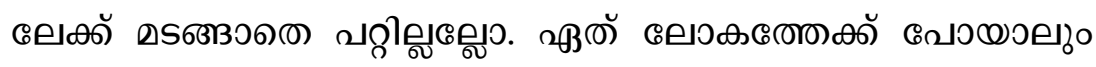

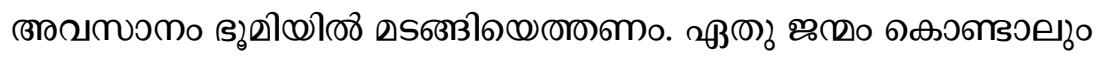

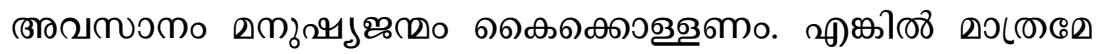

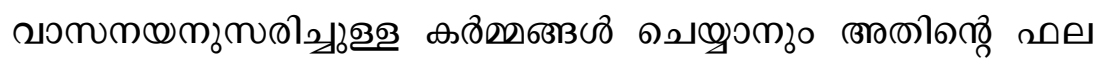

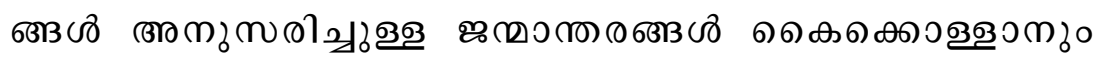

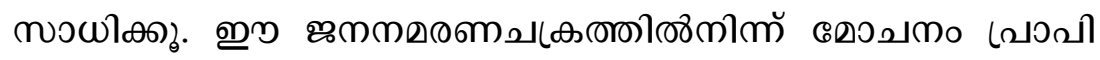




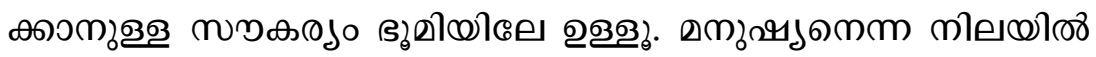

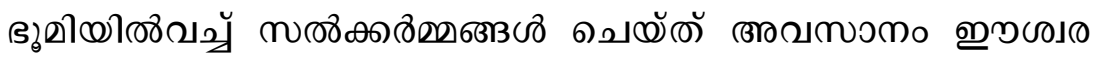

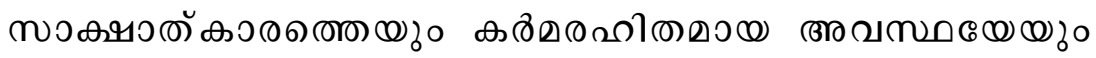

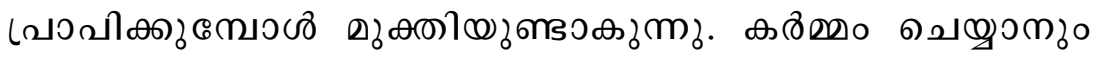

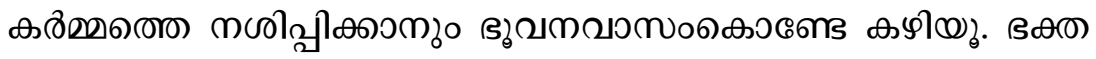

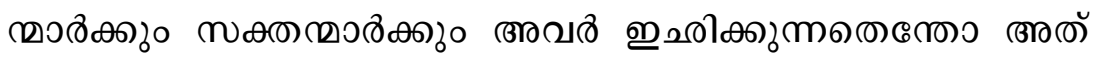

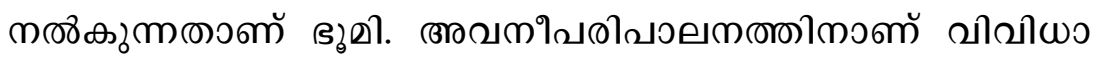

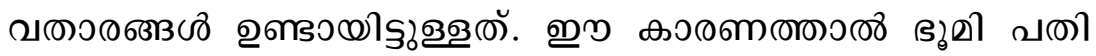

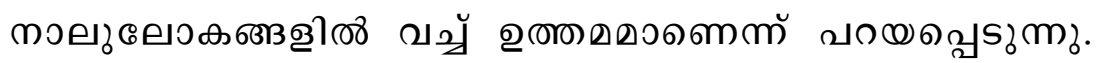

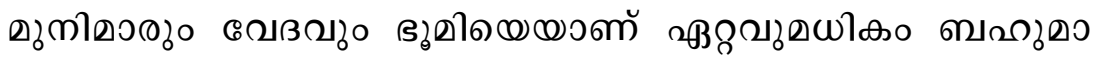
๓ிळூராளั.

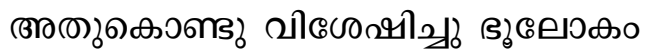

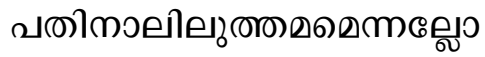

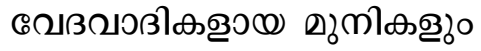

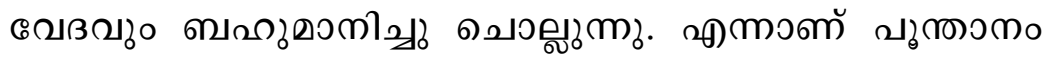

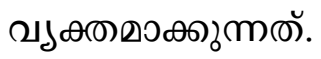

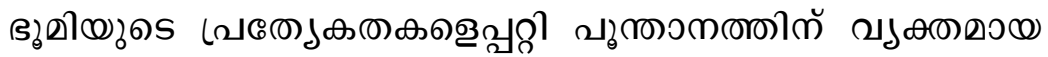

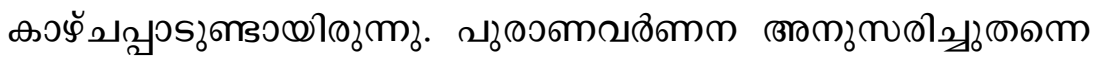

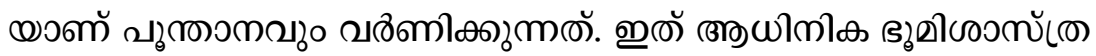

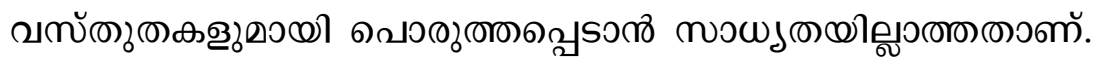

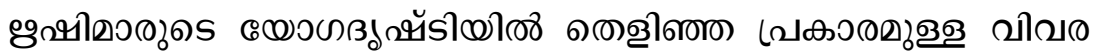

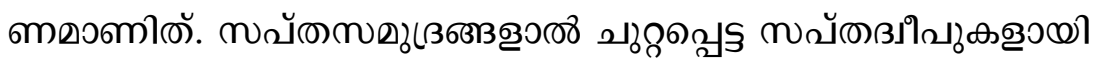

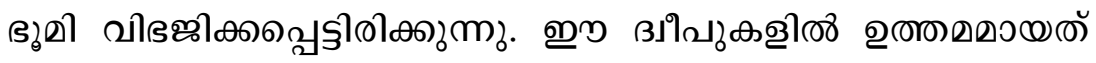
ஜంவకృ

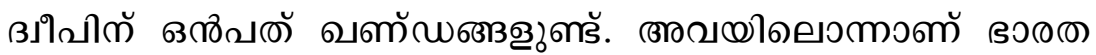

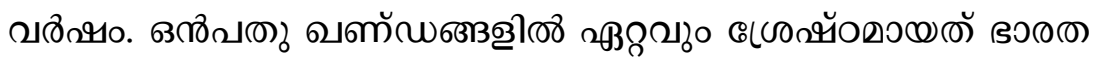




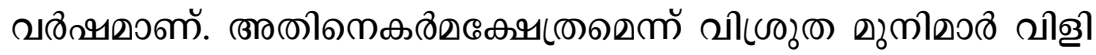

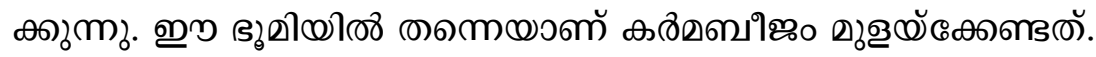

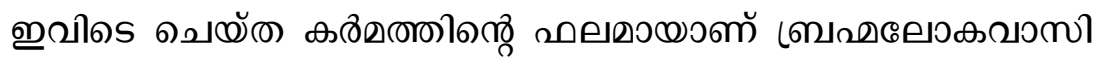

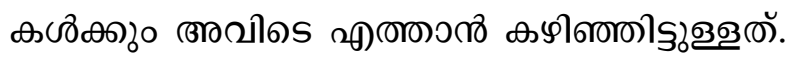

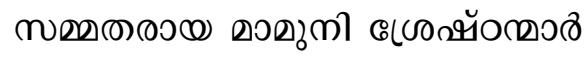

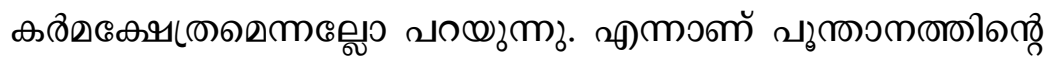

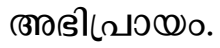

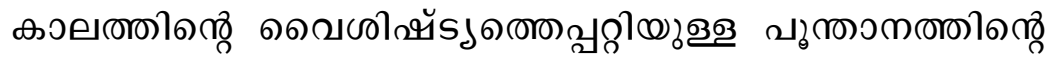
вன்

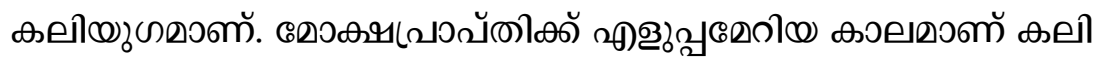

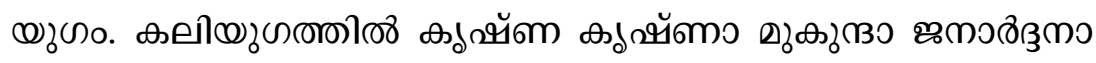

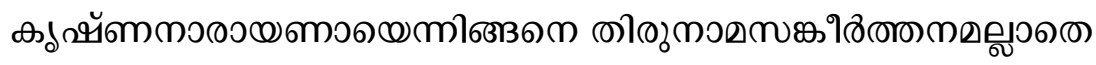

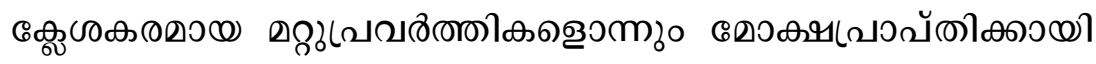

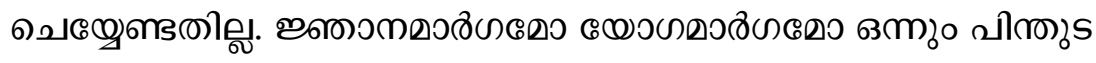

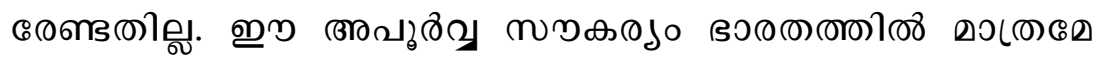

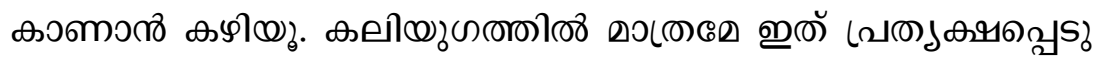

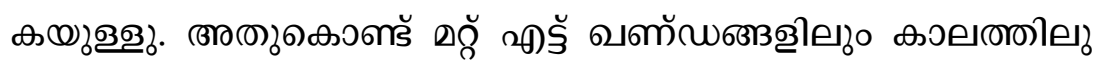

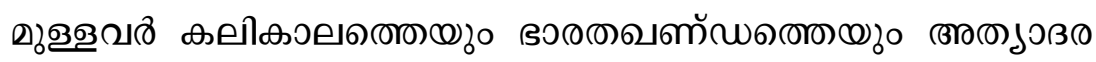

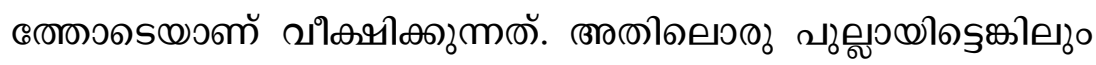

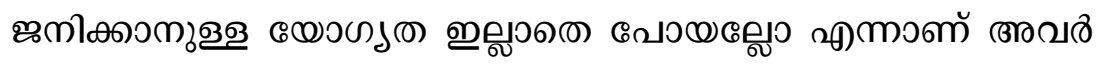

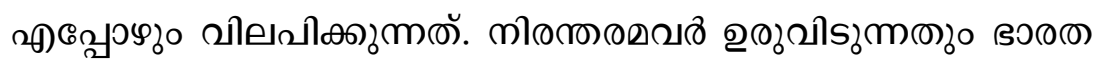

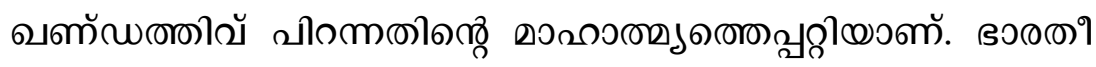

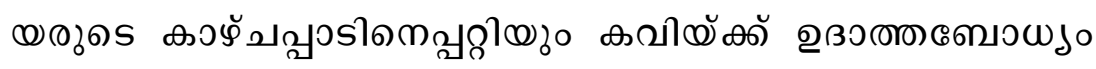

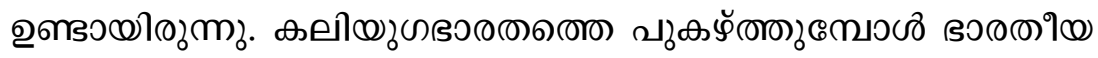

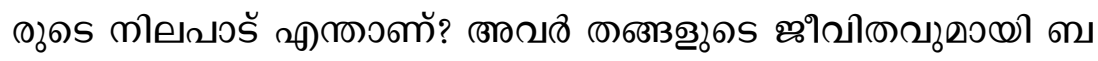

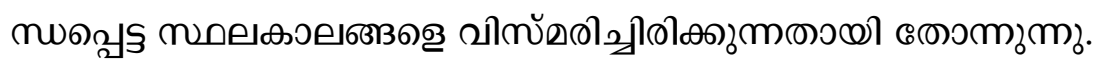




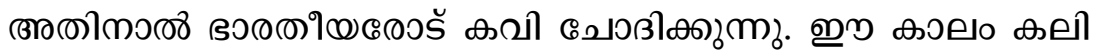

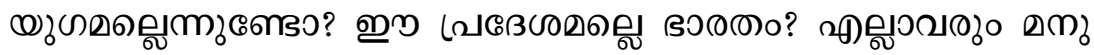

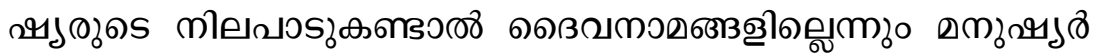

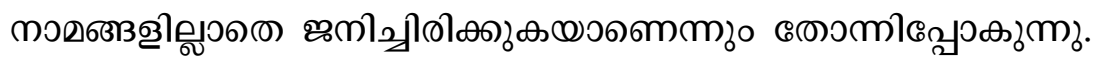

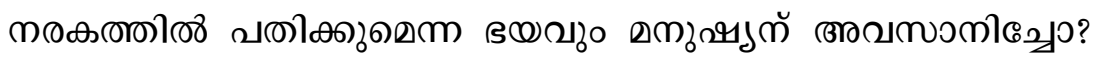

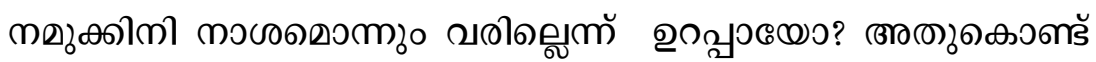

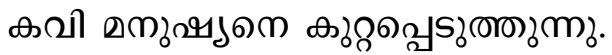

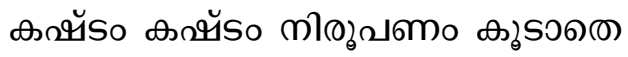

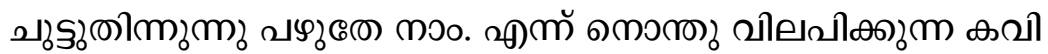

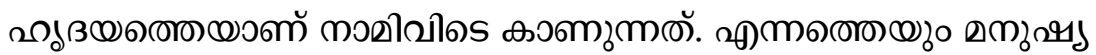

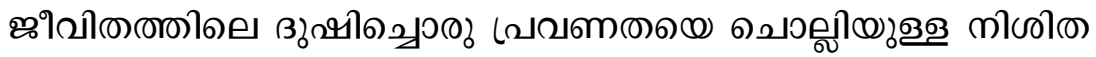

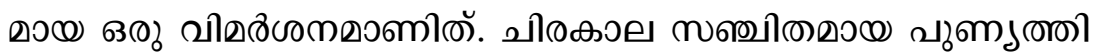

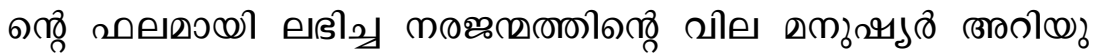

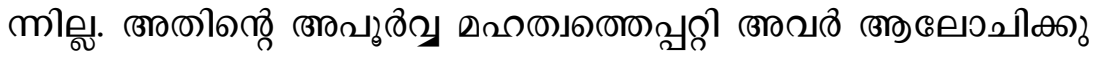

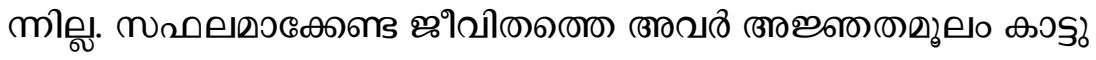

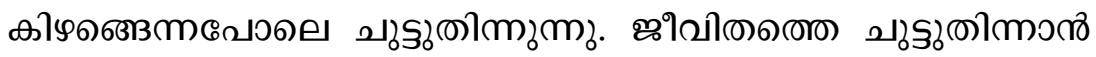

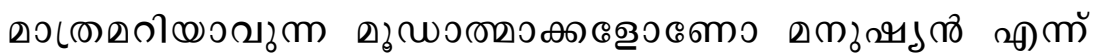

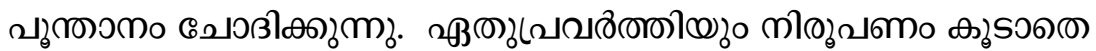

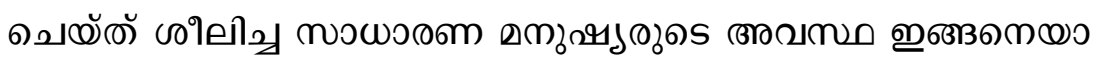

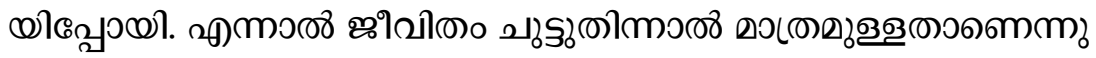

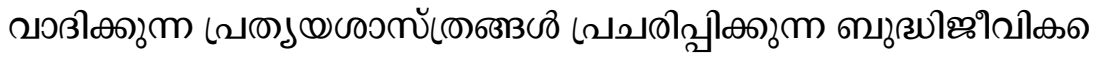

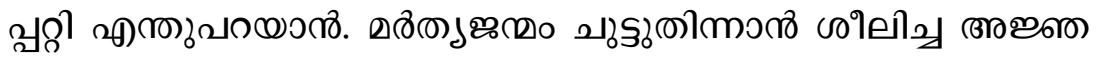

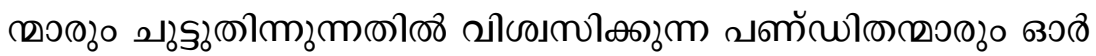

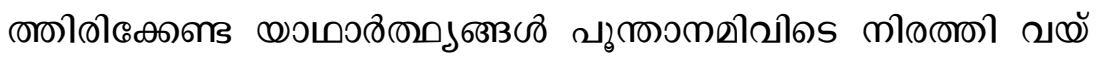

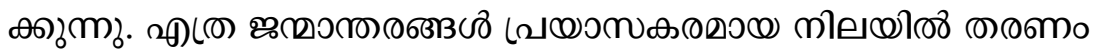

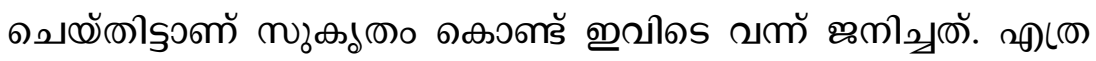

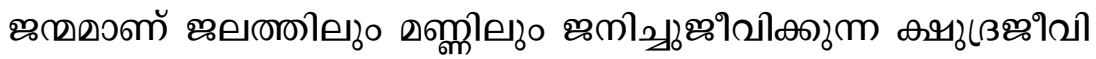




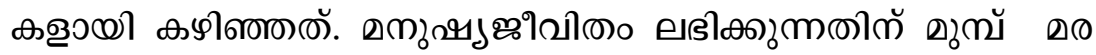

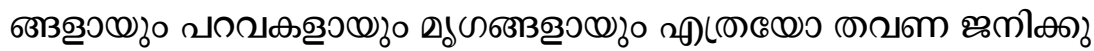

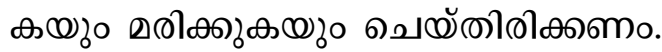

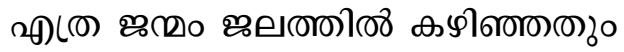

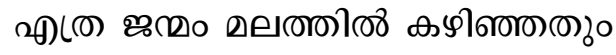

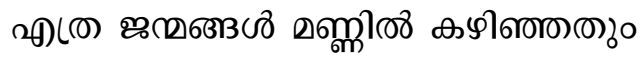

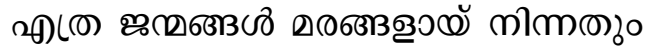

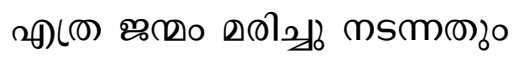

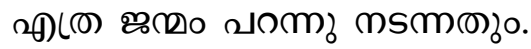

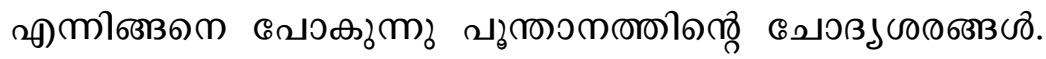

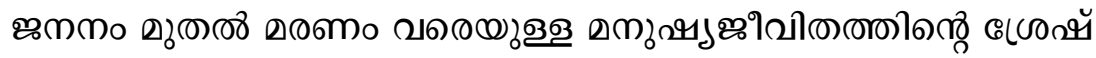

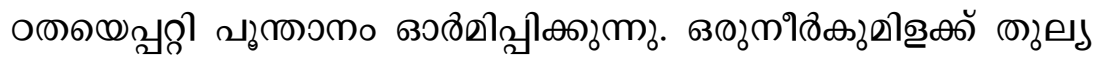

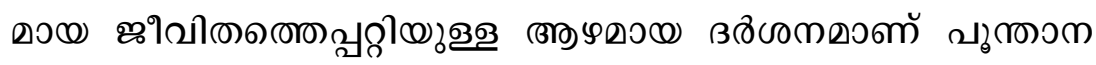

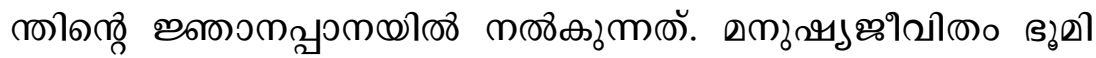

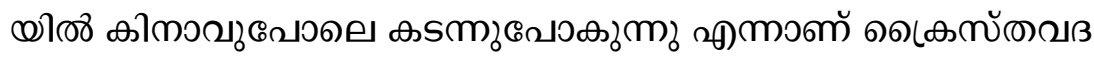

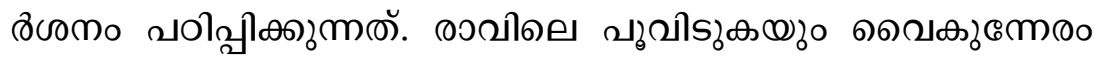

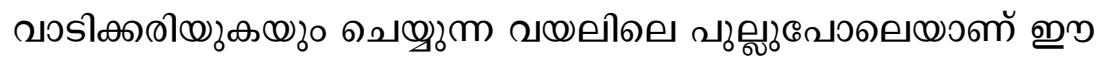

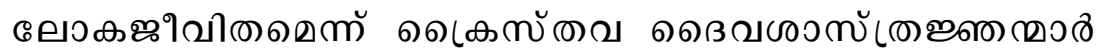

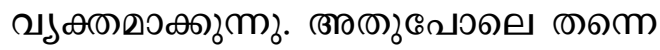

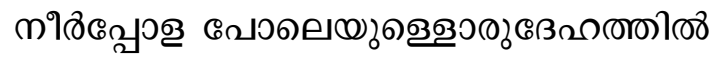

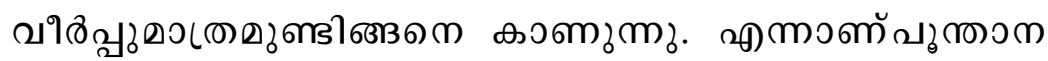
вชิธ0ก).

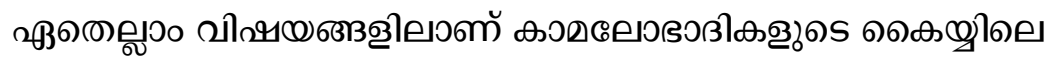

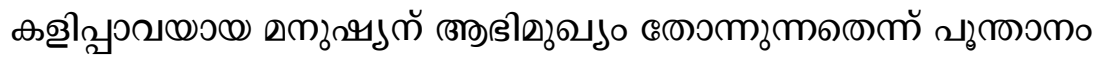




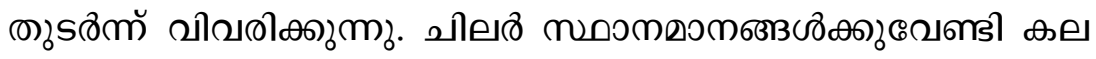

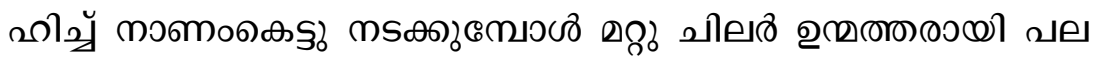

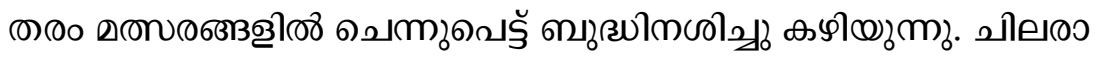

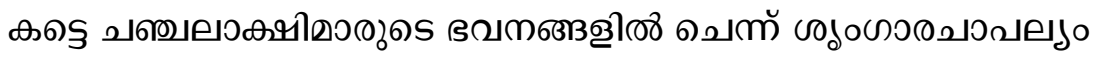

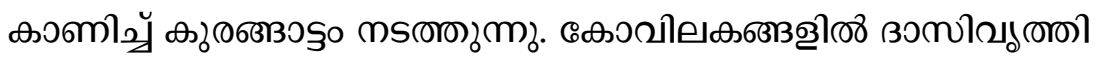

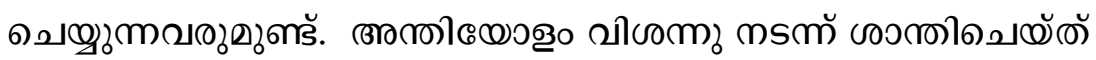

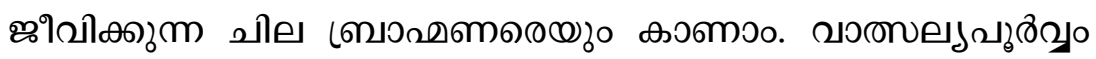

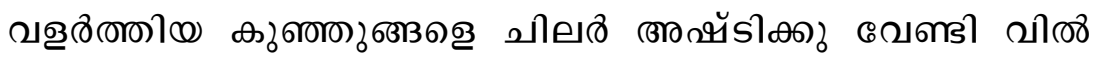

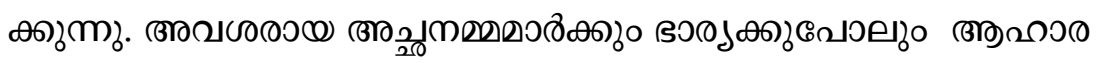

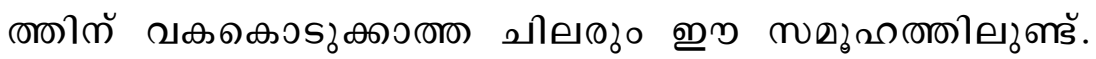

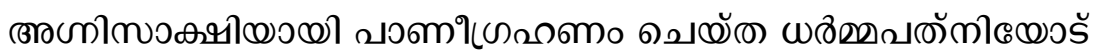

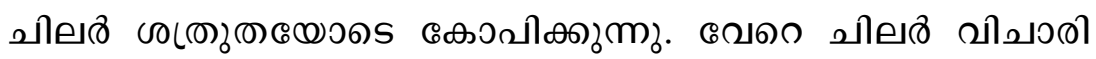

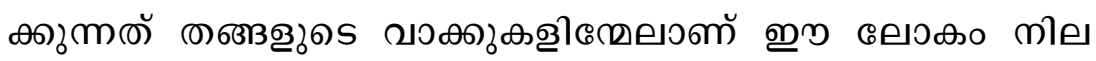

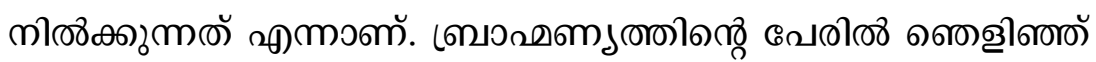

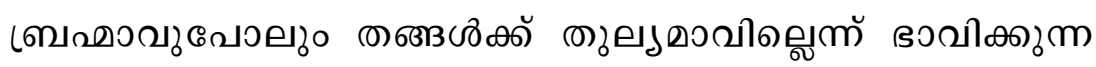

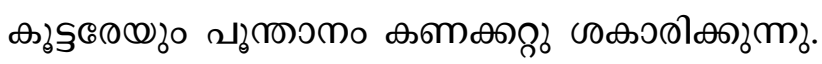

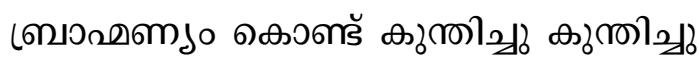

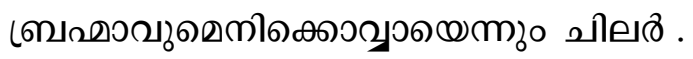

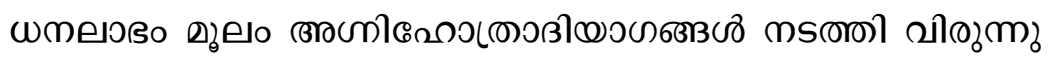

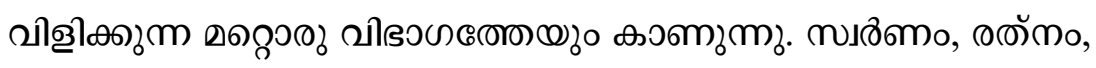

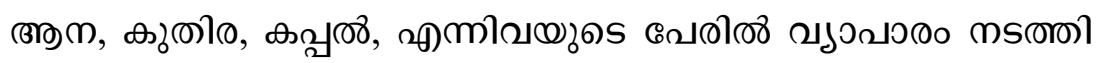

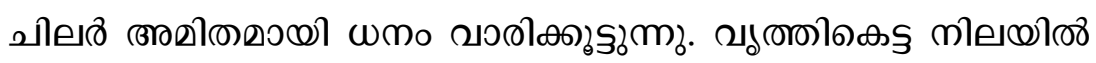

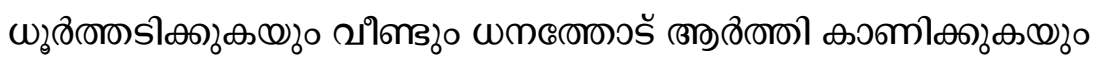

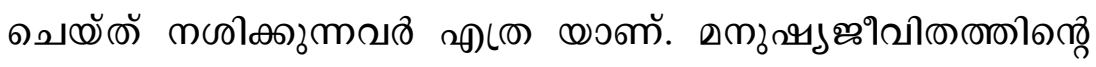

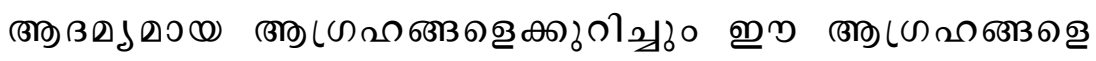

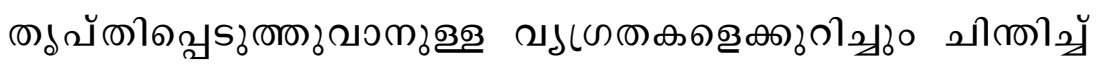




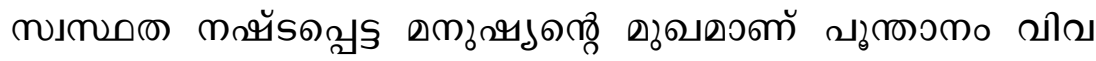

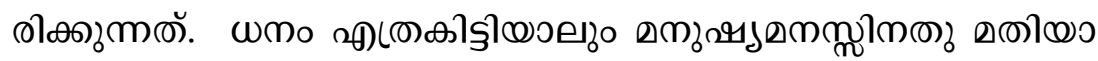

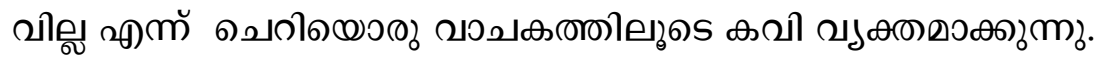

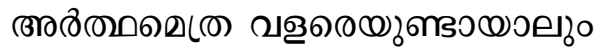

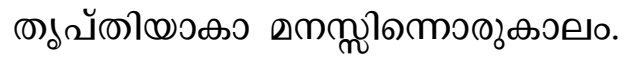

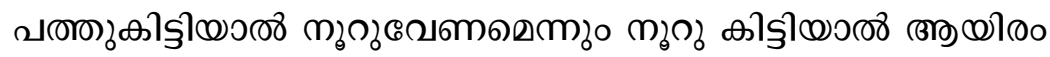

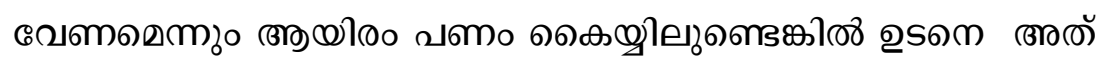

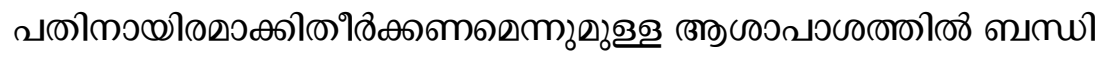

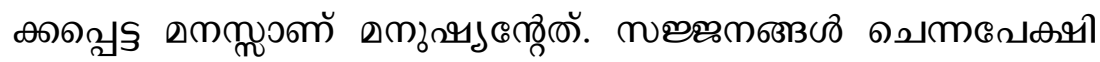

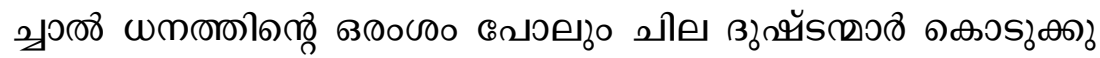

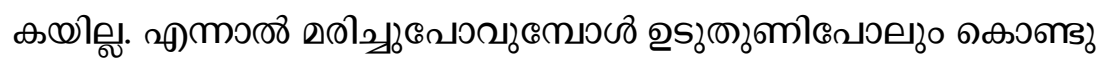

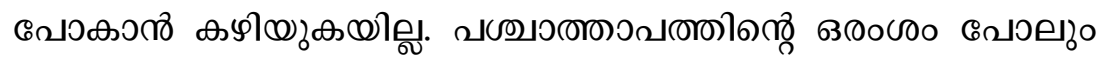

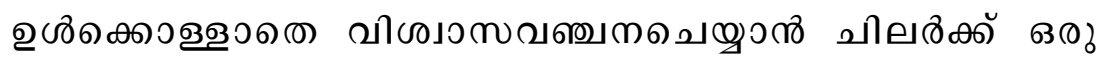

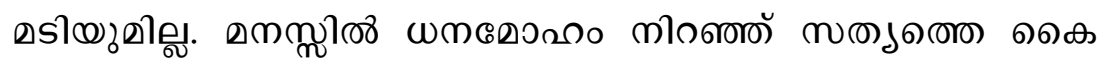

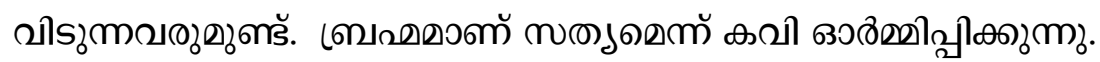

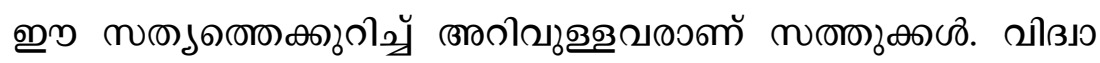

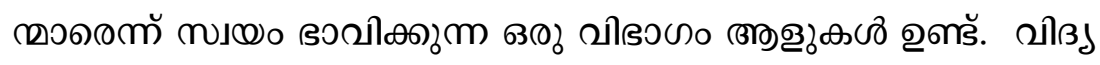

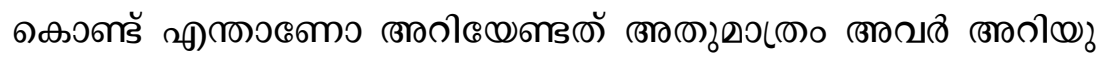

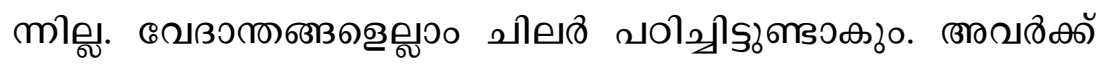

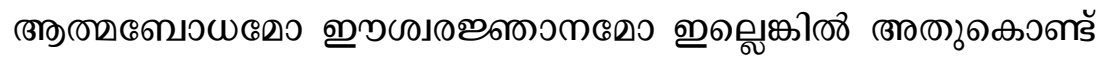

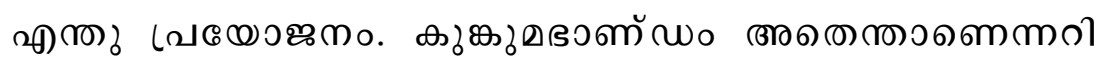

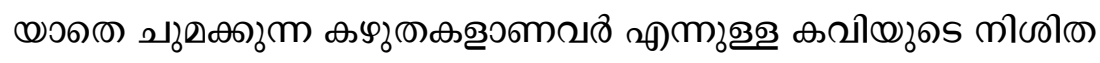

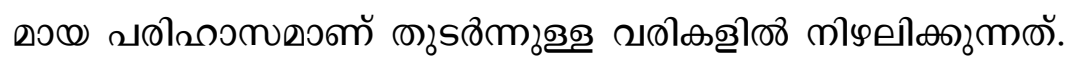

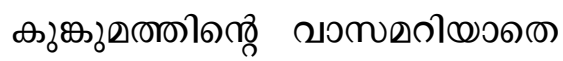

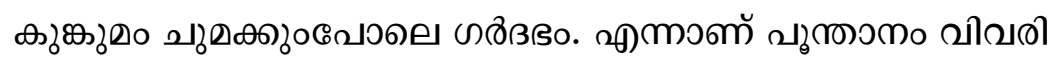
๑) 


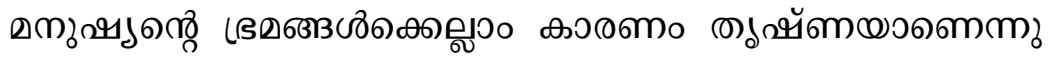

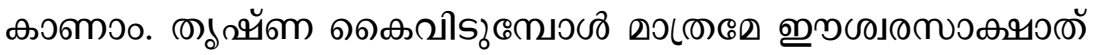

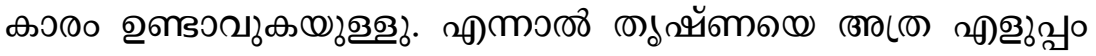

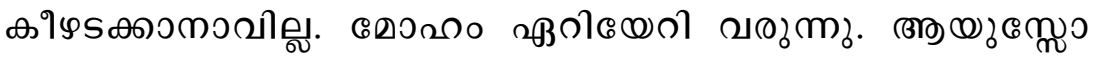

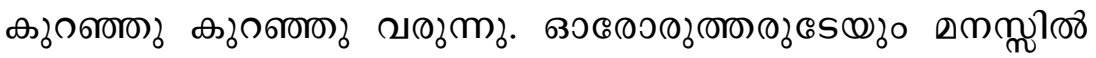

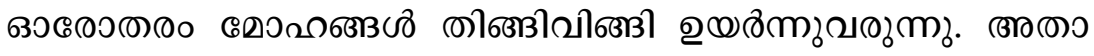

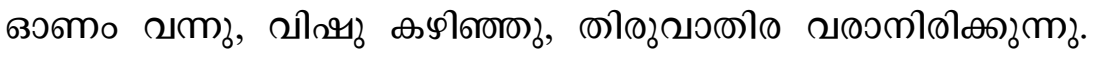

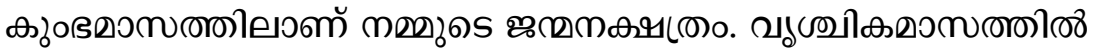

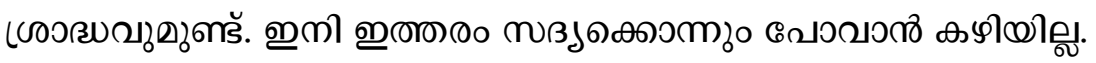

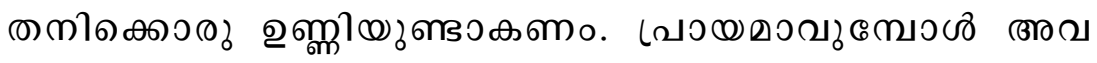

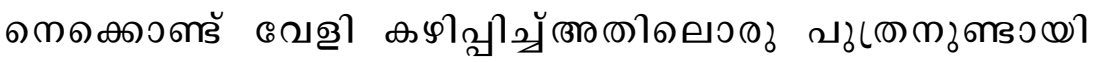

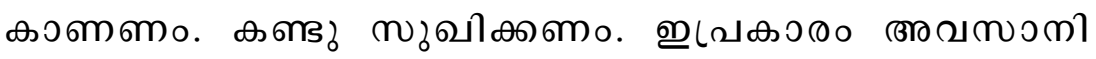

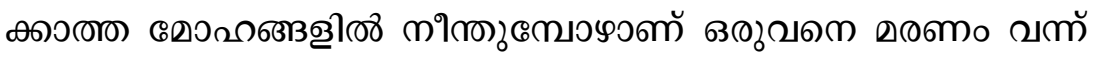

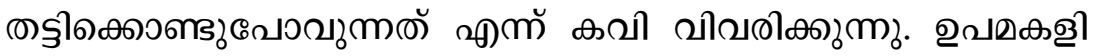

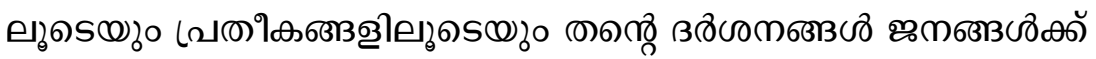

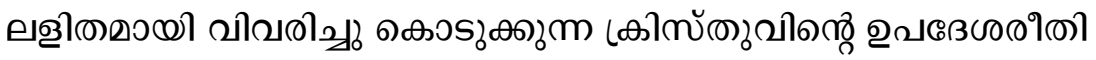

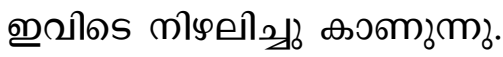

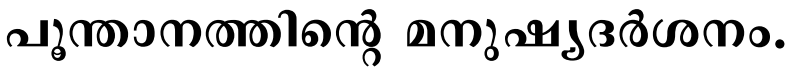

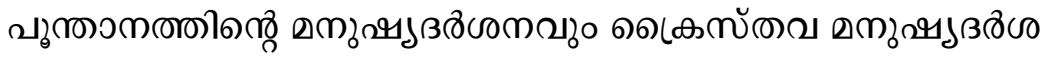

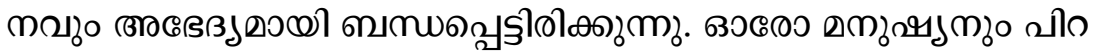

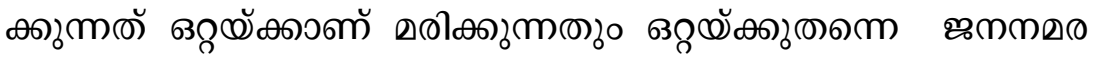

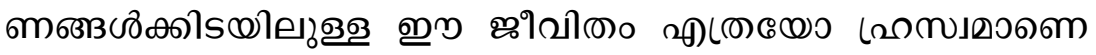

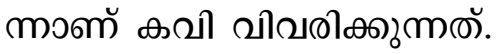




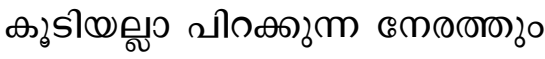

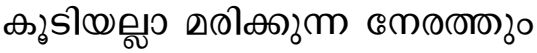

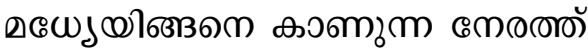

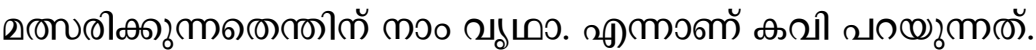

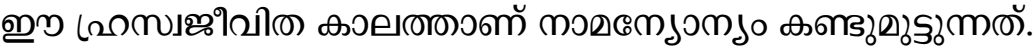

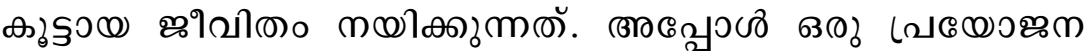

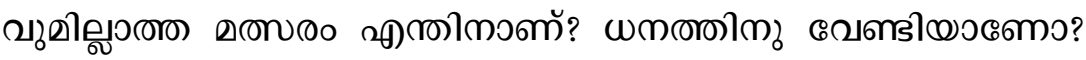

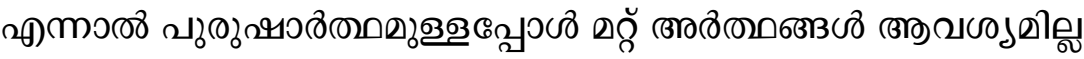

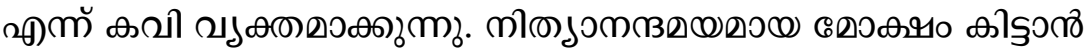

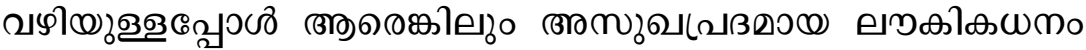

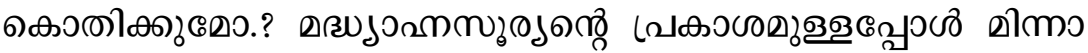

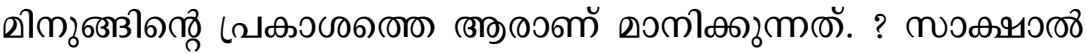

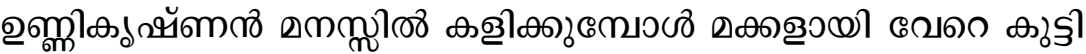

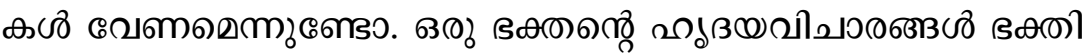

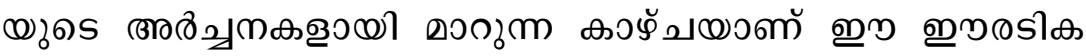

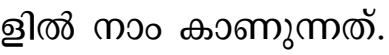

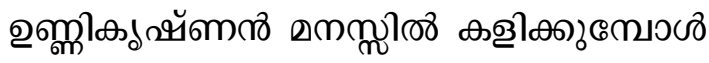

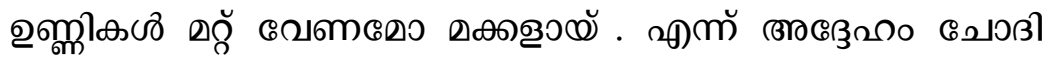

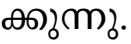

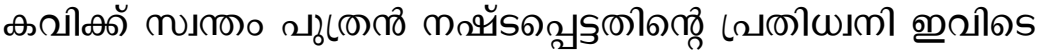

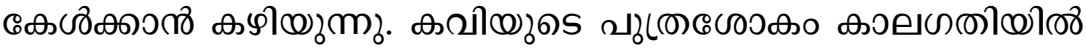

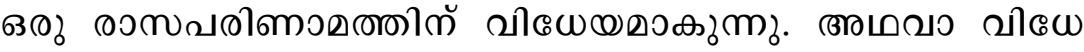

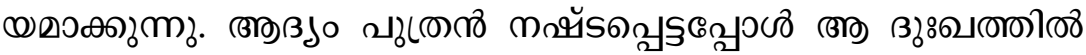

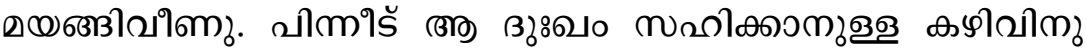

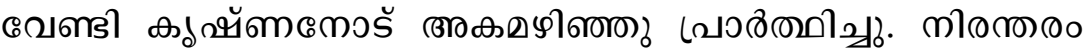




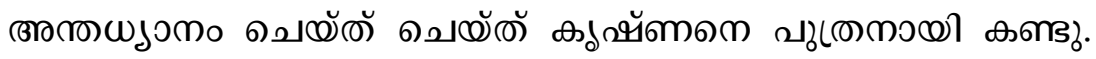

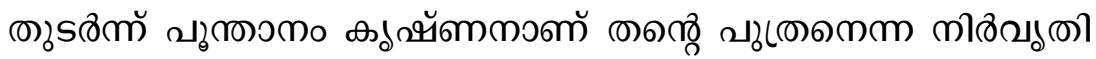

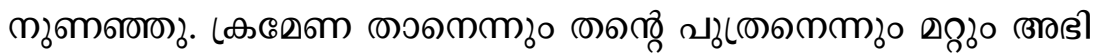

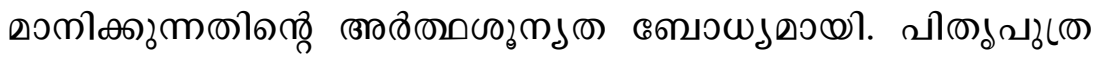

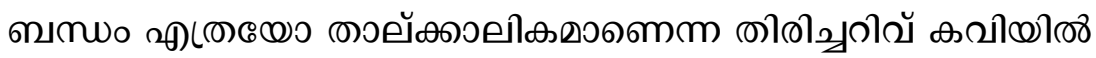

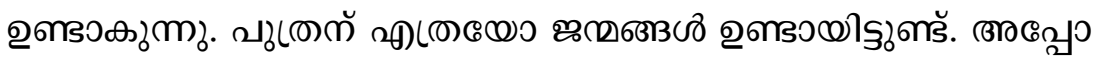

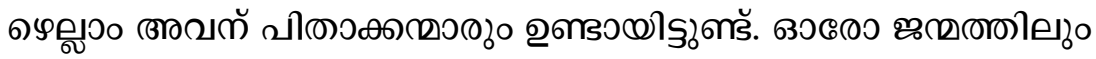

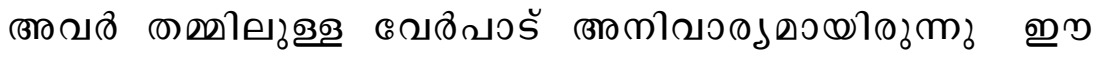

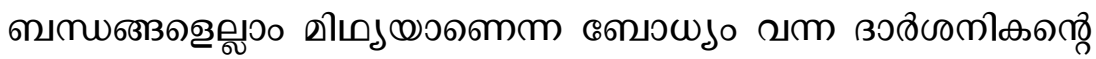

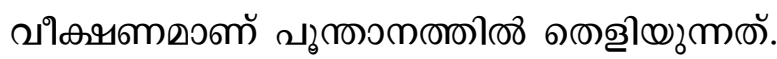

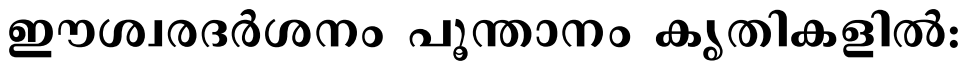

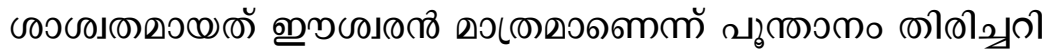

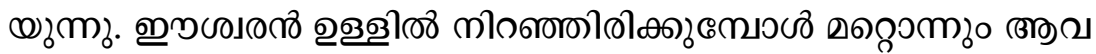

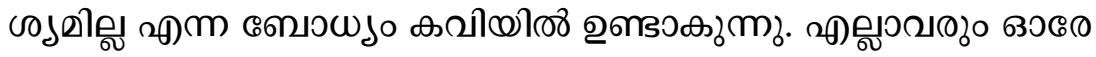

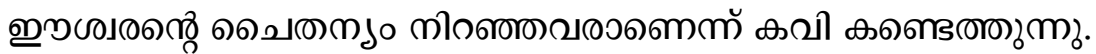

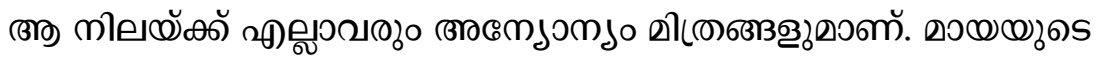

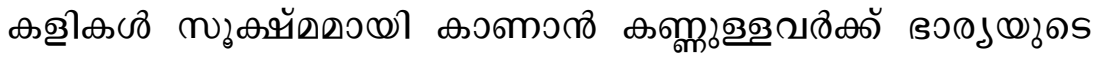

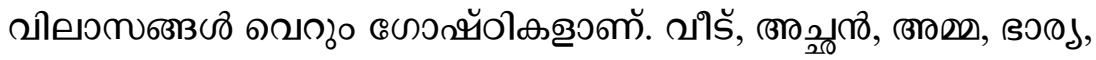

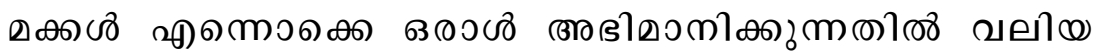

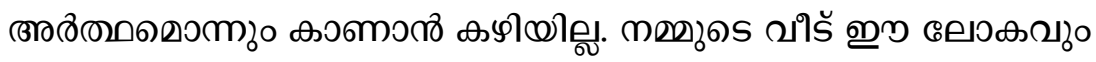

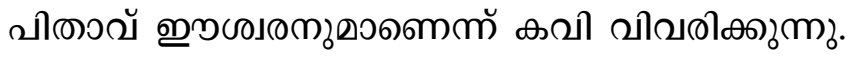

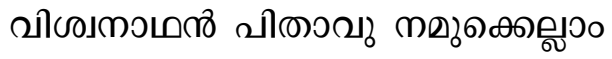

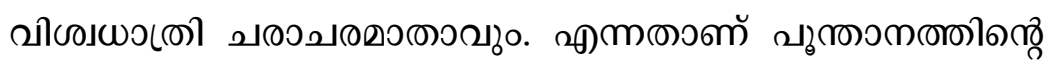

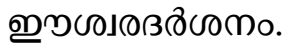




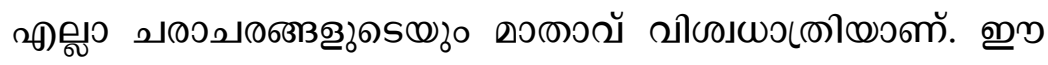

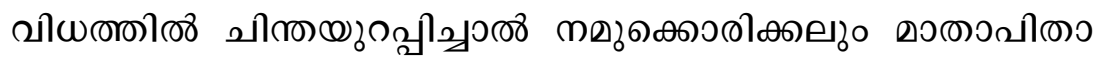

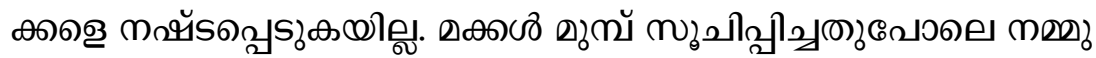

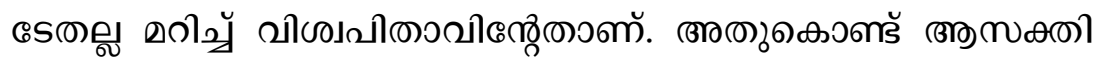

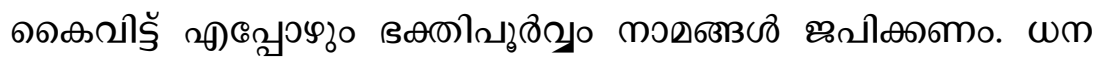

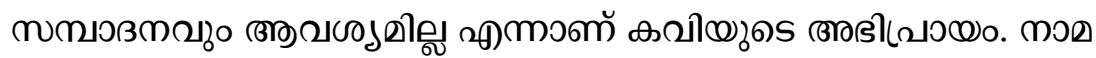

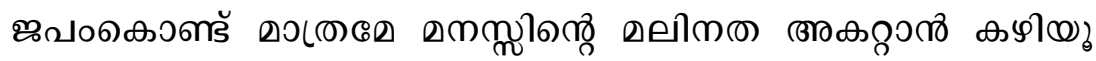
ஊாலஸั வ

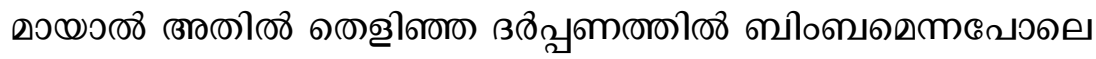

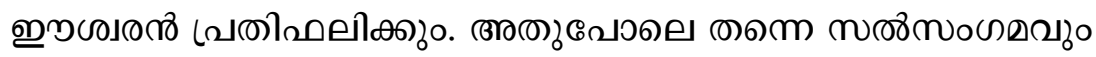

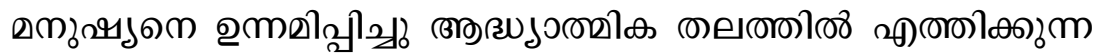

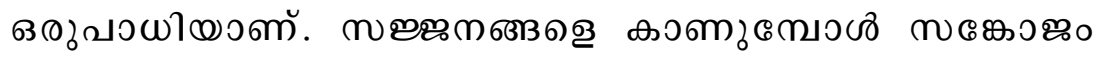
குకวஃக விறயவ

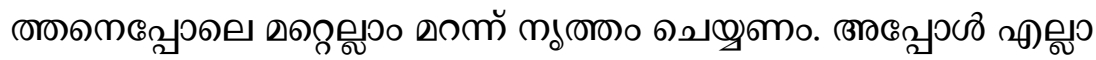

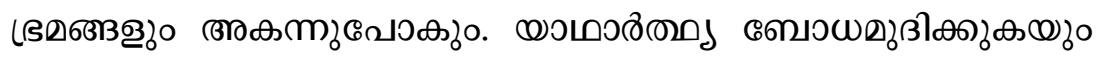

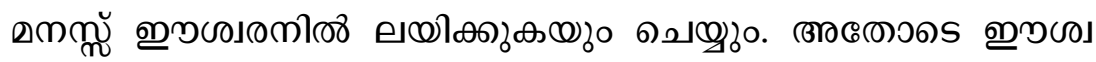

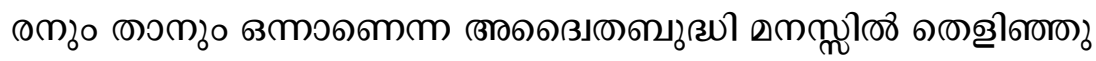

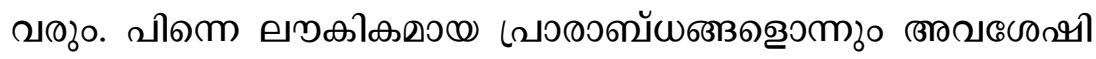

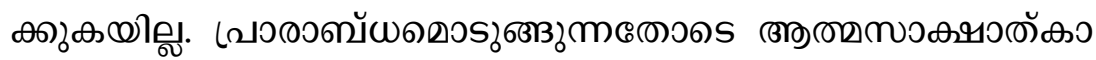

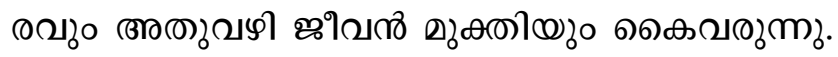

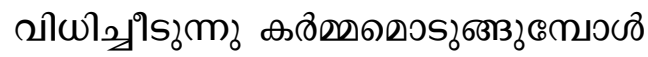

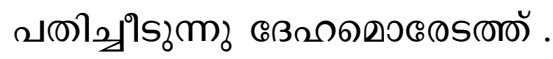

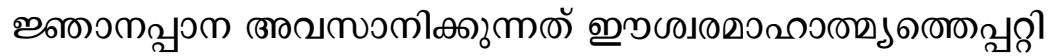

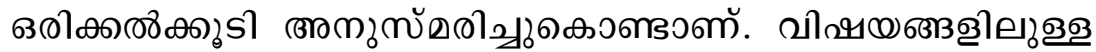

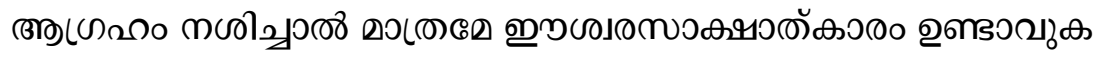

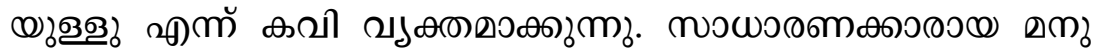




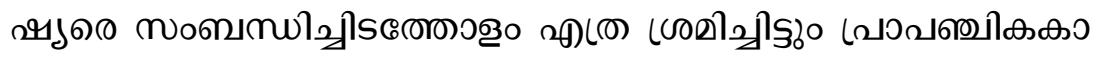

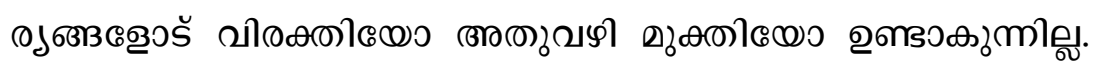

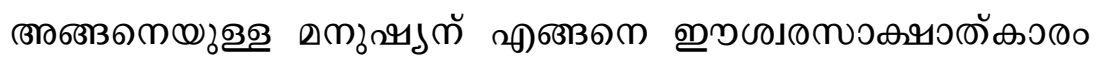

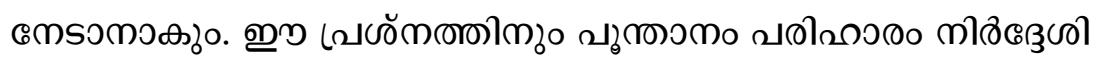

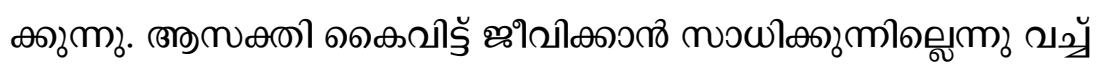

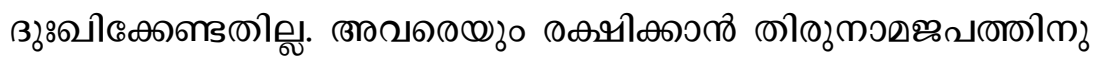

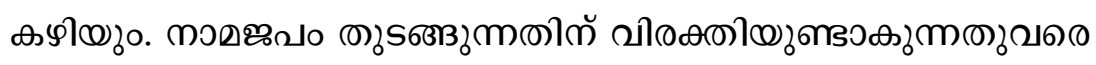

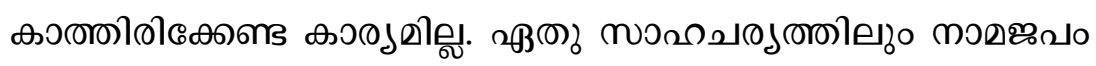

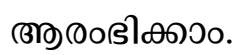

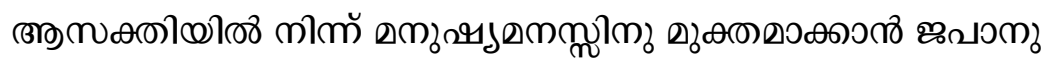

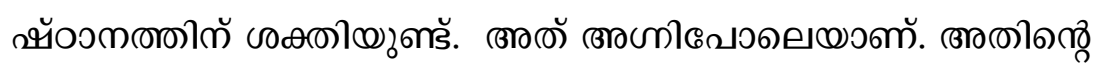

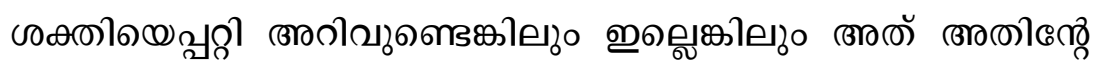

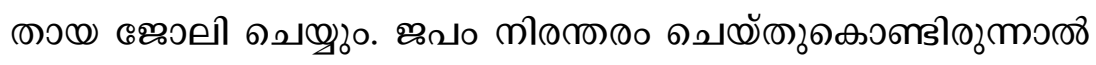

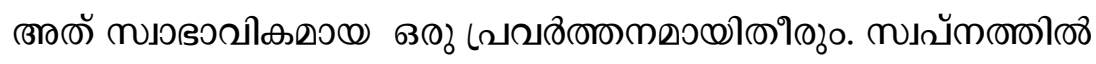

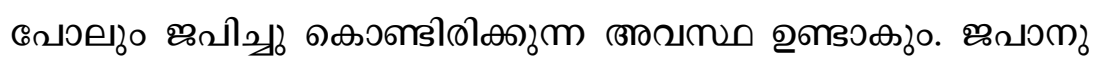

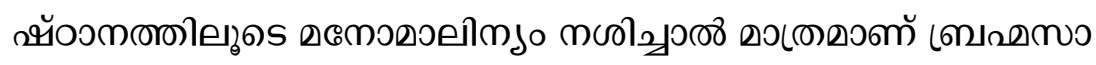

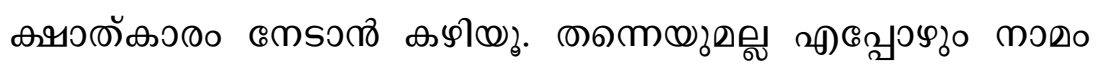

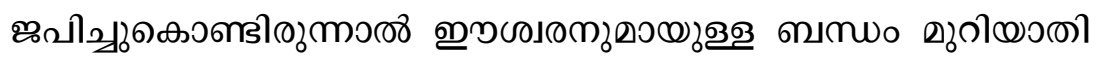

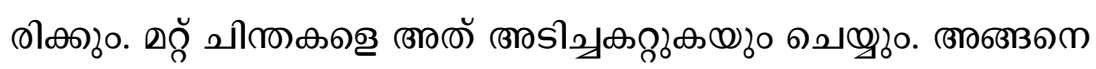

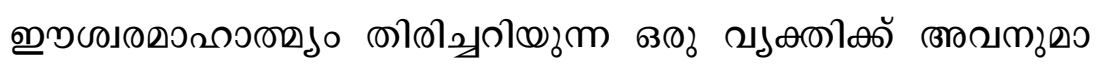

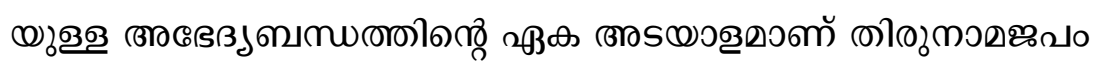

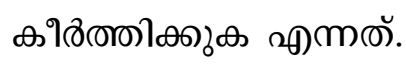

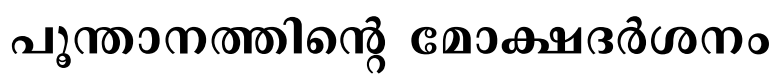

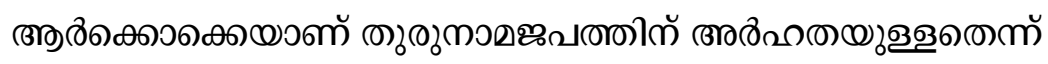

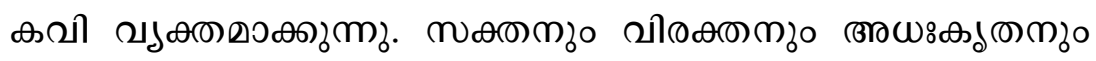

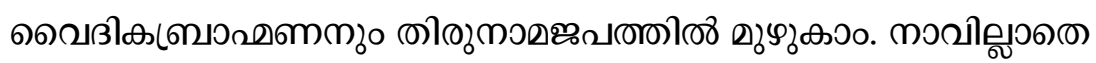




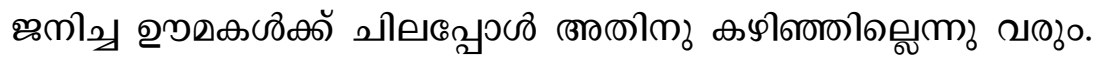

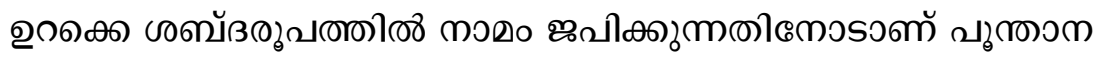

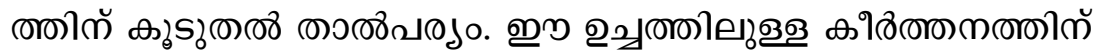

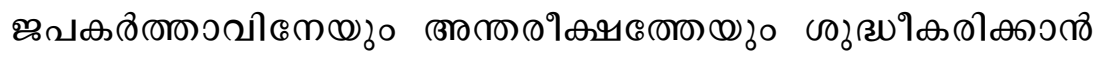

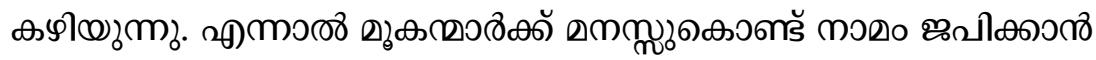

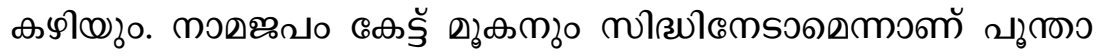

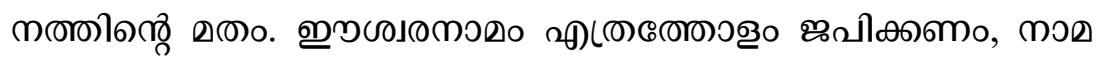

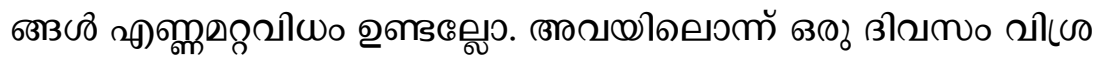

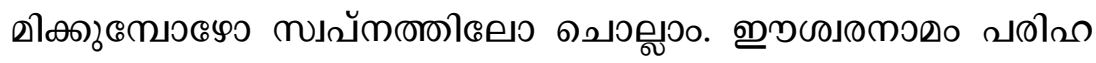

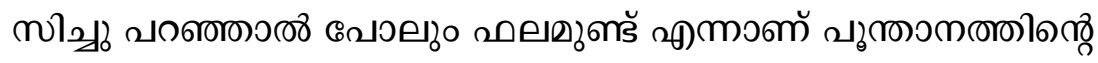

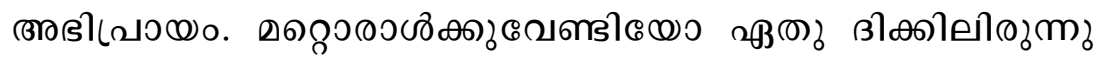

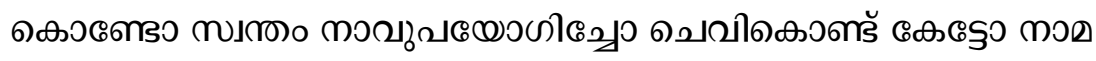

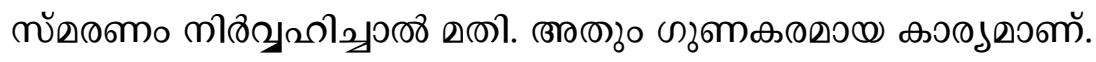

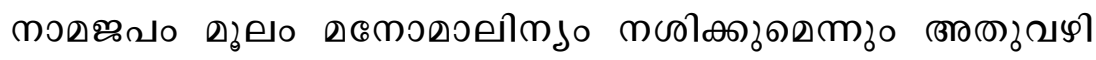

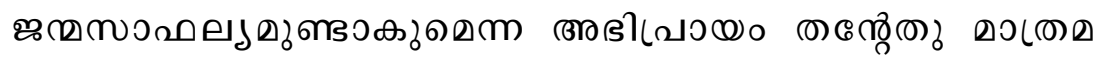

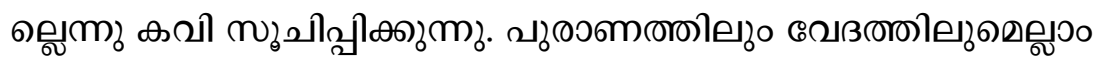

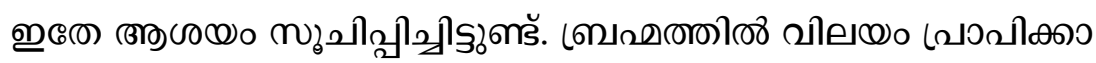

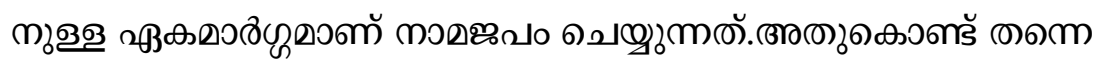

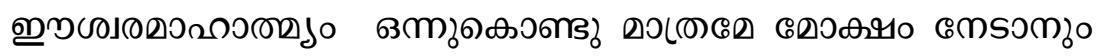

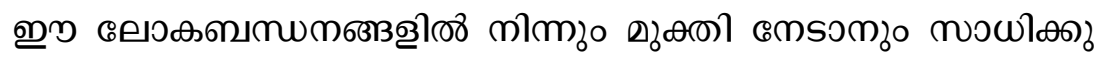

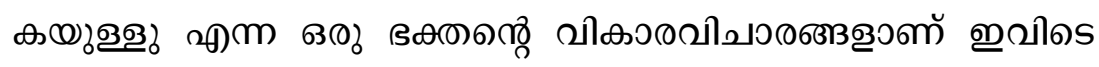

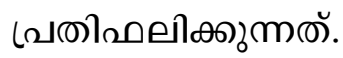




\section{5.

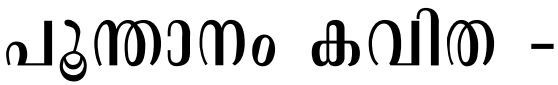

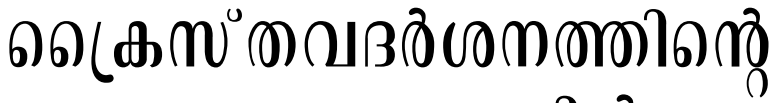

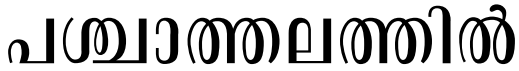

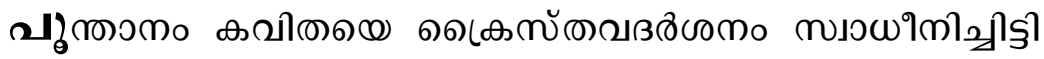

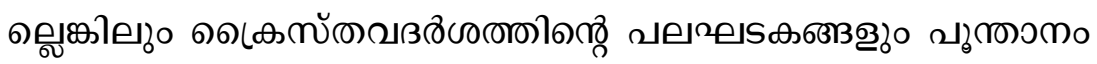

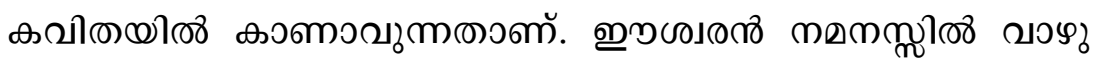

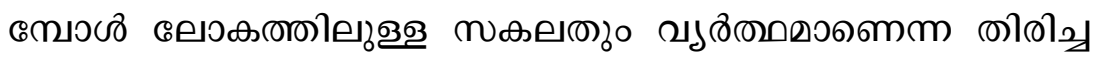

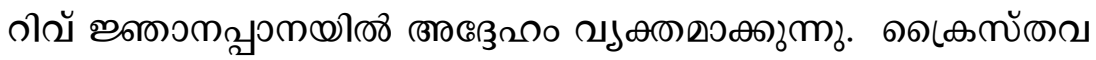
вன்

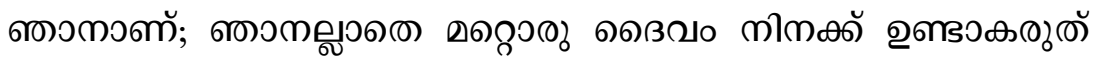

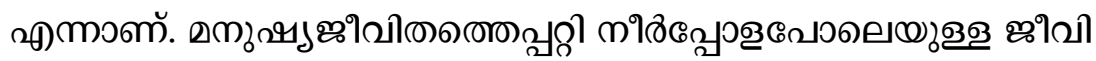

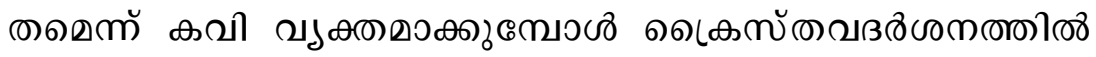

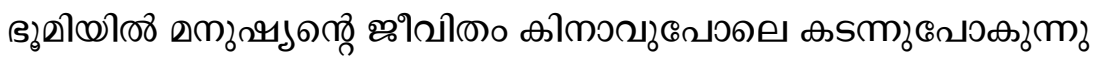

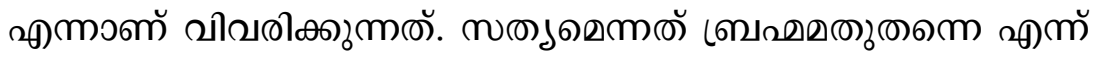

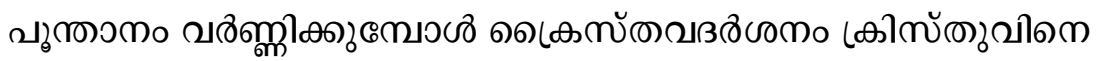

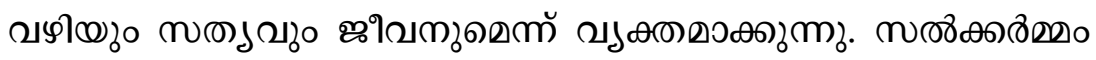

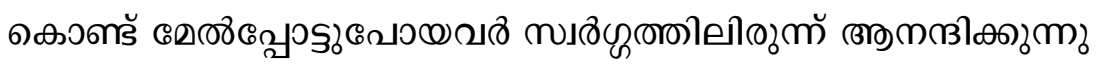




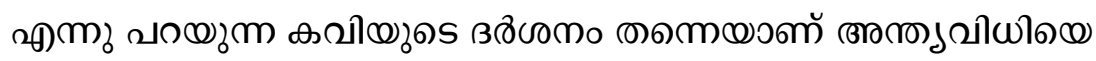

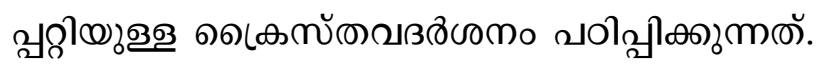

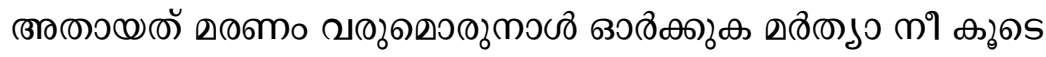

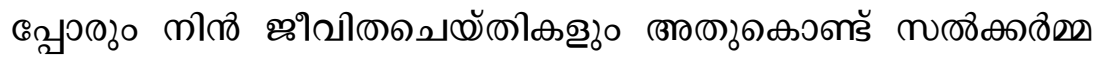

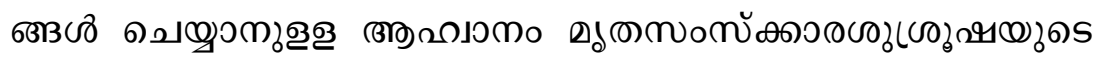

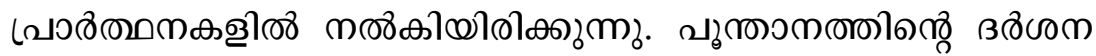
ஆஃ வெகாரைஃன்

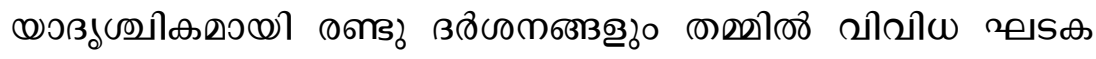

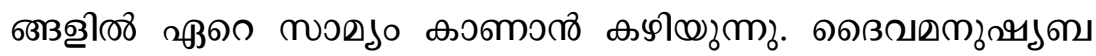

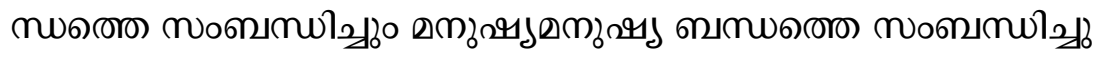

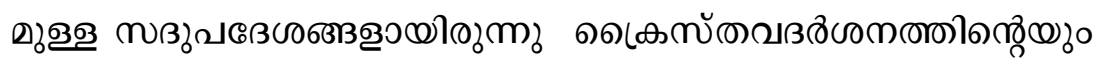

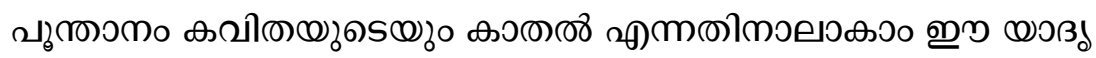

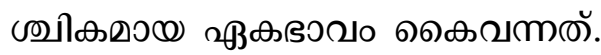

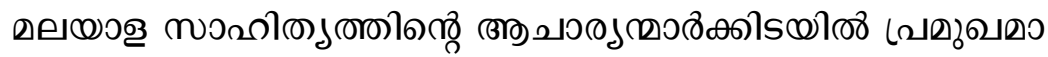
๑ఱगு ஈ

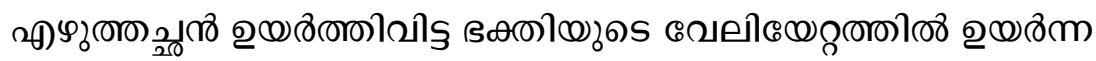

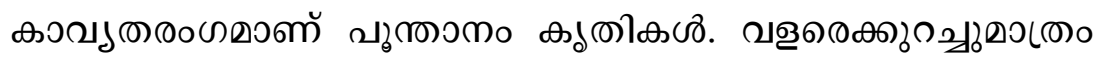

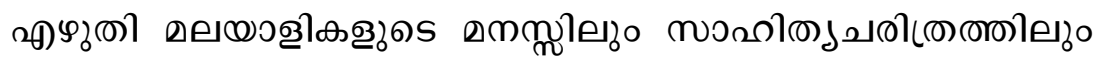

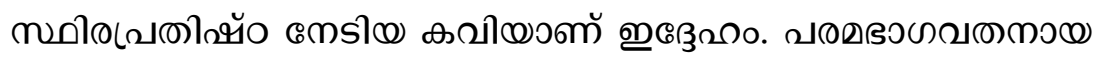

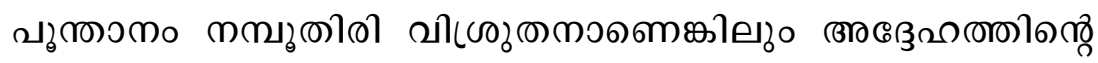

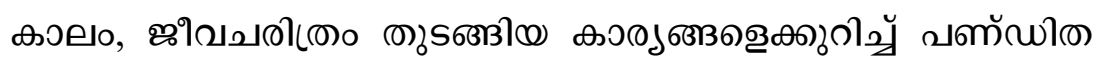

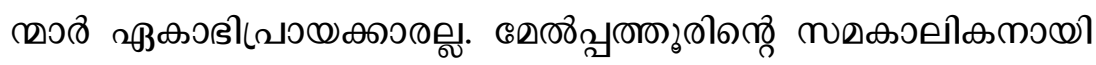

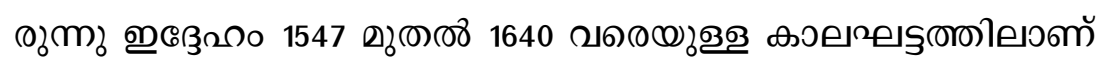

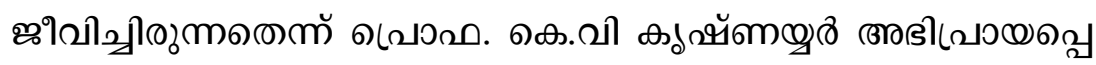
Sुmb. 


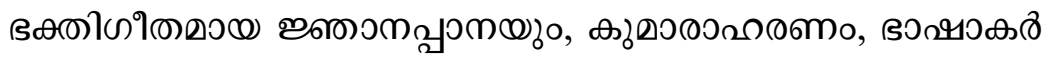

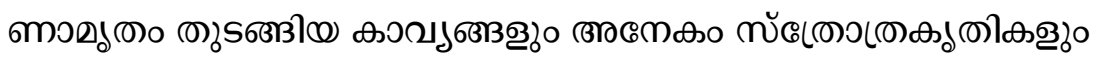

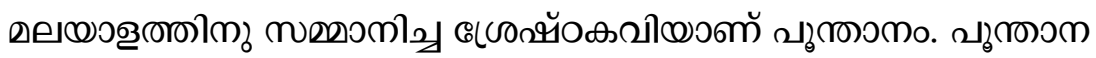

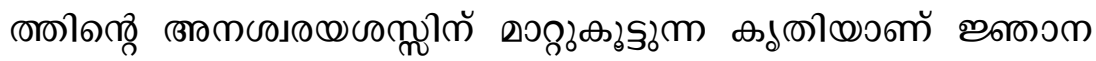

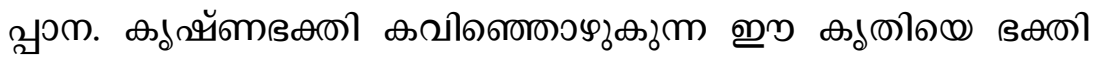

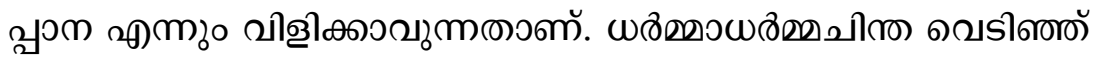

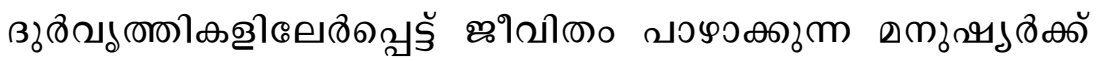

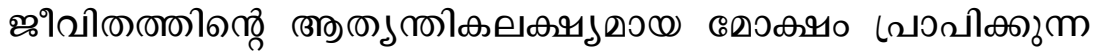

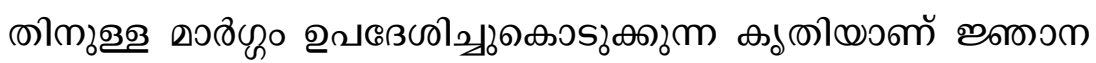

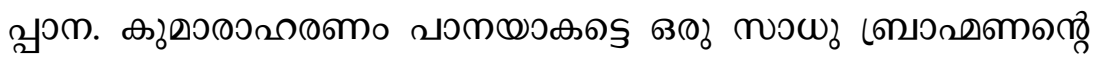

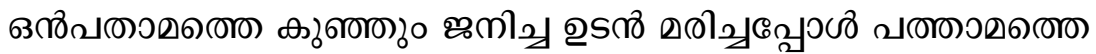

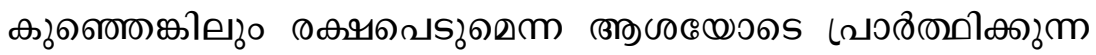

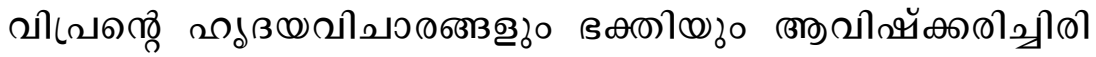

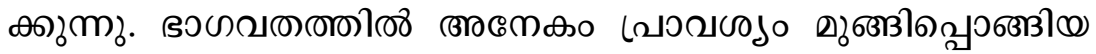

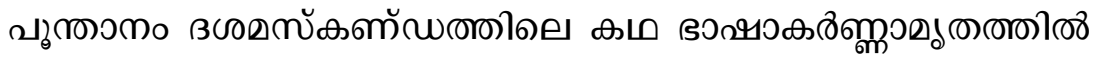

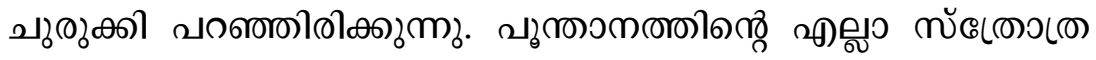

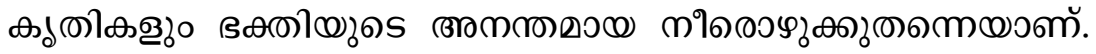

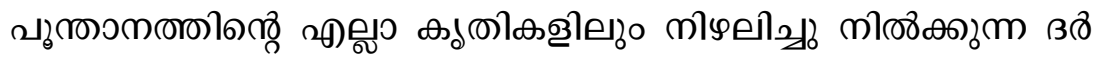

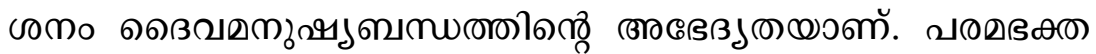

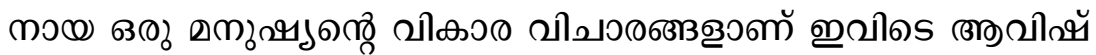

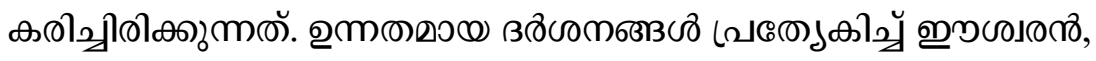

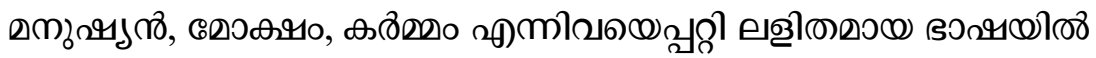

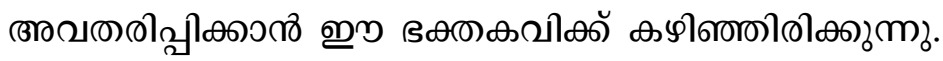

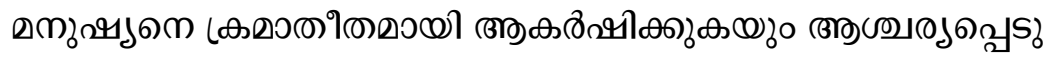

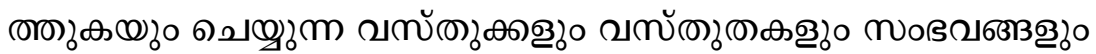

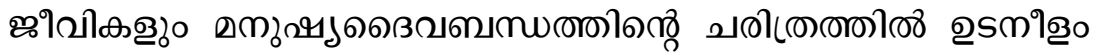




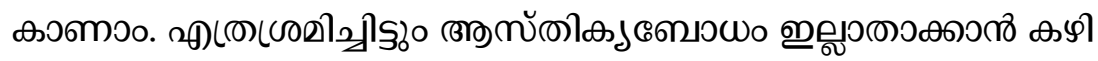

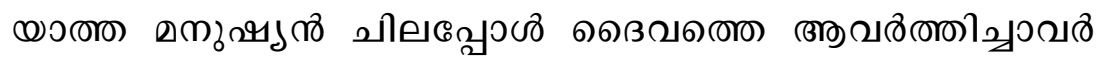

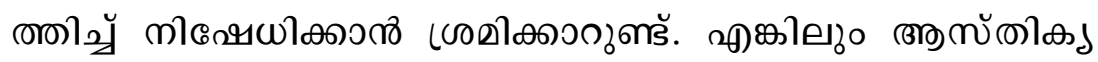

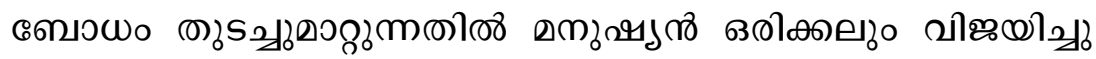

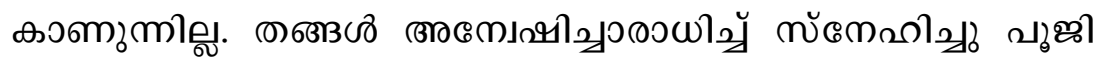

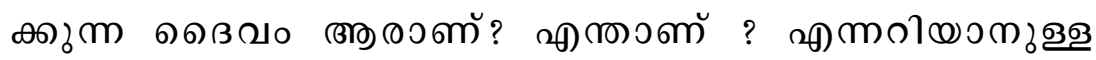

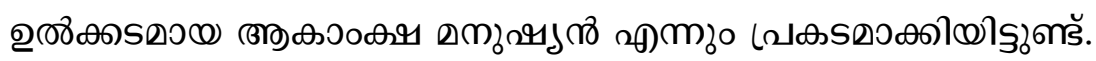

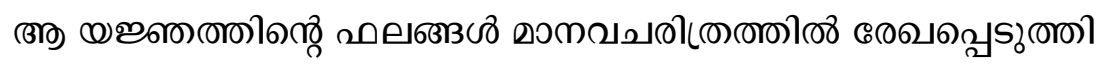

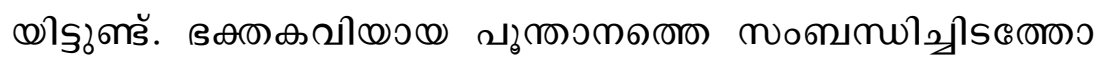

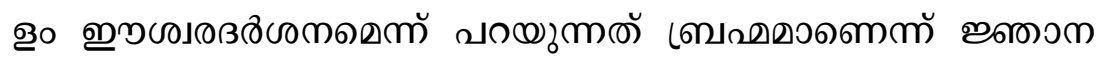

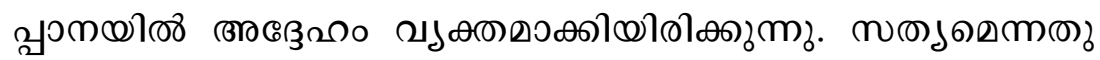

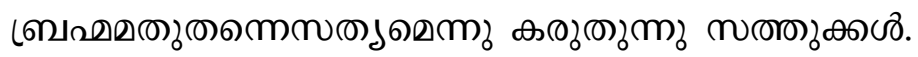

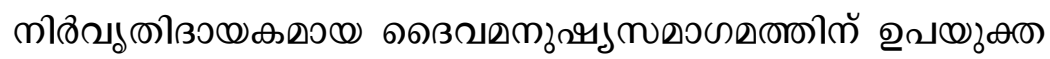

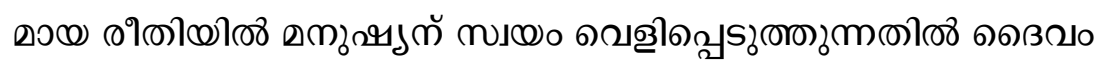

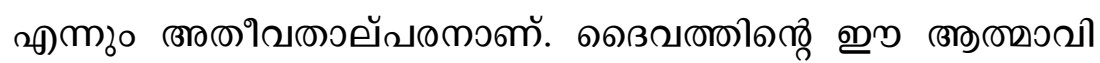

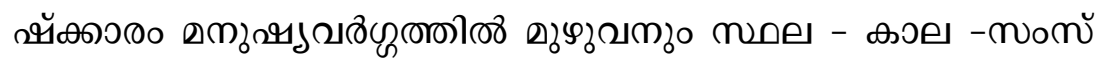

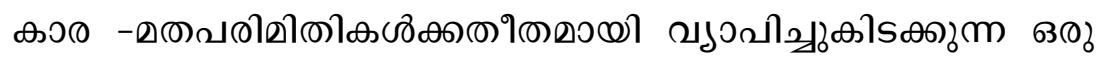

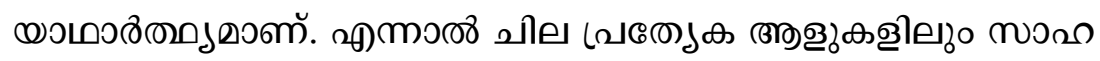

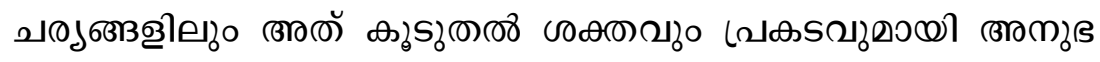

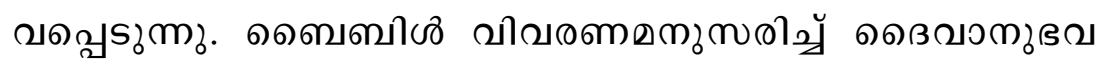

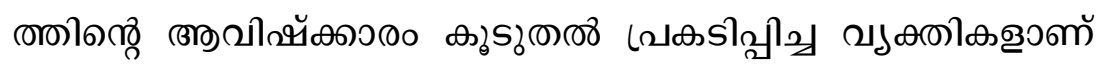

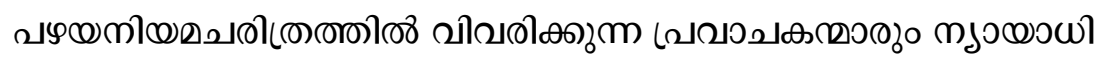

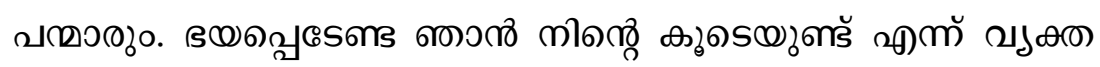

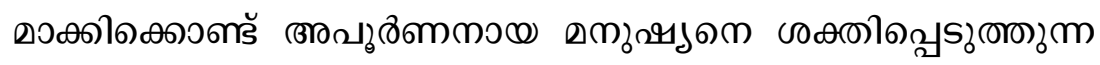

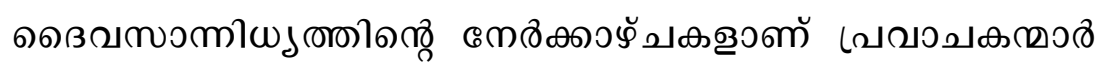

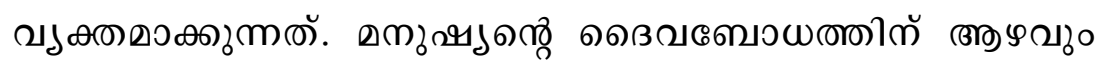




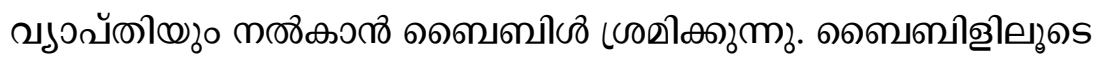

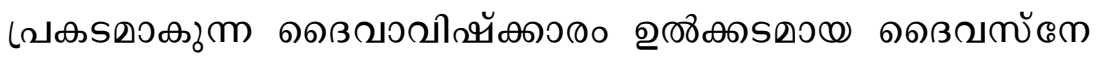

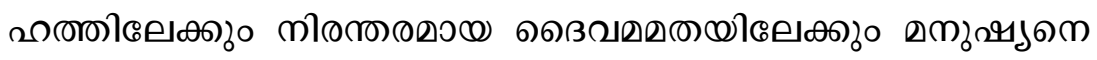

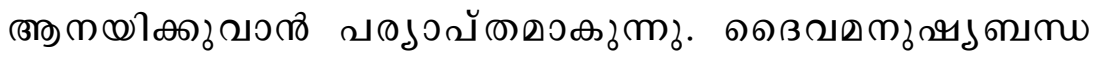

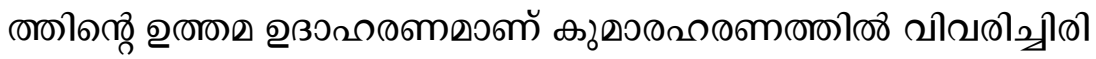

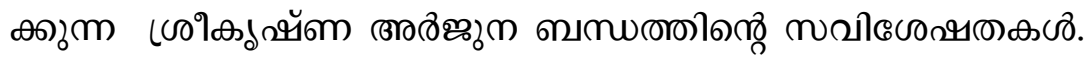

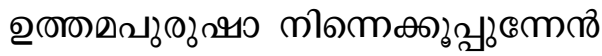

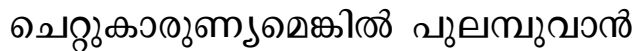

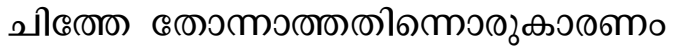

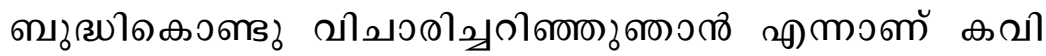
வรசவைலூாளั.

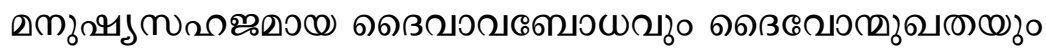

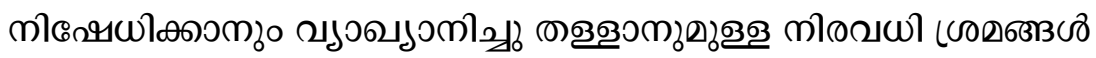

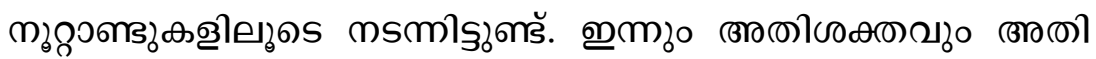

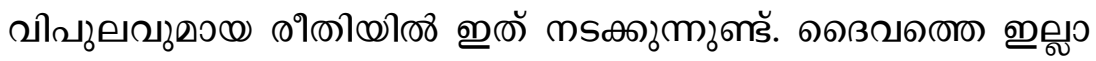

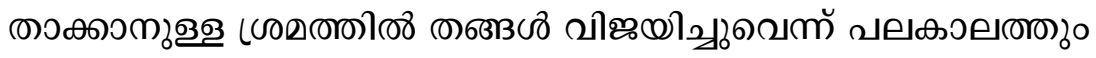

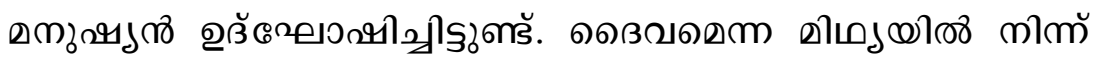

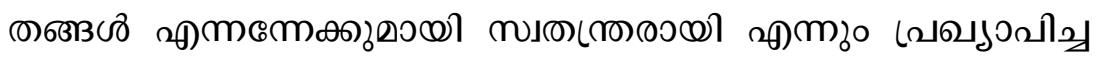

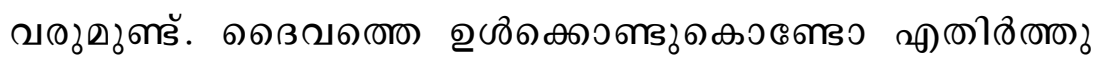

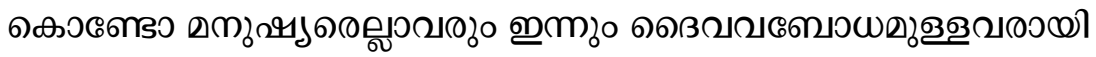

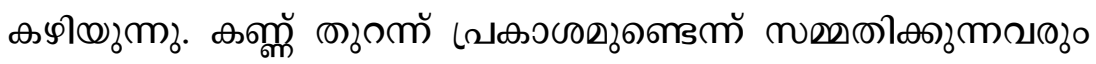

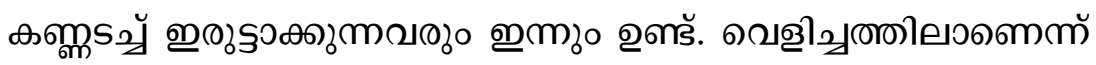

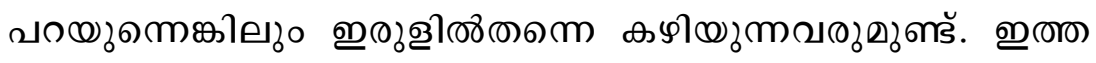

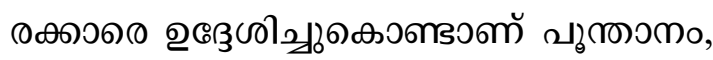




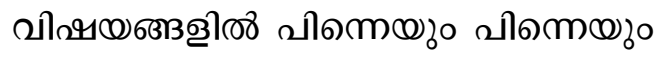

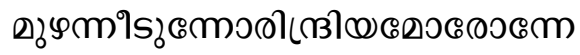

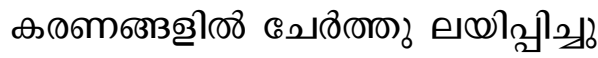

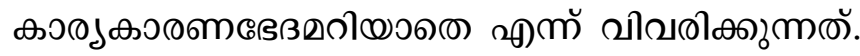

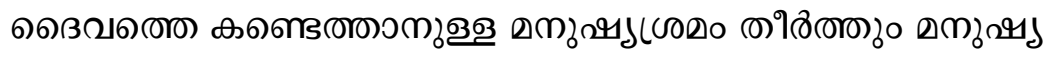

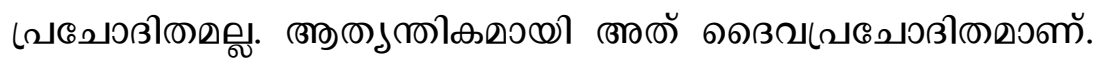

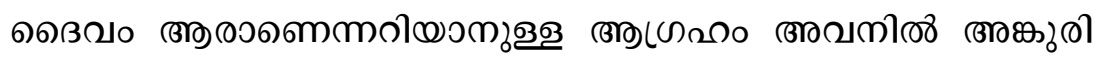

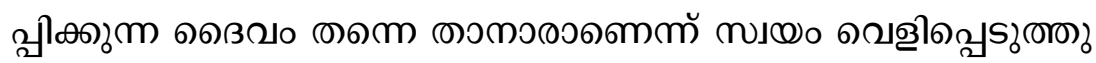

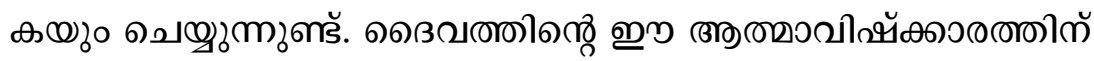

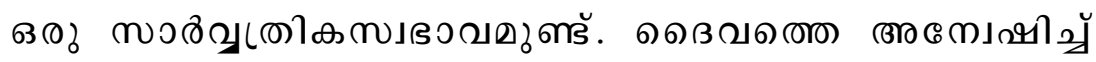

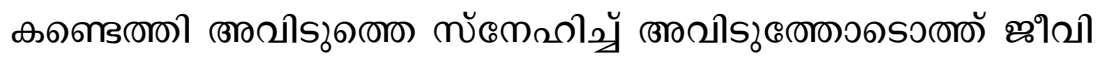

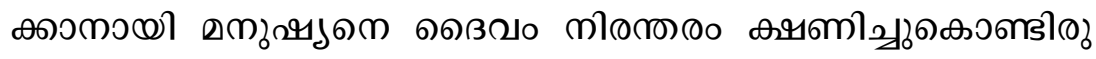

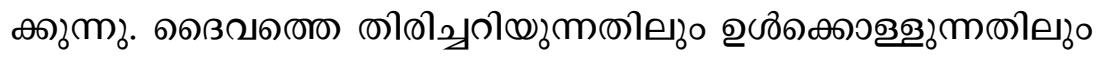

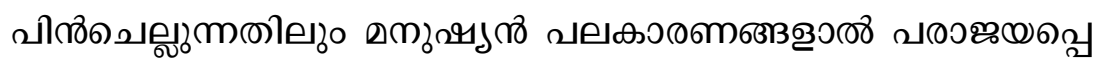

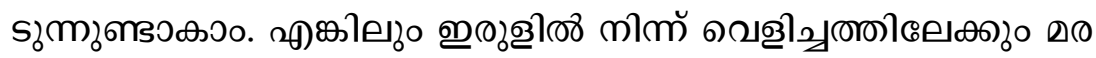

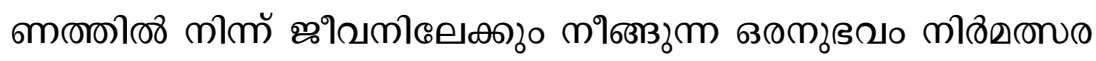

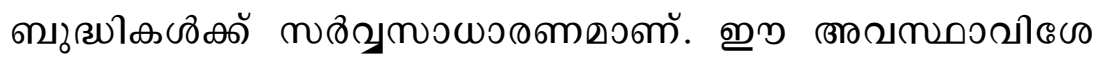
м⿻コ一ั

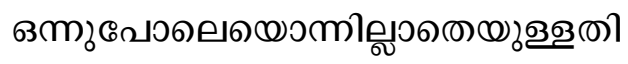

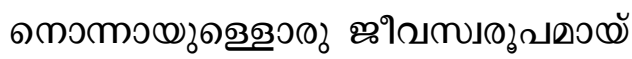

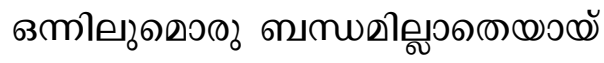

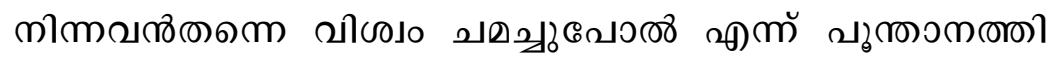

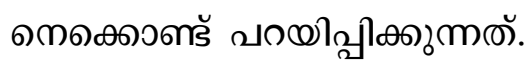

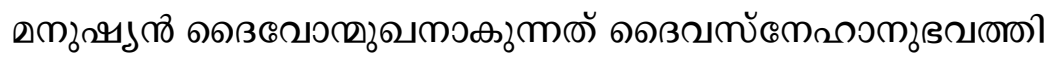

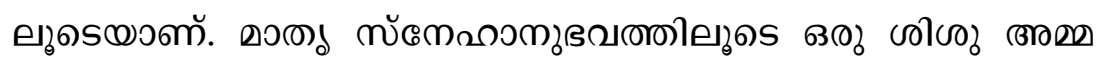




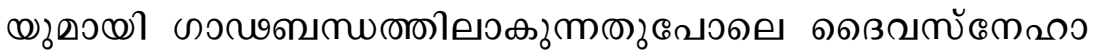

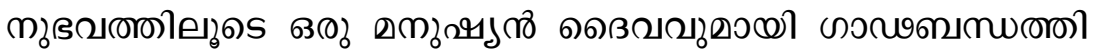

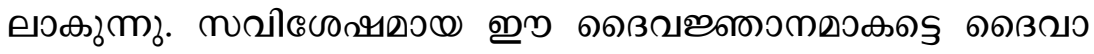

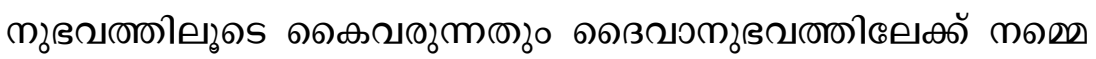

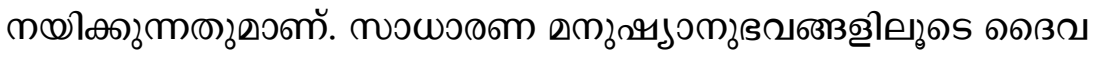

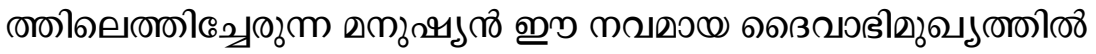

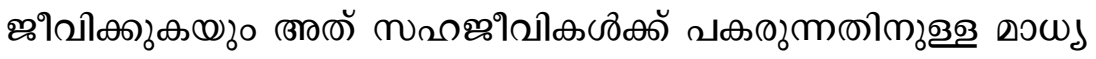

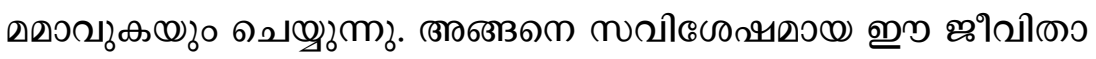

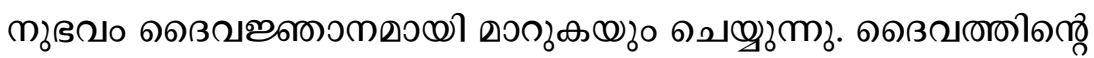

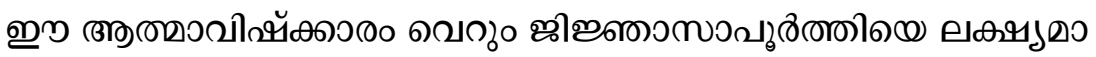

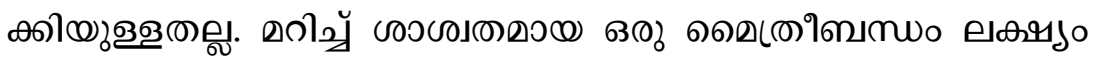

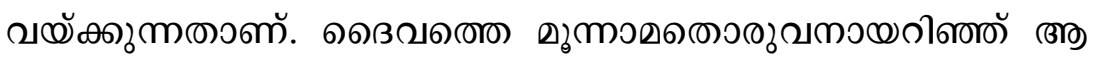

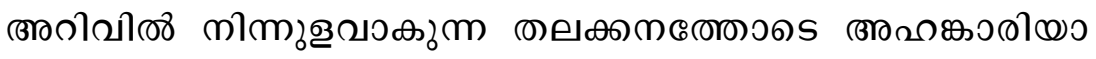

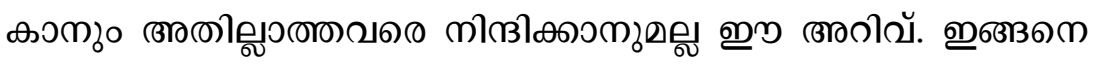

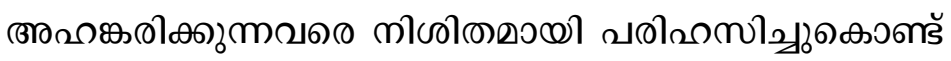

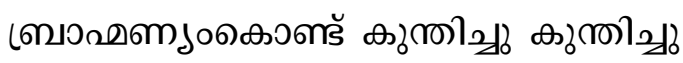

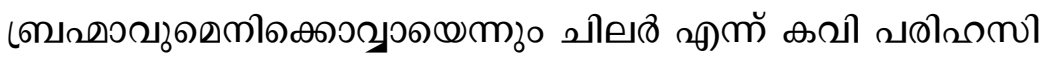
๑ூரก).

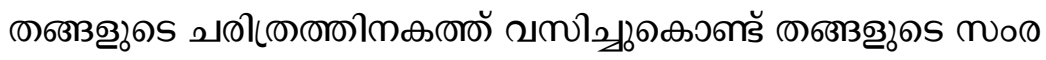

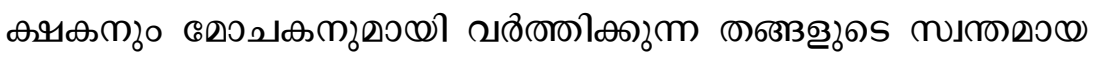
๑ெவ ஸன்

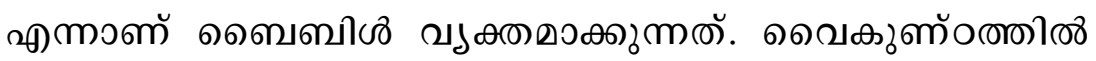

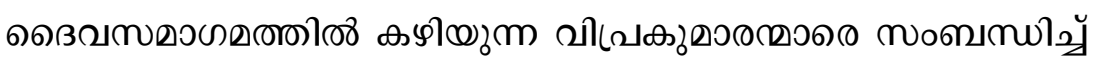

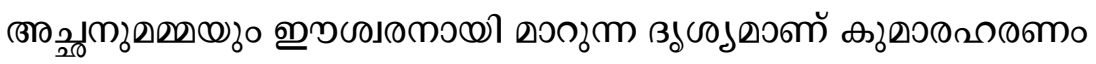

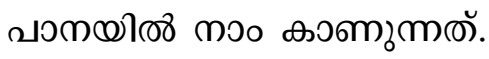


ஸையலூவாவ

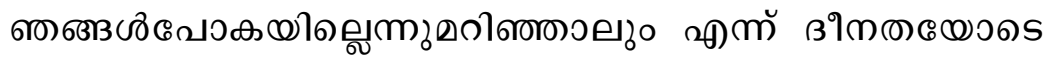

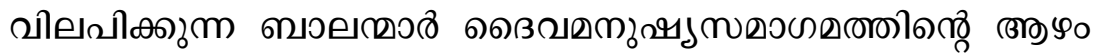

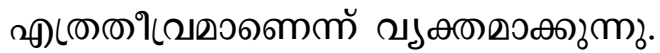

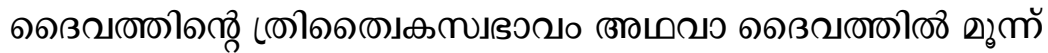

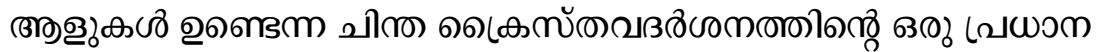

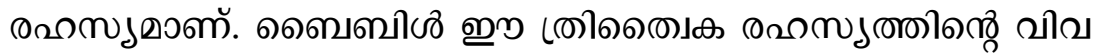

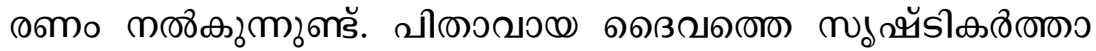

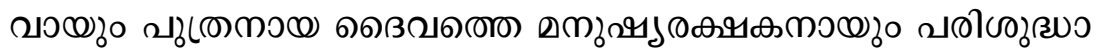

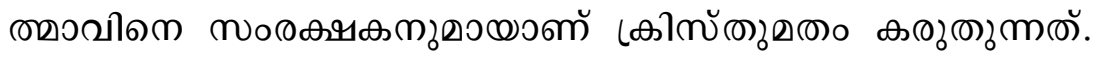

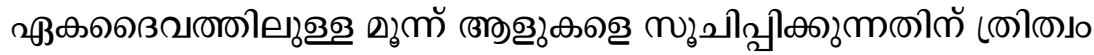

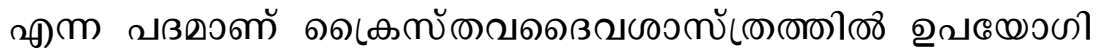

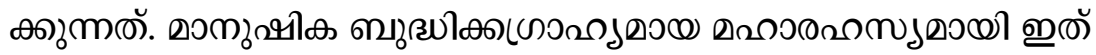

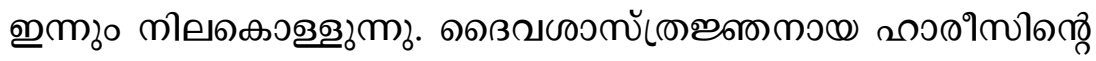

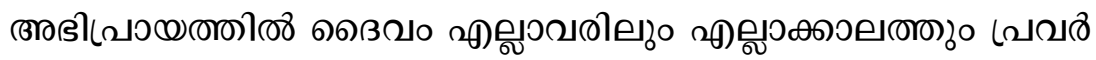

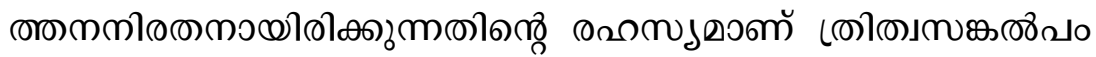

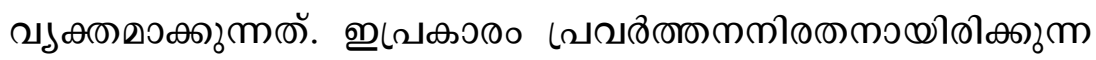

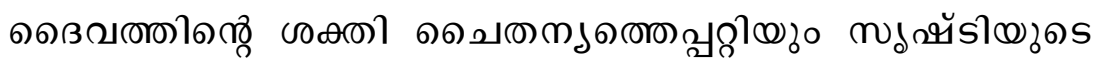

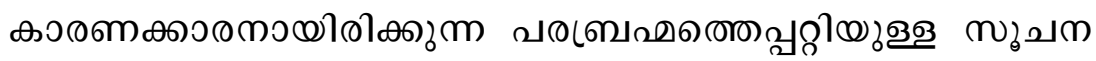

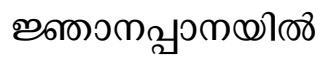

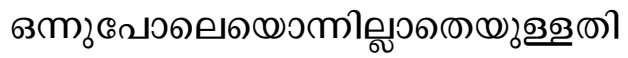

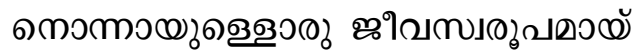

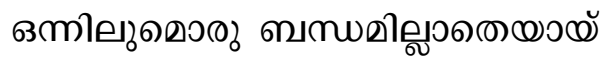

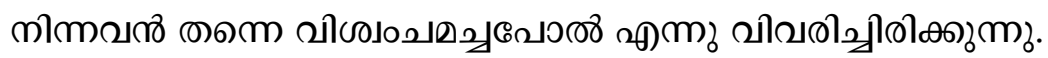




\section{องปmos)บ(00}

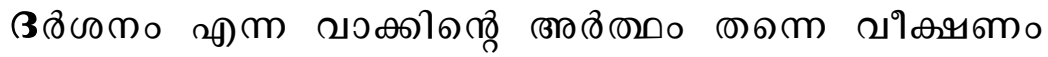

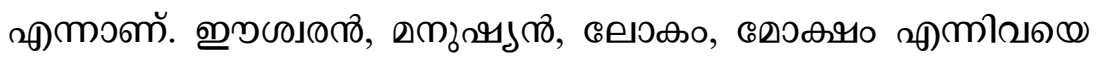

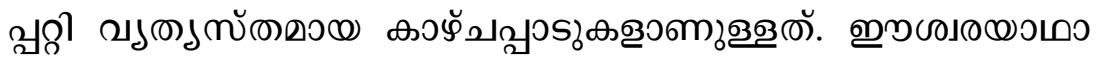

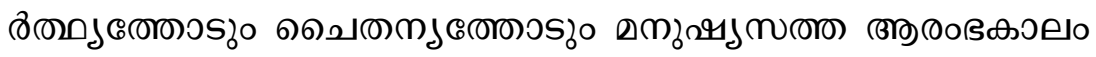

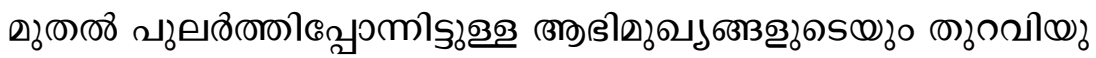

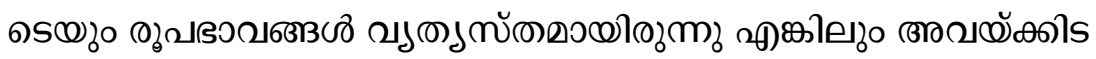

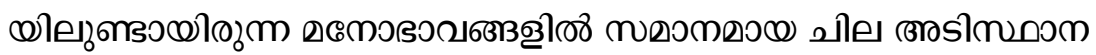

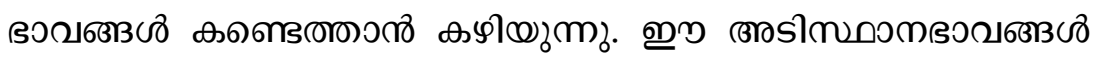

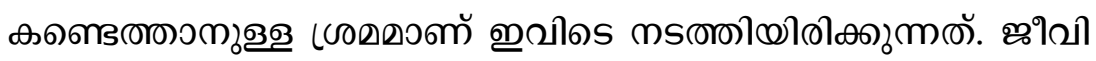

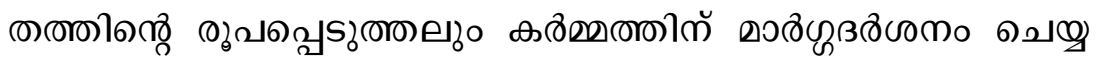

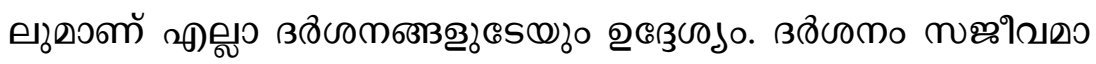

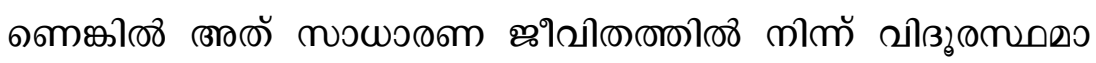

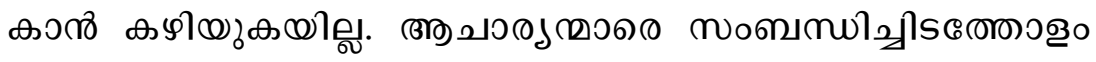

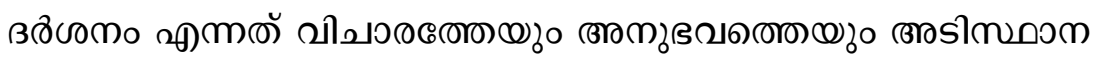

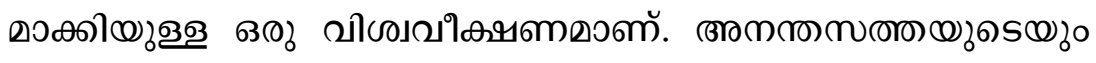

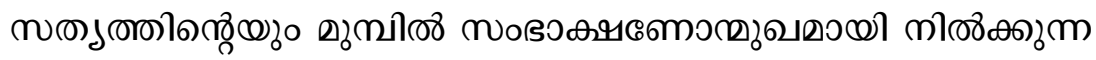

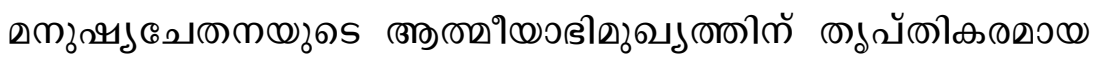

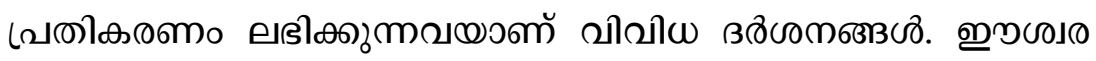

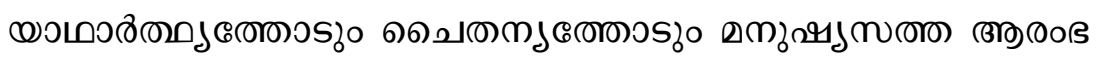




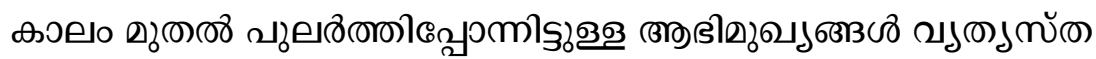

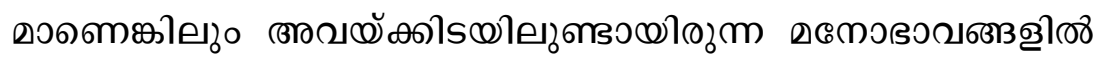

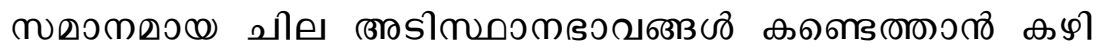

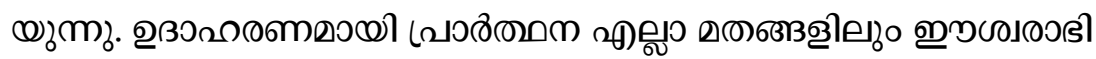

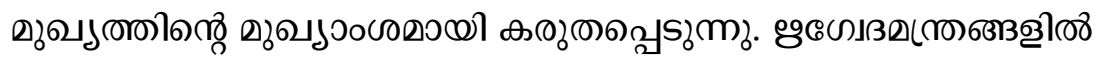

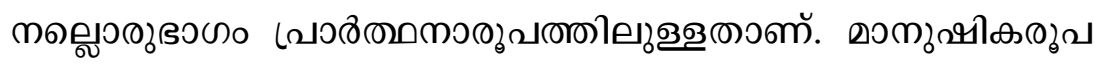

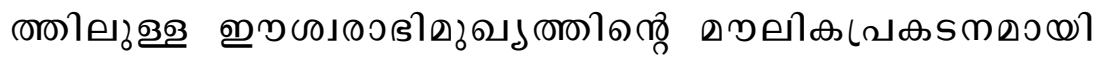

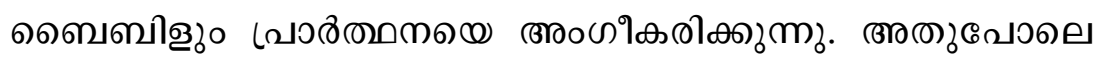

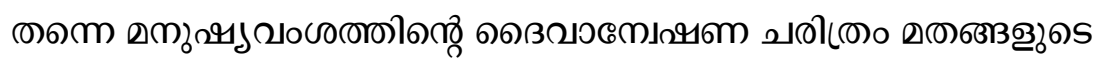

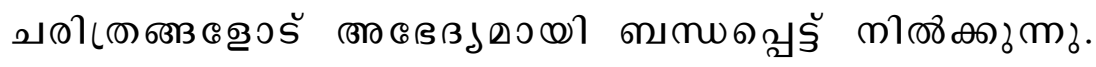

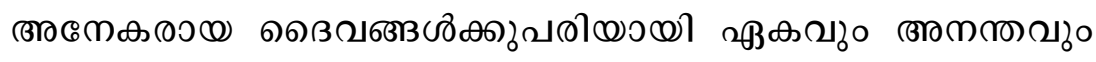

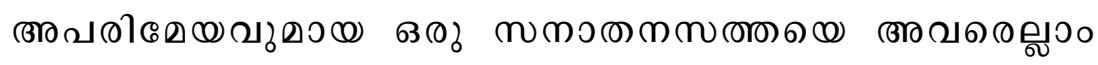

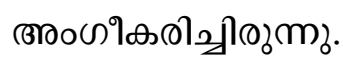

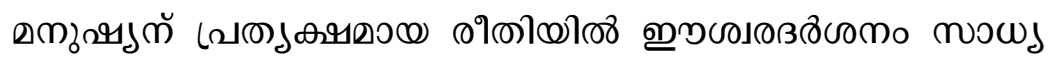

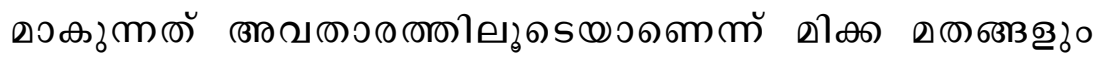

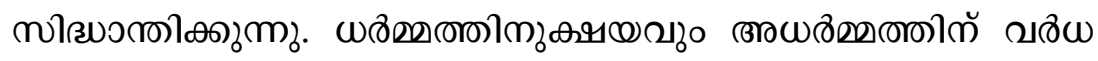

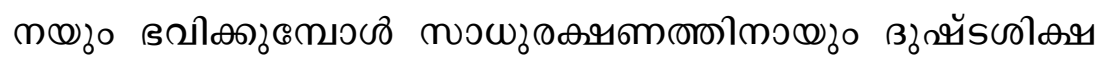

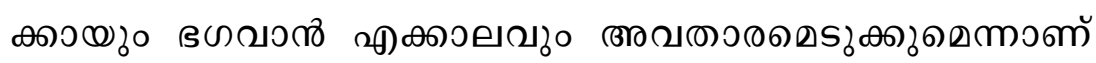

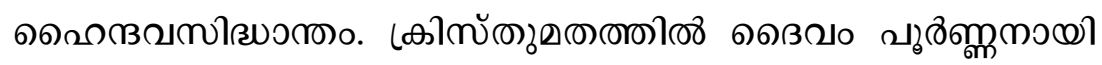

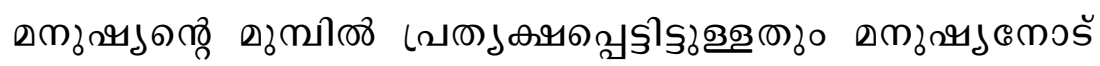

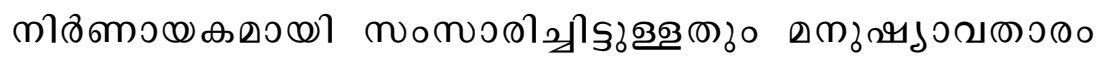

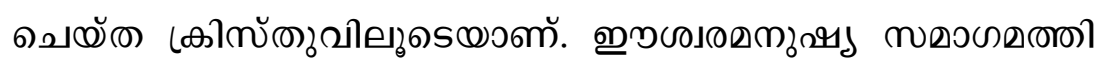

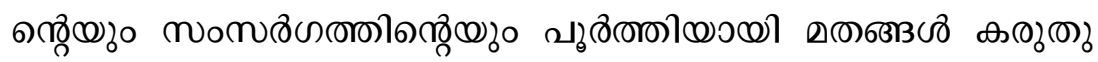

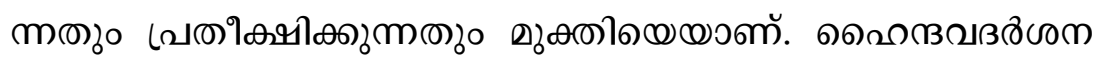

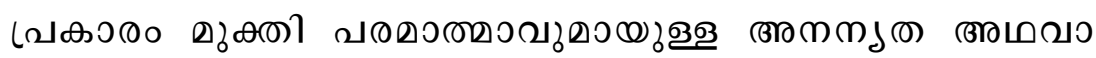

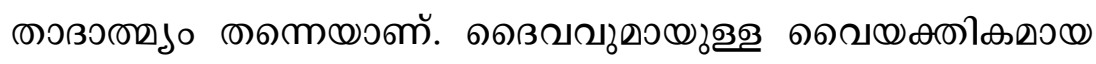




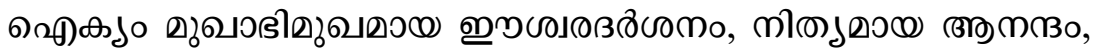

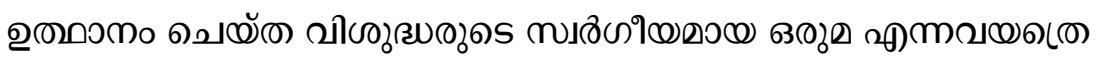

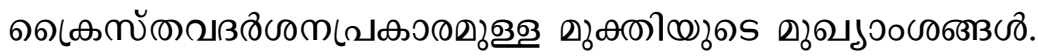

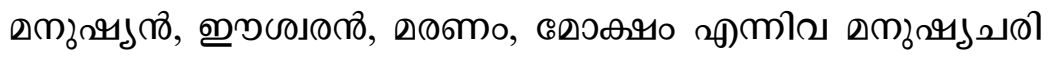

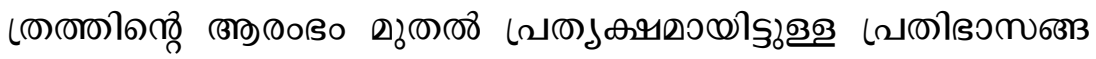

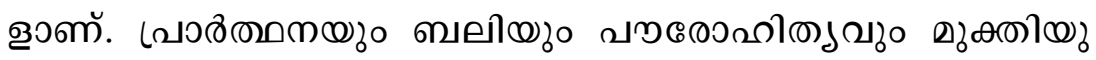

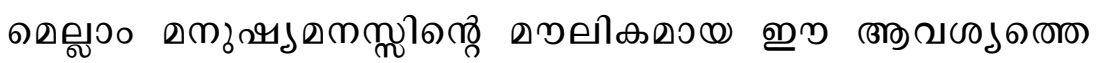

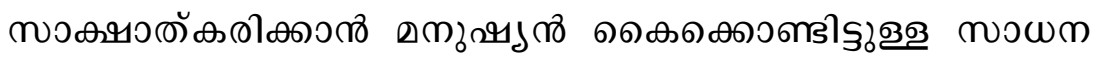

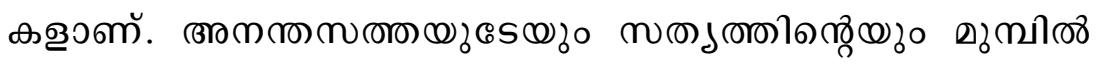

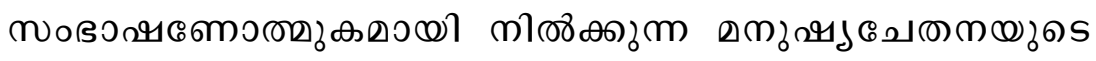

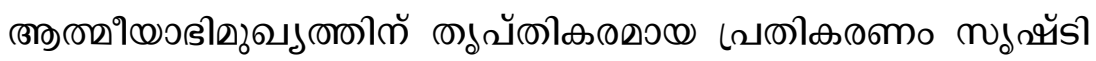

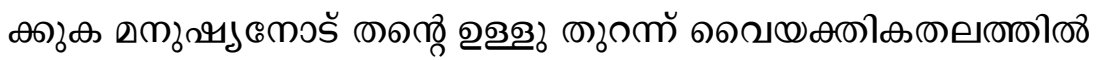

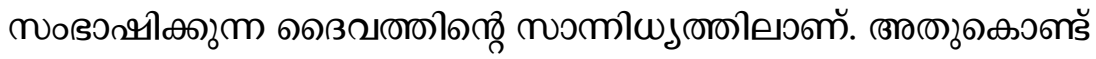

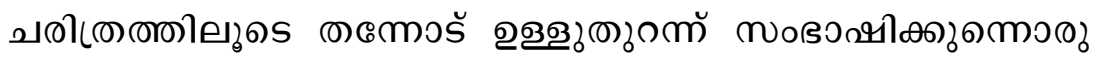

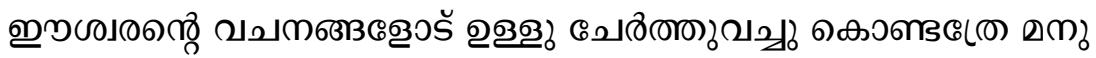

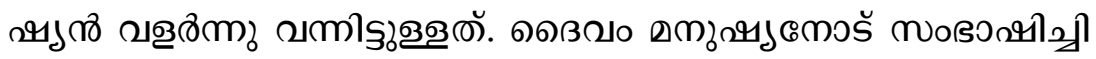
కృலరரைం வாங்

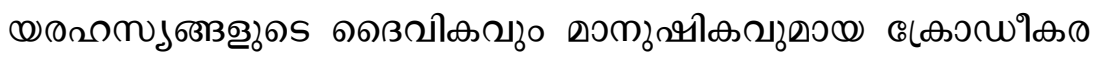

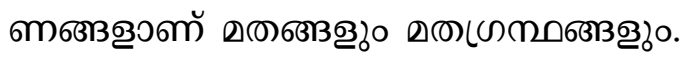

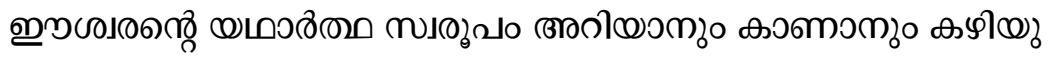

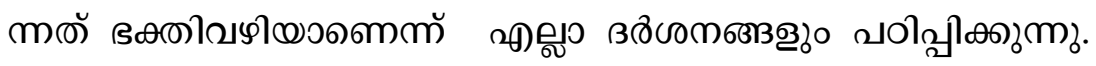

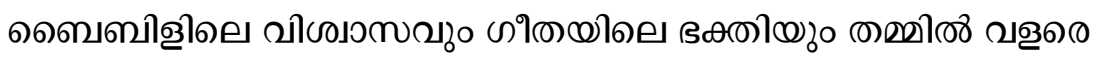

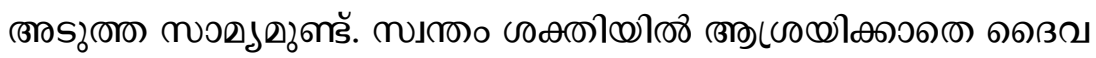

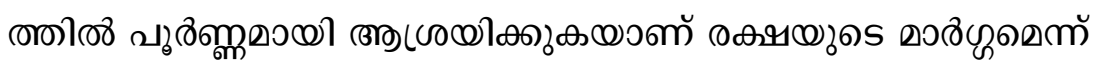

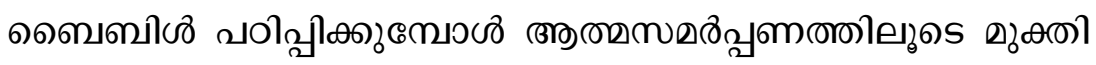

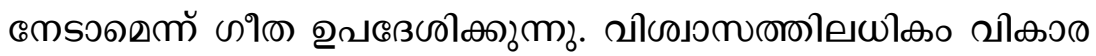




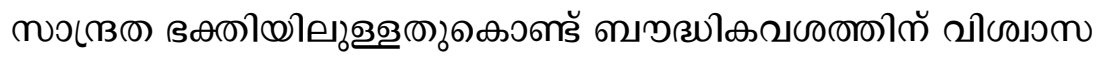

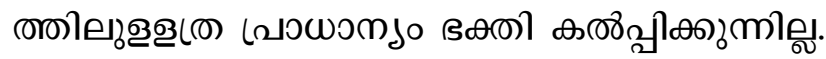

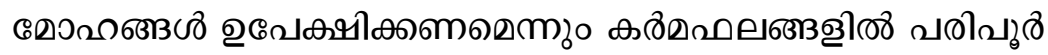

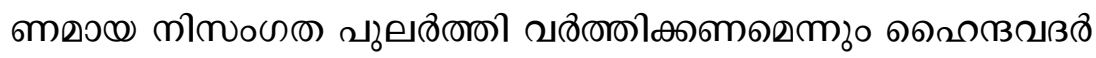

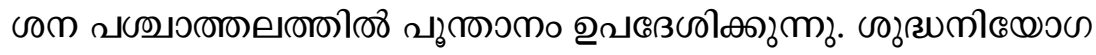

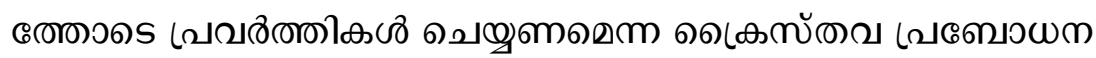

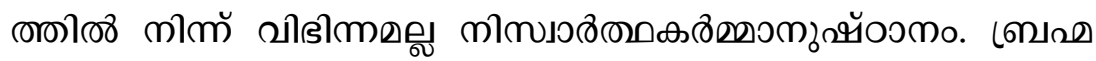

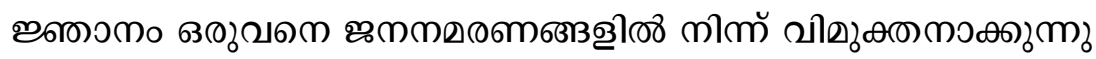

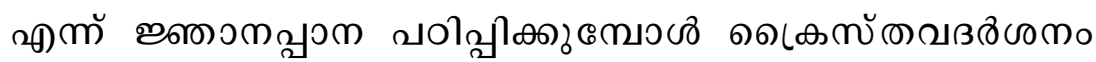

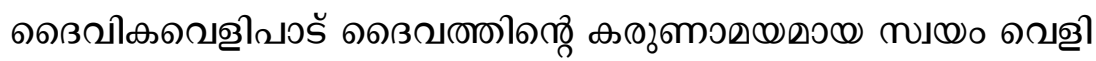

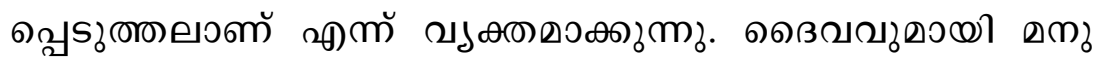

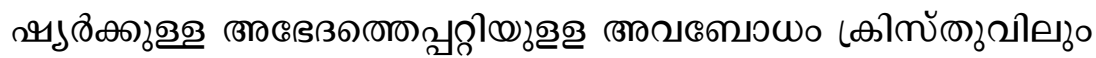

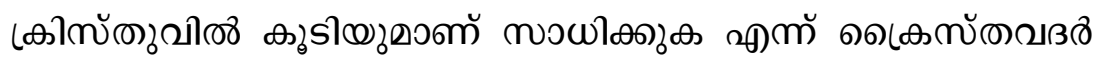

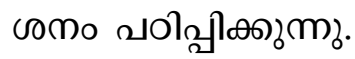

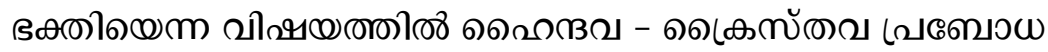

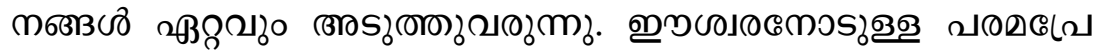

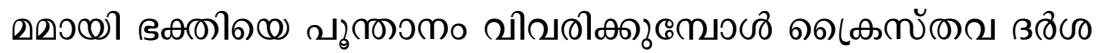

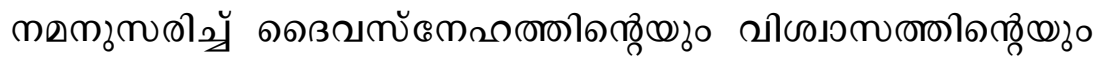

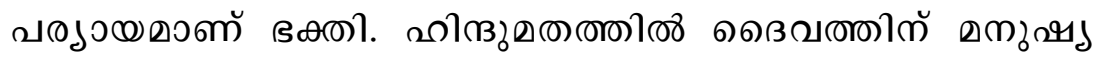

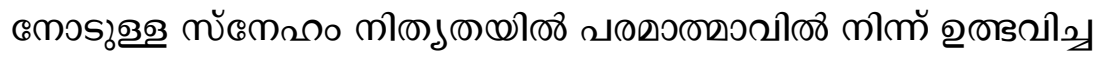

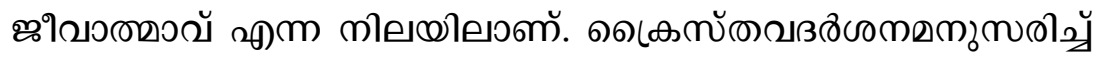

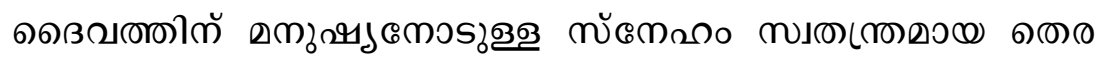

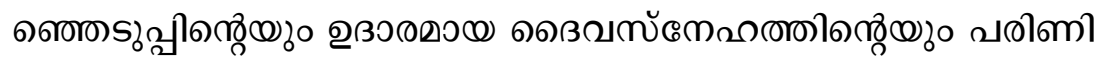

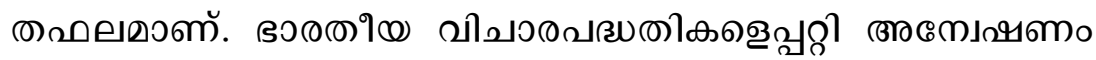

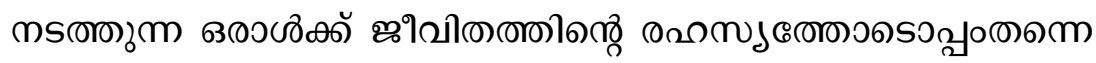

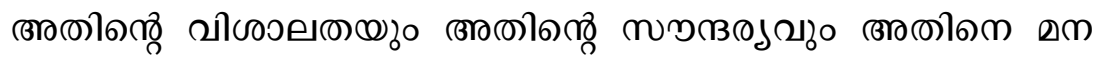




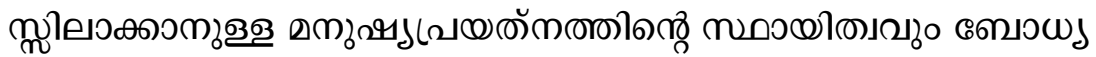

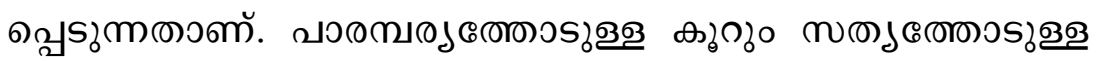

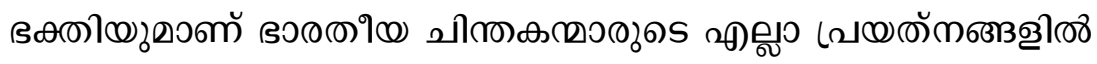

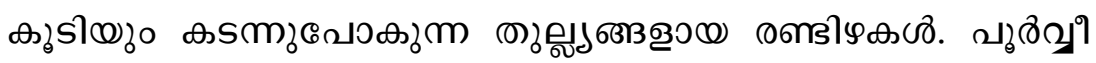

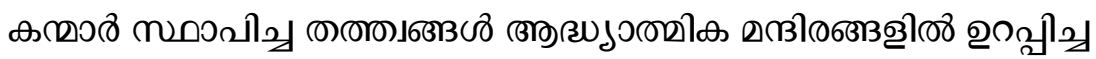

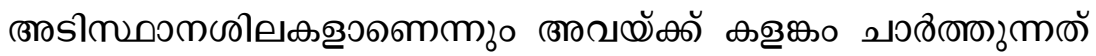

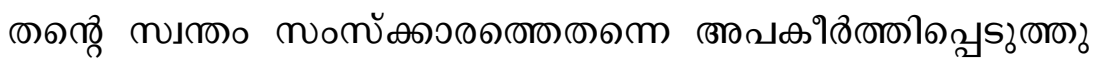

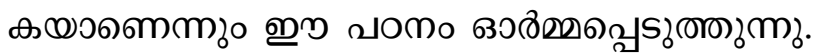

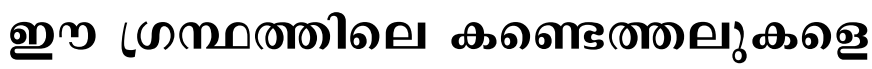

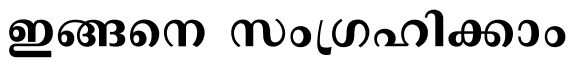

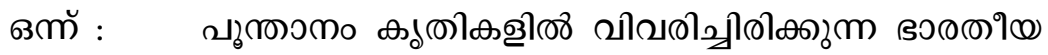

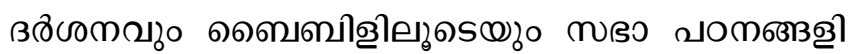

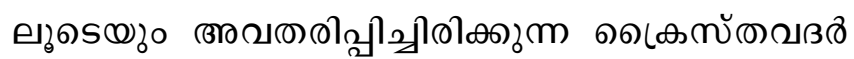

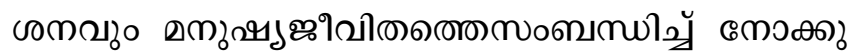

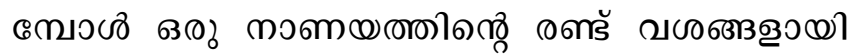

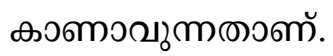

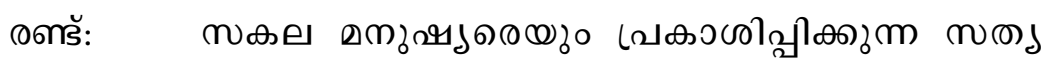

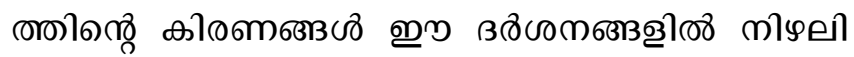
श्राळ०लाm).

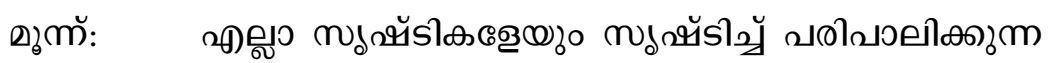

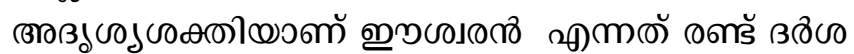

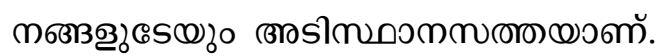

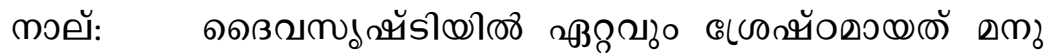

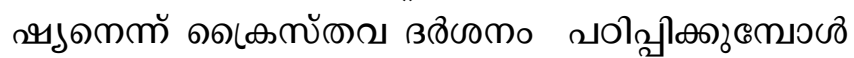

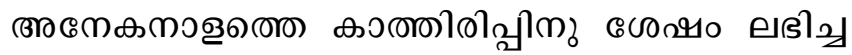




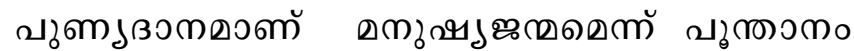
வூமவைலவாய).

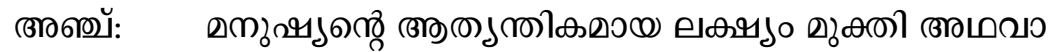

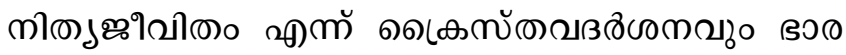

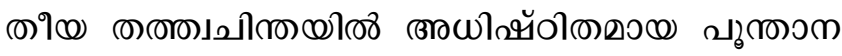

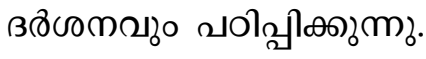




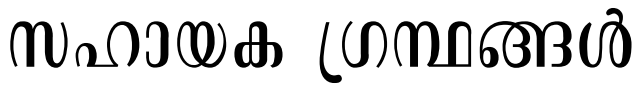

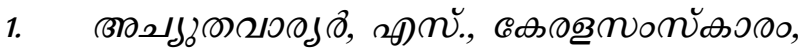

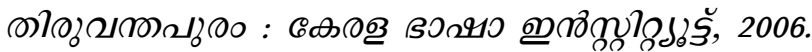

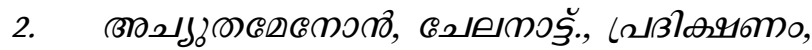

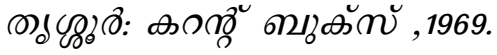

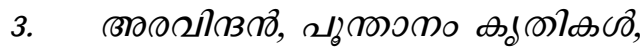

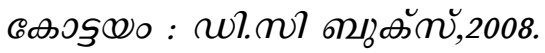

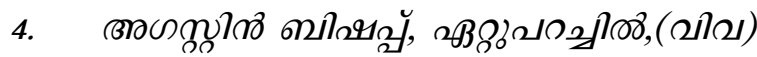

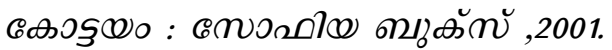

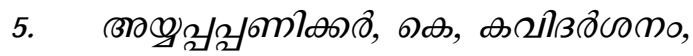

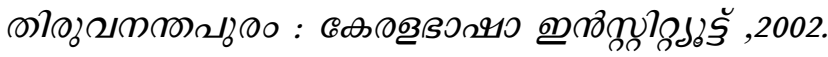

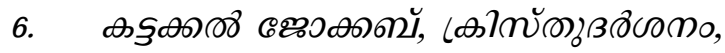

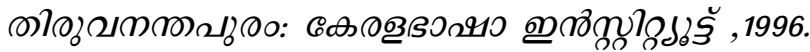

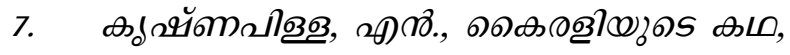

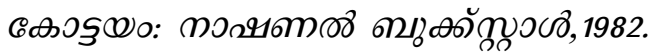

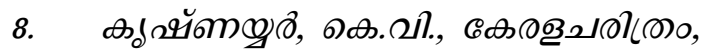

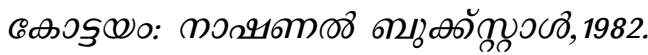

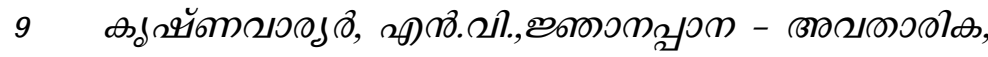

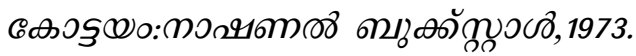




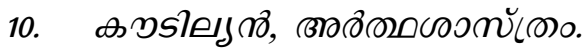

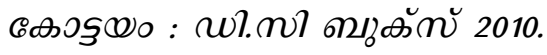

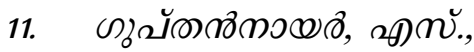

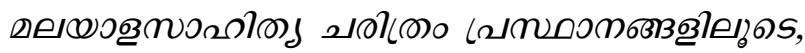

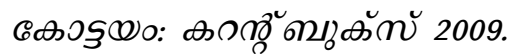

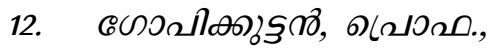

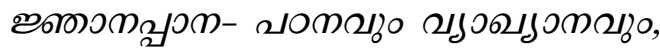

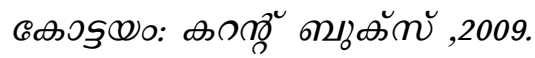

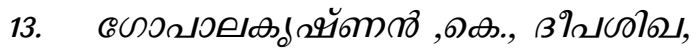

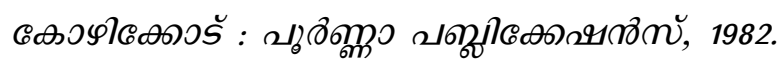

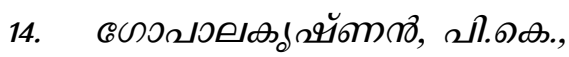

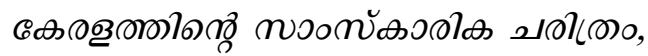

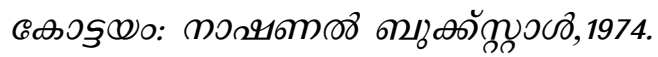

15. сேохीв

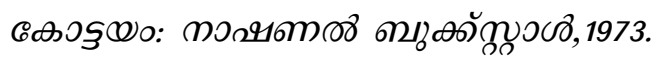

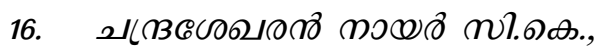

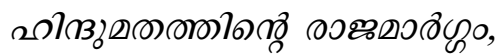

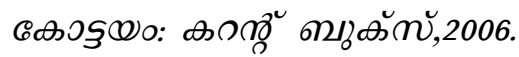

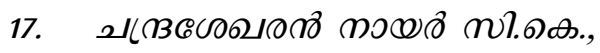

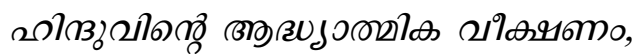

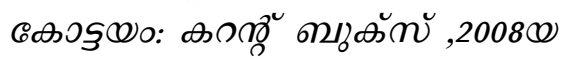

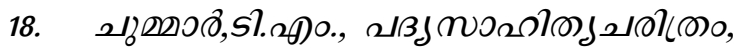

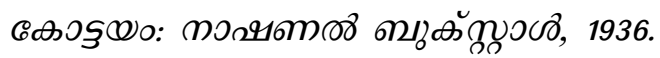

19. ஜே๐กคกั ๑ง

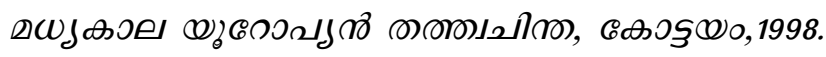




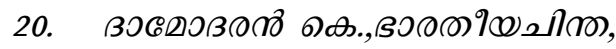

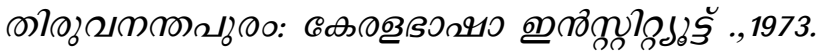

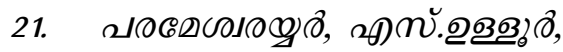

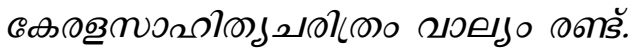

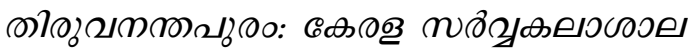

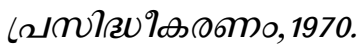

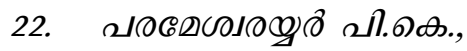

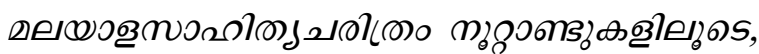

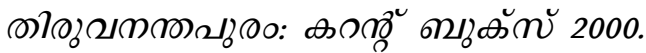

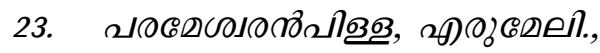

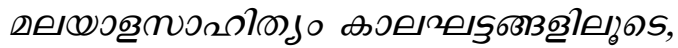

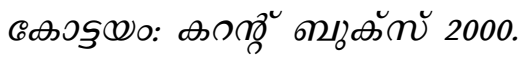

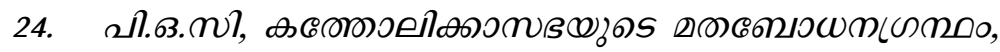

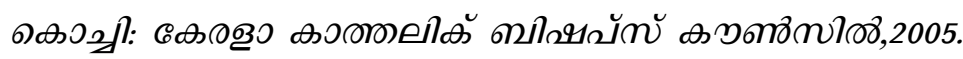

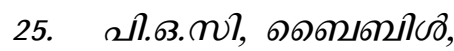

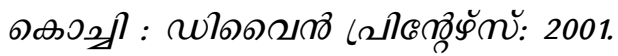

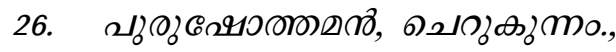

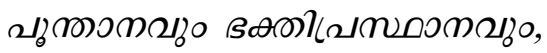

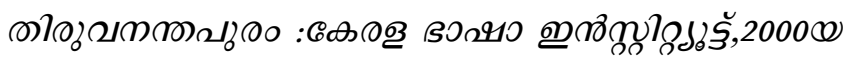

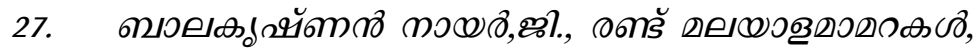

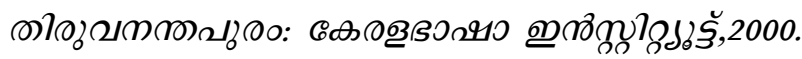

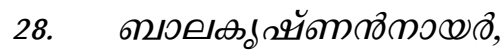

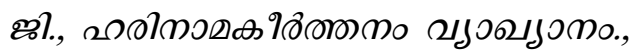

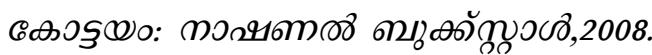

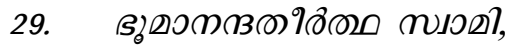

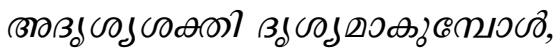

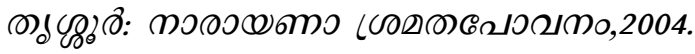




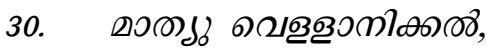

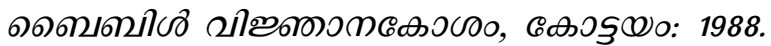

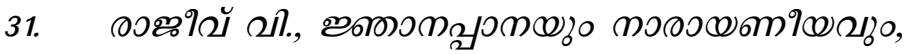

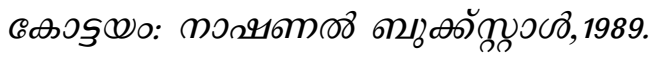

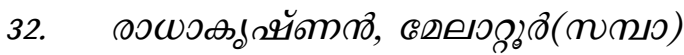

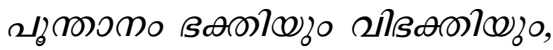

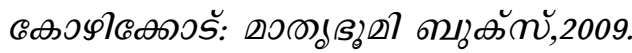

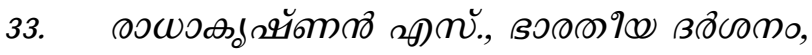

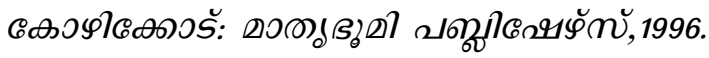

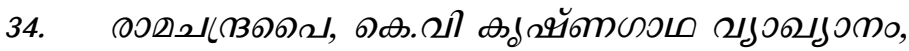

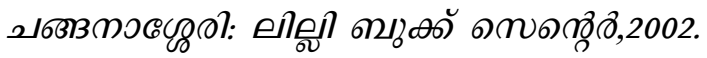

35. อाอง

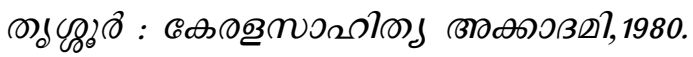

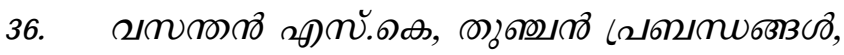

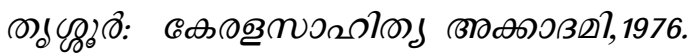

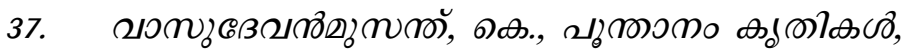

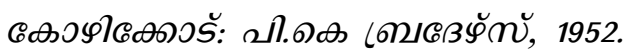

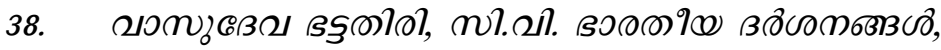

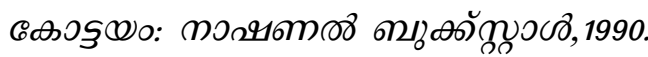

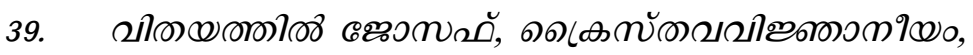

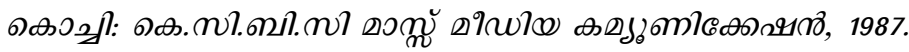

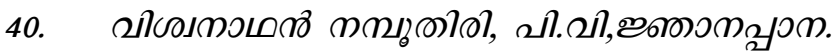

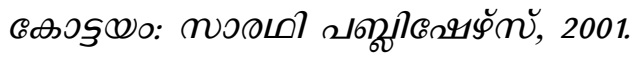

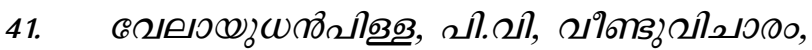

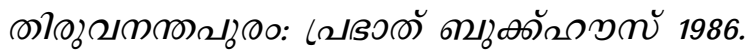




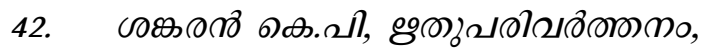

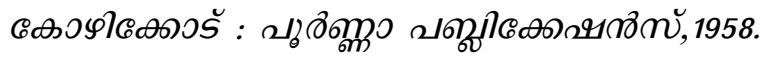

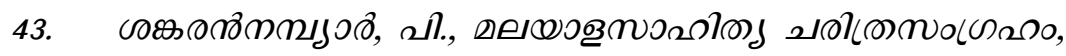

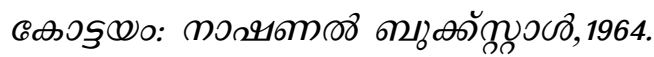

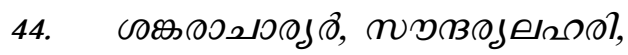

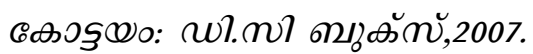

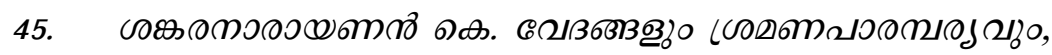

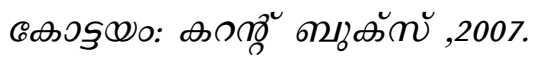

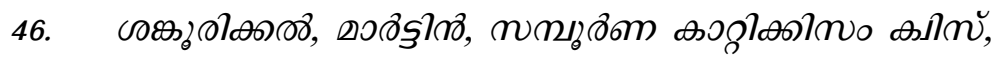

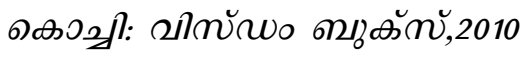

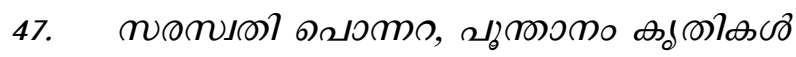

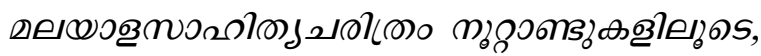

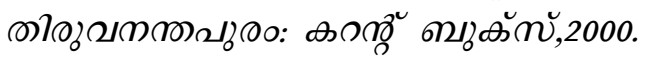

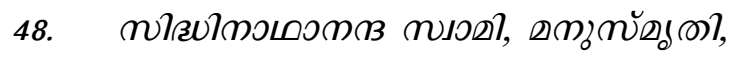

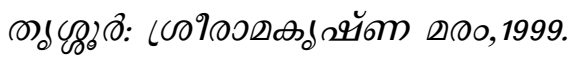

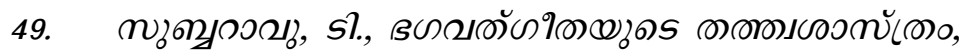

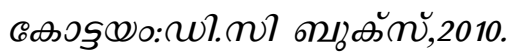

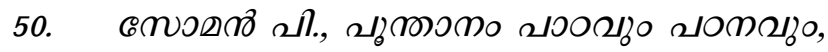

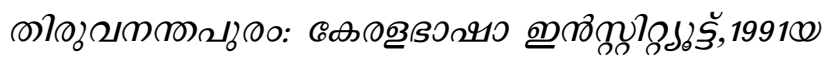

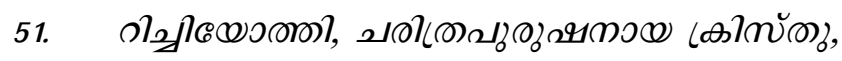

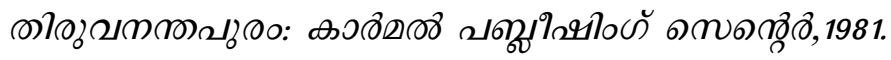

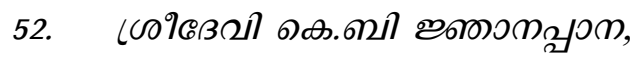

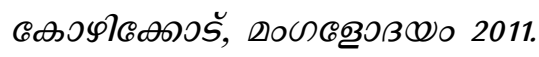

53. К К\%

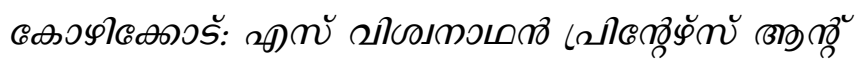

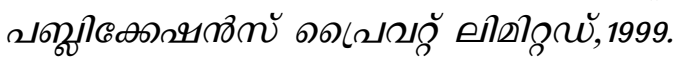




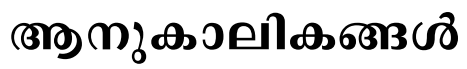

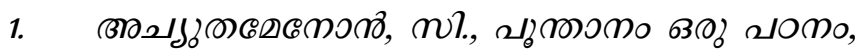

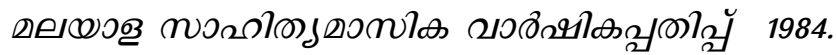

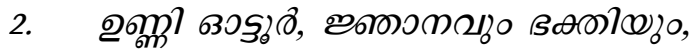

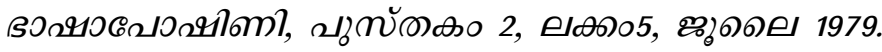

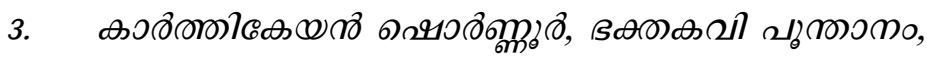

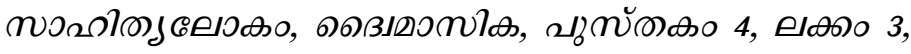
๑ேழூ 1973.

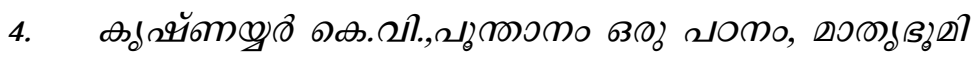

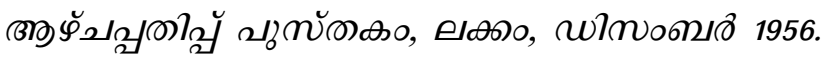

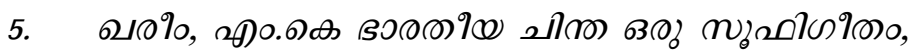

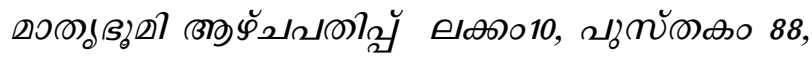

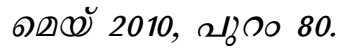

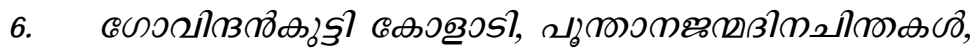

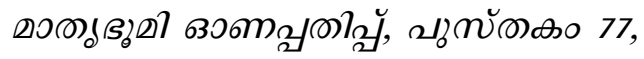

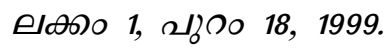

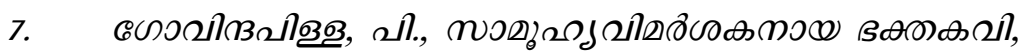

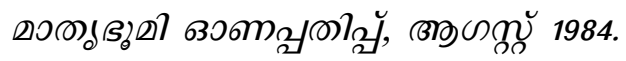

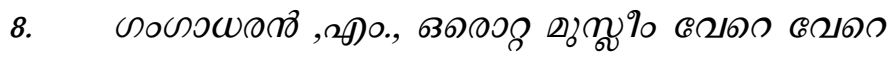
வுறู

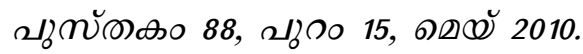

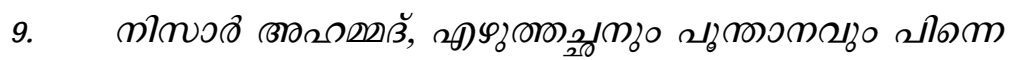
เคภา ๑กัณัณเช 2006. 


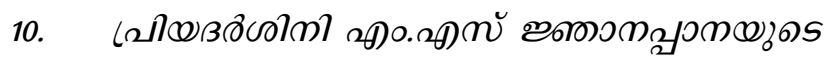

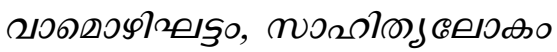

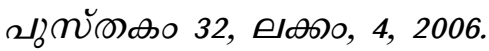

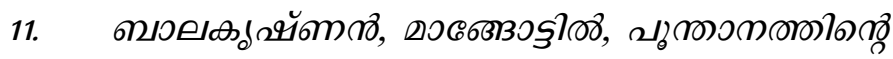

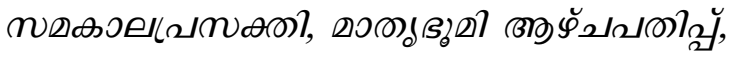

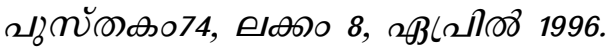

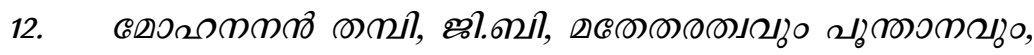

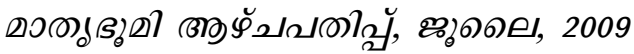

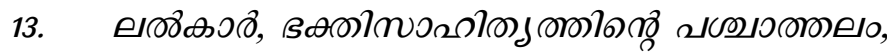

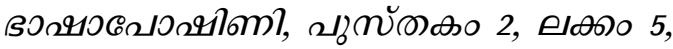

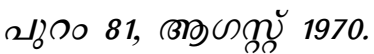

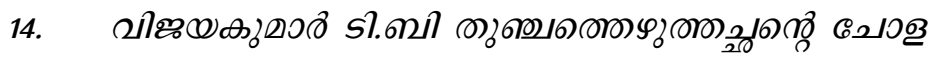

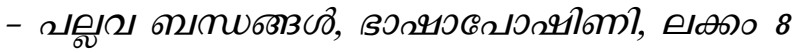
வூர்கை๐ 88, வேர 2, 2010.

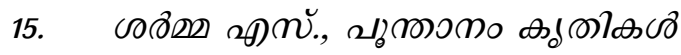

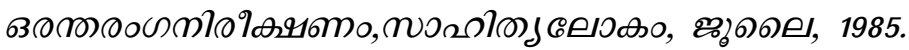

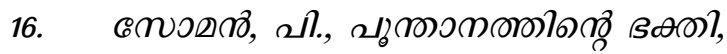

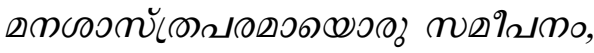

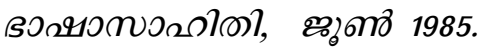


